


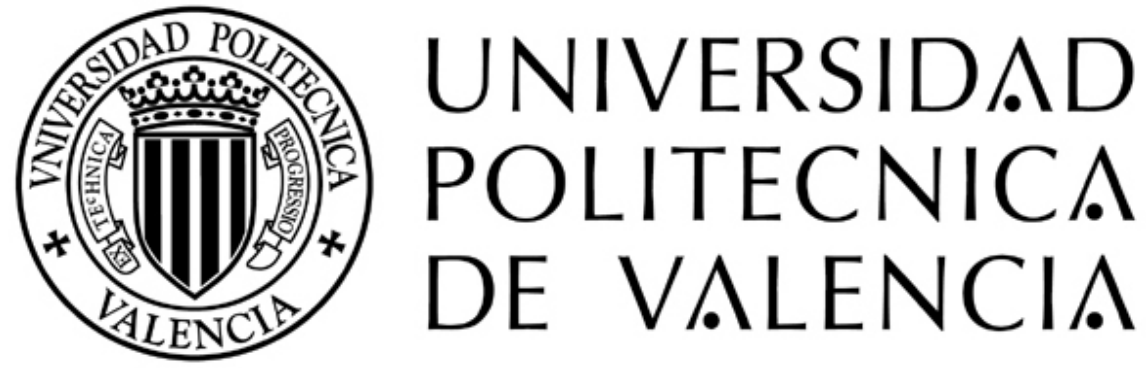

DEPARTAMENTO DE ORGANIZACIÓN DE EMPRESAS

\section{PROPUESTA DE UN MODELO DE INTEGRACIÓN PARA LA GESTION DE LA CADENA DE SUMINISTRO EN EL SECTOR DE LA CONSTRUCCION}

Doctorando: D. Juan Francisco Carbonell Ureña

Directores de Tesis:

D. Raul Poler

D. Francisco Cruz Lario

Valencia Enero de 2012 
UNIVERSIDAD

POLITECNICA

DE VALENCIA 


\title{
PROPUESTA DE UN MODELO DE INTEGRACIÓN PARA LA GESTION DE LA CADENA DE SUMINISTRO EN EL SECTOR DE LA CONSTRUCCION
}

\begin{abstract}
Resumen
Hoy en día, y en nuestro entorno, el sector de la construcción está experimentando grandes cambios en todos los aspectos relacionados con su negocio: el mercado, las relaciones entre competidores, los mecanismos de financiación, los recursos de mano de obra, etc. es por ello que en esta Tesis se pretende analizar modelos existentes de integración de la Cadena de Suministro que recojan una manera de enfocar los problemas a los que se tiene que enfrentar este sector y las cadenas de producción del mismo. Algunos modelos de integración que se estudian son del sector de la construcción, otros no, pero ambos pueden dar luz al modo de abordar esta problemática que el sector necesita resolver. Por último se propone un modelo de integración de la gestión de la cadena de suministro basado en las alianzas entre compañías y en la gestión con el cliente.
\end{abstract}


UNIVERSIDAD

POLITECNICA

DE VALENCIA 


\title{
PROPOSAL OF A MODEL OF INTEGRATION FOR MANAGING THE SUPPLY CHAIN IN THE CONSTRUCTION SECTOR
}

\begin{abstract}
Summary
Currently the construction industry is undergoing great changes in all aspects of their business: the market, the relationships between competitors, funding mechanisms, resources, manpower, etc. Now more than ever, when the global crisis requires the use of management systems more efficient, they require comprehensive models for managing supply chains in the construction sector. This Thesis discusses integration of existing models of the supply chain provide solutions to the problems that has to face this sector and the supply chains and proposes the Global Organization Model (GOM) characterized by the integration of productive chains of the companies participating in supply chain customer and vehicle as a main integrator of the entire process. Finally we propose a model for integrating the management of the supply chain based on partnerships between companies and customer management.
\end{abstract}


UNIVERSIDAD

POLITECNICA

DE VALENCIA 


\section{PROPOSTA D'UN MODEL D'INTEGRACIÓ PER A LA GESTIÓ DE LA CADENA DE SUBMINISTRAMENT EN EL SECTOR DE LA CONSTRUCCIÓ}

\section{Resum:}

Hui en dia, i en el nostre entorn, el sector de la construcció està experimentant grans canvis en tots els aspectes relacionats amb el seu negoci: el mercat, les relacions entre competidors, els mecanismes de de finançament, els recursos de mà d'obra, etc. Es per això que en esta Tesis es pretén analitzar models existents d'integració de la Cadena de Subministrament que arrepleguen una manera d'enfocar els problemes a què s'ha d'enfrontar este sector i les cadenes de producció del mateix. Alguns models d'integració que s'ésel teu Alguns models d'integració que s'estudien són del sector de la construcció, altres no, però ambdós poden donar llum a la manera d'abordar esta problemàtica que el sector necessita resoldre. Finalment es proposa un model d'integració de la gestió de la cadena de subministrament basat en les aliances entre companyies i en la gestió amb el client. 
UNIVERSIDAD

POLITECNICA

DE VALENCIA 


\section{Índice General del Documento:}

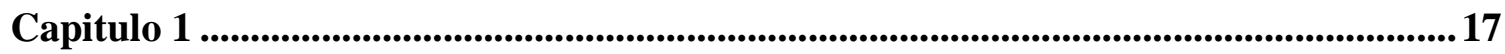

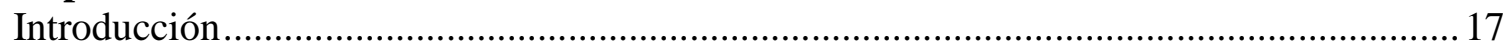

1 Breve descripción del entorno y objeto de la tesis: ............................................... 17

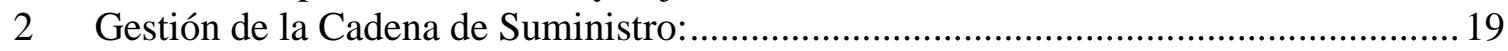

3 Antecedentes de la industria de la construcción:........................................................ 19

4 El sector: ¿qué es una vivienda? y características del sector de la construcción...........22

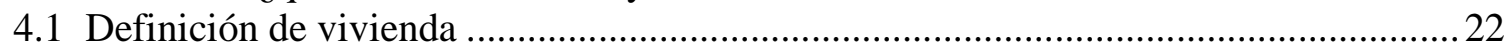

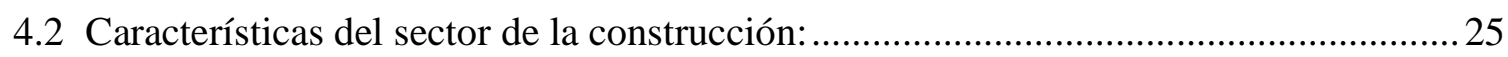

5 Conclusiones y enfoque del campo de investigación: ..................................................2

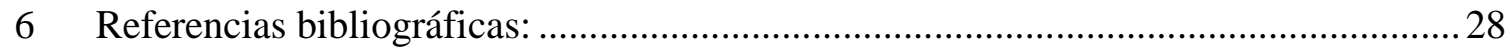

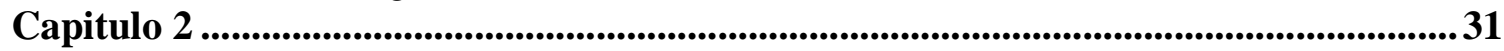

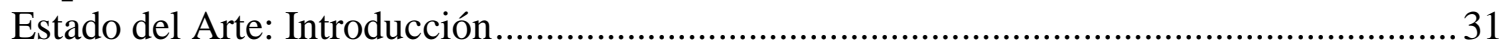

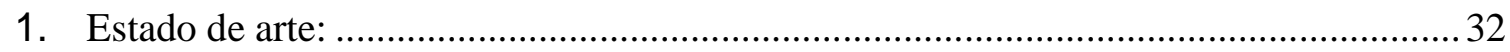

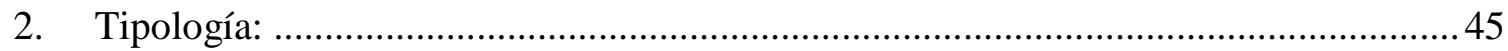

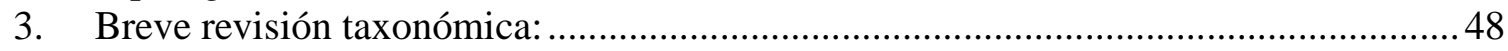

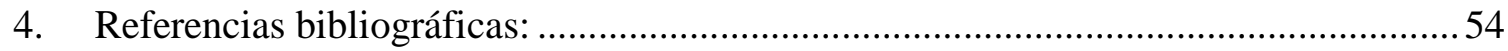

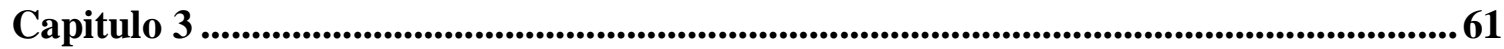

Estado del arte: Aspectos básicos en la Gestión de la Cadena de Suministro en el sector de la

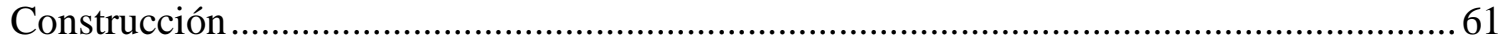

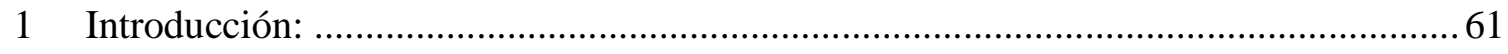

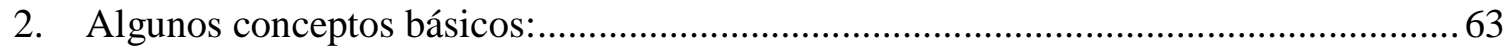

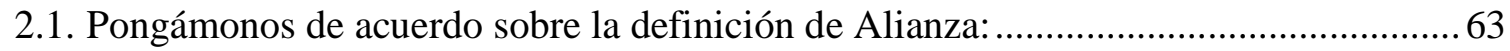

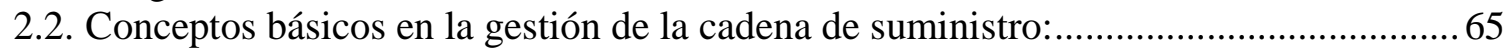

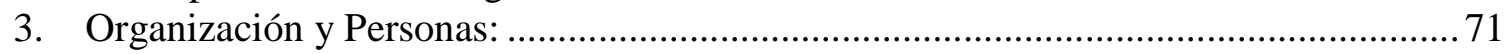

3.1. Las personas y sus relaciones como aspectos clave en el entendimiento entre

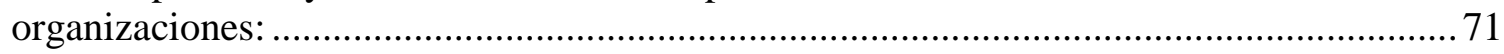

3.2. Habilidades requeridas para Partnering en la red de la cadena de suministro de la

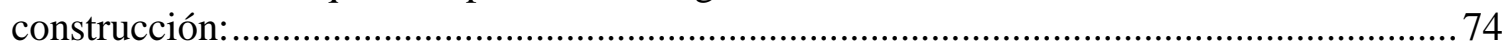

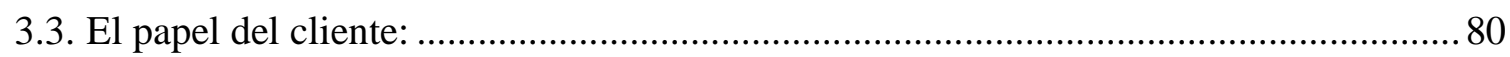

4. Técnica: La información y la integración de la Cadena de Suministro.......................... 83

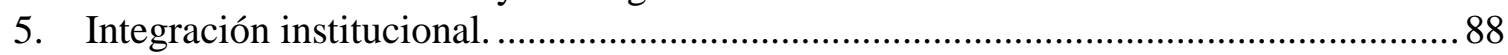

6. La base económica de la integración de la alianza.................................................. 95

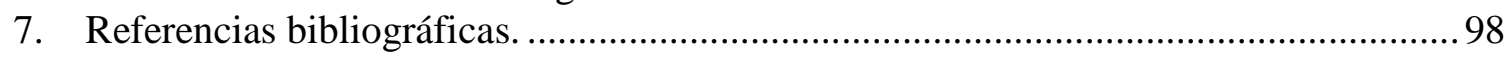




\section{Capitulo 4}

Estado del arte: Modelos de Integración de la Gestión de la Cadena de Suministro en el sector de la Construcción 109

1. Introducción:

2. Modelos de integración de la Cadena de Suministro:

3. Un Modelo para el funcionamiento interorganizacional en la cadena de suministro: 113

4. Modelo de integración en la cadena de suministro de la construcción:

5. Modelo para la creación de una relación de partenariado: .............................................120

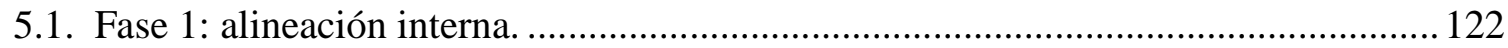

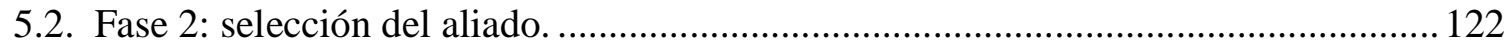

5.3. Fase 3: alineamiento de las relaciones de la alianza................................................... 122

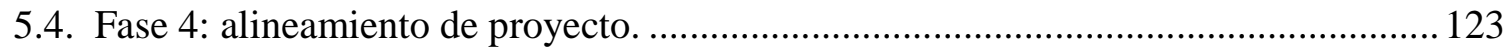

5.5. Fase 5: Alineamiento en el proceso de trabajo........................................................... 123

6. Modelo de integración de la cadena de suministro de la construcción: procesos de diseño

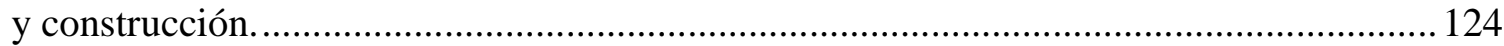

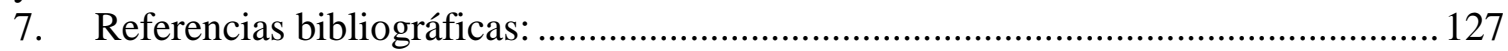

Capitulo 5 .............................................................................................................................. 135

Estado del arte: Zachman Framework una sistemática para la modelización......................135

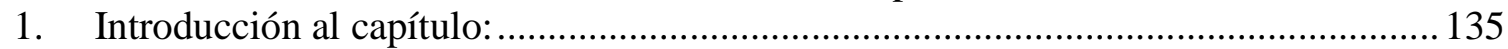

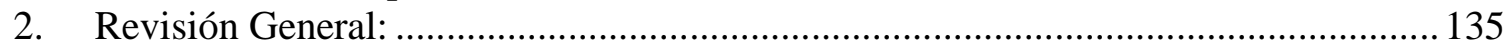

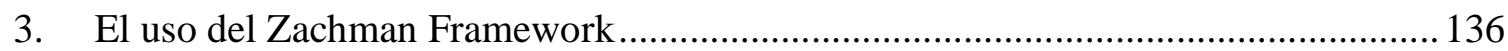

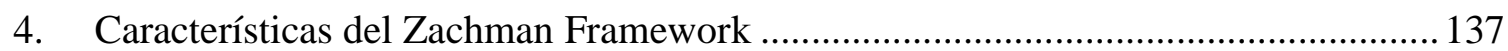

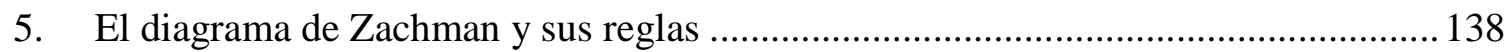

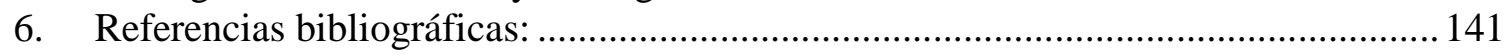

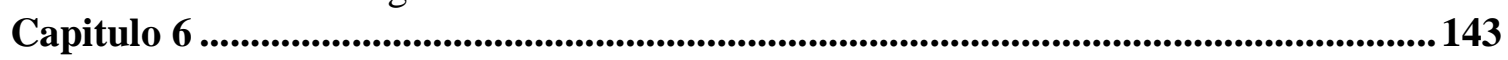

Propuesta de un modelo de integración para la cadena de suministro en el sector de la

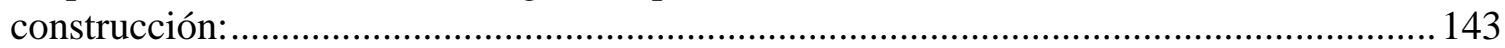

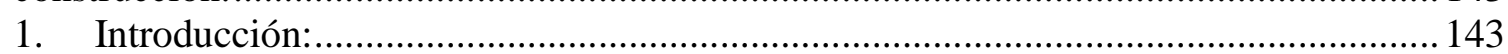

2. Funcionamiento general: Modelo de Organización Global:........................................... 143

3. Funcionamiento con el Cliente: El Círculo del Cliente................................................ 149

4. El funcionamiento con los Proveedores: Desarrollando una Alianza. ...........................152

5. El Modelo de Organización Global y el Zachman Framework...................................... 155

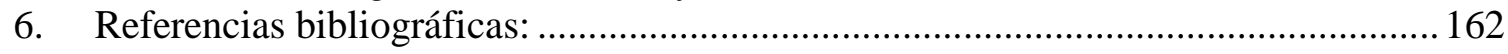




\section{Capitulo 7}

Propuesta de un modelo de integración en la Gestión de la Cadena de Suministro para el sector de la Construcción: Clientes y Proveedores..

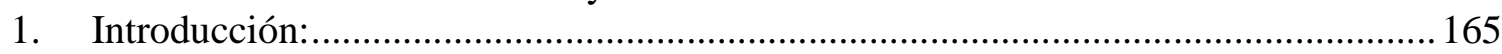

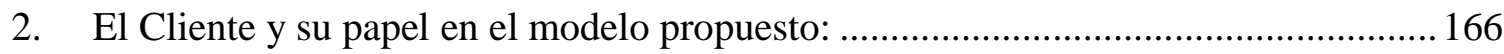

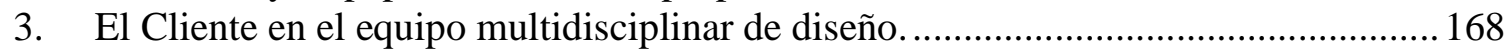

4. El funcionamiento de la alianza y el cliente como "pegamento" de la misma............171

5. Las relaciones con los proveedores: una estrategia a largo plazo.

6. La construcción de la alianza con los proveedores y sus aspectos más importantes.. 179

7. Referencias bibliográficas:

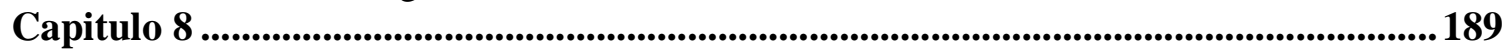

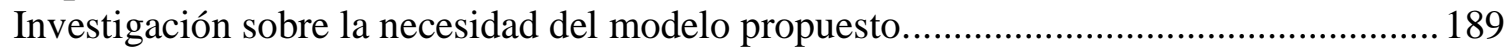

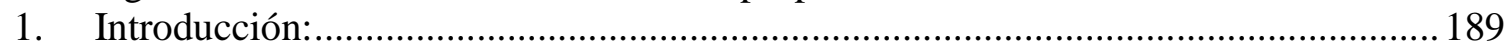

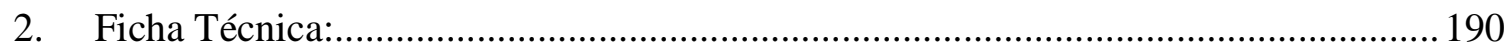

3. Implicación que la crisis inmobiliaria actual tendrá en un cambio de modelo............ 191

4. Tipos de empresas que surgirán después de la crisis inmobiliaria...............................192

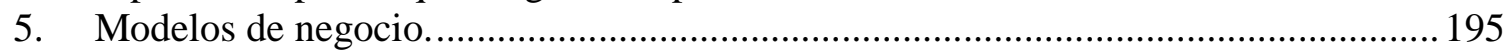

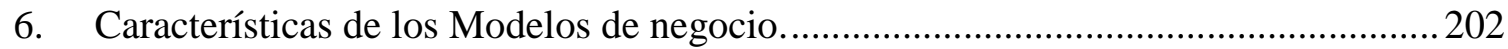

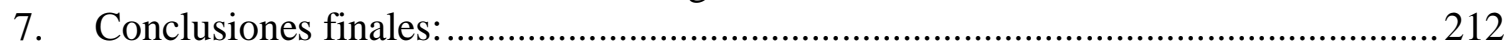

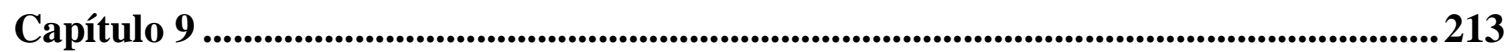

Conclusiones, recomendaciones y posibles líneas de investigación futuras. ......................213

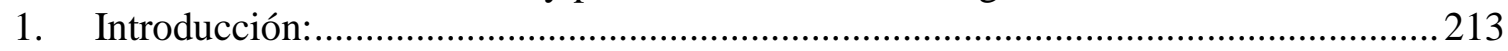

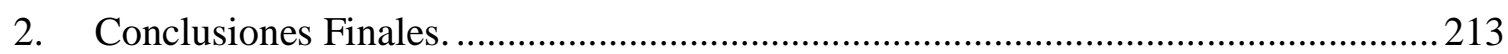

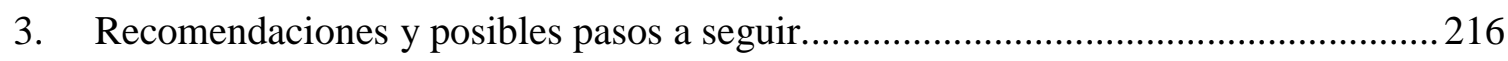

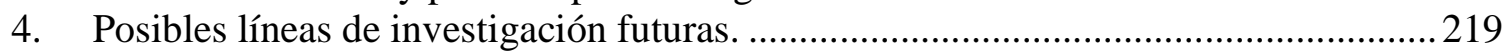

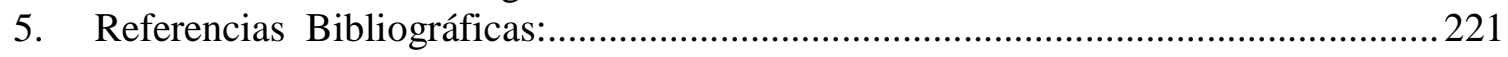


UNIVERSIDAD

POLITECNICA

DE VALENCIA 


\section{Agradecimientos}

En primer lugar desearía agradecer el trabajo realizado por todos aquellos maestros que he tenido durante mi vida, a ellos les debo mi amor por los estudios y el querer aprender cada día más, muchas gracias a todos de todo corazón.

Quisiera también agradecer el trabajo, la dedicación, el cariño, el apoyo, el afecto, la comprensión y todo el amor que mi familia: padres, mujer, hijos, hermana y cuñado me han sabido dar durante estos años de trabajo en los cuales seguro que he descuidado el tiempo que ellos se merecen.

También quiero resaltar el agradecimiento a las empresas que me han permitido aprender, investigar, escribir y publicar como ejemplo el presente trabajo.

Por ultimo, pero no por ello menos importante, a mis profesores de la Universidad Politécnica de Valencia y del Instituto de Estudios Superiores de la Empresa (Universidad de Navarra) que me han animado, corregido y empujado en este trabajo que hoy ve la luz. A todos ellos gracias de todo corazón. 
UNIVERSIDAD

POLITECNICA

DE VALENCIA 


\section{Capitulo 1}

\section{Introducción}

"No hay más alianzas que las que trazan los intereses, ni nunca las habrá."

CÁNOVAS del CASTILLO, Antonio

\section{Breve descripción del entorno y objeto de la tesis:}

La cadena de suministro en el sector de la construcción es posiblemente uno de los sistemas logísticos y productivos de mayor antigüedad y con un desarrollo e implantación más extenso a lo largo de todo nuestro planeta. Como comenta Capó Vicedo et al. (2005) el sector de la construcción está pasando actualmente por procesos de internacionalización y/o especialización de sus unidades productivas, debiendo ser su tendencia la de convertir sus cadenas productivas en auténticas "cadenas virtuales", en las que se incluyan los proveedores y subcontratas como parte de las mismas.

En la situación presente, sufre una de las mayores crisis conocidas en el sector debido, en gran parte, a los problemas generados por la estructura financiera y un exceso de demanda que ha llevado al sector a una burbuja de precios. La expresión burbuja inmobiliaria en España hace referencia a la existencia de una burbuja especulativa en el mercado de bienes inmuebles en España hasta finales de 2007 y principios de 2008, aproximadamente Wikipedia(s.f.). El principal síntoma de la misma fue el incremento anormal de los precios muy por encima del IPC, incrementos que se explican principalmente recurriendo a factores externos, como la falta de suelo edificable, los beneficios fiscales concedidos a la adquisición de viviendas, la inmigración, la especulación y la recalificación de suelos, así como el exceso de crédito.

Tesis Doctoral_definitiva_impresión 
Existen varias teorías acerca de la fecha de inicio de la burbuja inmobiliaria. La primera de ellas sostiene que la burbuja tuvo su inicio en 1985. Otra teoría que sostiene el Banco de España, afirma que la burbuja inmobiliaria se inició a finales de 1997, y explica que el origen de la escalada de precios se encuentra, en parte, en el anterior boom inmobilario que terminó en 1991 con "una excesiva corrección". Como consecuencia, el Banco de España habla de "la existencia de una cierta infravaloración de este activo en la segunda mitad de la década de los noventa". En ambos casos, el periodo se ha prolongado hasta agosto de 2007, manifestándose principalmente en una elevación sostenida de los precios superior al 10\% anual y llegando en algunos años hasta cerca del 30\% anual según ponen de manifiesto los informes elaborados por el portal inmobiliario español Idealista.com.

El resultado de la explosión de la burbuja es una brusca caída de la demanda y, por tanto, de los precios, y que podría estar provocada por la incapacidad del mercado para absorber la enorme oferta de vivienda construida y vacía disponible. Este cambio de ciclo inmobiliario español habría tenido lugar por factores internos y externos: por un lado, la falta de liquidez del sistema financiero, causada por la crisis de las hipotecas subprime en Estados Unidos en agosto de 2007, y por otro, por el deterioro interno de la economía española, la falta de financiación y el agotamiento del modelo de crecimiento (basado en la construcción), al reducirse los retornos de la inversión (provocando la salida del mercado de los especuladores) y contenerse el crédito.

En este entorno, por un lado un sector con una cadena de suministro como la que se definirá más adelante, y en una situación macroeconómica cómo la descrita, esta tesis pretende desarrollar y proponer un modelo de integración que permita a las compañías afrontar los problemas derivados de la gestión de la cadena de suministro en el sector de la construcción y desarrollar un modelo de negocio que mejore los resultados en los productos obtenidos. Por otro lado, según Briscoe G. et al (2001), en comparación con otros sectores, como puede ser el de la automoción, los principales contratistas en el mundo de la construcción están relativamente poco sofisticados en cuanto a la cadena de suministro se refiere. En definitiva, la presente tesis se centrará en la cadena de suministro de la construcción relacionada con la construcción de viviendas residenciales según la definición que se realizará a lo largo del presente trabajo. 


\section{Gestión de la Cadena de Suministro:}

La Gestión de la Cadena de Suministro es una metodología muy utilizada en diversos sectores industriales, como el del automóvil, para realizar una integración racional y sistemática entre los proveedores, los clientes y la empresa, es decir, una integración que consiga como resultado una verdadera empresa global según Capó Vicedo et al. (2005). Dadas las características productivas particulares del sector de la construcción la cadena de suministro se configurará para cada proyecto constructivo en particular. Así mismo se debe tener en cuenta las características y la cultura de este sector. Normalmente la organización central ejerce poco control o gestión global del proyecto. Cada nivel de la cadena controla al nivel inmediatamente anterior. Los problemas de integración entre empresas especialistas en cada nivel son muy comunes, por lo que las propuestas de integración son un aspecto de suma importancia para conseguir una buena configuración, coordinación y gestión de la cadena de suministro de cada proyecto constructivo.

Sin embargo, existe una presión para cambiar las operaciones a lo largo de la cadena de suministro de la construcción, especialmente debida a la exigencia de los clientes por tener un mejor producto y servicios relacionados, Crane (1999). Otro aspecto a definir es la Cadena de Suministro en sí, existe amplia bibliografía sobre la definición de la misma. Inicialmente se puede definir como: "red de organizaciones que están involucradas a través de uniones aguas arriba y aguas abajo en los diferentes procesos y actividades que producen valor en forma de productos y servicios para los clientes finales" (Christopher, 1998). En capítulos sucesivos veremos con más detalle los aspectos relacionados con la gestión de la Cadena de Suministro.

\section{Antecedentes de la industria de la construcción:}

Para seguir con la introducción se cree conveniente hacer una referencia a los antecedentes de la industria de la construcción. Como comenta Vélez Moreno (2001) los antecedentes referidos a la situación en las décadas de los años ochenta y noventa, se plantean los siguientes: la perdida de valor comercial de la propiedad raíz, la confusión en la medición de la creación arquitectónica, con una visión economista y competitiva que preside toda actividad productiva. Y por último el abandono del sector y de las universidades formadoras de profesionales, de los objetivos sociales y culturales para impulsar desarrollo. 
Estas tres situaciones no son aisladas, confluyen cuando se expone la perdida del valor comercial de la propiedad raíz, es más por el efecto de la atomización financiera del sector, donde el flujo de capital entre la banca y el sector, hace que exista más rentabilidad por operaciones financieras y bancarias que por el mismo ejercicio de construir. Y así para haber llegado a confundir la creación arquitectónica con competitividad y rentabilidad, se devalúa el concepto de habitación y se valora la función, entendiéndose habitación al acoger al hombre y a la que el hombre se hace. Y entendiendo la función como esa disposición espacial en la que se labora, se goza y se vive. Esta disposición espacial ya no es en detalle, biblioteca para estudiar y cocina para cocinar, si no, ese espacio reducido cuando hablamos de las muchas funciones que el hombre realiza; o será acaso que el hombre ya no hace hoy en día todo esto, y se ha convertido en máquina de vivir bajo la expresión de la necesidad del trabajo, ante la colectividad de lo social. Ahora bien, para estas máquinas de vivir, la universidad destaca perfiles profesionales en un sector competitivo por productos vendidos (Inmobiliarias) y no por gestar condiciones en torno a la calidad de vida, desde la habitabilidad en lo urbano.

Rey Román et al. (2005) comentan que la industria de la construcción se puede caracterizar por empresas que manejan muchos proyectos en diferentes zonas geográficas al mismo tiempo y que a su vez tienen invertidas grandes cantidades de dinero en dichos proyectos. Este cambio geográfico es uno de los principales factores que hace de los diferentes proyectos de construcción tanto inmobiliaria como de infraestructura, únicos e irrepetibles. Nunca se tendrán dos proyectos iguales al cien por cien.

Se puede encontrar en Pereira y Chaparro (2004) la idea que se expone a continuación, que en la época actual se caracteriza por ser de una naturaleza cambiante, cada segundo que transcurre implica nuevos retos y la problemática de estar preparados para enfrentarlos. Esta situación obliga a las empresas a asumir una posición diferente que no necesariamente debe ser la de anticipar el futuro, sino adaptarse rápidamente a los cambios del presente, y estar preparados para el futuro, a fin de cuentas éste último depende en gran medida de lo que ocurre en el presente.

Ante esta situación, es de esperar que se cuente con un sistema organizacional capaz de aprender a adaptarse al entorno que rodea a la empresa. Dentro del mismo, la gestión empresarial representa una parte fundamental, que requiere de soluciones imaginativas que permitan a las empresas buscar soluciones competitivas dentro del mercado que en cada momento se encuentre. 
Los citados autores, Pereira y Chaparro (2004), comentan también que especialmente las pequeñas y medianas empresas, aunque no sólo ellas, carecen a veces de los recursos necesarios para enfrentarse a todos estos retos. Como respuesta ha surgido el concepto de "cooperación entre organizaciones". Y dentro de esta cooperación surge el concepto de "organización virtual", que presenta como ventaja una enorme flexibilidad, tanto para el acoplamiento de las organizaciones participantes, como para su adaptación a los requisitos cambiantes del mercado.

Sin embargo, los argumentos racionales / económicos junto con la factibilidad técnica no son suficientes para consumar la alianza de colaboración. Los aspectos sociopolíticos, tales como la "química personal" e interacción entre directivos de las organizaciones, y la compatibilidad entre las propias organizaciones en aspectos culturales, filosóficos y estratégicos, determinan si la alianza se hará efectiva y madurará.

Por tanto, parece interesante poder desarrollar modelos de integración que permitan crear organizaciones que fomenten e implanten sistemas competitivos dirigidos a obtener importantes mejoras en los procesos de producción dentro del sector de la construcción. Estos modelos, como se verá más adelante, deben basarse en los pilares en los que se soportan las organizaciones virtuales, resolviéndolos y proponiendo marcos de relación dónde se puedan desarrollar convenientemente. 


\section{El sector: ¿qué es una vivienda? y características del sector de la construcción.}

En el presente apartado veremos dos aspectos del sector: la definición de vivienda como el producto a obtener del proceso productivo de la construcción y las características del sector de la construcción en sí mismo. Como punto de partida de la presente tesis se puede recordar al filósofo Martín Heidegger en conferencia que dio a un grupo de arquitectos de Darmstadt, en el año 1950, en plena reconstrucción (material y moral) del humillado sentido alemán del existir. Se pregunta ¿Qué es habitar?, ¿Hasta que punto el construir pertenece al habitar?, estas preguntas están hoy día también de actualidad. Se ha de construir pensando en que es habitar y desarrollando sistemas para que el que habite se encuentre cuando lo haga aquello que necesita, gusta, quiere y desea en una solución productiva que permita habitar.

\subsection{Definición de vivienda}

En el sector de la construcción se desarrollan multitud de proyectos que no solo tienen que ver con el habitar. Es por tanto necesario que se defina cuál es el ámbito o el sector en el que se quiere desarrollar el Modelo propuesto. El sector estudiado es el sector de la construcción de vivienda residencial. Para la definición de este sector sería bueno definir vivienda residencial como producto del proceso productivo que se obtiene. Viendo a L. Cortés (1995) la definición de vivienda la podemos empezar por lo que el Diccionario de la Lengua Española da de la palabra vivienda. Esta definición es ambigua al identificarla con morada o habitación. El término morada tiene dos significados distintos. El primero es el de casa o habitación, y el segundo algo más concreto, el de estancia de asentamiento o residencia algo continuada en un paraje o lugar.

En el caso de la habitación la definición dada por la Real Academia introduce nuevos elementos, aunque se mantiene un grado elevado de oscuridad. Puede tener tres significados: 1.- Acción y efecto de habitar; 2.- Cualquiera de los aposentos de la casa o morada; y 3.- Edificio o parte del mismo que se destina para habitarse.

El habitar es vivir o morar en un lugar o casa, y el morar es habitar o residir de asiento en un lugar. El residir se define de forma semejante, dándole un significado equivalente al considerarlo como estar de asiento en un lugar. La residencia sería la acción y efecto de residir, o bien el lugar en el que se reside. 
El círculo de las definiciones académicas se cierra con la palabra asiento ("estar de asiento","residir de asiento") que procede del verbo asentar, por lo que debe ser entendida dentro de estas definiciones en su significado de estabilidad y permanencia.

Para profundizar en su significado general y en un nivel elevado de abstracción se diría que la vivienda es un lugar con límites definidos, construida por la acción humana, en la que los hombres habitan con cierta estabilidad. Lo específico de la vivienda es por tanto el hecho de ser habitada, lo que implica necesariamente su ocupación. Es decir, cuando se plantea que exista una vivienda es necesario la instalación efectiva del hombre, la ocupación del sitio.

La adecuación entre las definiciones oficiales (normalmente estadísticas) que se utilizan en los censos y en otro trabajos empíricos, y la definición que se esta proponiendo es un problema que se debe abordar para conseguir su operatividad analítica.

En el Censo de Población y Viviendas se ha utilizado la siguiente definición: "Se entiende por vivienda a efectos de este Censo, a todo recinto estructuralmente separado e independiente que, por la forma en que fue construido, reconstruido, transformado o adaptado está concebido para ser habitado en la fecha del Censo, Instituto Nacional de Estadística (2001). Ahora bien, un recinto se considera separado sólo si “...está rodeado por paredes, muros, tapias, vallas, etc., y se halla cubierto por techo, que permite que una persona, o un grupo de personas, se aísle de otras con el fin de dormir, preparar, consumir alimentos y protegerse de las inclemencias del tiempo y del medio ambiente", Instituto Nacional de Estadística (2001). Y además “...se considera independiente si tiene acceso desde la calle o terreno público o privado, común o particular, o bien desde cualquier escalera, pasillo, corredor, etc., es decir, siempre que los ocupantes de la vivienda puedan salir o entrar de ella sin pasar por ningún recinto ocupado por otras personas" Instituto Nacional de Estadística (2001).

La definición censal de vivienda está concebida para contabilizar lo que se podría definir como "objeto vivienda", es decir, a todo recinto estructurado que ha sido construido para ser habitado. En esta definición se incluyen todos los recintos que aunque no estén ocupados en el momento del Censo, hayan sido concebidos para ello. En este caso se encontrarán tanto las viviendas vacías o desocupadas como aquellos recintos que son utilizados permanentemente como oficinas, almacenes, despachos, etc.; lo que evidentemente es muy confuso porque mezcla realidades y fenómenos muy diferentes. 
La definición de censal incluye el hecho de habitar para abarcar en este concepto a todos los recintos que sin ser concebidos como viviendas son utilizados como tal en el momento del Censo. Es curioso observar como esta definición se ajusta a la idea de vivienda del mundo occidental, pues evidentemente en países en los que dominan las tipologías de viviendas comunitarias, Schoenauer (1984), difícilmente podrían encajar algunos requisitos de la definición utilizada en nuestro país.

El Censo introduce el concepto de "vivienda familiar" para paliar los problemas originados por la definición anterior. Este concepto se concibe en los siguientes términos: "Se define como vivienda familiar (normal o corriente) a toda habitación o conjunto de habitaciones y sus dependencias, que ocupan un edificio o parte estructuralmente separada del mismo y que, por la forma en que han sido construidas, reconstruidas o transformadas, están destinadas a ser habitadas por una o varias personas, y en la fecha censal no se utilizan para otros fines. Las viviendas familiares serán incluidas en el Censo de Viviendas, con independencia de que estén ocupadas o no en el momento censal. No se incluyen en esta definición aquellos recintos construidos inicialmente para viviendas pero que en la época del Censo se utilizan exclusivamente para otro fines (viviendas que se ha transformado totalmente en oficinas, talleres, almacenes, etc.)" Comunidad de Madrid (1993)

Para resolver el caso de los recintos que a pesar de no haber sido concebidos para ser habitados, viven en ellos personas, el Censo introduce un nuevo concepto complementario al de "vivienda familiar". Este concepto es el de "alojamiento". Se entiende como alojamiento todos los recintos que no responden totalmente a la definición de vivienda familiar, bien por ser móviles, semipermanentes o improvisados, o bien porque no han sido concebidos en un principio con fines residenciales, pero que, constituyen residencia de una o varias personas en el momento del Censo", Comunidad de Madrid (1993). 
Para adecuar el concepto de vivienda que se propone al de vivienda censal puede bastar realizar las siguientes operaciones metodológicas:

- Eliminar del conjunto de "viviendas censales" aquellas que tienen un uso no residencial en exclusiva. Teóricamente con esta operación llegaríamos a lo que en el Censo se denominan "viviendas familiares".

- Partiendo de estas "viviendas familiares", incluir lo que el Censo define como "alojamientos".

En realidad el concepto de vivienda al que se ha llegado en este intento de definición coincide con la suma de los conceptos censales de "viviendas familiares" y de "alojamientos".

Introducido el concepto de vivienda, es en el proceso por el cual se define, proyecta, financia, construye, se termina y se habita lo que se entiende como viviendas destinadas a tal uso, el ámbito de trabajo de la presente investigación. Por tanto, en la promoción de viviendas residenciales enfocadas al uso de las mismas, a lo que se ha definido como habitar, el campo dónde se propone el modelo de integración que se desarrolla en el presente trabajo de investigación.

\subsection{Características del sector de la construcción:}

El sector de la construcción se ha caracterizado en alguna medida por la estacionalidad, baja especialización de las actividades, atomización financiera y organización piramidal vertical de las empresas. La estacionalidad ocasionada por la subcontratación de servicios y mano de obra, y el subarriendo de equipos, delimita la flexibilidad y eficiencia en el control de los procesos dentro de la empresa. La poca especialización de las actividades y tareas propias de la ejecución de las obras, producto de la baja cualificación de la mano de obra y de los bajos salarios. La organización del personal en las empresas es piramidal vertical, no son organizaciones matriciales que flexibilicen la toma de decisiones y haga controles paralelos en los diferentes frentes de trabajo, comenta Vélez Moreno (2001). 
González et al. (1997) señalan que en la actividad de construcción se presentan características propias que la diferencian notablemente de otros sectores, especialmente de la industria manufacturera. La naturaleza del producto final constituye la característica distintiva del sector. Ésta viene dada por su unicidad, inmovilidad y variedad.

a) Unicidad. Los productos de construcción son elaborados por proyecto, adaptándose al cliente o promotor, a su emplazamiento y a su funcionalidad. Esta unicidad de los proyectos desaconseja el uso de medios de producción especializados para cada proyecto, a diferencia de aquellas industrias que elaboran productos en serie. No obstante, en algunas actividades intermedias existe cierto grado de estandarización que facilita el aprovechamiento de las ventajas de especialización (prefabricación de vigas, paramentos, puertas, ventanas, etc.) .

b) Inmovilidad. La construcción se caracteriza por el levantamiento de una o varias estructuras inmóviles en un lugar predeterminado en el que se efectúan buena parte de las transformaciones. Por lo tanto, son los recursos productivos los que se desplazan hacia los productos en curso, y no éstos hacia los activos, tal y como suele ocurrir en la industria manufacturera. La consecuencia de esta ubicación exclusiva es que cada nuevo proyecto requiere un nuevo centro de trabajo, al no ser posible concentrar la actividad productiva en un único lugar.

c) Variedad. La tercera cualidad distintiva de la construcción es la elaboración de una gran variedad de productos finales, que incluye desde pequeñas reparaciones domésticas hasta grandes obras de infraestructura. Cada tipo de producto final incorpora su propia combinación de actividades intermedias heterogéneas. En consecuencia, a medida que una empresa integra horizontalmente tipos adicionales de construcción, ha de acometer actividades intermedias más dispares. Esto provoca que las actividades que realizan las empresas constructoras no sólo sean heterogéneas por su ubicación geográfica, sino también por su naturaleza.

Estas propiedades, relacionadas básicamente con la tecnología física, alteran algunas de las características de las transacciones ya comentadas y, en consecuencia, el tipo de mecanismos que los participantes deben introducir para salvaguardar sus intercambios. 
Las características expuestas en el presente apartado configuran un sector que presenta una alternativa interesante, para desarrollar modelos de integración que permitan a las empresas que participan en el mismo desarrollar ventajas competitivas de forma conjunta y animando a la integración de sus cadenas de suministro.

\section{Conclusiones y enfoque del campo de investigación:}

Durante el presente capítulo de Introducción se ha presentado un repaso al entorno macroeconómico, definido el ámbito de la tesis, repasado el concepto de la gestión de la Cadena de Suministro. Así mismo, se han visto los antecedentes del sector de la construcción y repasado dos aspectos para definir el ámbito de la tesis, por un lado la definición de vivienda y por otro las características del sector de la construcción. Cómo conclusión al presente capítulo, la tesis pretende presentar un modelo de integración en la cadena de suministro de la construcción de viviendas residenciales que une en el proceso a los distintos actores del mismo para obtener un resultado más acorde con la expectativa de los clientes finales del producto. 


\section{Referencias bibliográficas:}

$>$ ANTONIO PEREIRA RAMA y JULIAN CHAPARRO PELAEZ (2004). "Un sistema de información Interorganizacional como soporte a la Gestión en el sector de la edificación". ACEDE

$>$ BRISCOE, G., DAINTY, A. R. J. and MILLETT, S., (2001). "Construction supply chain partnerships: skills, knowledge and attitudinal requirements", European Journal of Purchasing \& Supply Management, Vol 7, Iss 4, pp.243-255.

$>$ BURBUJA INMOBILIARIA (s.f.) En Wikipedia, la enciclopedia libre. Recuperado el 19 de septiembre de 2011 de http://es.wikipedia.org/wiki/Burbuja_inmobiliaria_en_Espa\%C3\%B1a

$>$ CHRISTOPHER, M., (1998) "Logistics and Supply Chain Management". Strategies for reducing cost and improving service. Prentice Hall. Londres.

$>$ COMUNIDAD DE MADRID (1993a): "Censos de Población y Vivienda de 1991 de la Comunidad de Madrid. Tomo 1": Características demográficas básicas y fecundidad de la población. Madrid, Comunidad de Madrid, Consejería de Economía, Departamento de Estadística, 529 pp.

$>$ COMUNIDAD DE MADRID (1993b): "Censos de Población y Vivienda de 1991 de la Comunidad de Madrid. Tomo 7": Características de las viviendas. Madrid, Comunidad de Madrid, Consejería de Economía, Departamento de Estadística, 643 pp.

> CORTÉS ALCALÁ LUIS (1995). "La cuestión Residencial. Bases para una sociología del habitar”. ISBN 84-245-0709-6. págs 23-25.

$>$ CRANE, A., (1999). "The movement for innovation (M4I ) in construction in learning to succeed in construction". Conference Proceedings, CITB, November 25, London, pp. 2-8.

> GONZÁLEZ MANUEL, ARRUÑADA BENITO y FERNANDEZ ALBERTO (1997). "La decisión de subcontratar: el caso de las empresas constructoras". Investigaciones Económicas.vol. XXI (3), 501-521.

$>$ INSTITUTO NACIONAL DE ESTADÍSTICA (2001). "Censo de población y viviendas 2001: Definiciones Censales básicas”. http://www.ine.es/censo2001/6.pdf.

$>$ JOSEP CAPÓ VICEDO, MANUEL EXPÓSITO LANGA y, JOSÉ V. TOMÁS MIQUEL (2005). "La importancia de la gestión del conocimiento en la cadena de suministro de la construcción". IX Congreso de Ingeniería de Organización Gijón. 
MARTÍN HEIDEGGER (1950) Conferencia pronunciada el 7 de octubre de 1950 en Bühlerhöhe, en memoria de Max Kommerell; y repetida el 14 de febrero de 1951 en Stuttgart. Apareció publicada por primera vez en el volumen Unterwegs zur Sprache, Pfullingen, G. Neske, .

> REY ROMÁN, ANDRÉS FELIPE y ECHEVERRY, DIEGO (2005). "Prototipo para el control de obras y teorías para el manejo de excesos de liquidez". ICYA 2001-060.

> SCHOENAUER, NORBERT, (1984) "6.000 años de hábitat. De los poblados primitivos a la vivienda urbana en las culturas de oriente y occidente", Barcelona, Gustavo Gili.

> VÉLEZ MORENO LIGIA MARÍA (2001). "Construcción: Industrialización y Construcción." http://noticias.arq.com.mx/Detalles/1822.html. 
UNIVERSIDAD

POLITECNICA

DE VALENCIA 


\section{Capitulo 2}

\section{Estado del Arte: Introducción}

Desde la antigüedad el ser humano, ha tenido tendencia hacia las necesidades más básicas. Estas necesidades, al principio, se basaban únicamente en la comida. Esto llevó al ser humano a ser cazador. Posteriormente, y debido a una presencia más estable en un territorio, los seres humanos se convirtieron en ganaderos, agricultores, estableciendo colonias y creando comunidades. Estas comunidades, presentan los primeros asentamientos del hombre, y aparece por primera vez en la historia, la necesidad de la vivienda. Posiblemente una de las necesidades mayores del ser humano es la de la vivienda. Es por esto, que la construcción de viviendas, o espacios para vivir, entiéndase trabajar, relacionarse, etc. es sin duda uno de los procesos de producción más antiguos del mundo.

Asimismo, en la construcción de habitáculos para vivir, se han ido incorporando a lo largo del tiempo una serie nada despreciable de oficios. Al principio únicamente existían lo que identificaremos como albañiles, es decir, el oficio que se encarga de la construcción del habitáculo. Más adelante en la historia, aparecen los carpinteros que realizan las puertas y ventanas, los fontaneros que construyen las canalizaciones para llevar el agua o, más cerca del tiempo actual, para retirar las aguas fecales de los habitáculos. Ya en tiempos modernos aparecen nuevos oficios como pueden ser los electricistas que llevan la luz eléctrica a las casas, e industriales que se dedican a la instalación de aire acondicionado y otros oficios relacionados con las nuevas tecnologías. Esta diversidad de oficios da una idea de la complejidad del proceso de construcción de viviendas. En este proceso de construcción intervienen diversidad de empresas y de conocimientos que hay que abordar para conseguir lo que se propone. 
Sin embargo, si analizamos lo que se entiende por la cadena de suministro de la construcción, y la comparamos con otras cadenas de suministro, encontraremos que grado de evolución entre esta y las otras cadenas de suministro existe. En este análisis se pone de manifiesto que en la construcción queda mucho desarrollo por realizar. Por otro lado, es curioso, que precisamente la cadena de suministro de la construcción sea una de las cadenas de suministro con mayor complejidad dada la variedad de los oficios que en ella concurren, así como los procesos de montaje que en ella se realizan. Se enjuicia que por los motivos expuestos es suficiente para desarrollar y poder estudiar convenientemente cuáles han de ser las pautas que gobiernen en la gestión de la cadena suministro de la construcción.

Si se plantea desde cero como poder abordar la gestión de la cadena de la construcción se ha de estudiar las distintas disciplinas que aportan algo a ese complejo y viejo problema. Estas disciplinas, siendo muy diversas, se pueden englobar dentro de una de las siguientes categorías: gestión del conocimiento, gestión de la cadena de suministro, TQM, u otras disciplinas que han aparecido recientemente. Es por ello que se va a realizar un repaso al conocimiento que se ha puesto de manifiesto en este campo de la ciencia para poder clasificar, evaluar y buscar convenientemente una posible solución para abordar el complejo mecanismo de la cadena de suministro de la construcción. Es pues en este capítulo en el que se presentará un estado del arte en el tema referido.

\section{Estado de arte:}

Con el ánimo de recopilar todos aquellos textos donde se recogen referencias relacionadas con el aspecto del saber que ocupa en esta tesis se ha recogido en este apartado del documento una relación de dichos textos, haciendo constar el año, el autor, y un pequeño resumen de lo que se cita en él. En las referencias bibliográficas del final del capítulo se tienen todos aquellos aspectos necesarios para su localización.

Stevens G.C. (1989) en este artículo se recoge la necesidad de controlar los flujos de materiales desde los proveedores a través del proceso de adición de valor hasta el cliente. Existe una visión tradicional del problema enfocándolo como un análisis de la empresa únicamente. La propuesta es verlo de forma integral teniendo en cuenta la integración de toda la cadena de suministro. 
J. Sommerville (1994) en su trabajo Multivariate barriers to total quality management within the construction industry describe cuales son los problemas que se encuentra una sistemática de calidad como la TQM (Total Quality Management) cuando se enfrenta a un sector que se caracteríza por sus problemas históricos relacionados con la calidad. Es necesario tener en cuenta el factor humano, y especialmente los distintos tipos de personalidades existentes como un imperativo para poder obtener el éxito en la implantación de la filosofía TQM. El caso muestra las medias de la industria y los efectos en la organización y en los individuos aparecidos en la implantación de TQM.

Lambert et al. (1998) en 1998 The Council of Logistics Managements modificó su definición sobre logistica indicando que esta está relacionada con la cadena de suministro pero que no son términos sinónimos. Esta diferencia fue reconocida por las organizaciones profesionales de la logística y el desafío es como implementar con éxito una gestión de la cadena de suministro. Este artículo se concentra en la red sugerida en un artículo de 1997 de gestión de la cadena de suministro. Los casos estudiados demuestran la existencia de varias compañías que involucran a multiples miembros de la cadena de suministro usando los conceptos descritos.

Tah J.H.M. et al. (1998) en su trabajo Information modelling for case-based construction planing of highway bridge projects recogen que en la práctica de la planificación de construcción y el control de ejecucción en los proyectos de gran escala utilizando repositorios de datos están a menudo muy faltos de estructuración. Ellos proponen unos modelos que son usados para desarrollar repositorios de un gran número de información implementados en un sistema de gestión de base de datos para gestionar en la práctica de los grandes proyectos la información, la colaboración, la organización y la gestión del mismo. Proponen un prototipo de software desarrollado para los puentes como producto ejemplo de los grandes proyectos y para demostrar los conceptos y modelos propuestos en una aplicación práctica de los mismos.

Hong-Minh S.M. et al. (1999) hablan de las tendencias en la cadena de suministro de la construcción centradas en la orientación hacia los procesos de negocio e intercambios de personal. La evidencia viene de estrategias en primer lugar de partenariado, en segundo lugar de procesos de negocio enfocados a las necesidades del cliente y por último de relaciones de codesarrollo de la cadena de suministro. 
Ganeshan et al. (1999) este artículo se concentra en los modelos cuantitativos y computerizados que sirven de herramientas esenciales para tomar decisiones en los entornos de negocio. Estas herramientas son de particular importancia para el rápido crecimiento del área de conocimiento relacionada con la gestión de la cadena de suministro. El esfuerzo realizado en este artículo se concentra en mostrar un resumen sistemático de una gran variedad de nuevos temas para ser considerados, una nueva serie de modelos que están siendo desarrollados, nuevas técnicas para análisis, y nuevos métodos computerizados que se están poniendo a disposición de esta parte de la ciencia. La idea es que el artículo sirva como un test de graduación, referencia y guía para investigadores y futuros desarrollos en el área de modelos cuantitativos para la gestión de la cadena de suministro.

Lummus R.R. y Vokusrka R.J. (1999) el interés en la gestión de la cadena de suministro es creciente desde que las empresas vieron los beneficios de las relaciones de colaboración con sus propias organizaciones y sus proveedores y clientes. Este artículo define los conceptos de la gestión de la cadena de suministro y recoge su evolución histórica. En este artículo se recogen la importancia competitiva de relacionar la estrategia de la cadena de suministro y la estrategia de negocio así cómo algunas guías prácticas para el éxito en la gestión de la cadena de suministro.

Taylor J. y Bjornsson H., (1999) los citados autores proponen un sistema de mejora del inventario dentro de la cadena de suministro de la construcción basándose en un método de compartir información a través de Internet.

Wong A. y Fung P., (1999) Estos autores nos explican cómo aplicar TQM en una empresa constructora a lo largo de toda la cadena de suministro, contando un caso de aplicación en una empresa constructora de Hong Kong.

Croom S. et al. (2000) en su trabajo Supply chain Management: an analytical framework for critical literature review ofrecen un marco de análisis de gran parte de la literatura relacionada con la gestión de la cadena de suministro. Realizan una clasificación de toda esta literatura acorde a dos criterios, el contenido y la orientación metodológica.

Kumaraswamy M. et al., (2000) ponen de manifiesto, y demuestran, que la metodología de selección y las decisiones son críticas en la utilización de la cadena de construcción. 
Lambert M. y Cooper M.C. (2000) en su trabajo Issues in Supply Chain Management recogen que la exitosa gestión de la cadena de suministro requiere una integración funcional a través de la organización dónde el marketing juega un papel primordial. El desafío es determinar como de exitoso es el acoplamiento de esta integración.

Mathews J., et al. (2000) relatan cómo funcionan las alianzas en las relaciones de subcontratación en la cadena de suministro de la construcción: la calidad y la cadena de producción.

O’Brien W.J., (2000) hacen ver la gestión de la cadena de suministro como herramienta que permite reducir costos, aumentar el control y conseguir la planificación deseada en esta cadena de pequeñas empresas dedicadas a un proyecto común de construcción.

Vrijhoef R. y Koskela L., (2000) llegan a tres conclusiones importantes, la primera es que la cadena de suministro de construcción genera gran cantidad de desperdicios y problemas. La segunda es que estos desperdicios y problemas son generados en etapas anteriores a la etapa en que nos los encontramos. Y la tercera es que tanto los desperdicios como los problemas son generados mayoritariamente por el miope control y su obsolescencia en la cadena de suministro de la construcción.

Dainty A. R. J. et al. (2001) estos autores reflejan por qué la gestión de la cadena de suministro no ha tenido el éxito esperado en la integración de la cadena de suministro de la construcción. La existencia de pequeñas y medianas empresas en la cadena y su escepticismo hacia los métodos que se utilizan en la gestión de la cadena de suministro ha frenado la implantación de estas técnicas como procesos de mejora para obtener la integración de la cadena.

Briscoe G. et al. (2001) realizan un estudio y examinan las habilidades de las pequeñas y medianas empresas de la cadena de suministro de la construcción para integrarse en la gestión de la cadena de suministro. Estas habilidades son estudiadas bajo la perspectiva de las barreras que se pueden colocar hacia el futuro desarrollo de la gestión de la cadena de suministro. 
Fawcett S.E. y Magnan G.M. (2001) en este artículo encontramos que dentro de la terminología de la dirección de cadena de suministro es usada con frecuencia en el ambiente de dirección de materiales de hoy y generalmente es asociada con tecnologías avanzadas de la información, el servicio de logística rápido y sensible, la dirección de proveedor eficaz, y cada vez más con la dirección de relación con el cliente. La mayor parte de gerentes de materiales están familiarizados con la cadena de suministro. Sin embargo, la experiencia muestra que pocas empresas en realidad están en condiciones de integración de la cadena de suministro, lo que podríamos entender como la cadena de suministro extendida. Para obtener una visión exacta de la gestión de la cadena de suministro tal y como actualmente está en la práctica, se ha experimentado con los directores de las empresas buscando una vía, un multimétodo de acercamiento empírico, que implica revisiones y entrevistas de los casos estudiados. Las conclusiones revelan que la práctica de la cadena de suministro raras veces se parece al ideal teórico. Tres niveles diferentes de Gestión de la Cadena de Suministro implementada en la práctica es identificada con una serie de factores restrictivos. Los directores reconocen la tensión que existe entre el potencial competitivo de la Gestión de la cadena de Suministro y la dificultad inherente de colaboración entre empresas.

London K.A. y Kenley R., (2001) mantienen que la mezcla de los conceptos de la cadena de suministro con los modelos de organización industrial como metodología para entender el comportamiento de las empresas, la estructura de la industria y sus resultados es una importante contribución para ambos a la cadena de suministro de la construcción y la teoría económica de la misma.

Mentzer et al. (2001) en su trabajo Defining supply chain management aporta varias contribuciones al conocimiento de lo que los autores llaman el fenómeno de la Gestión de la Cadena de Suministro (SCM). La primera de ellas consiste en facilitar un marco integrador del SCM que sirva de guía a los que quieran implementar esta filosofía de entender los negocios y a los investigadores que deseen desarrollar el conocimiento en este área. La segunda es un análisis de los pre-requisitos que se deben tener para una correcta aplicación de la filosofía SCM poniendo de manifiesto cuales deben ser las condiciones tanto internas como externas para poder llegar a una gestión de la cadena de suministro integrando proveedores y clientes. En definitiva pone de manifiesto los campos que se abren ante los nuevos fenómenos de la SCM y la orientación hacia la cadena de suministro (SCO).

Tah J.H.M. y Carr V., (2001) explican como intentar desarrollar la posibilidad de integrar la gestión del conocimiento y las técnicas de la gestión de proyectos de riesgo en la cadena de suministro de la construcción. Como pueden ser almacenados en una base de datos como repositorio del conocimiento. 
Hong-Minh S. (2002) El objetivo de esta tesis es poner a prueba si el suministro de principios de gestión de la cadena se puede utilizar en el Reino Unido, la industria privada de construcción de viviendas y luego de analizar el efecto que tiene sobre el rendimiento. El rendimiento de las medidas utilizadas combina criterios de gestión de la cadena de suministro, criterios específicos y criterios de dinámica de sistemas, centrándose especialmente en la amplificación de la demanda. Los análisis de la investigación de tres diferentes cadenas de suministro de las principales materias primas necesarias para la construcción de viviendas. El impacto en el rendimiento de cada estrategia es analizada para entender las implicaciones de la ejecución específica y los principios de gestión de la cadena de suministro. Se concluye que la reducción de la base de proveedores y la concentración de la oferta ha mejorado considerablemente el rendimiento.

Love P.E.D. et al., (2002) demuestran que las relaciones de cooperación pueden ser utilizadas para crear una cultura donde aprender mutuamente y conseguir mejoras en los proyectos de construcción.

Min H. y Zhou G. (2002) en su trabajo Supply Chain Modeling: past, present and future nos muestran como algunas empresas han centrado sus esfuerzos en integrar las distintas funciones separadas en otra época, planificando, controlando y diseñando la cadena de suministro como un todo. En un esfuerzo por mejorar la integración de las cadenas de suministro así como las empresas que participan en ellas, el artículo resume los modelos pasados de cadena de suministro, los desafíos y las oportunidades clave asociadas con el modelado de la cadena de suministro. También ofrecen varias guías para el desarrollo e implementación de modelos de cadena de suministro.

Existe una propuesta consistente en introducir una investigación interdisciplinar sobre dos grupos de modelos que se pueden encontrar en los textos de O'Brien W.J. et al., (2002). Tanto en la organización industrial como los modelos analíticos de la gestión de la cadena de suministro, desde mediados de los años 90 se ha intentado mejorar la gestión de la cadena de suministro, la construcción de un modo incompleto y la propuesta que se recoge de sus autores es realizar una investigación interdisciplinar de ambos modelos. 
Shimizu y Cardoso (2002) exponen que debido a las recientes transformaciones estructurales en el sector de la construcción en muchos países como Brasil, se produce mucha mayor subcontratación en la actualidad que en el pasado. En consecuencia, la gestión de la cadena de suministro se ha hecho más importante, incluyendo la gestión de los subcontratistas. Las redes de cooperación parece ser una forma ventajosa de la organización de la cadena de suministro que es beneficiosa para los subcontratistas y para las empresas constructoras. Las redes de cooperación son consecuencia de las alianzas estratégicas entre algunos agentes de la cadena de suministro. Estas empresas se han organizado conjuntamente y cooperan, alcanzando mejores resultados de los que obtendrían individualmente. Con el objetivo principal de los subcontratistas y los constructores del edificio, este trabajo, basado en una revisión de la literatura, busca hacer frente a la decisión de hacer o comprar (subcontratación) y analiza su importancia en la formación y el desarrollo de redes de cooperación en la construcción de edificios.

Tserng H.P. y Lin P.H., (2002) estos autores, basándose en herramientas desarrolladas en plataformas sobre Internet, proponen un modelo llamado ASAP (Accelerated Subcontrating And Procuring) que pretende la optimización de la cadena de suministro de la construcción a través de la gestión integrada de los subcontratistas.

Arbulu R.J. et al., (2003) nos exponen que las técnicas de reingeniería de procesos y la gestión de la cadena de suministro pueden ser aplicadas para eliminar las ineficiencias producidas en la cadena de suministro de la construcción se analizan tiempos del ciclo así como los costes y valores añadidos de cada etapa dentro de la cadena.

Childerhouse P. et al., (2003) recogen procesos BPR (Business Process Reengineering) que son aplicados a las cadenas de suministro de la construcción en empresas del Reino Unido. Los resultados de mejoras son medidos y estudiados en otros casos.

Green S.D. y May S.C., (2003) hacen una revisión profunda y directa del proceso de reingeniería dentro de la cadena de suministro de la construcción, analizando los distintos factores en donde se puede aplicar y con qué consecuencias. 
Bertelsen S. and Koskela L. (2004) comentan que Lean Construction ha existido por derecho propio durante más de diez años. Al mismo tiempo los cinco principios lean, como se indica por Womack y Jones, han ganado una posición firme en las industrias manufactureras y el término magra se ha convertido en un término familiar en fabricación. Por desgracia y para confusión, la comprensión de la inclinación ha tomado trayectorias diferentes en estas dos comunidades. En la fabricación, a menudo se expresó que los principios (cinco) magra proporcionan una comprensión madura de la asignatura, es decir, el punto final. Sin embargo, al mismo tiempo la teoría basada en la comprensión de la gestión de la construcción ha ido más allá de las teorías genéricas magra y los principios, consagrados en la Toyota. Sistema de producción, que abarca disciplinas tales como la complejidad, emergencia, conversaciones, y el aprendizaje permanente. En la construcción, el Sistema de Producción Toyota es por lo tanto más bien un punto de partida. En el documento se establece una visión general de los principios rectores, la mejor gestión de los proyectos, y se argumenta que la construcción magra ha progresado más allá.

Briscoe G. et al., (2003) analizan el papel del cliente como factor clave con sus decisiones, en la integración y la ejecución de la cadena de suministro de la construcción. Resultados como este papel del cliente obtiene beneficios en una aplicación de la cadena de suministro.

Capó J.et al. (2004) exponen en su trabajo una revisión de la literatura existente sobre la relación entre la gestión del conocimiento y la estructura organizacional, para pasar posteriormente a analizar los requisitos que deben darse para crear y compartir conocimiento en un contexto interorganizacional, en concreto, en el caso particular de la cadena de suministro.

Se desprende de este estudio que, para que se de una correcta gestión del conocimiento, se hacen necesarios nuevos modelos organizativos para las empresas constituyentes de la misma y que no son otros que la configuración de la cadena de suministro como una red dinámica o verdadera Empresa Virtual.

H. J. y Tah M., (2004) desarrollan el funcionamiento de un simulador electrónico de gestión de la cadena de suministro que permite a las empresas, libres de riesgos y de problemas, ver la efectividad del modelo y captar sus ventajas. 
Hakanson H. and Jahre M. (2004) desde un punto de vista teórico de la industria la investigación realizada ha tomado diferentes perspectivas incluido el mercado, la relación y los enfoques basados en la red. En el documento presenta un revisión de la literatura de investigación sobre los costos de transacción (mercado), la gestión de la cadena de suministro (Relación) y la red industrial (red) centrándose en la industria de la construcción, y concluyendo que la "tecnología básica" de esta industria se caracteriza por diferentes lógicas económicas. Relativas a las lógicas de la clasificación de Thompson, el trabajo concluye que es necesario para la investigación que proporciona la comprensión de las distintas combinaciones posibles de la lógica, es decir, lo que ellos llaman híbridos.

Love P.E.D. et al., (2004) presentan la posibilidad de encontrarse con el desarrollo de su modelo de gestión de la cadena de suministro de la construcción sin fisuras. Adicionalmente estos autores muestran los comentarios de los partícipes en la cadena de suministro de la construcción.

Obonyo, E. A. (2004) presenta en esta tesis un estudio de la naturaleza fragmentada de las actividades involucradas en la especificación y adquisición de productos de construcción existentes a través de Internet. Estos enfoques han perpetuado la fragmentación en este ámbito y esto ha dado lugar a un problema conocido como "anarquía digital". La tesis describe el diseño y desarrollo de una aplicación basada en la metáfora de los agentes de software para solucionar este problema.

Ruikar K. (2004) los resultados de la investigación indican que el uso del comercio electrónico se encuentra todavía en su infancia dentro de la industria de la construcción. El uso actual del comercio electrónico ha dado lugar a la automatización de procesos, sin embargo, no hay evidencia de la reingeniería de procesos. Tales prácticas, aunque beneficiosas a corto plazo, pueden tener implicaciones a largo plazo en el que los usuarios finales no puedan realizar la plena utilización de la tecnología y por lo tanto no beneficiarse plenamente de ella. El modelo y el prototipo de e-readiness de evaluación desarrollado como parte de este estudio permitirá a las organizaciones de la construcción adoptar con éxito el comercio electrónico y explotar su potencial. 
Sobotka A. and Czarnigowska A. (2004). En este documento se expone una serie de problemas de logística del proyecto de construcción, con especial atención a los sistemas de abastecimiento, y presenta los resultados de un estudio de las rutinas de alimentación de contratistas polacos. Sobre la base de la encuesta, se han descrito los patrones de desarrollo de sistemas logísticos. Los resultados de las simulaciones de costos indican que en los procesos de externalización logística de suministros, teniendo en cuenta el estado actual del mercado de la construcción de Polonia, pueden reducirse los costes. El documento hace hincapié en que la creación de directrices logísticas de un proyecto en sus etapas iniciales de la planificación y un diseño de servicio logístico integrado para el proyecto puede ayudar a encontrar maneras de hacer un proyecto de construcción más eficaz.

Stadtler Hartmut (2004) en su trabajo Supply Chain Management and advanced planning-basics, overview and challenges intenta extraer lo esencial de la Gestión de la Cadena de Suministro (SCM) y planificación avanzada en forma de dos marcos conceptuales: la casa de SCM y la matriz de planificación de la cadena de suministro. Así mismo presenta las ultimas investigaciones en planificación avanzada y el software necesario para llevarla a cabo.

Xialong Xue et al, (2004) estos autores estudian la integración de los agentes de la cadena de suministro de la construcción entendida como una red de trabajo y su implicación. Se crea la figura del agente tecnológico y con multi atribuciones para el desarrollo del modelo.

Briscoe G. y Dainty A.R.J., (2005) en un artículo bastante crítico con las teorías desarrolladas hasta la fecha nos intentan determinar los problemas empíricos para poder integrar la cadena de suministro de la construcción revisando distintos aspectos prácticos, enfoques, etc.

C. Fortune y S. Setiawan (2005) recogen en su documento como las asociaciones de viviendas en el Reino Unido están siendo alentadas a cambiar la forma en que obtienen sus proyectos de construcción. Este trabajo pretende ofrecer una instantánea de la práctica actual en relación con el uso de la asociación como un método de contratación. 
Capó J. et al. (2005) recogen en su artículo "La importancia de la gestión del conocimiento en la cadena de suministro de la construcción", que dicho sector está pasando actualmente, por procesos de internacionalización y/o especialización de sus unidades productivas, debiendo ser su tendencia la de convertir sus cadenas productivas en auténticas "cadenas virtuales", en las que se incluyan los proveedores y subcontratas como parte de las mismas. En dicho trabajo se analizan las características principales de la cadena de suministro de los proyectos constructivos, así como la importancia de que se produzca una verdadera gestión del conocimiento en la misma, para aumentar la competitividad de las empresas constructoras.

CSCMP (2005) Council of Supply Chain Management Profesionals puso de manifiesto entre otras cosas que la integración de la cadena de suministro es más retórica que real en la mayor parte de las empresas europeas. Sin embargo, las investigaciones señalan una clara indicación del valor de la integración de los proveedores clave para mejorar la percepción del cliente. Es el primer trabajo empírico que mide el estado de integración de la cadena de suministro en las empresas europeas y el desafío que les aparece ante esta situación. Los profesionales de la gestión de la cadena de suministro pueden tener una idea clara de las áreas a mejorar, así como de los esfuerzos colaborativos a realizar.

Gielingh W. (2005). El método descrito en este libro es sobre enfoques de diseño y producción científica como proceso. Se basa en un modelo del ciclo Leaming de los seres humanos, las organizaciones inteligentes mediante las aplicaciones informáticas. El modelo cognitivo tiene dos polos: la realidad física y el conocimiento. En un proceso cognitivo, el conocimiento se obtiene de la realidad a través de impresión. Los seres humanos, las organizaciones y los sistemas pueden aprender de la realidad, pero también puede modificar la realidad sobre la base de las ideas. La metodología es compatible con una aproximación de diseño de arriba hacia abajo en los que las características únicas de un proyecto se traducen en especificaciones funcionales de la totalidad, así como sus partes.

Kärnä S. y Junnonen J., (2005) aquí se ponen de manifiesto sistemas de evaluación y feed-back de los clientes que se ponen en marcha no sólo cuando el producto ya ha sido terminado sino con anterioridad, durante el proceso de diseño y ejecución de la obra. 
Lejeune M. y Yakova N. (2005) en su trabajo On Characterizing the 4 C's in Supply Chain Management nos proponen una tipología de configuración de la cadena de suministro consistente y basada en la correspondencia entre la teoría de Fiske de las formas relacionadas (1990) y el concepto de interdependencia analizado en el contexto de la gestión de la cadena de suministro.

Samaddar et al. (2005) en su trabajo Inter-organizational information sharing: The role of supply network configuration and partner goal congruence presentan un marco teórico de investigación entre las relaciones del diseño de la red de suministro (SN) y el intercambio de información entre organizaciones (IIS). Los conceptos se desarrollan usando una clasificación según dos variables: el volumen de información compartida y la importancia estratégica de esa información. Argumentos teóricos y el análisis de datos secundarios son usados para el desarrollo de propuestas relacionadas con la asociación entre las configuraciones de SN y los tipos de IIS, así como el papel de la estructura de coordinación en dichas organizaciones.

Voordijk H. et al., (2006) estos autores estudian la utilidad y el encaje de un modelo avanzado en tres dimensiones en la cadena de construcción, y cómo se adaptan las distintas partes de la cadena a este modelo.

O. Salem et al. (2006) en su trabajo Lean Constrution de la teoría a la Implantación recogen las diferencias en las técnicas del Lean Manufacturing entre las cadenas de producción de la industria y los procesos de construcción. Aunque las técnicas de Lean Production están en forma embrionaria en los procesos de construcción día a día van ganando en la aplicación porque afectan a los resultados finales del proceso de construcción.

Cutting-Decelle A.F. et al. (2007). Con la creciente importancia de las tecnologías de comunicación basadas en la informática, la comunicación de redes se está convirtiendo en fundamental en la gestión de la cadena de suministro. Teniendo en cuenta los objetivos de la cadena de suministro: tener los productos adecuados en las cantidades adecuadas, en el lugar correcto, en el momento oportuno y a un costo mínimo, la gestión de la cadena de suministro se encuentra en la intersección de diferentes sectores profesionales. Este es particularmente el caso en la construcción. En este documento se hace una revisión de los principales enfoques para suministrar la información de la cadena de suministro que se utilizará principalmente en las industrias manufactureras. El documento analiza la medida en que éstas se han aplicado a la construcción. También hay reseñas de los acontecimientos en curso y las actividades de investigación en este ámbito. 
Vrjihoef R. and Ridder H. (2007). En este trabajo los autores aplican la teoría de sistemas e ingeniería de sistemas y la proponen como una solución para la sistemática mejora de la cadena de suministro de la construcción. A través de un proceso de configuración de ingeniería de organización, la investigación recogida tiene como objetivo construir de una forma integrada y mejorar las cadenas de abastecimiento en la construcción, con teóricos y empíricos bloques de construcción. Los bloques de construcción teórica se encuentran en cuatro tipos de teoría: sociales, económicos, de organización y producción. Más tarde, en la investigación empírica, se determinarán las aplicaciones de integración de la cadena de suministro de la construcción en comparación con otros sectores, para demostrar el potencial de mejora y las repercusiones de la integración de la cadena de suministro de la construcción.

Bishop et al. (2008) desarrollan un trabajo titulado "Aprendiendo en la construcción, las relaciones colaborativas y competitivas en la industria de la construcción Británica". En el marco del actual sistema, los contratistas deben competir únicamente en el precio, los riesgos se trasladan a los siguientes en la línea y los conflictos están institucionalizados a través de complicados, pero inevitablemente incompletos contratos. Sin embargo, en virtud del trabajo en colaboración de los costes y riesgos del proyecto son compartidos y las partes interesadas se comunican de manera abierta y libremente, a menudo en la ausencia de contratos bien especificados. El paso de la primera a la segunda se le pida y alentado por las investigaciones del gobierno, los grandes clientes del sector público y las normas de construcción - representa un cambio hacia un clima en el que los problemas son compartidos y resueltos independientemente de que se produzcan en el sistema productivo (un proceso conceptualizado como "knotworking" en la literatura). El documento sostiene que tales teorías del aprendizaje y las presiones políticas desde arriba no toman suficientemente en cuenta la pesada mano de la historia en el sector y la importancia de comprender la naturaleza de los sistemas productivos.

Una vez recogidos esta serie de autores y enfoques relacionados con la parte del conocimiento que se está estudiando se pasa a realizar un planteamiento de análisis que facilite el enfoque hacia el modelo de pensamiento que se propone en la parte de la ciencia que nos ocupa. En el siguiente capítulo se recogen distintos puntos de vista de cómo poder analizar, clasificar y poder extraer con mayor facilidad conclusiones acerca de los mismos. 


\section{Tipología:}

Una posible clasificación de los artículos publicados sobre la gestión de la cadena de suministro en la construcción puede basarse en las técnicas de resolución que se plantean en cada uno de los casos. Así, se encuentra que existen artículos que se enfocan en una resolución basada en el uso de herramientas informáticas que permitan conocer en tiempo real, o lo más ajustado posible, todo aquello que está ocurriendo a lo largo de la cadena. Un segundo grupo de artículos, o lo que se puede entender también como línea de pensamiento, basa la solución del problema en el empleo de técnicas relacionadas con el TQM. Otro gran grupo de artículos, o como se dice anteriormente de línea de pensamiento, se basa en la resolución del problema en la aplicación de técnicas relacionadas con la gestión de la cadena de suministro. Otro grupo de pensamiento utiliza la reingeniería de procesos como método para conseguir mejorar la gestión de la cadena suministro de la construcción. Se puede identificar también, otra línea de pensamiento que utiliza la gestión del conocimiento y la gestión de proyectos como herramientas para aportar mejoras a la gestión de la cadena de la construcción. Por último, aparece otro gran grupo de pensamiento que tiene en común la integración de los agentes de la cadena en distintas formas para aportar soluciones a la gestión de la cadena de suministro. De esta manera, y siguiendo las líneas de pensamiento que se acaban de citar se tiene que:

a.- La línea de pensamiento relacionada con la utilización de herramientas informáticas como aporte a la solución del problema de la gestión de la cadena de suministro de la construcción abarca varios artículos que van desde el uso de herramientas sobre internet, hasta el desarrollo de optimizadores y simuladores para el cálculo de las órdenes de reposición. (John Taylor y Hans Bjornsson,1999), (H. Ping Tserng y Pao H. Lin, 2002), (Joseph H. y M. Tah, 2004).

b.- Dentro de las soluciones propuestas por los autores que consideran el TQM como herramienta base para mejorar el acceso de la cadena construcción encontramos su aplicación en una empresa constructora en Hong Kong (Alfred Wong y Patrick Fung, 1999) Total quality management in the construction industry in Hong Kong: a supply chain management perspective. Existen dentro de esta línea de pensamiento otros artículos y autores como pueden ser: GK Kanji, A Wong (1998) Quality culture in the construction industry, Wong A., et al. (1999). Relationships for quality improvement in the Hong KongChina supply chain, Kanji G. K.; Wong A. (1999). Business Excellence model for supply chain management, y J. Sommerville (1994) Multivariate barriers to total quality management within the construction industry. 
c.- Dentro del grupo de las soluciones basadas en la gestión de la cadena de suministro se puede encontrar la consideración de esta técnica como una posibilidad de mejorar los niveles de costes y la optimización de la cadena de suministro de la construcción o la búsqueda de etapas dónde resolver los problemas de la cadena de suministro. Existe diversidad de enfoques hacia la misma problemática a resolver. (O.'Brien W.J., 2000), (Rubén Vrijhoef y Lauri Koskela, 2000), (Andrew R.J. Painty et al., 2001), (Peter E. D. Love, et al., 2004).

d.- Dentro del grupo de conocimiento que basa su estrategia en la reingeniería o en el estudio de procesos son un abordaje de la problemática desde un enfoque al análisis de procesos, búsqueda de la ineficiencia y la optimización de las etapas. (Roberto J. Arbulu et al., 2003), (Paul Childerhouse et al., 2003), (Stuart D. Green y Susan C. May, 2003)

e.- Como se ha comentado existe un grupo de pensamiento que basándose en el elevado peso del riesgo en la gestión de los proyectos de construcción intenta desarrollar la posibilidad de integrar la gestión del conocimiento y las técnicas de la gestión de proyectos de riesgo en la cadena de suministro de la construcción. O pueden ser almacenados en una base de datos como repositorio del conocimiento. Así se pueden hallar trabajos como los de J:H.M. Tah y V. Carr, (2001) Towards a framework for project risk knowledge management in construction supply chain, o V. Carr and J. H. M. Tah, (2001) A fuzzy approach to construction project risk assessment and analysis: construction project risk management system, o J. H. M. Tah, , V. Carr and R. Howes (1998) Information modelling for casebased construction planning of highway bridge projects Advances in Engineering Software. Elsevier y por ultimo el de Søren Degn Eskesen et al. (2004) Guidelines for tunnelling risk management: International Tunnelling Association, Working Group 2. Otros autores que han trabajado en la linea de investigación relacionando la gestión del conocimiento y la cadena de suministro en el sector de la construcción son Capó Vicedo J. et al. (2005) y Capó Vicedo J, et al. (2004)

f.- Dentro del grupo que se ha clasificado como integración de la cadena el enfoque de los autores de esta tipología es basar la integración de la cadena de suministro de la construcción en la relación existente entre los actores que intervienen en el proceso constructivo, las relaciones de colaboración, las habilidades y encaje de las empresas entre sí son parte fundamental de los textos que podríamos clasificar dentro de esta tipología. (S.M. Hong-Minh, et al., 1999), (Jason Mathews et al., 2000), (Geoffrey Briscoe et al., 2001), (Peter E.D. Love et al. 2002), (William J.O. Brien et al., 2002). 
Un artículo fuera de estas líneas de pensamiento que parece especialmente interesante como muestra de la complejidad de aplicación de las distintas técnicas y enfoques al problema de mejorar la cadena de suministro en la construcción es el que se titula integración de la cadena de suministro: una meta escurridiza (Geoffrey Briscoe y Andrew Painty, 2005) en donde se intenta determinar los problemas empíricos para poder integrar la cadena de suministro de la construcción revisando distintos aspectos prácticos, enfoques etc. 


\section{Breve revisión taxonómica:}

Es de interés para el modelo que se presenta poder realizar una breve revisión de las investigaciones realizadas sobre la Gestión de la Cadena de Suministro y unas propuestas taxonómicas de los trabajos realizados.

Se conocen diversos trabajos de investigación que de una manera u otra abordan esta misma temática, tenemos por ejemplo a Bowersox (1969) dónde se sugiere que la función de distribución puede proveer de una ventaja competitiva a través de su integración en la compañía. Shapiro (1984) propone un marco dónde balancear los sistemas logísticos y la estrategia competitiva dentro de la compañía. Houlihan (1985) refuerza la idea de la gestión de la cadena de suministro incorporando el focus logístico dentro de las decisiones estratégicas de la compañía. Langley (1992) divide la evolución logística en tres etapas: pasado (1950-1964), presente (1965-actual) y futuro. Desde este artículo diversos autores como son, Stevens (1989), Masters y Pohlen (1994), Mourits y Evers (1995), Thomas and Griffin (1996), Ganeshan R. et al. (1999) han añadido al cuerpo de la ciencia marcos conceptuales que ayuden al diseño y gestión de la cadena de suministro.

Ganeshan et al. (1999) clasifica las investigaciones sobre la gestión de la cadena de suministro en tres diferentes categorías: las que tienen que ver con la estrategia competitiva, las que tienen que ver con el enfoque táctico y las que tienen que ver con la eficiencia en las operaciones. Adjuntamos tres gráficos dónde se pueden ver las clasificaciones tal y como se recogen en sus estudios. 


\begin{tabular}{|c|c|c|c|}
\hline & $\begin{array}{l}\text { Subcategorias } \\
\text { Tácticas } \\
\text { Enfocadas }\end{array}$ & Definición & $\begin{array}{l}\text { Listado de artículos de temas } \\
\text { tácticos de la gestión de la } \\
\text { Cadena de Suministro }\end{array}$ \\
\hline$\overline{\mathbf{A}}$ & Objetivos & $\begin{array}{l}\text { Entendimiento de la dinámica de la } \\
\text { cadena de suministro y desarrollo } \\
\text { de objetivos para la cadena de } \\
\text { suministro global que incluye } \\
\text { análisis de cómo los objetivos dan } \\
\text { respuesta a las necesidades de la } \\
\text { compañía. Se incluye una } \\
\text { evaluación contextual de las } \\
\text { alternativas de la cadena de } \\
\text { suministro }\end{array}$ & $\begin{array}{c}\text { Beamon (1996); Bloemhof- } \\
\text { Ruwaard et al. (1995); Davis } \\
\text { (1993); Ernst y Kamrad (1996); } \\
\text { Fisher (1997); Forrester (1958); } \\
\text { Forrester (1961); Fuller et al. } \\
\text { (1993); Gopal (1992); Oliver y } \\
\text { Webber (1992); Shapiro (1984); } \\
\text { Slater (1976) }\end{array}$ \\
\hline B & Diseño & $\begin{array}{l}\text { Debe determinar la forma de la } \\
\text { cadena de suministro. Incluye el } \\
\text { diseño de cadenas de suministro o } \\
\text { las decisiones de localización. Debe } \\
\text { centrarse en los objetivos del } \\
\text { diseño y no sólo el desarrollo de } \\
\text { una herramienta utilizada en la } \\
\text { toma de decisiones. }\end{array}$ & $\begin{array}{l}\text { Amtzen et al. (1995); Berry y } \\
\text { Naim (1996); Camm et al. } \\
\text { (1997); Mourrits y Evers (1995); } \\
\text { Revelle and Laporte (1996); } \\
\text { Towill et al. (1992) }\end{array}$ \\
\hline C & $\begin{array}{c}\text { Ventajas } \\
\text { Competitivas }\end{array}$ & $\begin{array}{l}\text { Cómo la gestión de la cadena de } \\
\text { suministro puede incrementar la } \\
\text { competitividad de la empresa. } \\
\text { Incluye herramientas de } \\
\text { planificación estratégica. }\end{array}$ & $\begin{array}{c}\text { Cohen y Mallik (1997); } \\
\text { Copacino y Rosenfield (1992); } \\
\text { Heskett (1997); Houlihan } \\
\text { (1985); Jones y Riley (1984); } \\
\text { McMullan (1996); Roberts } \\
\text { (1990); Scott y Westbrook } \\
\text { (1991); Stevens (1989); Towill } \\
\text { (1997) }\end{array}$ \\
\hline D & $\begin{array}{c}\text { Perspectivas } \\
\text { Históricas }\end{array}$ & $\begin{array}{l}\text { Evolutivo o histórico perspectivas } \\
\text { que nos dan una visión de la } \\
\text { naturaleza estratégica de la gestión } \\
\text { de la cadena de suministro }\end{array}$ & $\begin{array}{c}\text { Bowersox (1969); Carter y } \\
\text { Narasimhan (1996); Lalonde } \\
\text { (1993); Langley (1992); Lee and } \\
\text { Billington (1995); Master y } \\
\text { Pohlen (1994); Thomas and } \\
\text { Griffin (1996) }\end{array}$ \\
\hline
\end{tabular}

Fig 2_1_Resumen de las investigaciones sobre estrategia competitiva. Ganeshan et al. (1999) 


\begin{tabular}{|c|c|c|c|}
\hline & $\begin{array}{c}\text { Subcategorias } \\
\text { Tácticas Enfocadas }\end{array}$ & Definición & $\begin{array}{l}\text { Listado de artículos de temas } \\
\text { tácticos de la gestión de la } \\
\text { Cadena de Suministro }\end{array}$ \\
\hline $\mathbf{A}$ & $\begin{array}{l}\text { Relaciones de } \\
\text { Desarrollo }\end{array}$ & $\begin{array}{l}\text { Desarrollando relaciones } \\
\text { hacia arriba de la cadena y } \\
\text { hacia debajo de la misma } \\
\text { con terceras partes }\end{array}$ & $\begin{array}{l}\text { Choi and Hartley (1996); Gentry } \\
\text { (1996); Henig et al. (1997); } \\
\text { Holmlund and Kock (1996); } \\
\text { Prida and Gutierrez (1996); } \\
\text { Tagaras and Lee (1996); Walton } \\
\text { (1996) }\end{array}$ \\
\hline B & $\begin{array}{l}\text { Operaciones } \\
\text { Integradas }\end{array}$ & $\begin{array}{l}\text { Gestión integrada de las } \\
\text { operaciones con alcance de } \\
\text { objetivos de eficiencia en } \\
\text { la dirección de las mismas, } \\
\text { incluyendo ingeniería, } \\
\text { producción, compras e } \\
\text { incluso relaciones arriba y } \\
\text { debajo de la cadena }\end{array}$ & $\begin{array}{c}\text { Cohen y Lee (1998); Lamming } \\
\text { (1996); Leenders et al. (1994); } \\
\text { Roy y Potter (1996); } \\
\text { Viswanathan y Mathur (1997) }\end{array}$ \\
\hline C & $\begin{array}{l}\text { Transporte y } \\
\text { Distribución }\end{array}$ & $\begin{array}{l}\text { Alcanzando eficiencias en } \\
\text { la gestión del transporte y } \\
\text { la distribución física como } \\
\text { un sistema integrado }\end{array}$ & $\begin{array}{l}\text { Anupindi y Bassok (1996); } \\
\text { Bowersox (1972); Caputo y } \\
\text { Mininno (1996); Geoffrion y } \\
\text { Graves (1974); Geoffrion y } \\
\text { Powers (1995); Min (1996); } \\
\text { Robison et al. (1993); Sttaerfield } \\
\text { y Robinson (1996) }\end{array}$ \\
\hline D & Sistemas & $\begin{array}{l}\text { Desarrollo de operaciones } \\
\text { y sistemas de información } \\
\text { o el uso de los sistemas de } \\
\text { información para alcanzar } \\
\text { los objetivos estratégicos }\end{array}$ & $\begin{array}{c}\text { Bhaskaran (1996); Bowersox y } \\
\text { Morash (1989); Hammel y } \\
\text { Kopczak (1993); Verwijmeren et } \\
\text { al. (1996) }\end{array}$ \\
\hline
\end{tabular}

Fig 2_2_Resumen de las investigaciones sobre

Enfoque Táctico. Ganeshan et al. (1999) 


\begin{tabular}{|c|c|c|c|}
\hline & $\begin{array}{l}\text { Subcategorias } \\
\text { Operativas }\end{array}$ & Definición & $\begin{array}{c}\text { Listado de artículos de temas } \\
\text { operativos de la gestión de la } \\
\text { Cadena de Suministro } \\
\end{array}$ \\
\hline$\overline{\mathbf{A}}$ & $\begin{array}{l}\text { Gestión y Control de } \\
\text { Inventario }\end{array}$ & $\begin{array}{c}\text { En cuanto a la eficiencia } \\
\text { operativa de la cadena de } \\
\text { suministro, la determinación y } \\
\text { medición de los resultados del } \\
\text { inventario. También incluye la } \\
\text { inversión en inventarios, los } \\
\text { niveles de servicio, los } \\
\text { sistemas de adjudicación y la } \\
\text { teoría multinivel del inventario }\end{array}$ & $\begin{array}{c}\text { Alderson (1957); Anupindi y } \\
\text { Akella (1993); Cachon y Fisher } \\
\text { (1997); Clark (1972); Clark y } \\
\text { Scarf (1960); Garg y Tang } \\
\text { (1997); Lee y Billington (1993); } \\
\text { Stenger (1994); Stenger (1996); } \\
\text { Zinn y Levy (1988); Zinn y } \\
\text { Bowersox (1988) }\end{array}$ \\
\hline B & $\begin{array}{l}\text { Producción, } \\
\text { Planificación y } \\
\text { Programación }\end{array}$ & $\begin{array}{c}\text { Determinar y medir el } \\
\text { rendimiento de la producción, } \\
\text { la planificación y } \\
\text { programación para contribuir } \\
\text { al eficaz funcionamiento de la } \\
\text { cadena de suministro }\end{array}$ & $\begin{array}{c}\text { Graves et al (1998); Kruger } \\
\text { (1997); Lederer y Li (1997); } \\
\text { Levy (1997); O’Brien y Head } \\
\text { (1995) }\end{array}$ \\
\hline C & $\begin{array}{l}\text { Compartir } \\
\text { Información, } \\
\text { Coordinar y } \\
\text { Monitorizar }\end{array}$ & $\begin{array}{c}\text { Especifica esquemas de } \\
\text { coordinación y control en el } \\
\text { intercambio de información } \\
\text { necesaria en la operación } \\
\text { eficiente de la cadena de } \\
\text { suministro. }\end{array}$ & $\begin{array}{l}\text { Fisher y Raman (1996); } \\
\text { Gavimeni et al. (1998); Lee et al. } \\
\text { (1997); Moinzadeh y Aggarwal } \\
\text { (1997); Srinivasan et al. (1994) }\end{array}$ \\
\hline D & $\begin{array}{l}\text { Herramientas } \\
\text { Operativas }\end{array}$ & $\begin{array}{c}\text { Desarrollo de herramientas que } \\
\text { ayudan en la operación } \\
\text { eficiente de la cadena de } \\
\text { suministro }\end{array}$ & $\begin{array}{c}\text { Bagahana y Cohen (1998); Slats } \\
\text { et al. (1995) }\end{array}$ \\
\hline
\end{tabular}

Fig 2_3_Resumen de las investigaciones relacionadas con la eficiencia en la operaciones. Ganeshan et al. (1999)

Adicionalmente el mismo Ganeshan et al. (1999) clasifica las investigaciones desde el punto de vista de soluciones metodológicas caracterizándolas en cuatro grupos: Conceptos y modelos no-cuantitativos, Estudios empíricos y orientados a casos prácticos, Marcos, Taxonomías y revisiones literarias y modelos cuantitativos. Así podemos ver en la tabla siguiente (Fig 2_4) el resumen de su clasificación. 


\begin{tabular}{|c|c|}
\hline $\begin{array}{c}\text { Metodología } \\
\text { de la Solución }\end{array}$ & $\begin{array}{l}\text { Lista de los artículos de la gestión de la cadena de suministro ordenados por } \\
\text { su solución metodológica }\end{array}$ \\
\hline $\begin{array}{l}\text { Conceptos y } \\
\text { Modelos no } \\
\text { Cuantitativos }\end{array}$ & $\begin{array}{c}\text { Alderson (1957); Beamon (1996); Bowersox (1969); Forrester (1958, 1961); } \\
\text { Gopal (1992); Heskett (1977); Houlihan (1985); Lamming(1996); Lee et al. } \\
\text { (1997); Lenders et al. (1993); Min (1996); Scott and Westbrook (1991); Slats et } \\
\text { al (1995); Towill (1997); Verwijmeren et al (1996) }\end{array}$ \\
\hline $\begin{array}{l}\text { Estudios } \\
\text { empíricos } \\
\text { orientados al } \\
\text { caso }\end{array}$ & $\begin{array}{l}\text { Bagahana y Cohen (1998); Cachon y Fisher (1997); Caputo y Mininno (1996); } \\
\text { Carter y Narasimhan (1996); Choi y Hartley (1996); Davis (1993); Fuller et al } \\
\text { (1993); Hammel y Kopczak (1993); Holmlund y Kock (1996); Jones y Riley } \\
\text { (1984); Lee y Billington (1995); Levy (1997); McMullan (1996); O’Brian y Head } \\
\text { (1995); Oliver y Webber (1992); Revelle y Laporte (1996); Roberts (1990); Roy } \\
\text { y Potter (1996); Srinivasan et al (1994); Stenger (1996); Walton (1996) }\end{array}$ \\
\hline $\begin{array}{l}\text { Marcos, } \\
\text { taxonomías y } \\
\text { revisiones } \\
\text { literarias }\end{array}$ & $\begin{array}{l}\text { Bloemhof-Ruward et al (1995); Clark (1972); Cohen y Mallik (1997); Coapcino } \\
\text { y Rosenfield (1992); Ernst y Kamrad (1996); Fisher (1997); Geoffrion y Powers } \\
\text { (1995); La Londe (1994); Lanley (1992); Masters y Pohlen (1994); Mourits y } \\
\text { Evers (1995); Prida y Gutierrez (1996); Shapiro (1984); Slater (1976); stinger } \\
\text { (1994); Stevens (1989); Thomas y Griffin (1996); Zinn y Levy (1988) }\end{array}$ \\
\hline $\begin{array}{c}\text { Modelos } \\
\text { Cuantitativos }\end{array}$ & $\begin{array}{l}\text { Anupindi y Akella (1993); Anupindi y Bassok (1996); Arntzen et al. (1995); } \\
\text { Berry and Naim (1996); Bhaskaran (1996); Bowersox (1972); Bowersox et al } \\
\text { (1989); Camm et al (1997); Clark y Scarf (1960); Cohen y Lee (1988); Fisher y } \\
\text { Raman (1996); Grag y Tang (1997); Gavimeni et al (1988); Gentry (1996); } \\
\text { Geoffrion y Graves (1974); Graves et al (1998); Henig et al (1997); Kruger } \\
\text { (1997); Lederer and Li (1997); Lee y Billington (1993); Moinzadeh y Aggarwal } \\
\text { (1997); Robison et al (1993); Sattyerfield y Robinson (1996); Tagaras y Lee } \\
\text { (1996); Towill et al (1992); Viswanathan y Mathur (1997); Zinn y Bowersox } \\
\text { (1988) }\end{array}$ \\
\hline
\end{tabular}

Fig 2_4_Resumen de las investigaciones según su solución metodológica. Ganeshan et al. (1999)

Posteriormente se realiza una clasificación a dos niveles teniendo en cuenta la solución metodológica y la categorización de los problemas. Una clasificación con doble entrada. Una clasificación, siguiendo el modelo de doble entrada de Ganeshan et al. (1999) que se puede aportar al estudio realizado de las investigaciones en el presente capítulo, es el que atiende a aquellos artículos que hacen referencia a la Gestión de la Cadena de Suministro propiamente dicha y aquellos que hacen referencia al diseño de la misma. Si esta clasificación la cruzamos con la realizada en el apartado anterior atendiendo al enfoque del problema, o lo que se ha denominado como tipología (herramienta empleada para la resolución de la problemática planteada), obtendríamos una tabla de doble entrada de la siguiente manera: 


\begin{tabular}{|c|c|c|}
\hline & $\begin{array}{l}\text { Artículos relacionados con la Gestión } \\
\text { de la Cadena de Suministro }\end{array}$ & $\begin{array}{l}\text { Artículos relacionados con el Diseño de la } \\
\text { Cadena de Suministro }\end{array}$ \\
\hline $\begin{array}{l}\text { Herramientas } \\
\text { informáticas }\end{array}$ & Tserng H.P. y Lin P.H. (2002) & Taylor J. Bjornsson H (1999), Joseph H. y Tah M. (2004) \\
\hline $\begin{array}{l}\text { Herramientas } \\
\text { TQM }\end{array}$ & $\begin{array}{l}\text { Wong A. y Fung P. (1999), Kanji G.K. y Wong A. } \\
\text { (1998), Wong et al. (1999), J. Sommerville (1994). }\end{array}$ & Kanji G.K. y Wong A. (1999) \\
\hline $\begin{array}{l}\text { Herramientas } \\
\text { optimización }\end{array}$ & $\begin{array}{l}\text { O’Brien W.J. (2000), Vrijhoef R. y Koskela L. } \\
\text { (2000), }\end{array}$ & Love P.E.D. et al. (2004) \\
\hline $\begin{array}{l}\text { Herramientas } \\
\text { reingeniería }\end{array}$ & Green S.D. y May S.C. (2003) & Arbulu R.J. et al. (2003), Childerhouse P. et al. (2003), \\
\hline $\begin{array}{l}\text { Gestión del } \\
\text { conocimiento }\end{array}$ & $\begin{array}{l}\text { Tah J.H.M., V. Carr y Howes R. (1998), Søren } \\
\text { Degn Eskessen et al. (2004), Capó J. et al (2005) }\end{array}$ & $\begin{array}{l}\text { Tah J.H.M. y Carr V. (2001), Carr V. y Tah J.H.M. } \\
\text { (2001b), Capó J. et al (2004) }\end{array}$ \\
\hline $\begin{array}{l}\text { Integración de } \\
\text { la Cadena }\end{array}$ & $\begin{array}{l}\text { Mathews J. et al. (2000), Briscoe et al. (2001), } \\
\text { Love P.E.D. (2002), O'Brien W.J. (2002) }\end{array}$ & Hong-Mihn S.M. et al. (1999) \\
\hline
\end{tabular}

Fig 2_5_Tabla con la clasificación de los artículos de investigación sobre Diseño o Gestión de la cadena atendiendo a la herramientas empleadas en los mismos. Elaboración Propia. 


\section{Referencias bibliográficas:}

> ARBULU R.J., TOMMELEIN I.D., WALSH, K. D., HERSHAUER J. (2003). "Value stream analysis of a re-engineered construction supply chain". Building Research and Information Vol. 31 No 2 pp. 161-171.

$>$ BOWERSOX, D.J. (1969). "Readings in Physical Distribution Management: The Logistics of Marketing". Eds. Bowersox, D.J. , La Londe, B.J., and Smykay, E.W., New York: MacMillan.

$>$ BERTELSEN, SVEN and KOSKELA, LAURI (2004). "Construction Beyond Lean: a new Understanding of Construction Management". Presented at the 12th annual conference in the International Grop for Lean Construction, Elsinore, Denmark, 2004.

$>$ BISHOP, DAN, FELSTEAD, ALAN, FULLER, ALLISON, JEWSON, NICK and UNWIN, LORNA (2008) "Constructing learning: adversarial and collaborative working in the British construction industry. Cardiff, Wales, Cardiff School of Social Sciences", 35pp. (Learning as Work Research Paper, 13)

$>$ BRISCOE, G., DAINTY, A. R. J. and MILLETT, S., (2001). "Construction supply chain partnerships: skills, knowledge and attitudinal requirements", European Journal of Purchasing \& Supply Management, Vol 7, Iss 4, pp.243-255.

$>$ BRISCOE, G. H., A. R. J. DAINTY, S. J. MILLETT and R. H. NEALE (2003) "Clientled Strategies for Construction Supply Chain Improvement". Construction Management and Economics, 22, pp. 193-201.

> BRISCOE G. y DAINTY A.R.J., (2005) "Construction supply chain intregation: an elusive goal?" Supply Chain Management: An International Journal. Volume: 10 Page: 319 - 326

> CAPÓ VICEDO JOSEP, GUILLERMINA TORMO, RAÚL POLER y JOSÉ V. TOMÁS (2004) "Aplicabilidad de la Gestión del Conocimiento a Cadenas de Suministro. Necesidad de constitución de Empresas Virtuales". VIII Congreso de Ingeniería de Organización, Leganés 9 y 10 de septiembre.

CAPÓ VICEDO JOSEP, MANUEL EXPÓSITO LANGA y JOSÉ VICENTE MIQUEL (2005). "La importancia de la gestión del conocimiento en la cadena de suministro de la construcción”. IX Congreso de Ingeniería de Organización, Gijón 8 y 9 de septiembre. 
$>$ CHILDERHOUSE P., LEWIS J., NAIM M., TOWILL D.R., (2003). "Re-engineering a construction supply chain: a material flow control approach" Supply Chain Management: An International Journal. Volume: 8 pp. 395 - 406

$>$ CHRIS FORTUNE y SHINTIA SETIAWAN (2005). "Partnering practice and the delivery of construction projects for Housing Assosiations in UK. Engineering, Construction and Architetural Management”. Volumen 12 Issue 2 pag 181-193.

$>$ CROOM, S., ROMANO, P. y GIANNAKIS, M. (2000). "Supply chain management: an analytical framework for critical literature review". European Journal of Purchasing \& Supply Management, 6(1): 67-83.

$>$ CSCMP (2005). "Council of Supply Chain Management Profesionals".

$>$ CUTTING-DECELlE, A. F.,YOUNG, B.I., DAS, B.P., CASE, K., RAHIMIFARD, S., ANUMBA, C.J. and BOUCHLAGHEM, D.M. (2007). "A Review of Approaches to Supply Chain Communications: from Manufacturing to Construction". http://itcon.org/2007/5/.

$>$ DAINTY, A.R.J., BRISCOE, G.H., and MILLETT, S.J. (2001). “ New perspectives on construction supply chain integration." Supply Chain Management: An international Journal 6 (4), 163-173.

$>$ FAWCETT, S. E. y MAGNAN, G. M. (2001). "Achieving World-Class Supply Chain Alignment: Benefits, Barriers, and Bridges". Center for Advanced Purchasing Studies

> FISKE A.P. (1990). "Relativity within Moose ("Mossi") culture: four incommensurable models for social relationships". Ethos 18, 180-204.Shapiro, R.D. (1984). Get leverage from logistics. Harvard Business Review 62:119-126.

$>$ GANESHAN, R., JACK, E., MAGAZINE, M. J. y STEPHENS, P. (1999). “A taxonomic review of supply chain management research". In S. Tayur, R. Ganeshan \& M. Magazine, Quantitative models for supply chain management (pp. 840-879). Boston, MA. Kluwer Academic Publishers.

$>$ GIANNOCCARO, I. Y PONTRANDOLFO, P. (2001). "Models for supply chain management: a taxonomy". Proceedings of the Production and Operations Management 2001.Conference POMS Mastery in the New Millennium, Orlando, Florida, USA

$>$ GIELINGH W. (2005). "Improving the Performance of Construction by the Acquisition, Organization and Use of Knowledge". Win >Gielinhg. Jan Campertlam 15. 2624 NZ Delft. The Netherlands. ISBN13 978-90-810001-1-6. 
> GREEN S.D. y MAY S.C., (2003). "Re-engineering construction: going against the grain”. Building Research \& Information, Volume 31, March pp. 97 - 106

> H. J., TAH M., (2004) "Towards an agent-based construction supply chain network modelling and simulation platform," Automation in Construction, 14, pp. 353-359.

$>$ HÅKANSSON, HÅKAN and JAHRE, MARIANNE. (2004). "The economic logic of the construction industry". Work-in-progress paper for IMP 2004.

$>$ HONG-MINH, S.M., BARKER, R. and NAIM, M.M. (1999). "Construction supply chain trend analysis." Proc. 7th Ann. Conf. of the Int'l. Group for Lean Construction (IGLC-7) Berkeley, California, USA, 26-28 July.

$>$ HONG-MINH, SEVERINE (2002). "Re-engineering the UK private house building supply chain”. Logistics Systems Dynamics Group .Cardiff Business School. University of Wales Cardiff.

$>$ HOULIHAN, J.B. (1985) "International Supply Chain Management". International Journal of Physical Distribution \& Materials Management 15:22-38.

$>$ KANJI G.K., A WONG (1998) "Quality culture in the construction industry". Total Quality Management, Volume 9, Number 4, , pp. 133-140(8).

$>$ KANJI G. K.; WONG A. (1999). "Business Excellence model for supply chain management". Source: Total Quality Management, Volume 10, Number 8, pp. 1147$1168(22)$

$>$ KÄRNÄ, S. and JUNNONEN, J-M. (2005), "Developing Customer Feedback Process in the Construction Supply Chain", Proceedings of the 14th IPSERA Conference, Archamps, April, 655-664.

> KUMARASWAMY M., PALANEESWARAN E., HUMPHREYS P., (2000). "Selection matters in construction supply chain optimisation". International Journal of Physical Distribution \& Logistics Management, Vol. 30 No 7/8, 2000, p. 661-680.

$>$ LANGLEY, C.J. (1992). "The Evolution of the Logistics Concept, from Logistics": The Strategic Issues, edited by Christopher, M.

> LAMBERT, D. M., COOPER, M. C. y PAGH, J. D. (1998). "Supply chain management: implementation issues and research opportunities". International Journal of Logistics Management, 9(2): 1-19.

$>$ LAMBERT D. and M. COOPER (2000) "Issues in Supply Chain Mangement". Industrial Marketing Management 29, 65-83. 
> LEJEUNE M. and N. YAKOVA (2005). "On characterizing the 4 C's in supply chain management". Journal of Operations Management 23 81-100.

$>$ LONDON, K. and KENLEY R. (2001). "An industrial organization economic supply chain approach for the construction industry: a review." Journal of Construction Management and Economics 19(8): 777-788.

$>$ LOVE, P.E.D., IRANI, Z., CHENG, E., and LI, H. (2002). "A model for supporting interorganizational relations in the supply chain." Engineering, Construction and Architectural Management 9 (1).

> LOVE, P.E.D., IRANI, Z. and EDWARDS, D.J. (2004), "A seamless supply chain management model for construction", Supply Chain Management: An International Journal, Vol. 9 No. 1, pp. 43-56.

$>$ MASTERS, J.M. and POHLEN, (1994) T.L. "Evolution of the Logistics Profession". from The Logistics Handbook, Eds. Roberson, Capcino \& Howe, Free Press:New York.

$>$ MATTHEWS, J., L. PELLEW, F. PHUA and S. ROWLINSON (2000). "Quality relationships: partnering in the construction supply chain". International Journal of Quality \& Reliability Management, Vol. 17, No. 4/5, pp. 493-510.

MENTZER, J. T., DE WITT, W., KEEBLER, J. S., MIN, S., NIX, N. W., SMITH, C. D. y ZACHARIA, Z. G. (2001). "Defining supply chain management". Journal of Business Logistics, 22(2): 1-25.

MIN H. and G. ZHOU (2002) "Supply Chain Modeling: past, present and future". Computer \& Industrial Engineering 43.Lummus, R. R. y Vokusrka, R. J. (1999). Defining supply chain management: a historical perspective and practical guidelines. Industrial Management \& Data Systems, 99(1): 11-17.

MOURITS, M. and EVERS, (1995) J.J. "Distribution network design". International Journal of Physical Distribution \& Logistics Management 25:43-57.

O. SALEM; J. SOLOMON, A. GENAIDY and I. MINKARAH (2006) "Lean Construction: From Theory to Implementation". J. Mgmt. in Engrg. Volume 22, Issue 4, pp. $168-175$

$>$ OBONYO, ESTHER ADHIAMBO (2004). "Apron: Agent-Based Specification and Procurement of Construction Products". Centre for Innovative Construction Engineering (CICE). Department of Civil \& Building Engineering. Loughborough University. Loughborough. Leics, LE11 3TU 
$>$ O'BRIEN, W.J. (1999), "Construction supply chain management: a vision for advanced co-ordination, costing and control", Proceedings of the Berkeley-Stanford Construction Engineering and Management Workshop: Defining a Research Agenda for AEC Process/Product Development in 2000 and Beyond, University of California, Berkeley, CA.,

$>$ O'BRIEN W J, LONDON K, VRIJHOEF R. (2002) "Construction supply chain modeling: a research review and interdisciplinary research agenda". Proceedings IGLC-10 Aug.

$>$ RUIKAR, KIRTI (2004). "Business Process Implications of E-commerce in Construction Organisations". Centre for Innovative Construction Engineering (CICE). Department of Civil \& Building Engineering. Loughborough University. Loughborough. Leics, LE11 3TU

> SAMADDAR, S., NARGUNDKAR, S. y DALEY, M. (2005). "Inter-organizational information sharing: The role of supply network configuration and partner goal congruence". European Journal of Operational Research, In Press, Corrected Proof.

$>$ SHAPIRO R.D. (1984) "Get leverage from logistics". Harvard Business Review 62: 119126.

$>$ SHIMIZU, JULIO Y. and CARDOSO Francisco F. (2002). "Subcontracting and Cooperation Network in Building Construction: a literature review". Proceedings IGLC10, Aug. 2002, Gramado, Brazil.

$>$ STEVENS, G. C. (1989). "Integrating the supply chain". International Journal of Physical Distribution \& Materials Management, 19(8): 3-8.

$>$ SOBOTKA A. and CZARNIGOWSKA A. (2004). "Analysis of Supply System Models for Plannig Construction Projects Logistics". Journal of Civil Engineering and Management. 2005, Vol XI, No 1, 73-82. ISSN 1392-3730.

$>$ SOMMERVILLE J.(1994) "Multivariate barriers to total quality management within the construction industry". Total Quality Management \& Business Excellence, Volume 5, Issue 51994 , pages 289 - 298

> Søren DEGN ESKESEN, PER TENGBORG, Jørgen Kampmann and Trine Holst Veicherts (2004) "Guidelines for tunnelling risk management": International Tunnelling Association, Working Group No. 2*1

> STADTLER H. (2004) "Supply Chain Management and advanced plannig-basics, overview and challenges". European Journal of Operational Research 163 575-588 
> TAH J.H.M. y CARR V., (2001) "Towards a framework for project risk knowledge management in construction supply chain". Advances in Engineering Software, Volume 32, Number 10, October pp. 835-846

$>$ TAYLOR, J., and BJORNSSON, H.(1999). "Construction supply chain improvements through internet pooled procurement." Proceedings of IGLC-7, Berkeley, CA, July 26-28, 1999,207-217.

$>$ THOMAS, D.J. and GRIFFIN, (1996) P.M. "Coordinated supply chain management". European Journal of Operational Research 94:1-15.

$>$ TSERNG, H. P. \& LIN, P. H. (2002), "An accelerated subcontracting and procuring (ASAP) model for construction projects". International Journal of Automation in Construction, 11(1), 105-25.

$>$ XIALONG XUE, XIADONG LI, QIPING SHEN, YAOW WANG, (2004). "An agentbased framework for supply chain coordination in construction". Automation in Construction. Volume 14, pp. 413-430

> V. CARR and J. H. M. TAH, (2001) "A fuzzy approach to construction project risk assessment and analysis: construction project risk management system". Advances in Engineering Software Elsevier.

$>$ VOORDIJK H, MEIJBOOM B, DE HAAN J (2006) "Modularity in supply chains: a multiple case study in the construction industry". Int J Oper Product Manage 26(6):600618

$>$ VRIJHOEF, R., and KOSKELA, L. (2000). "The four roles of supply chain management in construction." European Journal of Purchasing \& Supply Management 6 (2000), 169178.

$>$ VRIJHOEF, R., and RIDDER H. (2007). "Supply chain systems engineering in construction". Department for Design and Construction Processes. Faculty of Civil Engineering and Geosciences. Delft University of Technology. PO Box 5048. NL-2600 GA Delft. The Netherlands.

$>$ WONG, A., FUNG, P., (1999). "Total quality management in the construction industry in Hong Kong: a supply chain management perspective". Total Quality Management 10 (2), 199\}208.

$>$ WONG A., DEAN TJOSVOLD, WINNIE Y.L. WONG, C.K. LIU. (1999). Relationships for quality improvement in the Hong Kong-China supply chain. Journal: International Journal of Quality \& Reliability Management. Volume: 16 Issue: 1 Page: 24 - 41. 
UNIVERSIDAD

POLITECNICA

DE VALENCIA 


\section{Capitulo 3}

\section{Estado del arte: Aspectos básicos en la Gestión de la Cadena de Suministro en el sector de la Construcción}

\section{Introducción:}

Como ya se ha dicho anteriormente, la presente tesis se centra en la cadena de suministro de la construcción, la relacionada con la construcción de viviendas residenciales según la definición realizada en capítulos anteriores . Según Briscoe G. et al (2001) en comparación con otros sectores, como puede ser el de la automoción, los principales contratistas en el mundo de la construcción están relativamente poco sofisticados en cuanto a la cadena de suministro se refiere. 
Sin embargo, existe una presión para cambiar las operaciones a lo largo de la cadena de suministro de la construcción, especialmente debida a la exigencia de los clientes por tener un mejor producto y servicios relacionados, Crane (1999). Para realizar significativas mejoras en las operaciones relacionadas con la cadena de suministro de la construcción, especialmente si los principios de gestión de la producción quieren ser implementados, se necesita adentrarse en nuevas habilidades, Stannack (1995). Este énfasis se centra en razones abiertas entre los actores de la cadena de suministro y su interacción social, convirtiéndose en una importante reducción de problemas e incertidumbres entre las partes. Estas habilidades son de naturaleza general, en vez de ser habilidades vocacionales, Briscoe et al. (2001). Estos mismos autores, Briscoe et al (2001) proponen un rango de habilidades genéricas que son necesarias para el eficiente funcionamiento en la red de actores que forman parte significativa de la cadena de suministro de la construcción.

Otro aspecto a definir es la Cadena de Suministro en sí, existe amplia bibliografía sobre la definición de la misma. Inicialmente se puede definir como: "red de organizaciones que están involucradas a través de uniones aguas arriba y aguas abajo en los diferentes procesos y actividades que producen valor en forma de productos y servicios para los clientes finales" (Christopher, 1998).

En este capítulo, y desde el punto de vista del estado del arte, se pretende ver y repasar todos aquellos aspectos que se consideran críticos para el análisis, estudio y planteamiento definitivo del modelo que se mostrará y desarrollará más adelante.

En primer lugar se repasarán los aspectos generales y definiciones necesarias para la concepción del modelo. Cómo se determinará en los próximos capítulos y cómo se verá en el desarrollo del modelo, existen cinco aspectos básicos para el mismo, lo que se denominará el "pegamento" de las relaciones entre compañías, el Cliente, y los cuatro pilares: Organización (Personas), Técnica (Información), Institucional (Estrategia) y Economía (Beneficios). En este capítulo pues, también se presentará el estado del arte en estos aspectos del modelo y cuales son los estudios desarrollados en estas materias relacionados con la Cadena de Suministro de la Construcción. 


\section{Algunos conceptos básicos:}

\subsection{Pongámonos de acuerdo sobre la definición de Alianza:}

Como dicen M. Bresnen y N. Marshall (1999), antes de profundizar en el término alianza existen varias cuestiones por contestar. La más obvia de las mismas es ¿en qué momento en la práctica se puede decir que existe una alianza?. Una alianza es cómo tal mientras existe un acuerdo entre las direcciones de las compañías acerca de la alianza a desarrollar y una idea de la filosofía. Son un montón de variables que precisar incluyendo los papeles a desarrollar por cada uno de ellos, las personas que intervendrán, la duración, el sistema de incentivos, el equipo formal que la constituirá, etc. ( ver Barlow et al. 1997). Las alianzas son un concepto difuso e impreciso que tiene una variedad de comportamientos, actitudes, valores, prácticas, herramientas y técnicas.

Como Holti y Standing (1996) sugirieron que más que empezar a separar o a distinguir las iniciativas y su idoneidad, la alianza o el incremento de colaboración se entiende como resultado de realizar un progreso en el cual una o más de las interrelaciones técnicas y organizativas cambian sus iniciativas (Loraine, 1993; Nedo, 1991). En el fondo, estudios más recientes sobre alianzas han conseguido introducir mayor grado de sofisticación midiendo el grado de diversidad de las prácticas para formar una alianza y la evolución continua desde la competición a la colaboración, la colaboración y la coalición (Thompson y Sanders, 1998).

Sin embargo, el término alianza es frecuentemente utilizado como aspecto de cooperación que ocurre en algún tipo de proyecto colaborativo o de otro calado (Barlow y Cohen, 1996). Una consecuencia de esta ambigüedad semántica es que se hace difícil distinguir entre la alianza con una práctica distintiva y con una retórica de gestión (Hinks et al., 1996). Otro punto importante a tener en cuenta, es que el uso de métodos propios de una alianza en sí no produce necesariamente los beneficios esperados (o incluso si se habla de colaboración ocurre de la misma manera), de igual forma que utilizar las pautas tradicionales no es necesariamente garantía de obtener peores resultados o incluso conflictos (Green y McDermont, 1996). 
Con todas estas dificultades para su definición, existen algunos investigadores que insisten en la versión más pragmática e instrumentalista de la alianza. Con un énfasis muy fuerte en las herramientas y técnicas que, estas aproximaciones hacen sobre listas de sistemas y procedimientos que en las organizaciones deberían seguir para establecer acuerdos y alianzas. Esto incluye mecanismos de resolución de ejercicios para la creación de equipos, facilidades para el trabajo en equipo, procesos de mejora continua, la gestión de la calidad total, mapas de procesos de negocio, y benchmarking (ej. Nedo, 1991; Loraine, 1993; Bennet y Jayes, 1995; Evans y Baily, 1996).

No es aquí donde se debe discutir cada uno de los sistemas y prácticas, su idoneidad y adecuación a las alianzas. Sin embargo sí que se pueden entender algunos aspectos. El primero, que es posible definir una alianza como una estrategia coherente que implica el desarrollo de más o menos una serie universal de sistemas, prácticas y procedimientos. Ser conscientes de que el término alianza es lo suficientemente difuso y maleable para qué se pueda escribir alguna forma de relación distinta a la que se está buscando. Un segundo aspecto es la posibilidad de crear una alianza o una relación de colaboración en un corto plazo. Parece una creencia universalmente aceptada que las relaciones de alianza requieren cambios en la cultura tradicional de las relaciones basadas en la verdad, la dedicación a objetivos comunes y el entendimiento mutuo de las expectativas y valores (CII, 1991).

Existen como dos interpretaciones distintas acerca de la generación de alianzas. Por una parte se puede estudiar a Green y McDermontt (1996) que son partidarios de que una alianza debe ser el resultado de una evolución natural de una relación entre dos compañías durante un largo plazo. Entienden que durante esta relación deben haberse obtenido beneficios financieros para ambas al combinar procesos productivos salvando las tradicionales tendencias y a través de estas relaciones hayan empezado a creer uno en el otro. En el otro lado se pueden encontrar aquellos que entienden que una alianza se puede desarrollar en un corto período de tiempo si se emplean las técnicas y herramientas necesarias para desarrollar el proceso de la alianza (Lorraine 1993; Bennett et al., 1926). Aunque las ventajas de las alianzas de esta naturaleza específica no son igual que las alianzas a largo plazo, que Bennett y Jayes (1995) llaman alianzas estratégicas. El hecho es que se considera posible conseguir en un proyecto esta visión de las alianzas. 
Algunas conclusiones que sacan los autores M. Bresnen y N. Marshall (1999) en su texto son: en primer lugar, la implicación de que se necesita una mayor atención para identificar las condiciones económicas, institucionales, técnicas y organizativas que permitan fortalecer o inhibir las prácticas colaborativas. Otra implicación, es la esperanza de que es posible estandarizar en los modelos de alianza con las mejores prácticas y que, a través de la personalización de la alianza, se pueda adaptar a la sensibilidad de las condiciones locales. Una tercera conclusión es que el énfasis que se ha ido poniendo sobre la mesa en la exploración de las relaciones entre los aliados, tanto formal como informalmente, implica un mayor conocimiento y acercamiento entre las dos organizaciones. Esto, a su vez, pone sobre la mesa cuestiones como entender el trabajo del aparato técnico del aliado (contratos, formas de calcular el precio, trabajo en equipo, etc.) y en muchas ocasiones es suficiente para entender cómo trabajan las alianzas y como se puede hacer ingeniería de la colaboración aplicando estas técnicas.

\subsection{Conceptos básicos en la gestión de la cadena de suministro:}

La gestión de la cadena de suministro tiene sus orígenes en la distribución física y el transporte, aunque los últimos años se ha concentrado en las relaciones de proximidad entre las partes involucradas en el flujo de materiales desde el proveedor hasta el cliente final, Briscoe et al (2001). Estas relaciones se han ido extendiendo desde los intercambios de materiales o servicios por un precio, hacia otro tipo de servicios que se han incluido. Desde embalaje, diseño, distribución, marketing, intercambio de conocimiento y otros servicios especializados, Levy et al. (1995). Las teorías de la cadena de suministro indican que el valor durante el proceso debe añadirse más rápidamente que el coste, Lamming (1996) y Lockamy and Smith (1997). La gestión de la cadena de suministro es la gestión de una red de organizaciones involucradas en hacer fluir el proceso de negocio, Harland (1996). En el sector de la construcción, esta red a menudo es extremadamente compleja, particularmente en los grandes proyectos donde se puede encontrar un buen número de organizaciones de suministro que llegan a ser cientos, sino miles, Briscoe et al. (2001). 


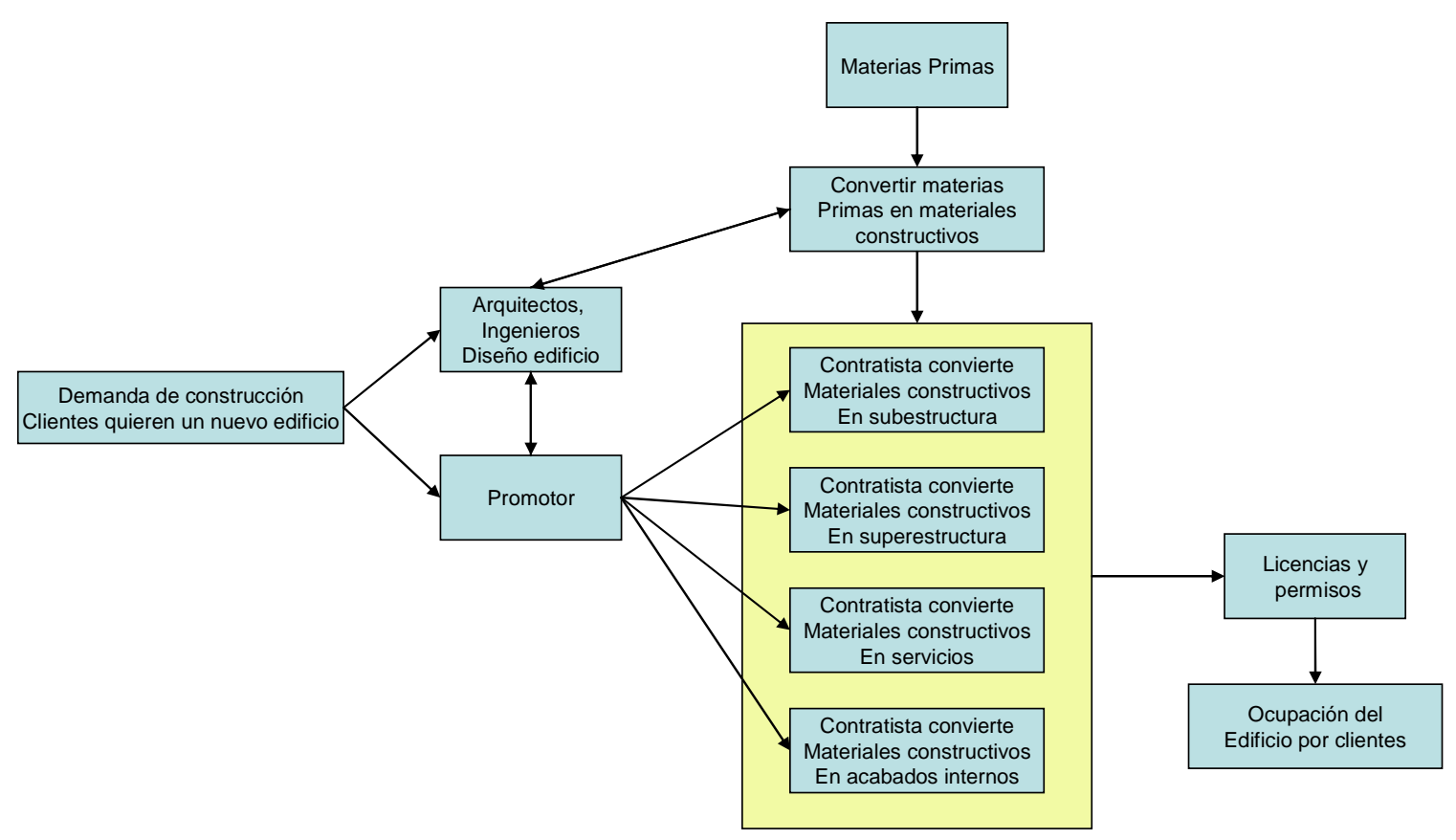

Fig 3_1_ Red de la Cadena de Suministro típica en construcción, Briscoe et al., (2001)

En la figura adjunta, Fig 3_1_Red de la cadena de suministro típica en construcción, Briscoe et al., (2001) se muestran sólo los principales elementos típicos de una red del sector de la construcción. Aún así, se puede ver la complejidad de la misma, y las funciones de los distintos autores que participan en ella. Existe una gran variedad de posibilidades dentro de esta misma red. A modo de ejemplo, y sin ser exhaustivos, se puede encontrar en lo que hemos remarcado con un cuadro amarillo, lo que se viene a entender en el sector como contratista principal.

Este contratista principal, es normalmente una sola compañía que a su vez contrataría distintas compañías para poder realizar las especialidades propias de la tarea de construcción. Asimismo, cada uno de los cuadrados azules pueden, a su vez, subcontratar ciertas tareas de su proceso. También a modo de ejemplo, estas tareas pueden ser: mano de obra especializada, acabados técnicos, análisis y estudios, controles de calidad, inspecciones técnicas, etcétera. 
Dentro de este apartado, es interesante ver cuáles han sido los caminos empleados para poder mejorar la gestión de la cadena de suministro. Y como se ha ido evolucionando en las técnicas de Lean Production, las técnicas de Partnering y Benckmarking, Brisco et al., (2001), Green S.D. y May S.C. (2003), O’Brien W.J. (2000), Vhrijhoef R. y Koskela L. (2000) técnicas relacionadas con la calidad y el TQM Wong A. y Fung P. (1999), Kanji G.K. y Wong A. (1998), Wong et al. (1999), Sommerville J. (1994), técnicas relacionadas con la Gestión del Conocimiento, Tah J.H.M., V. Carr y Howes R. (1998), Søren Degn Eskessen et al. (2004), o las técnicas de integración de la Cadena Mathews J. et al. (2000), Briscoe et al. (2001) Love P.E.D. (2002), O'Brien W.J. (2002). En adelante, se pretende realizar una pequeña reflexión sobre estas técnicas y su desarrollo dentro de la gestión de la cadena de suministro de la construcción.

\subsubsection{Lean Production:}

Lean Production nace en los trabajos que la compañía Toyota aplica en su cadena de producción y que recoge Womack et al. (1990). Otros autores con posterioridad, han aplicado los mismos conceptos a la cadena de suministro de la construcción entre ellos podemos ver Koskela (1997) y Melles (1997), donde se recogen las implicaciones que esta técnica tiene para su aplicación en la gestión de la cadena de suministro de la construcción. Si se fija la atención en los aspectos que esta técnica aborda dentro de la cadena de suministro, es evidente que la metodología está diseñada para reducir y simplificar las pérdidas y mejorar de forma continuada los procesos productivos dentro de la cadena, Briscoe et al., (2001). Tiene muchísima importancia la buena información y la comunicación entre las posiciones que forman parte en la red de la cadena de suministro, New y Ramsay, (1997).

Toda esta metodología hace mucho hincapié en la percepción del proceso, y alcanzar cero defectos en el producto final, en lugar de la cultura de hacerlo suficientemente bien, Briscoe et al., (2001). Estas técnicas requieren, como es obvio, habilidades relacionadas con el funcionamiento de equipos de trabajo. La aplicación en construcción que de esto se puede hacer, especialmente, requiere un cambio de mentalidad hacia el trabajo cooperativo con otros elementos de la cadena, en lugar de la actitud predominante de poder tomar ventaja ante cualquier proveedor, Briscoe et al. (2001). 


\subsubsection{Partnering:}

Los autores Latham (1994) y Egan (1998) recogen en algunos casos esta tipología dentro de la red de la cadena de suministro de la construcción. Existe también mucha literatura sobre esta técnica en general, por ejemplo Boddy et al.,(1998), y también mucha literatura aplicada a la construcción, Barlow y Jashapara (1998) y Crane et al., (1997). Muchas de las experiencias se han centrado en la aplicación de esta técnica entre el contratista principal y sus clientes, Bresnan y Marshall (1999). Sin embargo, la aplicación de estas técnicas entre los subcontratistas y los proveedores de las materias primas es mucho menos común, Briscoe et al. (2001).

Para la aplicación de esta técnica es requisito indispensable, como se puede entender, un cambio de actitud, Hines (1995). Existen autores como Crane et al. (1997) que muestran un modelo de proceso para conseguir, con una guía paso a paso, el desarrollo de la relación de partenariado en el ámbito de la construcción. En su investigación hacen especial énfasis en el problema de compartir información veraz, y en la formación y entrenamiento de los empleados involucrados en estos procesos, que tienen que estar mentalizados de los conceptos, beneficios y objetivos de esta relación. En otros estudios se puede encontrar la importancia que se le da a compartir información, la apertura de mentes, el compromiso, la visión compartida, la integridad, la veracidad, y todos aquellos aspectos que llevan a mejorar y mantener las relaciones de partenariado, ver entre otro a Reed (1999), Matthews et al. (1996) y Spekman et al. (1998).

\subsubsection{Benchmarking}

Según Briscoe et al., (2001) para poder asegurar el progreso una compañía de construcción debe alcanzar mejoras en las obras de la cadena de suministro y la creación mediante las técnicas de Benckmarking de referencias es una buena manera de poder monitorizar las mejoras. Todas estas técnicas se basan en la obtención de KPI's (Key Perfomance Indicators) como números de referencia que indican la evolución de ciertos aspectos dentro del proceso de mejora. Los mismos autores, Briscoe et al. (2001), indican que este proceso inevitablemente genera cambios en las prácticas de los procesos que requieren a menudo nuevas habilidades, conocimientos $y$ actitudes nuevas. Desgraciadamente estas técnicas no nos indican cómo debemos desarrollar esas actitudes ni cómo debemos cambiar a las personas que deben realizar las mejoras dentro del proceso; Briscoe et al. (2001). 


\subsubsection{Total Quality Management (TQM)}

Ibarra S. et al. (2004) comentan en su trabajo que la década de los años 80 del siglo XX fue testigo de una revolución en las filosofías de dirección y en las tecnologías aplicadas a la producción. Las filosofías Just in Time (JIT) y el Control Total de Calidad (TQC), ambas con una visión estratégica de la manufactura, constituyeron la "piedra angular" de las denominadas "buenas prácticas industriales" de numerosas empresas de excelencia. Las estrategias tecnológicas designadas a través de un sinnúmero de acrónimos de tres letras, tales como CAD, CAM, CIM, FMS, MRP, prometían espectaculares avances competitivos en logística.

Como se ha visto anteriormente y dentro de los autores que consideran a la Calidad como herramienta de trabajo para este propósito tenemos a Alfred Wong y Patrick Fung, (1999), GK Kanji, A Wong (1998), Wong A., et al. (1999), Kanji G. K.; Wong A. (1999). y J. Sommerville (1994).

\subsubsection{Gestión del Conocimiento:}

Andreu R.y Sieber S. (2004) recogen en su artículo que nadie discute en la actualidad que el desarrollo de conocimiento propio es indispensable para que una empresa pueda competir efectivamente. La globalización de los mercados, la continua evolución tecnológica y la tendencia desreguladora están cambiando de manera fundamental la estructura competitiva de los mercados. En el nuevo contexto, las fuentes tradicionales de ventaja competitiva de las empresas (activos físicos, financieros, acceso privilegiado a materias primas o a segmentos de mercado protegidos, e incluso a tecnología) no son ya suficientes porque todos ellos tienden a estar más y más a disposición de todo el mundo, en igualdad de condiciones, en mercados abiertos. 
Por tanto para competir efectivamente, es cada vez más necesario centrarse en el desarrollo de capacidades distintivas, en "maneras de hacer" propias que resulten difíciles de imitar para los competidores. En las empresas, esas capacidades distintivas tienen siempre una raíz en las personas, que son quienes las desarrollan y las aplican basándose en "lo que saben". Por esta razón el desarrollo de conocimiento idiosincrático propio es cada vez más importante para las empresas -un conocimiento que estructure y dé sentido a esas maneras de hacer distintivas y difíciles de imitar (Bell, 1973; Drucker, 1993). Ello implica por supuesto aprendizaje, tanto individual como colectivo, al fin y al cabo desarrollar conocimientos nuevos implica aprender. Muy a menudo, el aprendizaje como una de las maneras de hacer propias de una empresa es muy difícil de imitar y no se pueden comprar en el mercado, hay que aprenderlas, y eso requiere tiempo, esfuerzo, y casi siempre un contexto (organizativo, por ejemplo), que casi nunca es fácilmente reproducible o "transportable" de una organización a otra.

Los autores que piensan en el elevado peso del riesgo en la gestión de los proyectos de construcción intentan desarrollar la posibilidad de integrar la gestión del conocimiento y las técnicas de la gestión de proyectos de riesgo en la cadena de suministro de la construcción. De esta manera se encuentran estudios como los de J:H.M. Tah y V. Carr, (2001), V. Carr and J. H. M. Tah, (2001), J. H. M. Tah, , V. Carr and R. Howes (1998) y por último el de Søren Degn Eskesen et al. (2004). 


\section{Organización y Personas:}

\subsection{Las personas $y$ sus relaciones como aspectos clave en el entendimiento entre organizaciones:}

La colaboración entre las organizaciones se ha convertido en una norma y en una clave para la supervivencia en los tiempos turbulentos de los negocios actuales (Ackermann F. et al., 2005). En su estudio estos mismos autores hablan de las diferentes formas que pueden tener estas relaciones entre organizaciones pero que existen factores que hacen exitosa las relaciones y se pueden entender como diferentes estilos de dirección, diferentes culturas y diferentes modos de operar en las empresas. Proponen como una de las posibles maneras de abordar estos problemas lo que denominan GSS (Group Support System) para crear los grupos colaborativos entre las organizaciones.

La colaboración entre organizaciones emerge de la necesidad que las empresas tienen de permanecer en "competencia" bajo condiciones inciertas de la economía (Trist, 1983, Gray, 1989) o de obtener ventaja con la colaboración (Huxham and McDonald, 1992; Huxham 1996). A pesar de que el uso de estas relaciones de colaboración se está incrementando, las metas comunes son difícilmente alcanzables y las aventuras colaborativas a menudo acaban en fracaso y frustración (Webb, 1991; Bryson and Crosby, 1992). En el fondo, este tipo de relaciones entre organizaciones sufren los habituales conflictos internos de cada una de ellas y de alguna manera en el uso de la información compartida y en la estrategia compartida (Barret, 1986).

Ackerman et al. 2005 afirman que el estudio de las relaciones de colaboración entre organizaciones tiene una rica y variada historia. Algunos de los trabajos han descrito las relaciones en diferentes fases del procesos colaborativo, como por ejemplo Gray (1989) o los factores asociados con el éxito en la relación colaborativa, por ejemplo Mattessich et al. (2001). 
Huhtinen H. y V.M. Virolainen (2002) afirman que cuando tenemos en consideración las implicaciones estructurales de la cadena de suministro o las redes, aparecen las implicaciones organizativas y emergen varios aspectos a considerar. Ya no es solo cuestión de lo que ocurre en una empresa, sino más bien como las comunicaciones empiezan a ser un aspecto fundamental de toda la red y de las relaciones entre los distintos miembros. Conforme se profundiza en las organizaciones los temas de la comunicación toca los interfaces entre compañías, los equipos de los distintos niveles y los trabajos de los distintos individuos en los equipos creados al efecto.

La Industria de la construcción está muy fragmentada y la cadena de suministro sometida a grandes presiones ya que en ella generalmente no es posible encontrar una solución simple y/o sola para la mayor parte de los problemas (Thompson, 1998). Siguiendo el estudio de Palaneeswaran E. y M. Kumaraswamy (2003) las cadenas de suministro de construcción en este momento están afectadas por varios defectos que provienen de diversas causas que se pueden identificar, por ejemplo: las aproximaciones entre compañías fragmentadas, los objetivos a corto plazo, déficits, tácticas arriesgadas, competencia puramente a base de precio, selecciones de perfil bajo y carencia de comunicación, cooperación y confianza. Tales defectos de la cadena de suministro son claramente perjudiciales. Estas deformaciones y eslabones débiles podrían ser rectificados y reforzados a través de la introducción de compromisos bilaterales. En este contexto, la comunicación bilateral y multilateral, la imparcialidad, la transparencia, la confianza mutua, la refutabilidad, la cortesía, la competición(competencia) abierta y justa, y la perseverancia son algunos instrumentos de éxito claves en sistemas de contracción entre aliados. Para ilustrar esta situación Palaneeswaran E. y M. Kumaraswamy (2003) proponen un gráfico que recogemos a continuación en la Fig 3_2 Típico equilibrio entre el cliente y el contratista en las relaciones en el sector de la construcción. 


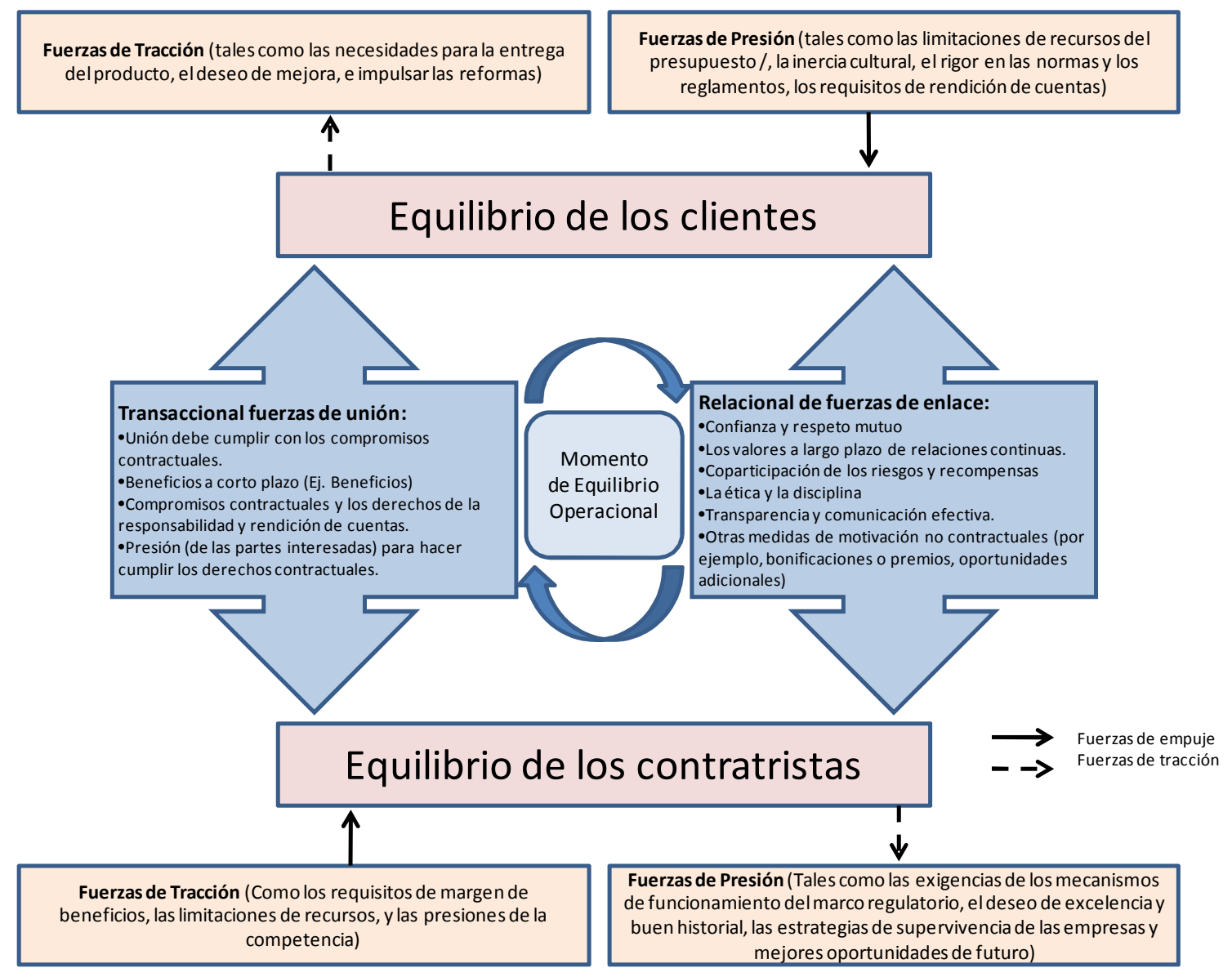

Fig 3_2 Típico equilibrio entre el cliente y el contratista en las relaciones en el sector de la construcción. Palaneeswaran E. y M. Kumaraswamy (2003). 


\subsection{Habilidades requeridas para Partnering en la red de la cadena de suministro de la construcción:}

Un estudio realizado por Ashton et al., (1999) fijaba el rango de habilidades genéricas que debería existir en cualquier sector industrial que quisiera aplicar técnicas de partenariado. Asimismo, Briscoe et al. (2001) realizaron una primera aproximación a los contratistas principales del sector de la construcción para poder aplicar las mismas técnicas dentro de este sector. Adicionalmente existen multitud de trabajos que están relacionados con esta materia, podríamos citar a modo de ejemplo a Huhtinen H. y V.M. Virolainen (2002), Anderson y Buvik (2001) y Brewton y Kingseed (2001). A continuación, y con base en estos estudios se recoge la variedad de las habilidades necesarias para realizar de manera efectiva la gestión de la cadena de suministro. Se puede concluir con los siguientes grupos de habilidades:

\subsubsection{Habilidades de escritura y lectura:}

La mayoría de los mandos que están al frente de las organizaciones de personas que trabajan en el sector de la construcción tienen habilidades orales y escritas a un nivel básico. Muchos de ellos han desarrollado estas habilidades a lo largo de la experiencia acumulada en su propio trabajo. Como recoge el estudio de Briscoe et al. (2001) sólo tres de veinte mandos se había graduado o habían tenido buenas calificaciones. Evidentemente las habilidades orales y escritas son necesarias para el desarrollo de relaciones de partenariado. Los mismos autores, Briscoe et al. (2001) reconocen que un ejemplo claro de esta falta de habilidades es la dificultad que se encuentra para rellenar y responder la documentación técnica y los contratos. Estos contratos a menudo son cumplimentados por empresas externas y esto inhabilita la posible comprensión de todos los puntos necesarios en las relaciones de partenariado. Evidentemente, el problema se centra más en la comunicación escrita que la comunicación oral como así recoge Briscoe et al. (2001).

Según se recoge en el trabajo de Huhtinen H. Y V.M. Virolainen (2002) cuando se enfatiza el papel de la comunicación en las relaciones o la gestión de la cadena de suministro en lugar de la gestión de redes nos encontramos con muchos estudios de la materia (ver Andersen and Buvik (2001), Brewton and Kingseed (2001), Briscoe, et al. (2001), Buvik and Halskau (2001), Forker and Stannack (2000), House and Stank (2001), Khalfan, et al. (2001), Papazoglou, et al. (2000), Poon and Lau (2000), Vrijhoef and Koskela (2000), Walter, et al. (2001), Webb and Gile (2001) y Zuckerman (2001)). 


\subsubsection{Habilidades numéricas y financieras:}

Briscoe et al. (2001) también recoge en el mismo estudio el incremento de interés en los mandos de estas compañías por las tecnologías de la información. En el estudio queda patente la gran diferencia que existe entre el conocimiento y uso de las tecnologías de información en las compañías grandes, normalmente contratistas principales, y las pequeñas compañías que forman parte de la red de la cadena de suministro de la construcción.

Asimismo, y relacionado con el punto anterior también se demuestra la falta de conocimiento y las habilidades de contabilidad y finanzas. En este aspecto las pequeñas compañías suelen utilizar servicios externos para que les lleven los libros de contabilidad así como las finanzas a un nivel básico. Éste tipo de deficiencias también dificulta el desarrollo de relaciones de partenariado dentro de la cadena como queda patente en el estudio de Briscoe et al., (2001).

\subsubsection{Las relaciones contratista-cliente:}

Los subcontratistas frente a los clientes o frente al contratista principal se presentan mostrando sus habilidades para llevar a cabo los requerimientos que el proyecto de construcción necesita para ser terminado con éxito. Esas mismas habilidades son necesarias en las relaciones de partenariado y deben reforzarse y precisarse, así como ser desarrolladas en todos aquellos actores que vayan a tener un papel relevante en estos procesos de relación, Briscoe et al., (2001). Como se recoge en el mismo estudio cuando estas relaciones toman cuerpo, la cercanía del subcontratista al cliente es mucho mayor. Esta cercanía hace necesario el desarrollo de habilidades de comunicación para poder afrontar con satisfacción y con los niveles de calidad necesarios el contacto con el cliente. También en el mismo ámbito aparecen nuevas necesidades como pueden ser el desarrollo de habilidades de marketing e incluso la necesidad de desarrollar habilidades relacionadas con la presentación y uso de herramientas de Internet. 


\subsubsection{Habilidades para publicación gráfica:}

Los subcontratistas que normalmente trabajan como parte de un equipo de construcción y proyectos están en contacto con profesionales del diseño gráfico, arquitectos y algunas veces ingenieros. Estas compañías necesitarán tener habilidades específicas de comunicación con otros profesionales, quienes frecuentemente poseen alto grado de desarrollo de habilidades y avanzado nivel de entrenamiento. En los últimos tiempos estas habilidades de comunicación gráfica tienen un soporte cada vez más importante que lo que son las tecnologías de la información. Por este motivo vuelven a ser importantes las habilidades desarrolladas en estas tecnologías, Briscoe et al., (2001).

\subsubsection{Habilidades con los proveedores:}

Habitualmente los subcontratistas tienen relación directa con las empresas que suministran los materiales de la construcción. Es por lo tanto importante y crítico que estas empresas subcontratistas tengan la habilidad de desarrollar contratos de suministro para la calidad requerida, el tiempo necesario y a los precios más favorables. Estas redes son necesarias para poder cumplir los plazos, terminación en calidades y compromisos en costes atribuibles a todo proyecto de construcción. Ambas habilidades, capacidades en compras y el conocimiento del producto son importantes atribuciones que deben desarrollarse en este tipo de relaciones, Briscoe et al. (2001).

\subsubsection{Trabajo en equipo:}

Normalmente las habilidades de dirección, liderazgo y motivación de la fuerza de trabajo son críticas. Es muy importante en los dueños y los directivos con mayor tiempo en la compañía de las pequeñas empresas proveedoras que tengan la habilidad de empujar al staff hacia las nuevas disciplinas relacionadas con el partenariado. A menos que los directivos de la compañía tengan una elevada cualificación de gestión es muy raro que se tengan habilidades formales de liderazgo sino que, al contrario se hayan desarrollado con la experiencia y el trabajo diario, Briscoe et al., (2001). 


\subsubsection{Planificación y resolución de problemas:}

La construcción es una secuencia de actividades que debe poseer un alto grado de planificación y programación. Habitualmente, ciertas actividades no pueden realizarse hasta que se hayan completado algunos procesos anteriores. Por todo ello las habilidades de planificación son muy importantes y estas habilidades una vez más, están asociadas con la necesaria utilización de tecnologías de información de hoy en día. Para resolver estos problemas habitualmente se necesitan habilidades relacionadas con el diseño, producción, construcción y dificultades de transporte. En muchas ocasiones los actores de la cadena de suministro de la construcción muestran un desarrollo elevado de las habilidades relacionadas con este área, habilidades que se han desarrollado con el "learnig by doing" del día a día, en vez de ser adquiridas de una forma formal, Briscoe et al., (2001).

\subsubsection{Habilidades manuales:}

La gran mayoría de los responsables que están al frente de las compañías que intervienen en la cadena de suministro de la construcción han alcanzado esa posición después de haber desarrollado trabajos en puestos de menor responsabilidad dentro de la misma compañía o de compañías similares. Esto tiene la implicación de que estos mandos tienen altas cualificaciones en las habilidades manuales que implica el desarrollo de un proceso constructivo. Los trabajadores que forman parte de estas compañías esperan desarrollar sus carreras profesionales más por el desarrollo de sus habilidades manuales que por el necesario desarrollo que deberían de tener sus habilidades de dirección. Sin embargo, en compañías pequeñas, el líder de las mismas frecuentemente tiene que realizar ambas tareas, de alguna manera es un todo-terreno. Ese tipo de organizaciones permiten una mayor flexibilidad y un mejor encaje de las razones de partenariado, Briscoe et al., (2001). 


\subsubsection{Habilidades futuras:}

Dentro de la misma forma de analizar todas aquellas habilidades necesarias para llevar una relación de partenariado dentro de la gestión de la cadena de suministro, y basándonos en los estudios de Briscoe et al., (2001), aparece un objetivo secundario donde se fijan las necesidades en habilidades para el futuro cercano. Según indica este mismo estudio, el $90 \%$ de los entrevistados dicen que las nuevas tecnologías y el uso de ordenadores son habilidades de creciente importancia de cara al futuro. Esto es debido al gran crecimiento de la necesidad de la información y de su tratamiento a lo largo de la gestión de la cadena de suministro no solamente en el sector de la construcción sino en otros sectores industriales. Un aspecto que parece también tener muchísima importancia, son las habilidades para saber entender e interpretar los contratos legales.

A continuación mostramos dos tablas en donde se recogen los valores del estudio realizado por Briscoe et al., (2001) y se indican los desarrollos de las habilidades actuales y las futuras habilidades. (Tabla 3_1 Resumen del estudio de habilidades de Briscoe et al., 2001) 
Evaluación de habilidades futuras: Porcentaje de empresas que indican habilidades específicas que esperan que aumente su importancia en el futuro
Ratios de las Habilidades actuales:

(Nota las habilidades se ha valorado sobre una evaluación del 1 al 5 , siendo 1 no aplica y 5 esencial, La variación es la desviación estándar de la media, expresado en porcentaje)

\begin{tabular}{|c|c|c|c|c|c|c|c|c|}
\hline & & $\%$ & Pos & & & $\%$ & Pos & Var \\
\hline A & Habilidades de escritura y lectura & & & A & Habilidades de escritura y lectura & & & \\
\hline 1 & Escribir cartas e informes & 26,3 & 16 & 1 & Escribir cartas e informes & 4,11 & 9 & 26,1 \\
\hline 2 & Leer documentación técnica & 47,4 & 8 & 2 & Leer documentación técnica & 4,58 & 2 & 14,7 \\
\hline 3 & Entender contratos & 73,7 & 2 & 3 & Entender contratos & 4,62 & 1 & 17,8 \\
\hline B & Habilidades numéricas y Financieras & & & B & Hab. numéricas y Financieras & & & \\
\hline 4 & Cálculos básicos & 10,5 & 20 & 4 & Cálculos básicos & 4,16 & 8 & 21,0 \\
\hline 5 & $\begin{array}{l}\text { Ordenadores y tecnologías de la } \\
\text { Información }\end{array}$ & 90,0 & 1 & 5 & $\begin{array}{l}\text { Ordenadores y tecnologías de la } \\
\text { Información }\end{array}$ & 3,42 & 17 & 28,9 \\
\hline 6 & Gestión Financiera & 48,5 & 7 & 6 & Gestión Financiera & 3,63 & 14 & 18,3 \\
\hline C & Relaciones cliente proveedor & & & C & Relaciones cliente proveedor & & & \\
\hline 7 & Presentaciones verbales & 38,8 & 9 & 7 & Presentaciones verbales & 4,47 & 4 & 13,3 \\
\hline 8 & Técnicas de Marketing (Internet) & 49,5 & 6 & 8 & Técnicas de Marketing (Internet) & 4,05 & 12 & 20,4 \\
\hline 9 & Habilidad Negociadora & 52,6 & $4=$ & 9 & Habilidad Negociadora & 4,53 & 3 & 13,2 \\
\hline D & Diseño de Comunicaciones & & & D & Diseño de Comunicaciones & & & \\
\hline 10 & Comunicación con diseñadores & 31,6 & $13=$ & 10 & Comunicación con diseñadores & 3,68 & 13 & 35,3 \\
\hline 11 & Comunicaciones con Ingenieros & 15,8 & 18 & 11 & Comunicaciones con Ingenieros & 2,79 & 20 & 54 \\
\hline E & Comunicaciones con Proveedores & & & $\mathbf{E}$ & Com. con Proveedores & & & \\
\hline 12 & $\begin{array}{l}\text { Realización/Seguimiento ordenes } \\
\text { compra }\end{array}$ & 12,5 & 19 & 12 & $\begin{array}{l}\text { Realización/Seguimiento ordenes } \\
\text { compra }\end{array}$ & 4,11 & 11 & 19,2 \\
\hline 13 & Conocimiento del producto & 37,4 & 10 & 13 & Conocimiento del producto & 4,32 & 7 & 21,3 \\
\hline $\mathbf{F}$ & Trabajo en equipo en la empresa & & & $\mathbf{F}$ & Trabajo en equipo en la empresa & & & \\
\hline 14 & Motivación & 36,8 & 11 & 14 & Motivación & 4,42 & 6 & 13,4 \\
\hline 15 & Liderazgo & 33,3 & 12 & 15 & Liderazgo & 4,45 & 5 & 13,3 \\
\hline 16 & Entrenamiento & 57,9 & $3=$ & 16 & Entrenamiento & 3,53 & 16 & 32,6 \\
\hline G & Planificación y solución de problemas & & & G & Planf. y solución problemas & & & \\
\hline 17 & Planificación del trabajo & 31.6 & $13=$ & 17 & Planificación del trabajo & 4,11 & 9 & 17,5 \\
\hline 18 & Resolución y Solución de problemas & 52,6 & $4=$ & 18 & Resolución y Solución de problemas & 3,63 & 15 & 24,0 \\
\hline $\mathbf{H}$ & Habilidades manuales & & & $\mathbf{H}$ & Habilidades manuales & & & \\
\hline 19 & Habilidades artísticas & 26,6 & 15 & 19 & Habilidades artísticas & 3,21 & 19 & 43,6 \\
\hline 20 & Operar plantas y maquinaría & 25,4 & 17 & 20 & Operar plantas y maquinaría & 3,26 & 18 & 48,6 \\
\hline
\end{tabular}

Tabla 3_1 resumen del estudio de habilidades de Briscoe et al., (2001) 


\subsection{El papel del cliente:}

Los trabajos de investigación sobre el papel del cliente en la cadena de suministro tienen diversos enfoques. En el trabajo de Storey J. et al (2005) se recoge que el papel del cliente y la respuesta que se le da desde la cadena de suministro se presentan en este caso claramente diferenciados entre las pinturas idealizadas en la literatura de dirección de la cadena de suministro y la realidad sobre el terreno. Este salto es más significativo cuando las circunstancias son relativamente menos favorables y cuando se enfrentan a un minorista sofisticado e importante. El estudio revela que "una cadena de suministro sensible al cliente" con mínimas roturas de stock, minima obsolescencia y respuesta flexible al mercado es técnicamente factible. Este hecho es un hallazgo importante. Durante un período corto al menos, y en condiciones restringidas, el concepto puede aportar enormes ventajas. El estudio también revela que incluso cuando realmente funciona no es ninguna garantía de apoyo de los directivos a su continuación.

Como los mismos autores Briscoe et al., (2003) reconocen en su estudio la industria de la construcción ha sufrido durante un largo período de tiempo sobre costes, retrasos en sus programaciones y una baja productividad. Al mismo tiempo los beneficios de las obras de construcción son frecuentemente desconocidos y extremadamente escasos en comparación con otras industrias. En el mismo Latham report (1994) se señala la idea de la competitividad dentro del sector de la construcción y la tendencia a la subcontratación de trabajos y se remarca las actitudes adversas comúnmente existentes entre los contratistas principales y sus proveedores. En el estudio de Egan (1998) se critica la industria y se demandan mejoras en términos relacionados con la reducción de costes, tiempos, defectos y accidentes. Se identifican como posibles soluciones para alcanzar estas mejoras el "Benchmarking", "Lean production", "La gestión de la cadena de suministro" y "las alianzas", como técnicas potenciales para aportar soluciones. Todas estas ideas se han aportado como potenciales mecanismos y aspectos de mejora en las relaciones entre empresas (O`Brien y Fisher,1993, Naum y Mustapha ,1994, Agapiou et al., 1998, Green y Lenard, 1999, Murray et al., 1999, Reed , 1999). Más recientemente, en un estudio llamado Accelerating Change (Strategic Forum, 2002), se construye a través del progreso de las recientes iniciativas. Este estudio sugiere que integrar proveedores y clientes es posible para alcanzar un mejor valor de los proyectos. 
La integración de procesos y las organizaciones trabajando juntas para añadir valor a través del flujo de mercancías y servicios, y en algunos casos hasta la fabricación del producto final (Stevens, 1989, Alber y Walker 1997, Lockamy y Smith 1997). La integración de la cadena de suministro se ha definido a tres diferentes niveles, incluyendo cooperación, coordinación y colaboración, en relación a la integración de flujos de mercancías, flujos de dinero, información y entregas para minimizar las barreras organizativas necesarias en la mejora dentro de la integración (Christopher 1992, Levy et al, 1995, Speakman et al, 1998). Estudios más recientes se han centrado específicamente en las relaciones entre la cadena de suministro de la construcción, los clientes y el contratista principal (Himes, 1995,Bresnen y MarshalI, 1998, 1999), y las relaciones entre los contratistas principales y los subcontratistas (Uher y Runeson, 1985,Hinze y Tracey, 1999, Matthews et al., 1996). Las investigaciones a través de más de dos eslabones dentro la cadena de suministro de la construcción han sido muy pocas (London et al., 1998, Murray et al., 1999), pero ha reconocido los beneficios de las relaciones a largo plazo de estabilidad entre varios agentes.

Briscoe et al., (2003) recoge en su investigación la manera en que el cliente puede influir en la integración de la cadena de suministro de la construcción. En los negocios en general, New y Payne (1995) investigaron un modelo para el propósito de la cadena de suministro. Indicaron una relación entre el entorno, la práctica y los resultados. Sin embargo, Briscoe et al., (2003) modificaron este modelo (como podemos ver en la Fig. 3_2 Modelo de Investigación de la cadena de suministro de la construcción, Briscoe et al., 2003). En esencia en él se indica que el entorno de la organización de negocios tendrá influencia en la manera de aprovisionarse. Y este cambio afectará al nivel de integración de la cadena de suministro, y el nivel de integración de la cadena de suministro afectará a las futuras decisiones de aprovisionamiento. 


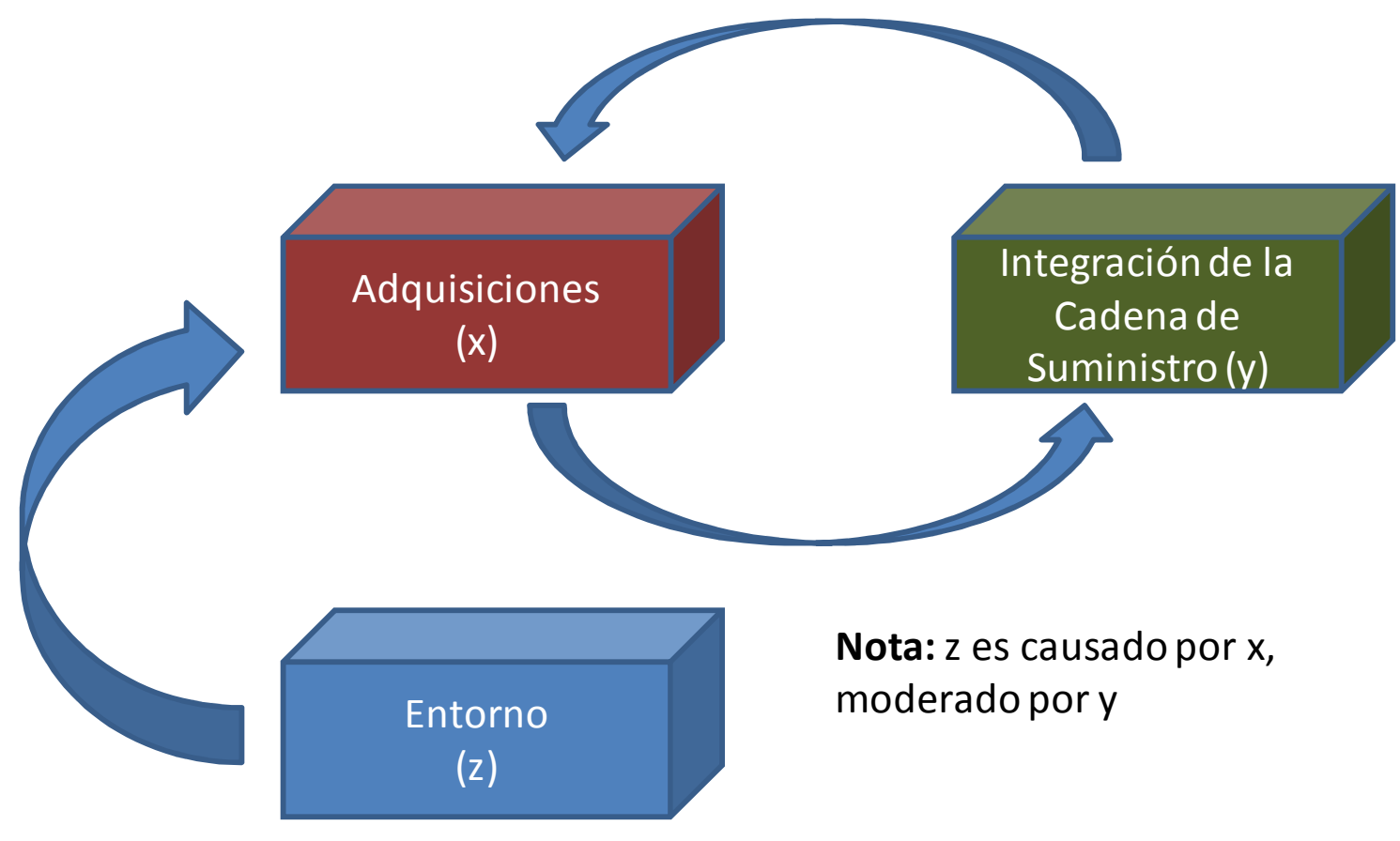

Fig 3_3_ Modelo de Investigación de la cadena de suministro de la construcción, Briscoe et al., (2003).

Las conclusiones a las que llegan Briscoe et al., (2003) en su estudio apuntan a que el cliente es el factor más significativo en el éxito de la integración de la cadena de suministro y que con el cliente se deben desarrollar prácticas que faciliten dicha integración en el proceso de construcción para alcanzar mejoras. Asimismo comentan que en las discusiones para alcanzar el máximo grado de integración del equipo es esencial tener en cuenta a los clientes que deben participar activamente en la creación e integración de los equipos. 


\section{Técnica: La información y la integración de la Cadena de Suministro.}

Si entendemos que la información y la comunicación son aspectos de suma importancia como elementos integradores en la empresa en Domínguez G. y Vera J. (2006) se puede ver cómo integrar conceptos que ubiquen a la comunicación y a la información como elementos integradores para la generación de competitividad de una organización. Para ello, se intentan retomar elementos para establecer ideas estratégicas de competitividad bajo la guía de los de la comunicación. Asimismo, se distingue entre los conceptos de comunicación e información que, aunque son diferentes, se encuentran relacionados, por una parte se argumenta que la comunicación es un agente de cambio que puede ayudar al logro de los objetivos de una empresa en cosas como imagen corporativa, eficiencia de procesos administrativos, revalorización de la presencia humana en las organizaciones, mejorar relaciones con clientes y mejorar el flujo de información acerca del entorno y la competencia, por otra, se retoma el enfoque de información como producto que tiene la finalidad de proporcionar al usuario información de calidad. Si es así en una organización, se entiende que en la relación entre organizaciones este papel de la información es si cabe más importante. La información es uno de los elementos que nos garantizan la integración de la cadena de suministro.

Mientras muchos autores han argumentado que las prácticas de gestión en la mejora pueden conseguir mayor integración a lo largo de los diferentes actores de la cadena de suministro de la construcción (por ejemplo Bresnen y Marshall, 1999; Briscoe et al., 2004), la realidad demuestra que es muy difícil conseguirlo. En otros sectores industriales, como son la fabricación de automóviles o el sector de la distribución comercial, se dan significativos progresos hacia la mejora de eficiencia y una mayor integración de las cadenas de suministro. En el sector de la construcción y sus suministros se tienen características diferenciales frente a otros sectores (ver Koskela, 1997), aunque no parecen suficientes para mantener que esta industria continúe con sus ineficiencias. 
Aparte de las dificultades que muestra la industria, es esencial que los desarrollos de las prácticas de la cadena de suministro de la construcción sean para añadir valor al cliente, y a su vez para simplificar o acortar los tiempos y ahorrar costes (Lockamy y Smith, 1997). Akinitoye et al., (2000), y energía de crecimiento en la tendencia de la colaboración dentro de la cadena de suministro, pero está principalmente localizada en clientes y constructores principales en vez de en una profunda y extendida cadena de subcontratistas y proveedores. Éstos aumentos delimitan las oportunidades para llegar a una completa integración del proceso a través de la integración de la cadena y dan una aparente explicación de por qué la industria no es capaz de acelerar sus ratios de mejora en este ámbito (ver Strategic Forum for Construction, 2002).

Los contratistas principales frecuentemente cambian de proveedores, y esto hace difícil compartir información estratégica, dificulta asimismo, el retorno de información del proceso a esos proveedores e incluso puede retrasar hasta los pagos (Briscoe y Dainty, 2005). Problemas similares fueron observados en un estudio de Thorpe et al., (2003), donde supuestamente los subcontratistas mejores tenían desventajas en algunas prácticas de la cadena de suministro. Briscoe et al.,(2001), también se centran en la relaciones entre los contratistas principales y sus subcontratistas y en este estudio se encuentran significativas barreras actitudinales que evitan la plena colaboración a este nivel. Una posible explicación a los problemas de la industria que impiden el trabajo colaborativo dentro de la gestión de la cadena nos la facilitan Dubois and Gadde, (2000), quienes hacen notar que el énfasis en esta industria será hacia la transacción en lugar de hacia la relación. Éstas dudas impiden la integración y alejan la innovación, particularmente cuando son combinadas con un pobre concepto comercial de coordinación y un ineficiente sistema de planificación (ver Reed, 1999).

Desde un aspecto más positivo, algunas investigaciones recientes sugieren que existen oportunidades de mejora en las prácticas de integración. Childerhouse et al.,(2003), muestran como el sector de la construcción de casas en el Reino Unido, que rechazó trabajar en procesos de reingeniería partiendo de unos pobres resultados, al final se están dando los pasos necesarios para el cambio, y desarrollando sus propias herramientas de integración en la cadena de suministro. Asimismo, Humphreys et al., (2003), describe una nueva aproximación para que los principales contratistas establezcan colaboraciones de calidad con los subcontratistas y que produzcan significativas mejoras en el trabajo colaborativo. Investigaciones recientes muestran dificultades significativas en la aplicación de estos modelos en empresas de pequeño y medio tamaño quienes no pueden jugar un papel importante en la integración de la cadena de suministro (Quayle,2003). 
Las primeras investigaciones en los aspectos de integración en la cadena de suministro mostraban algunos puntos significativos. Por ejemplo, Murray et al., (1999), mantienen que en las relaciones estratégicas de colaboración a largo plazo es importante mantener la integración y muestran como estas relaciones pueden cambiar la naturaleza de las relaciones proyecto a proyecto, mostrándonos un modelo de medir la continuidad dentro de la cadena de suministro. London et al, (1998), aseguran que el contenido de la dirección estratégica combinada con los flujos de información son críticos en la creación de valores a lo largo de la cadena de suministro. Graham and Hardaker, (1998), subrayan la importancia de la gestión de las relaciones a todos los niveles en la red de proveedores y la necesidad de construir relaciones a largo plazo basadas en la colaboración. Los estudios de O’Brien (1997) y Green y Lenard, (1999), también llaman la atención sobre la importancia que unas buenas comunicaciones y el compartir información entre varias partes de la cadena de construcción son un aspecto de suma importancia en la relación y el desarrollo de la colaboración entre los actores de la cadena de suministro. Las recomendaciones de estos estudios son concluyentes y se pueden enfatizar con lo que recoge Latham, (1994), que señala que la verdad es un prerrequisito para alcanzar las mejoras buscadas en el sector. Estudios posteriores de la realidad sugieren, sin embargo que la industria esta alejada un largo trecho de este camino señalado para la integración de la cadena de suministro (Thorpe et al., 2003).

Además de la literatura señalada y específica sobre el sector de la construcción también ayuda el gran cuerpo de trabajo acerca de la integración de la cadena de suministro y de las relaciones de colaboración en todo tipo de negocios. Son particularmente interesantes los estudios de Macbeth y Ferguson (1991) y Wargner al. (2002). Estos estudios muestran como las relaciones de colaboración frente a los métodos tradicionales de suministro, ofrecen más fiabilidad y mejor calidad en el servicio en la cadena de suministro. Los trabajos de colaboración son mejores cuando las partes tienen objetivos comunes y sus esfuerzos individuales se soportan mutuamente el uno en el otro. Harland et al. (1999) muestran cómo las empresas que persiguen reducciones de costo a largo plazo lo consiguen formando relaciones de trabajo cercanas con sus principales proveedores. Estas investigaciones son de extrema importancia para la integración de la cadena de suministro de la construcción. Más recientemente, Besant et al. (2003) sugieren que las compañías pueden aprender de las mejores prácticas a través de la información de su cadena de suministro y esto contribuirá significativamente a la mejora de los rendimientos de sus negocios. Todos estos hallazgos se recogen en las recomendaciones que nos hace Egan (1998) para la construcción. 
Llegados a este punto se exponen algunos de los aspectos que Briscoe y Dainty (2005) recogen en su estudio como crítico para poder alcanzar la integración dentro de la cadena de suministro de la construcción. Estos autores establecen ocho aspectos que consideran importantes según su estudio:

Gestión de la comunicación: Establecer caminos directos de comunicación con los contratistas principales y los segundos contratistas son críticos para el éxito de los proyectos.

Gestión de los flujos de información: donde la confianza en las relaciones de trabajo entre el cliente y el contratista, a veces hacen que el intercambio de información sea muy pobre.

Mecanismos para la solución de problemas: la rápida acción es requerida para minimizar los problemas de la cadena de suministro en un estadio inicial.

La ingeniería como valor añadido de los proyectos: existe un gran conocimiento especializado que si es involucrado desde el inicio en el proyecto puede darle al cliente mucho más valor añadido.

El alineamiento de los sistemas de la cadena de suministro: es muy importante para la eficacia de la gestión de la cadena de suministro que los principales contratistas y sus proveedores gestionen sus sistemas de información en línea unos con otros.

Asegurando estándares de calidad elevada: siempre se está buscando hacer mejoras en la calidad, pero a veces esto es demasiado caro para pequeñas organizaciones así es que se depende de los clientes y de su iniciativa para encontrar estas inversiones de calidad. 
> Asegurar el compromiso del cliente y los objetivos del proyecto: donde se ha sido capaz de construir asociaciones a largo plazo con clientes particulares, con un número importante de contratos, que han desarrollado una fuerte lealtad hacia el cliente y han conseguido hacer un buen trabajo en todos los proyectos.

Establecer relaciones de suministro en la cadena a largo plazo: en muchas ocasiones se tiene miedo de establecer relaciones a largo plazo con los proveedores siendo éstas mucho más prestigiosas y beneficiosas en términos globales.

En este estudio Briscoe y Dainty (2005) exploran las prácticas de tres importantes clientes para integrar su cadena de construcción. Las alianzas con éxito requieren una combinación de procesos formales e informales y en el estudio se atiende a la exploración de algunos aspectos dinámicos y la relación entre ellos. La investigación cruzada del estudio de la organización del mayor cliente revela una aproximación a la gestión de la cadena de suministro de diferente manera, y puede verse como el grado de integración alcanzado en la cadena de suministro varía significativamente. La integración es efectivamente constreñida por las políticas de la organización del cliente en relación a las partes que se cogen como relación durante la vida del proyecto y como esas relaciones se aproximan. En general, hay una preferencia por estructuras menos formales o informales y se pierden alianzas que no han sido moderadas o recogidas en un contrato previo. Las relaciones a largo plazo se establecen sólo con los principales contratistas y los clientes. Los principales contratistas son forzados a tener sus propias relaciones con los subcontratistas y, a este nivel, a menudo aparece insuficiente credibilidad hacia una colaboración formal y una relación duradera que hace que sea limitante el efecto de la integración.

Este mismo estudio también señala que aunque existe una vasta experiencia en términos de compras en construcción ningún cliente del estudio puede decir que ha alcanzado un grado satisfactorio de integración de la práctica de la cadena de suministro. El informe Egan señala que alrededor de las dificultades potenciales inherentes a la adopción de metodologías de integración de la cadena de suministro en el contexto del sector de la construcción, en el fondo, las características de esta industria de proyectos individuales que empiezan y acaban, la dispersión geográfica, la existencia de muchas pequeñas empresas, la demanda cíclica de sus productos, y el servicio podrían hacer imposible que se llegaran a producir los frutos de una integración de la cadena. 


\section{Integración institucional.}

Con este título se quiere enmarcar aquellos estudios que tratan de darle un marco conceptual a las organizaciones compuestas no por una sola empresa sino por una variedad de las mismas. Como recogen Llanos Cuenca y Angel Ortiz (2002) con la aparición de la empresa extendida, empresa virtual, y en general las nuevas formas organizativas que están surgiendo, entender la naturaleza y composición de las operaciones empresariales que atraviesan los límites de las organizaciones se convierte en un prerrequisito para iniciar y mantener las relaciones de negocio. También se hace patente el modelado de procesos de negocio para representar y entender las operaciones de la empresa. Dentro de este apartado, por tanto, se tienen distintos conceptos que se manejan en los trabajos de investigación, así aparecen los conceptos de Integración Empresarial ver Sempere Ripoll F. et al. (2002), Alfaro Saiz et al (2002), Chen y Vernadat (2004), Shorter (1997), Doumeingts et al. (1998), Empresa Virtual Camarinha-Matos et al., (1997), Hayfron et al., (1998), NIIIP (1999), Capó Vicedo J. et al (2002), Preiss y Murray (2005), Capó Vicedo et al. (2007), Masiá Buades E. y Capó Vicedo J. (2004) y Empresa Extendida, Hidalgo Nuchera A. (2002), Moller et al. (1998), Hayfron et al. (1998).

La integración empresarial para Sempere Ripoll F. et al (2002) es que cuando dos empresas se asocian o se fusionan, se deben al menos conectar y en la mayoría de los casos integrar sus sistemas de información y coordinar sus procesos de negocio. La modelización empresarial se entiende como un facilitador de la Integración Empresarial, para construir el acuerdo general y la visión común de representación de conocimiento, las tecnologías de la información y las operaciones del negocio.

Alfaro Saiz et al. (2002) recogen que ante la complejidad de analizar, sintetizar y en general abordar la problemática de la empresa como un conjunto de subsistemas interrelacionados, se empezó a plantear modelos que integraban a éstos subsistemas, buscando representar la entidad como un todo y no como la suma de las partes. A este concepto se le denominó Integración Empresarial. Este término consiste en facilitar los flujos de los materiales, información, decisiones y control a través de la organización, ligando las funciones con los sistemas de información, recursos, aplicaciones y personas, con la finalidad de mejorar la comunicación, la cooperación y la coordinación en la empresa, de tal forma que ésta se comporte como un todo, y que funcione alineada con la estrategia de la empresa. 
La NIIIP (National Industrial Information Infraestructure Protocols Consortium) recoge en NIIIP (1999) que una Empresa Virtual es un consorcio temporal de empresas independientes que explotan conjuntamente las oportunidades de fabricación que surgen a nivel global en este mundo tan cambiante (un examen riguroso al respecto es el presentado por Camarinha-Matos et al., 1997).

Organización Virtual, según Preiss y Murray (2005), es un conjunto de unidades de negocio en el que el personal y los procesos de trabajo de las distintas unidades de negocio interactúan intensamente para alcanzar resultados que las beneficien a todas. Se Incluyen diversas formas, pasando por las alianzas estratégicas y formas de Joint Ventures.

Masiá Buades E. y Capó Vicedo J. (2004) afirman en su articulo que en los últimos años se ha hablado mucho sobre el concepto de organizaciones virtuales, pudiéndose encontrar muchos términos relacionados con las mismas, como puedan ser los de Empresa Virtual, Empresa Extendida, Organizaciones en Red, etc. Todas las definiciones existentes de EV (Empresa Virtual) coinciden en definirlas como redes de empresas colaboradoras, aportando cada una lo que sabe hacer mejor que ninguna otra (Core Business), para afrontar una determinada oportunidad de mercado, operando todas ellas de cara al cliente como si de una única empresa se tratara. El resultado será la consecución de una estructura de costes óptimos.

Como comentan Capó Vicedo J. et al. (2002) la revisión de la literatura nos aporta muchas definiciones de Empresa Virtual (EV). Una de las primeras fue presentada por The Economist en un artículo del 6 de febrero de 1993: "Red temporal de empresas que se unen para explotar una oportunidad específica de mercado apoyada en las capacidades tecnológicas de las empresas que forman la red". Otras definiciones posteriores son las de Walton, J.; Whicker, L., (1996) como "Consorcio o alianza temporal de empresas, formado para reducir costes y aprovechar las oportunidades de un mercado rápidamente cambiante", y las de Camarinha-Mathos, L. M. y Afsarmanesh, H., (1999) como "Alianza temporal de empresas que se unen buscando compartir conocimientos, competencias básicas y recursos para responder mejor a las oportunidades de mercado, y cuya cooperación se basa en las TIC" 
Empresa Virtual (Virtual Enterprise) se caracteriza según Hayfron et al., (1998) por las contribuciones complementarias que aportan las diferentes empresas que la forman, dentro de las cuales una representa el papel de líder (broker o corredor), explora los nuevos mercados y se organiza para satisfacerlos. Entre las características comunes de dichas organizaciones encontramos que están dirigidas por planes estratégicos de mutuo acuerdo, se estructuran a través de los equipos humanos que existen dentro de cada compañía participante y que se soportan en el desarrollo de TIC, lo que permite eliminar la dependencia física y de proximidad temporal de los miembros de los distintos equipos, a la vez que sus herramientas permiten los equipos múltiples de proceso, y la resolución de los problemas dentro de la propia empresa y en los socios de la cadena.

Capó Vicedo J. et al. (2007) en su trabajo" La Gestión del Conocimiento en la Cadena de Suministro: Análisis de la Influencia del Contexto Organizativo" muestran una tabla de definiciones de Empresa Virtual que por el interés que tiene y la síntesis de la misma se adjunta a continuación.

\begin{tabular}{|l|l|}
\hline Trabajo & Definición \\
\hline $\begin{array}{l}\text { Davidow y } \\
\text { Malone (1992) }\end{array}$ & $\begin{array}{l}\text { Conjunto de cadenas de valor configuradas entre clientes, } \\
\text { proveedores, competidores, otras organizaciones y la propia } \\
\text { empresa }\end{array}$ \\
\hline Byrne (1993) & $\begin{array}{l}\text { Red temporal de empresas independientes, conectados mediante } \\
\text { Tecnologías de la Información, para compartir costes y acceder a } \\
\text { los mercados del resto de socios. No cuentan con organigrama ni } \\
\text { oficinas centrales, ni jerarquía establecida, ni integración vertical }\end{array}$ \\
\hline NIIIP (1996) & $\begin{array}{l}\text { Consorcio o alianza temporal de empresas formada para } \\
\text { compartir costes y habilidades y aprovechar las oportunidades de } \\
\text { un mercado rápidamente cambiante }\end{array}$ \\
\hline $\begin{array}{l}\text { Walton y } \\
\text { Whicker } \\
\text { (1996) }\end{array}$ & $\begin{array}{l}\text { Serie de nodos con competencias nucleares, organizados en una } \\
\text { cadena de suministro para afrontar una oportunidad de mercado } \\
\text { específica }\end{array}$ \\
\hline $\begin{array}{l}\text { Camarinha- } \\
\text { Matos (2002) }\end{array}$ & $\begin{array}{l}\text { Alianza temporal de empresas que se unen para compartir } \\
\text { recursos, habilidades y competencias fundamentales, para } \\
\text { responder mejor a oportunidades de negocio, y cuya cooperación } \\
\text { se sustenta en redes informáticas }\end{array}$ \\
\hline
\end{tabular}

Fig 3_4_ Tabla de definición de Empresa Virtual. Capó Vicedo J. et al (2007)

Siguiendo a Chen y Vernadat (2004) diremos que la integración empresarial puede ser abordada desde distintas perspectivas. Por una parte el Comité Europeo de Normalización (CEN) reconoce tres niveles de integración:

- Integración entre dispositivos físicos, conexión de dispositivos, máquinas de control numérico, conexión de redes, etc. 
- Integración de aplicaciones, relacionado con la interoperabilidad del software y sistemas de bases de datos heterogéneos.

- Integración de negocio, coordinación de las funciones que gestionan y controlan los procesos de negocio.

Otras aproximaciones completan las consideraciones anteriores, Shorter (1997) ve la integración a través del modelado de empresa, y Doumeingts et al. (1998) como una aproximación metodológica para la consistencia en la toma de decisiones.

Hidalgo Nuchera A. (2002) en su trabajo recoge que a través del análisis del impacto de las nuevas tecnologías en la estructura de la organización se identifica a la empresa extendida como la organización que integra las siguientes características básicas:

$>$ Generación de una red de funciones que interactúan constantemente y las personas actúan de acuerdo con una visión y un compromiso compartido.

Integración en redes para aprovechar las sinergias, eliminar duplicidades funcionales y reducir definiciones conflictivas o imprecisas sobre las responsabilidades dentro de los procesos multifuncionales.

Desarrollo de una eficaz red de comunicaciones que permita, con independencia del espacio y del tiempo, a cualquier profesional o equipo de trabajo comunicarse e intercambiar información con cualquier otro profesional o equipo de la misma organización o de otra perteneciente a la red.

Diseño horizontal a través de la estructuración de equipos de proyectos multidisciplinares y multifuncionales que se adapten de forma continua a las condiciones cambiantes de los negocios y permitan la producción de forma personalizada. 
Establecimiento de acuerdos de cooperación a través de convenios específicos de colaboración tecnológica o científica con centros de prestigio en los diferentes campos de la gestión avanzada y de las tecnologías de la información y las comunicaciones.

Empresa Extendida (Extended Enterprise) es para Moller et al., (1998) un concepto que se ha utilizado para caracterizar la cadena global de suministro, de un producto sencillo, en un entorno de redes dinámicas de compañías implicadas en diferentes relaciones entre ellas con un nivel de complejidad. En concreto puede definirse la Empresa Extendida como un grupo de instituciones que desarrollan enlaces, comparten el conocimiento y los recursos, y colaboran para crear un producto y/o servicio. Esta colaboración aumenta al máximo las capacidades combinadas y permite a cada institución alcanzar sus propias metas estratégicas proporcionando soluciones integradas a los clientes. Para Hayfron et al. (1998), la Empresa Extendida se caracteriza por la presencia de una compañía dominante que extiende la visión y alcance de sus operaciones a una Red, liderándola y determinando su funcionamiento. Dentro de la Red las relaciones entre sus miembros están perfectamente estructuradas y responden a acuerdos formales. Normalmente se cita como ejemplo de estas redes las formadas por empresas de fabricación y montaje de automóviles y sus proveedores.

Otra definición que puede ser de interés es la de Spinak (2007) de Empresa-red que se aplica a cómo se organiza la actividad. El modelo estratégico y organizativo basado en la descentralización en red de las líneas de negocio. La forma organizativa construida en torno a un proyecto de negocio que resulta de la cooperación entre los diferentes componentes de varias empresas, operando en red, durante el periodo de duración de un proyecto de negocio y reconfigurando sus redes para llevar a cabo cada proyecto, Castells Manuel. (2001). 
Capó Vicedo J. et al. (2007) comentan en su trabajo la diferencia entre empresa extendida y empresa virtual, que se resume de la siguiente manera: dentro de la cadena de suministro, lo habitual es que se creen agrupaciones entre la empresa, sus proveedores y sus clientes, conformando alianzas estratégicas de carácter permanente en el marco de negocio establecido (Empresa Extendida), o bien que una empresa se alíe con varios de sus proveedores y clientes para el desarrollo de un producto o proyecto concreto, acabándose la relación cuando se alcanza dicho objetivo (Empresa Virtual). Como se ha visto en los párrafos anteriores, la Empresa Extendida es una configuración en red, en la cual una empresa es la dominante de la cadena, estableciendo las pautas a seguir por las demás, así como los procesos a realizar y la forma de llevarlos a cabo. En cambio, el modelo de Empresa Virtual es un modelo más avanzado, en el cual no existe una empresa dominante, sino que todas tienen el mismo peso e importancia en la red, por lo que es un modelo mucho más participativo y "democrático".

En ese aspecto existe un trabajo realizado por J. Capó et. al. (2003) en donde se señala que la cadena de suministro establece una relación de negocio común entre proveedor y cliente, desde el punto de vista de una mejora conjunta de la integración global, lo cual permite desarrollar estrategias de gestión eficaces.

En el caso particular que nos ocupa, la construcción, se considera que la cadena se configura para cada proyecto constructivo concreto, por lo que los conceptos que más ayudarán a definir un modelo avanzado de gestión serán aquéllos relacionados con integración empresarial y la empresa virtual.

En cuanto a integración empresarial, los autores citados, J. Capó et al. (2003) señalan que dicha integración consiste en facilitar los flujos de materiales, información, decisiones y control a través de la organización ligando las funciones con la información, los recursos, las aplicaciones y las personas, con la finalidad de mejorar la comunicación, la cooperación y la coordinación en la empresa, de tal forma que ésta se comporte como un todo, y que funcione alineada con la estrategia de la empresa.

Existen diversas propuestas de proyectos de integración empresarial, la mayoría soportadas por una metodología que proporciona una guía y una estructura que abarca todo el ciclo de vida del proyecto. En las distintas arquitecturas y metodologías de intervención, encontramos tres que son las que se consideran las propuestas más conocidas: CIMOSA, PERA Y GRAI/GIM. 
En cuanto a las redes interorganizacionales, empresa virtual, J. Capó et al. (2003) señalan que un modelo que puede presentar ventajas importantes es el de empresa virtual por el carácter temporal de las alianzas establecidas (para cada proyecto de construcción en particular).

La empresa virtual aparece como respuesta estructural basada en la flexibilidad, la adaptabilidad, la oportunidad y la optimización de la estructura de costes, de tal forma que sea capaz de responder eficaz y mentalmente a las necesidades de los clientes.

Cada vez que se presenta una oportunidad de mercado se configura la empresa virtual. Gracias a las estructuras de sistemas abiertos y a la utilización de las TIC, se establece una rápida comunicación, con lo que se produce su configuración en un intervalo corto de tiempo, ajustándose así a una de las premisas competitivas en el sector.

Esta necesidad de una rápida configuración implica que la información pueda fluir a través de los nodos de la red. Todos los participantes potenciales en la empresa virtual tienen acceso a la información disponible para poder tomar decisiones en consecuencia. Si este modelo es capaz de explotarse adecuadamente daría lugar a una red de conocimiento. 


\section{La base económica de la integración de la alianza.}

Otro aspecto de importancia para el desarrollo del modelo, son los beneficios económicos y la gestión económica de la unión de las organizaciones involucradas, para alcanzar los objetivos comunes. Es por ello, que en este apartado se pretende recoger cual es el estado del arte de esta materia para poder construir a partir de dicha base.

Los profesores H. Hakansson y M. Jahre, 2004, explican que la lógica económica de la industria de la construcción está caracterizada por una combinación de distintas lógicas económicas. En relación a las lógicas según la clasificación de Thompson, 1967, estos profesores afirman que la lógica económica del sector es posiblemente una combinación de lógicas. Basándose en un estudio en el que tiene en cuenta el costo de transacción (mercado), la cadena de suministro (relaciones) y la red industrial como aproximación a la industria de la construcción, concluyen que la base tecnológica de la industria está caracterizada por diferentes lógicas económicas.

Uno de los aspectos más interesantes en el estudio de la cadena de suministro de la construcción es el desarrollo no excesivamente positivo de los resultados económicos. En la mayoría de los países la construcción es la que ha experimentado descensos o ha permanecido estable en cuanto a su productividad se refiere en la pasada década (BNL 2002, Dainty et al. 2001, Love et al. 2004., Person y Solberg 1994). Los aspectos de innovación y los relacionados con la organización de los proyectos de construcción también han sido muy poco desarrollados durante este período (Andersen et al. 2004, BNL 2002, Dubois y Gadde 2002, Person and Solberg 1994). Es pues un sector con un gran potencial de mejora y es a su vez una importante industria en muchos países (BNL 2002, Cox y .Thompson 1997, Thompson 1998, Persson and Solberg 1994, Vordijk et al 2000). 
Otro aspecto que parece muy interesante en el estudio económico desde el punto de vista estructural, es que es un sector muy tradicional, fragmentado y dominado por pequeñas compañías (BNL 2002, Dainty et al. 2001, Love et al. 2004, Persson y Solberge 1994, Vordijk et al. 2000). Además, existen buenas razones empíricas para investigar como la industria está funcionando en diferentes tipos de compañías involucradas unas con las otras. Al mismo tiempo hay algunas otras razones teóricas para hacerse la misma pregunta. En una perspectiva de mercado tradicional cada compañía funciona como una isla con claras fronteras en relación con las otras compañías u organizaciones. En las últimas décadas, ha habido numerosas aproximaciones, que nos hacen cuestionarnos esas asunciones y nos sugieren cadenas y redes alternativas que complementan la visión tradicional. Hay muchas razones para creer que estas aproximaciones han sido aplicadas en la cadena del suministro de la construcción y han dado diferentes resultados. En este punto del documento debemos preguntarnos sobre la lógica económica de la cadena de construcción y en qué se diferencia de las otras industrias.

Según comentan los profesores H. Hakansson y M. Jahre, 2004, existe mucha literatura previa que habla de las diferentes lógicas económicas relacionadas con la industria incluyendo objetivos a corto contra el largo plazo, transaccional contra relacional, redes estables contra redes temporales, diferentes tipos de cadenas de suministro, estandarización contra personalización, varios actores, perspectivas etc. dichos profesores dan un paso más allá basándose en la existencia de una variedad de interdependencias. Los tres tipos básicos identificados por Thompson (1967) son importantes en la industria de la construcción, y la lógica económica se puede describir como la creación de un híbrido entre ellos.

Como recoge Vrijhoef (2007) en términos económicos la cadena de suministro es una serie de actores económicos, empresas que se compran y venden unas a otras. Desde el punto de vista económico la mejor opción para la coordinación de este mecanismo o el gobierno de la estructura sería la optimización de la suma total de los costes de producción y transacción de la cadena, Williamson (1979). Los costes de transacción (CT) nos ofrecen una explicación de la estructuración entre las empresas participantes y de su coordinación dentro de la cadena de suministro, Hobbs (1996). Cuando los costes de transacción son bajos, se utiliza la contratación (ej. la estructura de mercado). Mientras que con la internalización prevalecerán los costes de transacción son altos (ej. la jerarquización). Los modos intermedios son modelos híbridos de comportamiento económico, Williamson (1991). 
TC es el reconocimiento de que las transacciones no tienen lugar sin fricción. Los costes surgen de la interacción entre las empresas y dentro de ellas como costes de transacción: costes de información, costes de negociación y costes de gestión y control, Hobbs (1996). Según Vrijhoef (2007), los costes de transacción podrían ser cero si los humanos fueran honestos y tuvieran una racionalidad ilimitada. Los costes de transacción para un caso particular dependen de tres dimensiones críticas de la transacción: los aspectos específicos, la incertidumbre y la frecuencia, Williamson (1985). Ademas de estos aspectos, racionalidad limitada, oportunismo, razones específicas, incertidumbre y frecuencia, Milgrom y Roberts (1992) añaden dos temas más: la dificultad de medir la percepción del entorno y la conectividad con otras transacciones. Ambos son relevantes desde el punto de vista de la gestión de la cadena de suministro. Evidentemente la mejora de la colaboración y la comunicación en la cadena de suministro proporcionará una reducción de los costes de transacción. 


\section{Referencias bibliográficas.}

ACKERMAN F., L. ALBERTO FRANCO, BRENT GALLUPE y MICHAEL PARENT (2005). "GSS for Multi-Organizational Collaboration: Reflections on Process and Content". Group Decision and Negotiation 14: 307-331.

$>$ AGAPIOU, A., CLAUSEN, L.E., FLANAGAN, R., NORMAN, G. and NoTMAN, D. (1998) "The role of logistics in the materials flow control process". Construction Management and Economic, 16(2), 131-7.

$>$ ALBER, K. and WALKER, W. (1997) "Supply chain management: a practitioner's approach", in 40th International Conference Proceedings: Target Breakthrough Ideas, APICS, Washington, DC, pp. 203-10.

$>$ ALFARO SAIZ J.J., ÁNGEL ORTIZ BAS y RAÚL POLER ESCOTO (2002). "Definición de Parámetros de Prestaciones bajo un Enfoque de Integración Empresarial”. II Conferencia de Ingeniería de Organización. Vigo, 5-6 Septiembre

Andersen, O. and Buvik, A., (2001). "Inter-firm co-ordination: international versus domestic buyer-seller relationships", Omega, Vol 29, Iss 2, pp.207-219.

$>$ ANDERSEN, P.H., COOK, N. and MARCEAU, J. (2004) "Dynamic innovation strategies and stable networks in the construction industry" - Implanting solar energy projects in the Sydney Olympic Village, Journal of Business Research, Vol.57, pp.351-360.

$>$ ANDREU RAFAEL y SANDRA SIEBER (1999). "La gestión integral del conocimiento y del aprendizaje". Economía Industrial.

$>$ ASHTON, D., DAVIES, B., FELSTEAD, A., GREEN, F., 1999. "Work skills in Britain". Centre for Skills, Knowledge and Organisational Performance (SKOPE), Oxford and Warwick Universities.

BARLOW, J., JASHAPARA, A., (1998). "Organisational learning and inter-firm partnering in the UK construction industry". The Learning Organisation 5 (2), 86-98.

$>$ BARRETT, S. S. (1986). "Strategic Alternatives and Inter-Organizational System Implementation: An Overview," Journal of Management Information Systems 3(3), 516.

BELL, D. (1973): “The Coming of Post-industrial Society": A Venture in Forecasting, New York, Basic Books. 
BESANT, J., KAPLINSKY, R. and LAMMING, R. (2003), "Putting supply chain learning into practice", International Journal of Operations \& Production Management, Vol. 23 No. 2, pp. 167-84.

BNL (2002) "Research and Development in the Construction Industry" (In Norwegian: Forskning og utvikling i bygg-, anleggs- og eiendomsnæringen), http: www.bnl.no.

BODDY, D., CAHILL, C., CHARLES, M., FRASER-KRAUS, H., MACBETH, D., (1998). "Success and failure in implementing supply chain partnering: an empirical study". European Journal of Purchasing and Supply Management 4, 143-151.

BRESNEN, M. and MARSHALL, N. (1998) "Partnering strategies and organizational cultures in the construction industry", in Hughes, W. (ed.) ARCOM 14th Annual Conference, Reading, 9-11 September, pp. 465-76.

D BRESNEN, M. and MARSHALL, N. (1999) "Achieving customer satisfaction? Client-contractor collaboration in the UK construction industry", in Bowen, P. and Hindle, R. (eds) CIBW55 \& '65 Joint Triennial Symposium, Cape Town, South Africa.

BREWTON, T. and KINGSEED, K., (2001). "Getting the most from your B2Benabled supply chain", Journal of Business Strategy, Vol 22, Iss 1, pp.28-31.

BRISCOE, G., DAINTY, A. R. J. and MILlETT, S., (2001). "Construction supply chain partnerships: skills, knowledge and attitudinal requirements", European Journal of Purchasing \& Supply Management, Vol 7, Iss 4, pp.243-255.

BRISCOE G., ANDREW R.J. DAINTY, SARAH J. MILLET and RICHARD H. NEALE (2003) "Client-led strategies for construction supply chain improvement", Construction Management and Economics.

BRISCOE G., and ANDREW R.J. DAINTY (2005) "Construction supply chain integration: an elusive goal?" Supply Chain Management: An International Journal 10/4 (2005) 319-326

BrYSON, J. and B. C. CroROSBY. (1992). "Leadership for the Common Good": Tackling Public Problems in a Shared-Power World. Jossey-Bass: San Francisco.

BUVIK, A. and HALSKAU, Ø. (2001). "Relationship duration and buyer influence in just-in-time relationships", European Journal of Purchasing \& Supply Management, Vol 7, Iss 2, pp.111-119.

BYRNE, J. A. (1993). “The virtual corporation”, Business Week, 
CAMARINHA-MATOS L.M., H. AFSARMANESH, C. GARITA y C. LIMA (1997). "Towards an architecture for virtual enterprises". Journal of Intelligent Manufacturing. Springer Netherlands. ISSN 0956-5515 (Print) 1572-8145 (Online) Volume 9, Number 2 / marzo de 1998 189-199.

CAMARINHA-MATOS, L. M.; AFSARMANESH, H., (1999) "Infrastructures for Virtual Enterprises. 1.The Virtual Enterprise Concept", Kluwer Academic Publishers

CAMARINHA-MATOS, L.M. (2002). "Collaborative Business Ecosystems and Virtual Enterprises". Kluwer Academic Publishers.

CAPÓ VICEDO JOSEP, GUILLERMINA TORMO CARBÓ y FRANCISCO CRUZ LARIO ESTEBAN (2002). "Las Redes inter organizacionales como Alternativa Competitiva en las Empresas Constructoras". II Conferencia de Ingeniería de Organizació. Vigo, 5-6 Septiembre.

> CAPÓ J.et.al. (2003), “Integración Empresarial y Redes Inter. organizacionales en la Gestión de la Cadena de Suministro. Aplicación al Sector de la Construcción". V Congreso de Ingeniería de Organización: Valladolid-Burgos, 4-5 Septiembre.

> CAPÓ VICEDO, JOSEP, TOMAS MIQUEL, JOSÉ V y EXPÓSITO LANGA, MANUEL (2007). "La Gestión del Conocimiento en la Cadena de Suministro": Análisis de la Influencia del Contexto Organizativo. Inf. tecnol, vol.18, no.1, p.127136. ISSN 0718-0764.

CASTELLS, MANUEL. (2001) "La galaxia internet”. Barcelona: Areté, 316 pp.

$>$ CHEN D., F. VERNADAT (2004) "Standard on enterprise integration and engineering-state of the art". Int.J. Computer Integrated Manufacturing, vol.17 no.3 235-253. Taylor \& Francis

> CHILDERHOUSE, P., LEWIS, J., NAIM, M. and TOWILL, D.R. (2003), "Reengineering a construction supply chain: a material flow control approach", Supply Chain Management, Vol. 8 No. 4, pp. 395-406.

> CHRISTOPHER, M. (1992) "Logistics and Supply Chain Management", Pitman Publishing, London.

CHRISTOPHER, M., (1998) "Logistics and Supply Chain Management". Strategies for reducing cost and improving service. Prentice Hall. Londres.

COX, A. and THOMPSON, I. (1997) 'Fit for purpose' contractual relations: determining a theoretical framework for construction projects, European Journal of Purchasing and Supply Management, Vol.3, No. 3, pp. 127-135.

CRANE, A., (1999). "The movement for innovation (M4I ) in construction in learning to succeed in construction". Conference Proceedings, CITB, November 25, London, pp. 2-8. 
CRANE, T.G., FELDER, J.P., THOMPSON, P.J., THOMPSON, M.G., SANDERS, B.R., (1997). "Partnering process model". ASCE Journal of Management in Engineering 13 (4), 57-63.

> CUESTA FERNÁNDEZ, F. (1998) "La Empresa Virtual. La estructura Cosmos. Soluciones e Instrumentos de transformación en la empresa". Mc Graw Hill.

DAINTY, A.R.J., BRISCOE, G.H. and MILLETT, S.J. (2001) "Subcontractor perspectives on supply chain alliances", Construction Management and Economics, Vol. 19, pp. 841-848.

DAVIDOW W.H.y M.S. MALONE. (1992). "The Virtual Corporation: Structuring and Revitalising the Corporation for the 21st Century", HarperCollins Publishers, Nueva York.

DOUMEINGTS, BRUNO VALLESPIR y DAVID CHEN(1998) "Decision modelling" GRAI grid. Handbook on Architectures of Information Systems. ISBN 978-3-540-25472-0 (Print) 978-3-540-26661-7 (Online) Páginas 321-346

DRUCKER, P. (1993): “Post-capitalist Society”, Oxford, Butterworth-Heinemann.

$>$ DUBOIS, A. and GADDE, L. (2000), "Supply strategy and network effects purchasing behaviour in the construction industry", European Journal of Purchasing and Supply Management, Vol. 6 No. 2, pp. 207-15.

$>$ DUBOIS, A. and L-E GADDE (2002) "The construction industry as a loosely coupled system": implications for productivity and innovation, Construction Management and Economics, Vol.20, pp. 621-631.

D EGAN, J. (Construction Task Force) (1998) "Rethinking Construction", DETR, London.

FORKER, L. B. and STANNAKC, P., (2000). "Cooperation versus competition: do buyers and suppliers really see eye-to-eye?" European Journal of Purchasing \& Supply Management, Vol 6, Iss pp.31-40.

D GRAHAM, G. and HARDAKER, G. (1998), "Defence sector procurement and supply chain relationships", Supply Chain Management, Vol. 3 No. 3, pp. 142-8.

$>$ GRAY, B. (1989). "Collaborating: Finding Common Ground for Multiparty Problems". Jossey-Bass: San Francisco.

> GREEN, S.D. and LENARD, D. (1999), "Organising the project procurement process", in Rowlinson, S. and McDermott, P. (Eds), Procurement Systems: A Guide to Best Practice in Construction, E. \& F.N. Spon, London, pp. 57-82.

GREEN S.D. y MAY S.C., (2003). "Re-engineering construction: going against the grain”. Building Research \& Information, Volume 31, March pp. 97 - 106 
H KANSSON, H. and PERSSON, G. (2004) "Supply Chain Management: The logic of supply chains and networks", under review for publication in International Journal of Logistics Management.

HARLAND, C.M., (1996). "Supply chain management: relationships, chains and networks". British Journal of Management (Special Issue) 7, S63-S80.

HARLAND, C.M., LAMMING, R.C. and COUSINS, P.D. (1999), "Developing the concept of supply strategy", International Journal of Operations \& Production Management, Vol. 19 No. 7, pp. 650-73.

HAYFRON, L.E., CARRIE, A.S., BITITCI, U.S. y K. PANDYA, (1998). "Manufacturing Franchising and Enterprise Networks". En Bititci, U.S. y A.S. Carrie (ed.): Strategic Management of the Manufacturing Value Chain. Kluwer Academic Publishers, Dordrecht.

> HIDALGO NUCHERA, ANTONIO (2002) "La planificación del desarrollo de nuevos productos en la empresa extendida". Economía Industrial N 347

HIMES, P.E. (1995) "Partnering in the construction process: the methodology for the 1990s and beyond". Facilities, 13(6), 13-15.

HINZE, J. and TRACEY, A. (1994) "The contractor-subcontractor relationship: the sub-contractors view". Journal of Construction Engineering and Management, 120(2), 274-87.

HINES, P.E., (1995). "Partnering in the construction process: the methodology for the 1990s and beyond". Facilities 13 (6), 13-15.

> HOBBS, J.E. (1996). "A transaction cost approach to supply chain management." Supply chain management 2 (1), 15-27.

> HOUSE, R. G. and STANK, T. P., (2001). "Insights from a logistics partnership", Supply Chain Management: An International Journal, Vol 6, Iss 1, pp.16-20.

$>$ HUHTINEN. y VELI-MATTI VIROLAINEN (2002) "Studying network management from the communication perspective - a literature review".

$>$ HUMPHREYS, P., MATHEWS, J. and KUMARASWAMY, M. (2003), "Preconstruction project partnering: from adversarial to collaborative relationships", Supply Chain Management, Vol. 8 No. 2, pp. 166-78.

$>$ HUXHAM, C. and D. MACDONALD. (1992). "Introducing Collaborative Advantage: Achieving Interorganizational Effectiveness Through Meta-Strategy," Management Decision 30(3), 50-56.

$>$ HUXHAM. (1996). “Creating Collaborative Advantage”. Sage: London. 
HUXHAM, C. (1996). "Group Decision Support for Collaboration," In Huxham, C. (ed.), Creating Collaborative Advantage. Sage, London, pp. 141-151.

IBARRA MIRÓN S., WILLIAM ARIEL SARACHE CASTRO y MAIDELY SÚAREZ GARCLA (2004) "La estrategia de producción: una aproximación al nuevo paradigma en investigación en manufactura" Universidad Eafit, vol. 40, niimero 136 pp. $65-77$

$>$ KANJI G.K., A WONG (1998) "Quality culture in the construction industry". Total Quality Management, Volume 9, Number 4, 1 July 1998 , pp. 133-140(8).

$>$ KHALFAN, M. M. A., ANUMBA, C. J., SIEMIENIUCH, C. E. and SINCLAIR, M. A., (2001). "Readiness Assessment of the construction supply chain for concurrent engineering", European Journal of Purchasing \& Supply Management, Vol 7, Iss 2, pp.141-153.

KOSKELA, L. (1997), "Lean production in construction", in Alarcon, L. (Ed.), Lean Construction, A.A. Balkema Publishers, Rotterdam, pp. 1-10.

DAMMING, R., (1996). "Squaring the lean supply with supply chain management". International Journal of Operations and Production Management 16 (2), 188-196.

LATHAM, M., (1994). “Constructing the Team”. HMSO, London.

DEVY, P., BESSANT, J., SANG, B. and LAMMING, R. (1995) "Developing integration through total quality supply chain management". Integrated Manufacturing Systems, 6(3), 4-12.

LOCKAMY, A. and SMITH, W. (1997) "Managing the supply chain: a value-based approach", in 40th International Conference Proceedings: Target Breakthrough Ideas, APICS, Washington, DC.

LONDON, K., KENLEY, R. and AGAPIOU, A. (1998) "Theoretical supply chain network modelling in the building industry", in Hughes, W. (ed.) ARCOM 14th Annual Conference, Reading, 9-11 September, pp. 369-79.

LÓPEZ PAREDES ADOLFO y JUAN JOSÉ DE BENITO MARTÍN (2002). "Empresas Virtuales Autónomas. La Cadena de Suministro como un sistema multiagente".

LOVE, P.E.D., IRANI, Z., CHENG, E., and LI, H. (2002). “A model for supporting interorganizational relations in the supply chain." Engineering, Construction and Architectural Management 9 (1).

LOVE, P.E.D., IRANI, Z. and EDWARDS, D.J. (2004) “A seamless supply chain management model for construction", Supply Chain Management: An International Journal, Vol. 9, No. 1, pp.43-56. 
LLANOS CUENCA y ÁNGEL ORTIZ. (2002). "La Importancia del Marco de Modelado en las Arquitecturas de Referencia para Integración Empresarial”. II Conferencia de Ingeniería de Organización. Vigo, 5-6 Septiembre 2002

MACBETH, D.K. and FERGUSON, N. (1991), "Strategic aspects of supply chain management", Integrated Manufacturing Systems, Vol. 2 No. 1, pp. 12-15.

MASIÁ BUADES ENRIQUE y JOSEP CAPÓ VICEDO (2004). "Propuesta de una metodología para la creación de redes inter organizacionales dentro de un microcluster". VIII Congreso de Ingeniería de Organización. Leganés, 9 y 10 de septiembre.

MATTESSICH, P.,M. MURRAY-ClOSE, and B. MONSEY. (2001). "Collaboration": What Makes itWork, aEeviewof Research Literature on Factors Influencing Successful Collaboration

MATTHEWS, J., TYLER, A. and THORPE, A. (1996) "Pre-construction project partnering: developing the process". Engineering, Construction \& Architectural Management, 3(1, 2), 117-31.

MATTHEWS, J., L. PELlEW, F. PHUA and S. ROWLINSON (2000). "Quality relationships: partnering in the construction supply chain". International Journal of Quality \& Reliability Management, Vol. 17, No. 4/5, pp. 493-510.

$>$ MELLES, B., (1997). "What do we mean by lean production in construction? In: Alarc!on", L. (Ed.), Lean Construction. Balkema, Rotterdam, pp. 11-16.

MILGROM, P. and ROBERTS, J. (1992). "Economics, organization, and management". Prentice-Hall, New Jersey.

$>$ MOLLER, C. J.O. RIIS y M. HANSEN, (1998). "Interorganisational network classification". A framework for studying industrial networks. U.S. Bititci, A.S. Carrie (Edits.) Strategic Management of the Manufacturing Value Chain, Kluwer Academic Publishers.

MURRAY, M., LANGFORD, D., HARDCASTLE, C. and TOOKEY, J. (1999) "Organisational design", in Rowlinson, S. and McDermott, P. (eds) Procurement Systems: A Guide to Best Practice in Construction, E \& FN Spon, London, pp. 83118.

NAOUM, S.G. and MUSTAPHA, F.H. (1994) "Influences of the client, designer and procurement methods on project performance", in Rowlinson, S. (ed.) Proceedings of CIB W92 - Procurement Systems: East Meets West, Hong Kong University, December. 
NEW, S.J. and PAYNE, P. (1995) "Research frameworks in logistics: three models, seven dinners and a survey". International Journal of Physical Distribution and Logistics Management, 25(10), 60-77.

$>$ NEW, S., RAMSAY, J., (1997). "A critical appraisal of aspects of the lean chain approach". European Journal of Purchasing and Supply Management 3 (2), 93-102.

$>$ O'BRIEN, W.J. and FISCHER, M.A. (1993) "Construction supply chain management: a research framework". Civil Comp 93: Information Technology for Civil and Structural Engineers, pp. 61-4.

$>$ O'BRIEN, W.J. (1997), "Construction supply-chains: case study, integrated cost and performance analysis", in Alarcon, L. (Ed.), Lean Construction, A.A. Balkema Publishers, Rotterdam, pp. 187-222.

$>$ O'BRIEN, W.J. (1999), "Construction supply chain management: a vision for advanced co-ordination, costing and control", Proceedings of the Berkeley-Stanford Construction Engineering and Management Workshop: Defining a Research Agenda for AEC Process/Product Development in 2000 and Beyond, University of California, Berkeley, CA.,

O'BRIEN W J, LONDON K, VRIJHOEF R. (2002) "Construction supply chain modeling: a research review and interdisciplinary research agenda". Proceedings IGLC-10 Aug.

PALANEESWARN E., KUMARASWAMY M. y THOMAS N.G. (2002) "Formulating a framework for relationally Integrated construction supply chains". Journal of Construction Research, Vol. 4, No. 2. 189-205

PAPAZOGlOU, M. P., RIBBERS, P. and TSAlGATIDOU, A., (2000). "Integrated value chains and their implications from a business and technology standpoint", Decision Support Systems, Vol 29, Iss 4, pp.323-342.

PERSSON, G. (1994) "Central research areas within the construction industry. Some views concerning the quality and productivity of the building process". (In Norwegian: Sentrale forskningsområder innen byggenøringen. Noen synspunkter på byggeprosessens kvalitet og produktivitet), Research report 7, Norwegian School of Management, BI.

PERSSON, G. and SOLBERG, M. (1994) "Time based strategies as part of the internationalisation of the Norwegian construction industry" (In Norwegian: Tidsbaserte 19 konkurransestrategier som virkemiddel for $\varnothing \mathrm{kt}$ internasjonalisering av norsk Bygge- og anleggsnæring), Research report 2, Norwegian School of Management, BI

POON, W. K. and LAU, K. H., (2000). "Value challenges in supply chain management", Logistics Information Management, Vol 13, Iss 3, pp.150-155. 
PREISS, K.J. y P.A. MURRIA:(2005) "Fashions of learning: improving supply-chain relationships". Supply Chain Management: An International Journal, 10 (1): 18-25

Q QUAYLE M. (2003) "A study of supply chain management practice in UK industrial SMEs". Supply Chain Management: An International Journal. Volume: 8 Issue: 1 Page: 79 - 86

$>$ REED, M. (1999) "Working Together": Tools for an Integrated Construction Supply Chain, Trant Engineering, Cardiff University and Southampton University.

SEMPERE RIPOLL F., RAÚL POLER ESCOTO y ÁNGEL ORTIZ BAS. (2002) "Un Acercamiento a un Lenguaje Unificado de Modelización Empresarial". II Conferencia de Ingeniería de Organización Vigo, 5-6 Septiembre.

SHORTER, D.N.(1997) "Requirements for enterprise model execution and integration services".

> SOMMERVILLE J.(1994) "Multivariate barriers to total quality management within the construction industry". Total Quality Management \& Business Excellence, Volume 5, Issue 51994 , pages 289 - 298

SØREN DEGN ESKESEN , PER TENGBORG , JØRGEN KAMPMANN AND TRINE HOLST VEICHERTS (2004) "Guidelines for tunnelling risk management": International Tunnelling Association.

> SPEKMAN, R.E., KAMAUFF JR, J.W. AND MYHR, N. (1998) "An empirical investigation into supply chain management: a perspective on partnerships." International Journal of Physical Distribution and Logistics Management, 28(8), 63050 .

SPINAK ERNESTO (2007) "Una nueva definición de "empresa-red"”. El profesional de la información, v.16, n. 1, enero-febrero.

STANNACK, P., (1995). "Building organisational communities: The role of purchasing and supply chain management". In: Kemp, R. A., Lamming, R. C. (Eds.), Proceedings of the First Worldwide Research Symposium on Purchasing and Supply Chain Management, Arizona State University, Tempe, USA.

STEVENS, G.C. (1989) "Integrating the supply chain". International Journal of Physical Distribution and Logistics Management, 19(8), 3-8.

STOREY J., CAROLINE EMBERSON Y DAVID READE (2005). "The barriers to customer responsive supply chain management". International Journal of Operations \& Production Management Vol. 25 No. 3, 2005 pp. 242-260.

STRATEGIC FORUM (2002) "Rethinking Construction: Accelerating Change, consultation paper", Strategic Forum for Construction, London. 
THOMPSON, J.D. (1967) “Organizations in Action”, Mc Graw Hill Inc.

THOMPSON, I. (1998), "No pre-fab solution”. Supply Management, 3(13), 30- 31. UDOT (1997), I-15 Corridor Reconstruction Project: Special Experimental Project 14 Design/Build Contracting, Initial Report, Octo, Utah Department of Transportation, USA.

THOMPSON, I., COX, A. AND ANDERSON, L. (1998) "Contracting strategies for the project environment", European Journal of Purchasing and Supply Management, Vol.4, Special Issue, pp. 31-41.

THORPE, A., DAINTY, A.R.J. AND HATFIELD, H. (2003), “The realities of being preferred: specialist subcontractor perspectives on restricted tender list membership", Journal of Construction Procurement, Vol. 9 No. 1, pp. 47-55.

$>$ TRIST, E. (1983). "Referent Organizations and the Development of Interorganizational Domains”, Human Relations 36(3), 269-284.

UHER, T.E. AND RUNESON, G. (1985) "Subcontractor-general contractor relationship in Australian building industry". Project Management, 3(1), 35-8.

$>$ VRIJHOEF, R. AND KOSKELA, L, (2000) "The four roles of supply chain management in construction", European Journal of Purchasing and Supply Management, Vol.6, Special Issue, pp. 169-178.

$>$ VRIJHOEF RUBEN. (2007). "Supply Chain Integration in Construction. Design and construction processes". TuDelft Technische Universitiet Delft. Paper series 2.

> WAGNER, B.A., MACBETH, D.K. AND BODDY, D. (2002), "Improving supply chain relations: an empirical case study", Supply Chain Management, Vol. 7 No. 4, pp. 253-64.

WALTER, A., RITTER, T. AND GEMÜNDEN, H. G., (2001). "Value Creation in Buyer-Seller Relationships; Theoretical Considerations and Empirical Results from a Supplier's Perspective", Industrial Marketing Management, Vol 30, Iss 4, pp.365-377.

> WALTON, J.; WHICKER, L., (1996) "Virtual Enterprise: Myth \& Reality", J. Control.

WEBB, A. (1991). “Co-Ordination: A Problem in Public Sector Management," Policy and Politics 19(4), 229-241.

WEBB, J. AND GILE, C., (2001). "Reversing the value chain", Journal of Business Strategy, Vol 22, Iss 2, pp.13-17.

WILLIAMSON, O.E. (1979). "Transaction-cost economics: the governance of contractual relations." Journal of law and economics 22, 233-261. 
WILLIAMSON, O.E. (1985). "The economic institutions of capitalism: firms, markets, relational contracting". Free Press, New York.

WILLIAMSON, O.E. (1991). "Comparative economic organization: the analysis of discrete structural alternatives.” Administrative Science Quarterly 36 (2), 269-296.

WOMACK, J.P., JONES, D.J., ROOS, D., (1990). "The Machine that Changed the World". Macmillan, New York.

WONG, A., FUNG, P., (1999). "Total quality management in the construction industry in Hong Kong: a supply chain management perspective". Total Quality Management 10 (2), 199\}208.

WONG A., DEAN TJOSVOLD, WINNIE Y.L. WONG, C.K. LIU. (1999). "Relationships for quality improvement in the Hong Kong-China supply chain". Journal: International Journal of Quality \& Reliability Management. Volume: 16 Issue: 1 Page: $24-41$.

ZUCKERMAN, A., (2001). "Managing Global Logistics Operations", Transportation and Distribution, Vol 42, Iss 6, pp.4-9. 


\section{Capitulo 4}

\section{Estado del arte: Modelos de Integración de la Gestión de la Cadena de Suministro en el sector de la Construcción}

\section{Introducción:}

En este capítulo se pretende analizar los modelos que se creen de importancia o de utilidad para el desarrollo y comprensión del modelo que se propone. Para ello, y citando a Crespo Márquez A. et al. (2002) se debe definir el concepto "administración de la cadena de suministro" (acuñado en inglés como Supply Chain Management, SCM), que se usa en esta tesis haciendo alusión a los medios por los cuales, las empresas abordan la creación, distribución y venta de sus productos (Poirier, 1999). En este apartado se discute en primer lugar el concepto de integración de una cadena de suministro y se revisan las contribuciones principales encontradas en este tema. A pesar de la relevancia del tema de la integración dentro de la cadena de suministro, este ha sido abordado de forma amplia por relativamente pocos investigadores. Entre las contribuciones principales están las realizadas por Stevens (1989), Scott y Westbrok (1991), Towill et al. (1992), Cooper et al. (1993), Hewitt (1994) y Bowersox (1997), Campuzano F. et al (2008), Campuzano et al. (2008_2), Ros L. et al. (2004), McCullen P. et al. (2004) y Jusii Heikkila (2002). 
Stevens (1989) presentó un modelo de integración con cuatro fases: integración básica, integración funcional interna, integración del suministro y la demanda de las propias compañías a lo largo de la cadena, y la integración total de la cadena de suministro. Hewitt (1994) extendió el modelo de Stevens a una quinta fase que se podría dedicar a una mejor administración y re-diseño de los procesos de negocio globales, buscando mejorar la eficiencia y la eficacia globales de tales procesos. Scott y Westbrook (1991) sugirieron un modelo de tres fases para obtener una cadena de suministro integrada: 1) la "fase de estudio", donde se analizan los lead times y los niveles de inventario para ver mejoras potenciales, 2) una "fase de posicionamiento", para identificar nuevas oportunidades que surgen como consecuencia de las actividades de colaboración entre los miembros de la cadena, y 3) una "fase de acción" para llevar a cabo los planes anteriores. Towill et al. (1992) presentaron un enfoque de integración, similar al de Stevens, y se basaron en principios de dirección de operaciones para reducir la amplificación de la señal de la demanda a lo largo de la cadena. Bowersox (1997) plantea la idea de dos tipos de integración: interna y externa y sugiere la creación de beneficios de tiempo y ubicación en la cadena, exige compartir la información permitiendo acuerdos comerciales convenientes con ese propósito, y también exige la existencia de un ambiente apropiado para las transacciones financieras.

Se analizarán varios modelos de integración de la cadena de suministro, algunos de ellos relacionados con el sector de la construcción, otros no. De los relacionados con el sector de la construcción se consideran de mayor interés tres modelos por su relación con el modelo propuesto. En primer lugar, se analizará y verá con más detalle lo que los autores llaman "Seamless supply chain management model for construction" propuesto por P.E.D. Love et al., 2004. Este modelo de integración, como se podrá ver más adelante, se basa en un núcleo donde un equipo multidisciplinar de diseño trabaja de forma colaborativa en el aprendizaje y desarrollo del producto. El segundo modelo que se va a analizar en este capítulo es una propuesta de sistematización para la creación de relaciones de alianza entre compañías, "Partnering Process Model" propuesto por Crane T.G. et al. 1997. En el se verá como crear un modelo para la constitución y desarrollo de las relaciones de alianza entre compañías. Por último veremos los trabajos realizados por Vrijhoef Ruben (2007) y los modelos de integración propuestos para la cadena de suministro en el sector de la construcción. 


\section{Modelos de integración de la Cadena de Suministro:}

En el presente apartado se pretende recoger algunos trabajos de investigación relacionados con los modelos para la gestión de la cadena de suministro. En los siguientes apartados se recogerán los correspondientes al sector de la construcción de mayor interés para la exposición del modelo que se presenta. Shidar Tayur et al. (1998) recogen en su libro Quantitative Models for Supply Chain Management un resumen de los modelos cuantitativos destinados a la mejora de la gestión de la cadena de suministro. De la misma manera Hartmut Stadtler y Christoph Kilger (2004) en su libro "Supply Chain Management and Advanced Planning: Concepts, Models, Software" recogen con énfasis los modelos para la gestión de la cadena de suministro y su implementación en distintas empresas.

Así mismo es interesante el trabajo de Narasimhan R. y Santosh Mahapatra (2004) en dónde los autores recogen una tabla resumen de modelos de decisión para la integración global de la cadena de suministro. (Fig 4_1_Tabla resume de modelos de decisión en la cadena de suministro. Narasimhan R. y Santosh Mahapatra (2004). 


\begin{tabular}{|c|c|c|}
\hline $\begin{array}{l}\text { Investigaciones en la cadena d } \\
\text { Area de la Problemática }\end{array}$ & $\begin{array}{l}\text { Ninistro } \\
\text { Tema } \\
\end{array}$ & Autores y año de la investigación \\
\hline $\begin{array}{l}\text { Toma de Decisisones Estratégica } \\
\text { Capacidad de Panifificación }\end{array}$ & $\begin{array}{l}\text { La capacidad de planificación robusta frente a la incertidumbre de la } \\
\text { demanda por minimización de la función objetivo que paraliza }\end{array}$ & $\begin{array}{l}\text { Parakesvopoulus, Karakitsos y } \\
\text { Rustem (1991 }\end{array}$ \\
\hline Cadena de Suministro Global & Modelo para situaciones multiestado y multiproducto en procesos de & Amtzen, Brown, Harrison y Traftion \\
\hline $\begin{array}{l}\text { Rediseñando la Cadena de } \\
\text { Suministro }\end{array}$ & $\begin{array}{l}\text { Produccíón ndistrtibución Global } \\
\text { Cuantificando las mejoras de rendimiento en una Cadena de } \\
\text { Suministro de la producción a través del rediseño de la Cadena de } \\
\text { Suministro }\end{array}$ & $\begin{array}{l}\text { (1995) } \\
\text { Beny y Naim (1996) }\end{array}$ \\
\hline $\begin{array}{l}\text { Configuración de la Cadena de } \\
\text { Suministro }\end{array}$ & La base de suministro hacia la configuración de respuesta rápida y & Fisher y Raman (1996) \\
\hline Ubicación de las instalaciones & $\begin{array}{l}\text { Maximizando el Retorno de la linversión teniendo en cuenta las } \\
\text { limitaciones en la capacidad a considerara, varios productos, el } \\
\text { transporte de carga fija, yla interacción espacial entre las } \\
\text { instalaciones de producción }\end{array}$ & Revelle y Laporte (1996) \\
\hline $\begin{array}{l}\text { Reestructurando la Cadena de } \\
\text { S Sumictrat }\end{array}$ & Optimización de la ubicación en la planta y su influencia en la & Camm et al.(1997) \\
\hline $\begin{array}{l}\text { Difierentes puntos de localización } \\
\text { para localizaciones de instalaciones }\end{array}$ & $\begin{array}{l}\text { Resolvivendo las optimas localizaciones cuando se incorporán a la } \\
\text { vez objetivos cualtativos y cuantitativos en simultaneo para }\end{array}$ & Jayaraman (1999) \\
\hline $\begin{array}{l}\text { de sevvicio } \\
\text { Aspectosticos de la Cadena de } S\end{array}$ & $\begin{array}{l}\text { demandas locatizadas a traves de diferentes zonas de clientes } \\
\text { Suministro }\end{array}$ & \\
\hline $\begin{array}{l}\text { Incentivos compatibilidade en una } \\
\text { descentralización de is Cadena de }\end{array}$ & $\begin{array}{l}\text { Proponer un sistema de medición del desempeño que es efectivo en } \\
\text { la armonización de los incentivos a través de una cadena de }\end{array}$ & Chen (1 \\
\hline $\begin{array}{l}\text { Suministro } \\
\text { Gestionando la descentralización de } \\
\text { la cadena de Suministro }\end{array}$ & 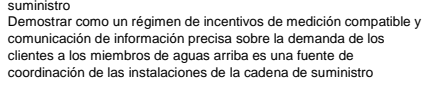 & Heing, Gerchak, Ernst y Pyke (1997) \\
\hline Contratos & Optimización conjunta de los paramentros de los contratos y de las & Bassok y Amupindi (1997) \\
\hline Contratos & $\begin{array}{l}\text { politicas de inventario en entornos de demanda incierta } \\
\text { Analisisis de la ficiciencia de los contratos de suministro para un } \\
\text { determinados producto con demanda incierta }\end{array}$ & Nair y Narasimban (2003) \\
\hline Relaciones Cliente Proveedor & Los Incentivos entre compañías de socios colaboradores pueden & Tagaras y Lee (1996) \\
\hline Subcontratación & $\begin{array}{l}\text { Explorando las relaciones entre el coste de la acalidad de } \\
\text { proveedores, la calidadd de entrada de proveeddores, y las } \\
\text { imperfecciones en los procesos de fabricación }\end{array}$ & Talluri (2002) \\
\hline Pujas & $\begin{array}{l}\text { El diseño efectivo de las ofertas por un postor no seleccionados } \\
\text { sobre la base de la intormación histórica }\end{array}$ & Narasimba et al. (2003a, 2003b) \\
\hline Selección de Proveedor & $\begin{array}{l}\text { Selección de un proveedor para una subcontratación estratégica y } \\
\text { una subcontratación táctica }\end{array}$ & Talluri y Narasimba (2003) \\
\hline Evaluación del Proveedor & $\begin{array}{l}\text { La evaluación de los proveedores mediante la incorporación de } \\
\text { medidas de la variabilidad del rendimiento }\end{array}$ & Raghunnathan (1999) \\
\hline Planificación Colaborativa & $\begin{array}{l}\text { Evaluación del impacto de la previsión ne colaboración y la } \\
\text { reposición de una cadena de suministro con la demanda al azar }\end{array}$ & Moinzadeh (2002) \\
\hline Aspectos Operativos de la ge & 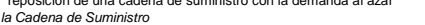 & \\
\hline Integración de Operaciones & 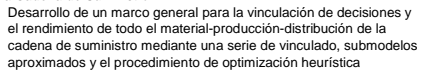 & Cohen y Lee (1998) \\
\hline Integración de la Distribución & 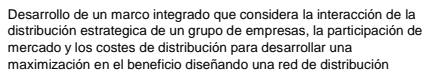 & \\
\hline $\begin{array}{l}\text { Capacidad de Respuesta } \\
\text { Planificación y Programación }\end{array}$ & $\begin{array}{l}\text { La asignación de la capacidad, y programación envios para una } \\
\text { variedad de productos fabricados por varios proveedores con } \\
\text { capacidades varuadas en virtud de la demanta incierta }\end{array}$ & Agrawal, Smith, y Tsay (2002) \\
\hline Adquisiciones & $\begin{array}{l}\text { Determinar las cantidades optimas de compra para un sistema multi- } \\
\text { invetario }\end{array}$ & - Clark y Scar \\
\hline Adquisiciones & $\begin{array}{l}\text { La evaluación de las repercusiones de la asignación de la cantidad } \\
\text { de inventario al componente o materia prima de origen es doble por }\end{array}$ & Anupindi y Ake \\
\hline Politica de Reposición & 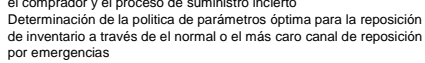 & Mo \\
\hline $\begin{array}{l}\text { Politica para inventarios competitivos } \\
\text { en la Cadena de Suminisistro }\end{array}$ & $\begin{array}{l}\text { Investigación en la teoría de juegos sobre los negativos efectos de } \\
\text { la competición en dos estadios de una cadena de suminisistro en } \\
\text { serie con una demanda estocástica }\end{array}$ & Cachon y Zipkin (1999) \\
\hline $\begin{array}{l}\text { Politica de Reposición en los } \\
\text { sistemas de inventario para la } \\
\text { gestión de distribuididores }\end{array}$ & $\begin{array}{l}\text { Teoria del optimo de la cantidadd de reposición y frecuencia de } \\
\text { servicio en el caso de una demanda de Posisson en sistemas VMI }\end{array}$ & Centikaya y Lee (2000) \\
\hline Gestión de Inventario & $\begin{array}{l}\text { Analisis de los efeectos de desestabilización en los inventarios } \\
\text { multiesslabones en cadenas de suministro de distribución/producción }\end{array}$ & Bagahama y Cohen (1998) \\
\hline $\begin{array}{l}\text { Producción, Planificación y } \\
\text { Programación }\end{array}$ & $\begin{array}{l}\text { Análisis de los impactos de las incertidumbres en la producción y la } \\
\text { demanda a para los productost finales en la polanififacición de la } \\
\text { producción, el control de inventarios, la mejora de la calidad y la } \\
\text { planificación de la capacidad }\end{array}$ & Tang (1990) \\
\hline Sistemas de Producción multietapas & 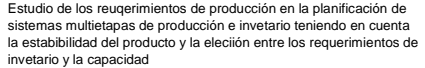 & Graves, Kletter y William (1998) \\
\hline Planificación de la Producción & 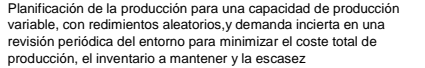 & Wang y Gerchak (1996) \\
\hline Programación de la Producción & $\begin{array}{l}\text { Evaluación de los méritos de la programación integrada de la } \\
\text { producción para reducir los efectos negativos de la revisiones de los } \\
\text { programas. }\end{array}$ & Lee y Wei (2001) \\
\hline $\begin{array}{l}\text { Aplazamientos Logisticos } \\
\text { Fiabilidad de los envios }\end{array}$ & $\begin{array}{l}\text { Evaluación del coste de varios estratégias de aplazamientos } \\
\text { Análisis del impacto de las especificaciones del cliente en los } \\
\text { rendimientos de los envios de los suministradores }\end{array}$ & $\begin{array}{l}\text { Zinn y Bowersox (1988) } \\
\text { Grout (1998) }\end{array}$ \\
\hline Envios laterales & $\begin{array}{l}\text { rendimientos de los envios de los suministradores } \\
\text { Los efectos de los envios laterales y los envios directos en el coste } \\
\text { de inventario }\end{array}$ & Alfredsson y Verrijdt (1999) \\
\hline $\begin{array}{l}\text { Coordinación en la Cadena de } \\
\text { Suministró } \\
\text { Información compartida }\end{array}$ & $\begin{array}{l}\text { Análisis de la eficacia de los descuentos por cantidad como } \\
\text { mecanismo de coordinación en la comprosas y en la producción } \\
\text { Analisis de larelación entre los beneficicos en la cadena de suministr } \\
\text { yla información compartida }\end{array}$ & Munson y Rosenblatt (2001) \\
\hline
\end{tabular}

Fig 4_1_ Tabla resumen de modelos de decisión en la cadena de suministro. Narasimhan R. y Santosh Mahapatra (2004). 
En este mismo trabajo, Narasimhan R. y Santosh Mahapatra (2004), los autores recogen cinco ejemplos de modelos de decisión en la gestión de la cadena de suministro donde ilustran y demuestran la importancia que la integración de las decisiones tiene a través de la cadena de suministro.

\section{Un Modelo para el funcionamiento interorganizacional en la cadena de suministro:}

Como recoge Bygballe L. et al. (2007) la gestión de la cadena de suministro es un tópico "caliente" en el sector de la construcción (ver Akintoye et al 2000, Love et al. 2004, Proverbs and Holt 2000 y Vordijk et al. 2000). Esto a pesar de que la industria es considerada como una tipología distinta a otras industrias de construcción como puede ser la industria de automóviles cuya gestión de la cadena de suministro está mucho más desarrollada (Vhijhoef y Koskela 2000, Ballard y Howell 2003, Winch 2003). En este apartado y en los siguientes se recogerán modelos de integración de la cadena de suministro que se plantean como más interesantes para el desarrollo de la tesis presentada.

Con independencia de los modelos de integración de la cadena de suministro en el sector de la construcción que se verán más adelante, existen varios autores y trabajos desarrollados que tratan esta materia de alguna manera. A modo de ejemplo y sin pretender ser exhaustivo podemos citar a J. Sommerville (1994), Tah J.H.M. et al. (1998), Hong-Minh et al. (1999), Ganeshan et al. (1999), Taylor J. y Bjornsson H. (1999), Min H. y Zhon G. (2002), O'Brien W.J. et al. (2002), Tserng H.P. y Lin P.H. (2002), H.J. y Tah M. (2004) y Xialong Xue et al. (2004). 
Como señalan Love P.E.D. et al (2002) la industria de la construcción está altamente fragmentada y esto está en el origen de los críticos y pobres resultados que se obtienen, así como en la baja innovación de los procesos. Para mejorar los resultados, particularmente las relaciones inter organizacionales, las organizaciones necesitan considerar la formación de alianzas con sus principales proveedores. Algunas organizaciones de construcción han empezado a hacer alianzas a corto plazo con sus clientes y proveedores como parte de una estrategia de gestión de la cadena de suministro. Sin embargo, estas alianzas a corto plazo no proporcionan el feed-back necesario. Según los autores es necesario desarrollar una cooperación, confianza y desarrollo del conocimiento a largo plazo. Es por esto que Love P.E.D. et al (2002) nos proponen la necesidad que tienen las organizaciones de desarrollar alianzas a largo plazo, como parte necesaria del desarrollo del conocimiento en el sector. Las implicaciones de formar diferentes tipos de estrategias para alianzas en la construcción han sido muy discutidas. El modelo interorganizacional que ellos proponen puede ser usado para ir desarrollando el aprendizaje y está basado en las principales reglas del TQM.

El modelo para la construcción de alianzas basado en TQM y que integra la cadena de suministro lo podemos ver en la figura Fig 4_5 Modelo de alianzas para la construcción de Love P.E.D. et al (2002). 


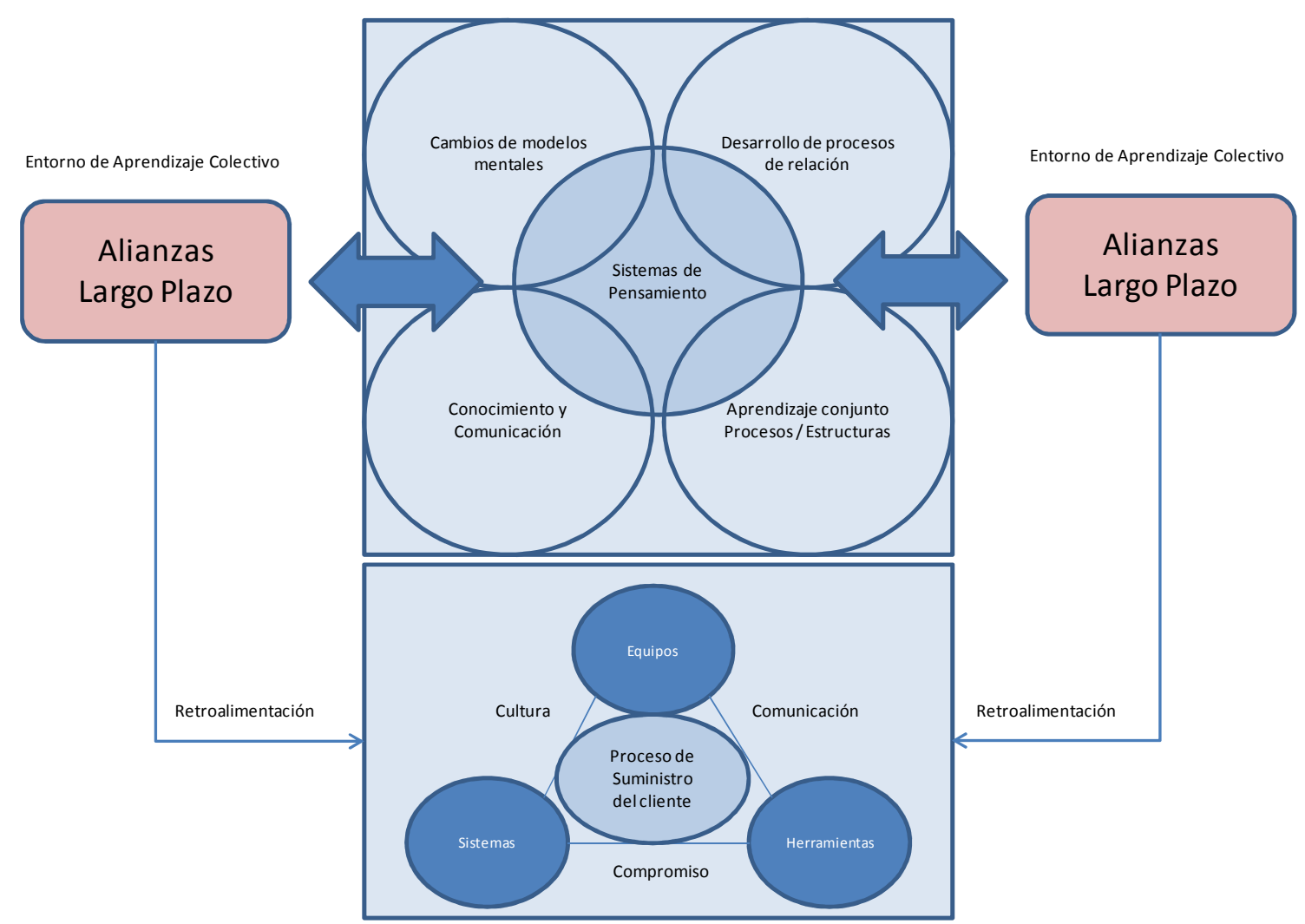

Fig 4_5 Modelo de alianzas para la construcción de Love P.E.D. et al (2002).

Una revisión detallada de las relaciones que se proponen en TQM y el aprendizaje de las mismas se pueden encontrar en Love et al. (2000). El paso innovador que este modelo presenta es el concepto de lo que los autores llaman Systems Thinking. Como se puede ver en el modelo de la figura, los componentes esenciales incluyen: aprendizaje conjunto de procesos y estructuras, desarrollo de los procesos de relación, y sistemas de pensamiento. Este es un modelo que está inspirado en la estructura de aprendizaje propuesta por Morrison y Mezentseff (1997) pero adaptado a la estrategia de las empresas de construcción. 


\section{Modelo de integración en la cadena de suministro de la construcción:}

Lo que se conoce como "seamless supply chain management model for construction" propuesto por P.E.D. Love et al., 2004 habla de un modelo de integración para la gestión de la cadena de suministro de la construcción. Los citados autores comentan que iniciativas como estas son a menudo usadas en conjunción con las prácticas tradicionales de dirección y control de proyectos en la cadena de suministro, dando como resultado una sensación de mejora que está limitadas a nivel de su proceso (Vrijhoef y Koskela, 2000). Más todavía, procesos basados en el T.Q.M. no han sido puestos en práctica como filosofía en las organizaciones de construcción, quizá porque muchas compañías no tienen las habilidades y la experiencia requeridas para utilizar de forma efectiva las herramientas y técnicas necesarias para mejorar la cadena de suministro de la construcción (Love y Sohal, 2002). Más que aplicar iniciativas específicas en la gestión de la cadena de suministro de forma fragmentada y orientada a sosegar problemas, el propósito de este modelo es realizar un acercamiento a las necesidades y soluciones de la gestión de la cadena de suministro de la construcción de forma global. Con este modelo se pretende integrar el diseño y los procesos constructivos y presentar un modelo para su discusión.

Love P.E.D. et al. (2004) mantienen en su modelo que la separación del diseño y los procesos de producción en proyectos han sido altamente criticados durante los últimos 50 años (ejemplo: Simon Report, 1944; Banwell 1964; Latham 1994; y Egan 1998). Consecuentemente, puede aparecer finalmente lo que se llama un puente para superar este "gap", creando el modelo que los autores proponen, donde la relación cara a cara entre las varias fases del proyecto se integra de forma circular y única. Love et al., (2002), esta organización involucrada con el proyecto es a la vez cliente y proveedor, y debe considerarse de ambas maneras, de esta forma pueden ir dando y creando valor a través de la cadena de suministro, ver Fig. 4_2 Interface de relación cliente proveedor en un proyecto de cadena de suministro P.E.D. Love et al., (2004). En el fondo, y de acuerdo con lo expresado por Lamming (1996), el valor debe darse más por las personas en la atención en el proceso que porque sea un coste. 


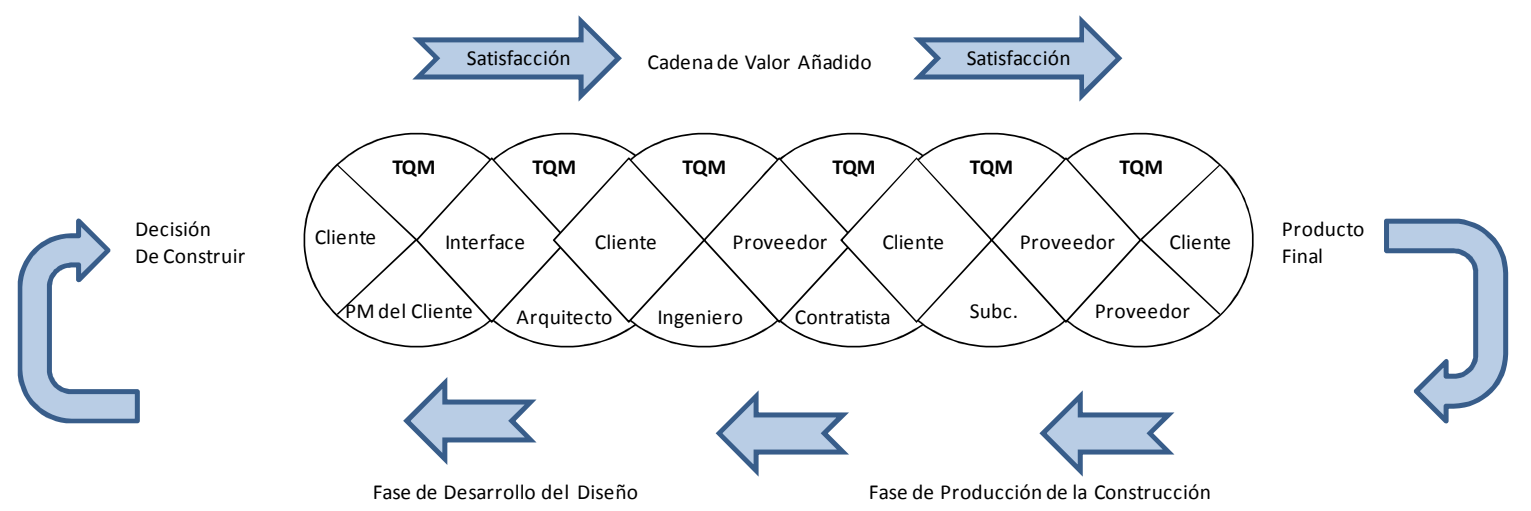

Fig 4_2_ Interface de relación cliente proveedor en un proyecto de cadena de suministro P.E.D. Love et al., (2004)

Para mejorar la comunicación y minimizar las barreras de los flujos de información en los proyectos, Love et al., (1998), proponen que la tradicional forma de estructurar los proyectos, usada en procesos de procuración, debe ser reemplazada por una estructura horizontal basada en un equipo multidisciplinar. Esto implica que los individuos y los grupos trabajan juntos de forma continuada en vez de secuencialmente, para diseñar y desarrollar los productos y los procesos, así como para identificar o innovar en los materiales y equipos necesarios para el proceso productivo.

En la Fig 4_3 Modelo de integración en la cadena de suministro de la construcción P.E.D. Love et al., (2004), estos miembros del equipo mantienen un contacto directo con el cliente a través de un proceso de desarrollo de diseño de producto. Adicionalmente el modelo proyectado ha sido diseñado para estimular el conocimiento colectivo, trabajo en equipo y desarrollar un sistema psicosocial que influya en el desarrollo del modelo. Una fundamental presunción es que cada organización implemente una filosofía T.Q.M. para garantizar la asunción de las mejores prácticas industriales. El propósito del modelo diseñado en la figura anterior ofrece una manera de trabajar de forma colaborativa donde el diseño y la resolución de conflictos deben de ser resueltos continuamente. Esencialmente la percepción de los miembros del equipo es mejor cuando las responsabilidades del proyecto de desarrollo son compartidas (Nesan y Holt, 1999). Esto hace que exista un efecto positivo en la reducción del tiempo necesitado para el desarrollo y del nivel de iteracciones, variaciones y compromisos en la calidad. El proceso de modelo garantiza que se mantengan juntos, en una estructura de grupo integrada e innovadora, donde la gestión del diseño y los procesos de compra son implementados en una novedosa forma de ver la industria de la construcción. 
El facilitador del proyecto, a menudo también se refiere con este nombre al director del proyecto, debe ser un hábil negociador, conocedor de los recursos y su uso, y periódicamente evaluar junto con el cliente, el avance en el diseño del producto (Smith y Jackson, 2000). En lugar de asumir responsabilidades sobre un solo punto, es preferible dividirlas equitativamente y asignarlas a cada uno de los miembros del equipo. La forma efectiva de implementar el modelo en la práctica requiere a un líder el cual pueda coordinar e integrar actividades y recursos a través de los procesos de procuración. 


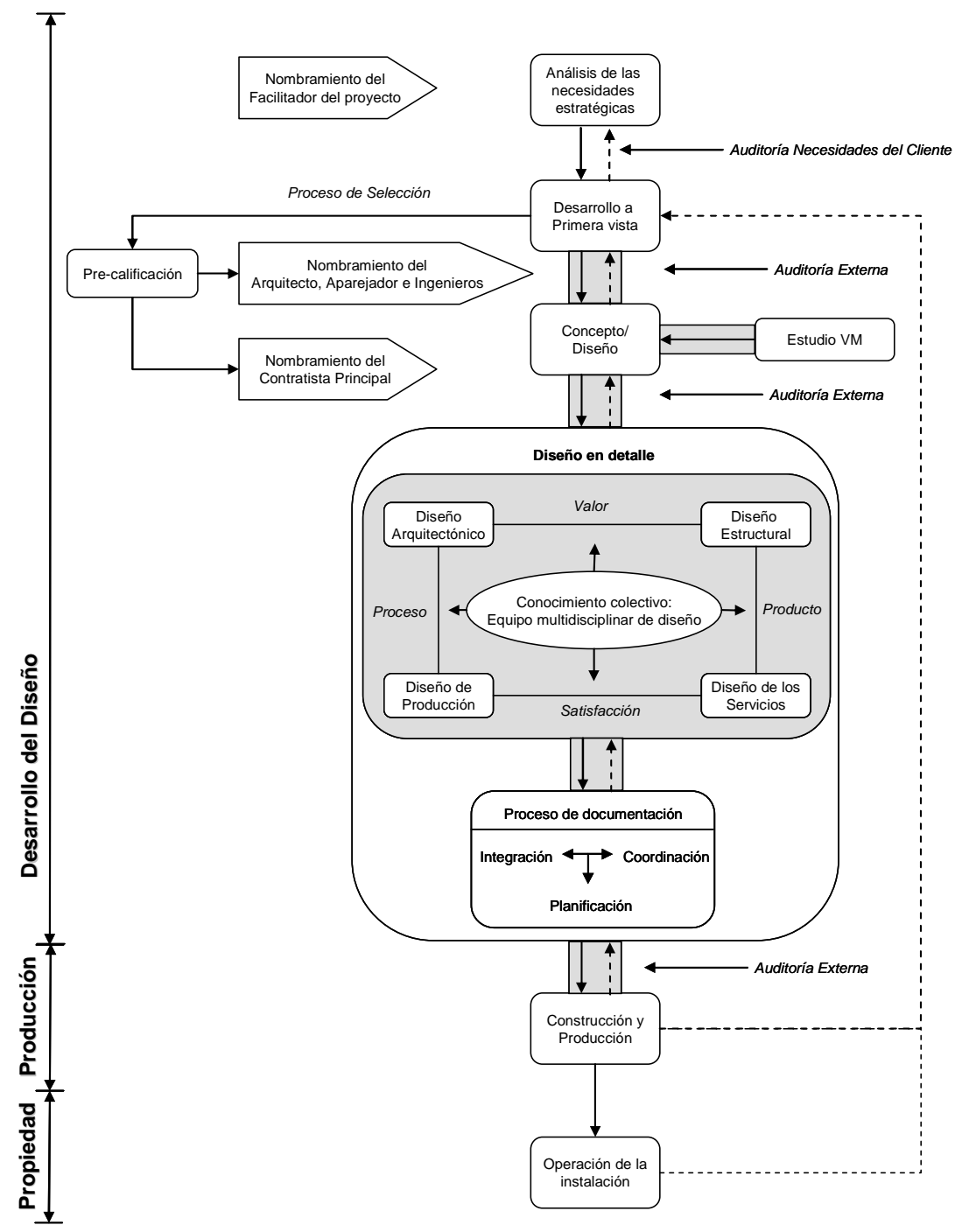

Fig 4_3. Modelo de integración en la cadena de suministro de la construcción P.E.D. Love et al., (2004) 
Anteriormente en las investigaciones se sugería que un facilitador del proyecto independiente pudiera hacer de forma efectiva la estimulación y desarrollo racional así como la comunicación entre los participantes del proyecto mejorando finalmente los resultados del mismo (Ofori, 2000). En este caso, el director del proyecto actúa como un conductor a través del cual existen caminos de ida y vuelta de comunicación entre el equipo del proyecto y el cliente. Esto puede ser, sin embargo, una dificultad especialmente cuando los plazos y los costes se tienen en cuenta desde el punto de vista de consecución de objetivos.

\section{Modelo para la creación de una relación de partenariado:}

En este apartado se verá un modelo para la creación de relaciones de partenariado. Estas relaciones se pueden entender como uno de los caminos para llegar a integrar procesos dentro de la gestión de la cadena de suministro, y es en esta medida, se cree de interés ver el detalle de este modelo por su aportación al que se presenta en la tesis actual. En los últimos tiempos como indica G. Crane et al. (1997), las relaciones de alianzas se han ido incrementando paulatinamente en empresas de ingeniería y construcción. Asimismo muchas investigaciones se han realizado para describir el concepto de partenariado, y como se deben estructurar los grupos de trabajo y los beneficios del mismo (Abudayyeh 1994; Brown1993; In Search 1991; Crane 1995; Liska 1993; Poirier and Houser 1993). Estas publicaciones han demostrado que las relaciones de partenariado creadas en entornos armoniosos, han facilitado la reducción de costes y litigios legales, incrementando la calidad de la productividad y los beneficios. Existen trabajos que han hablado de cómo crear esas relaciones de partenariado, incluso de las barreras existentes para llegar al éxito en estas relaciones (Sanders et al. 1996).

Como dicen los autores citados en los párrafos anteriores, existen muchos aspectos a considerar en la identificación de las mejoras a realizar en la alianza, la evaluación de la evolución de la relación de la alianza por aquellos factores que se consideran claves, la identificación y la medida de los beneficios generados. En un estudio realizado sobre veintiuna relaciones de alianza exitosas mediante entrevistas, revisando las metas y viendo cómo se alcanzan los objetivos G.. Crane et al (1997) nos proponen un proceso para realizar una alianza con éxito. Los autores basan su modelo en cinco fases que según indicamos en la Fig 4_4 Partnerig Process Model, G. Crane y et al. (1997), van desde la alineación interna de la empresa hasta la alineación del proceso de trabajo. 


\section{Objetivos:}

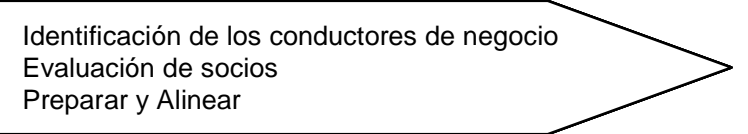

Fase 1

Alineación Interna

Del propietario

\section{Objetivos:}

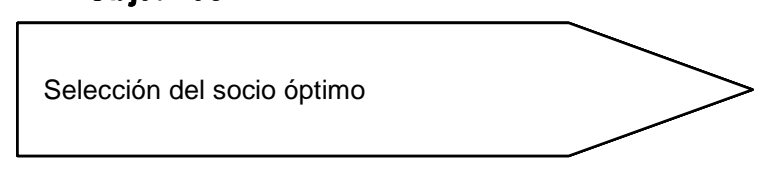

\section{Objetivos:}

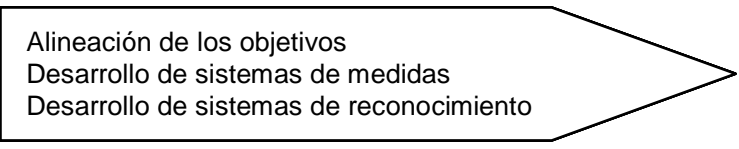

Fase 3

Desarrollo de sistemas de reconocimiento

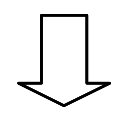

Fase 2

Selección del socio

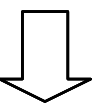

Alianza de alineación

\section{Objetivos:}

Desarrollo de objetivos "ganar/ganar" Recompensas por la consecución de los Objetivos

Fase 4

Alineación de Proyectos

\section{Objetivos:}

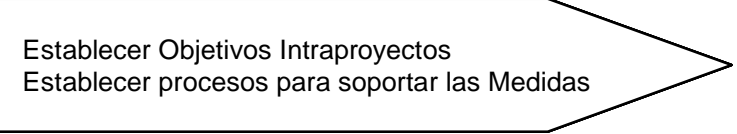

Fase 5

Alineación de Procesos de trabajo

Fig 4_4 Partnerig Process Model, G. Crane y et al. (1997)

Cada una de estas fases tiene sus objetivos y sus factores críticos pero muestran una hoja de ruta que permite desarrollar el modelo. Los factores críticos se pueden ver en el estudio citado pero se cree de mayor interés para el desarrollo del modelo propuesto ver someramente cada una de las fases y sus objetivos para poder entender cómo funcionan. 


\subsection{Fase 1: alineación interna.}

La organización de la empresa debe determinar cuáles son las razones para realizar una alianza. La fase uno crea una estructura para definir las necesidades de la organización, evaluar la alianza y para dar respuesta a las necesidades de la misma, ubicando responsabilidades como punto de partida de la relación. Los objetivos según. G. Crane et al. (1997) de esta fase son: identificar los drivers de negocio, evaluar la alianza como la mejor solución para establecer esos drivers y preparar el alineamiento de la organización para la alianza.

\subsection{Fase 2: selección del aliado.}

En la fase dos, según los autores, se deben desarrollar los criterios que en la fase uno han llevado a la decisión de aliarse, con el fin de optimizar la selección del aliado. El proceso de selección del aliado puede verse en In Search of partnerig excellence (1991), donde se detalla una metodología para la evaluación y selección de aliados. Los objetivos de esta fase, siempre siguiendo las indicaciones de G. Crane et al. (1997), son dar poder a un equipo de selección para desarrollar una lista de criterios en la selección de aliados, desarrollar una lista de potenciales, y analizarlos.

\subsection{Fase 3: alineamiento de las relaciones de la alianza.}

Según comentan los autores, la fase tres está diseñada para ayudar a los participantes en la alianza estratégica a entenderse unos a otros, en las metas y los objetivos a largo plazo. Alcanzado el entendimiento mutuo de las partes pueden trabajar juntos en llevar a la realidad planes de futuro, mejorar las relaciones de la alianza formando una estructura general de cooperación entre las dos compañías y estableciendo las bases de un mayor acercamiento necesario para llevar los proyectos individualmente en la fase cuatro y organizar el proceso de trabajo de la fase cinco. Los objetivos de esta fase son desarrollar: el alineamiento de las relaciones soportándolas en objetivos, las medidas que determinarán el éxito y un método para reconocer el éxito y el cumplimiento de los objetivos. 


\subsection{Fase 4: alineamiento de proyecto.}

Como nos describen los propios autores citados, la fase de alineamiento del proyecto presenta actividades de soporte para el éxito de la alianza en determinados proyectos construidos sobre el desarrollo de los conceptos de la fase tres. Las alianzas estratégicas necesitarán del alineamiento a nivel de proyecto, así como de las relaciones a nivel para alcanzar los detalles necesarios y su consistencia. Los objetivos de esta fase son desarrollar objetivos ganar-ganar en los proyectos que complementen a los objetivos de la alianza, y recompensar el acoplamiento de los equipos con los objetivos del proyecto.

\subsection{Fase 5: Alineamiento en el proceso de trabajo.}

Durante esta fase del trabajo las metas de la alianza son trasladadas a la acción. Los empleados deben haber entendido la definición de la alianza y haber fijado las metas para que ellos puedan visualizar cuál es el camino y los objetivos perseguidos. En esta fase se establecen metas intra proyecto que sean consistentes con los objetivos de la alianza, establecer procesos de trabajo para alcanzar la dinámica y las mesas de trabajo. 


\section{Modelo de integración de la cadena de suministro de la construcción: procesos de diseño y construcción.}

En este apartado se verá el modelo de integración de la cadena de suministro del sector de la construcción propuesto por Vrijhoef R. (2007). Stevens (1989) señala la importancia y las posibilidades que la integración de la cadena de suministro tiene para las compañías que quieren reaccionar a las condiciones de mercado y reducir sus niveles de costes. Para alcanzar esto, todas las empresas y funciones deberían estar conectadas, operando como si fueran una fabrica sin muros. Fawcett y Magnan (2002) argumentan que a menudo la integración de la cadena de suministro es una tarea difícilmente alcanzable en su totalidad.

El autor empieza explicando una manera de entender la demanda y la cadena de suministro en el sector de la construcción basándose en Vrihoef y De Ridder (2005) ver Fig 4_5_ Demanda y cadena de suministro en la construcción. Vrihoef y De Ridder (2005).

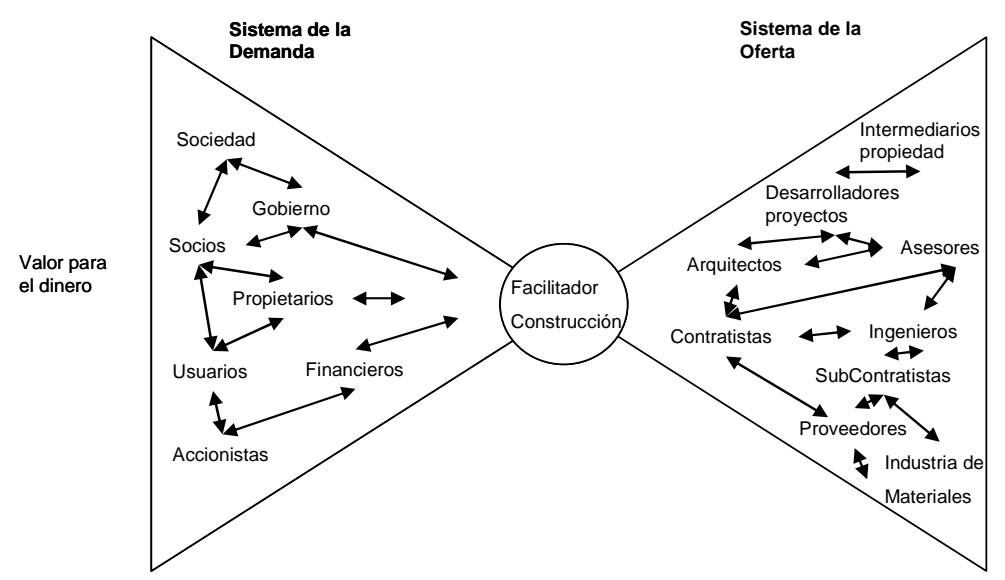

Fig 4_5_ Demanda y cadena de suministro en la construcción. Vrihoef y De Ridder (2005) 
En la construcción, la demanda y la cadena de suministro no están a menudo, bien integradas. En definitiva parece lógico debido a que en la práctica la integración de los sistemas debe ser costosa y compleja, en una industria que debe organizarse principalmente en proyectos. Por otra parte, aparece la necesidad de integración de ambas partes, la demanda y la cadena de suministro. Según Vrijhoef (2007) aparecen dos nuevos roles, un sistema integrador de la demanda y un sistema integrador de la cadena de suministro. Fig 4_6_El papel del integrador de la demanda y la cadena de suministro. Vrijhoef y De Ridder (2005).

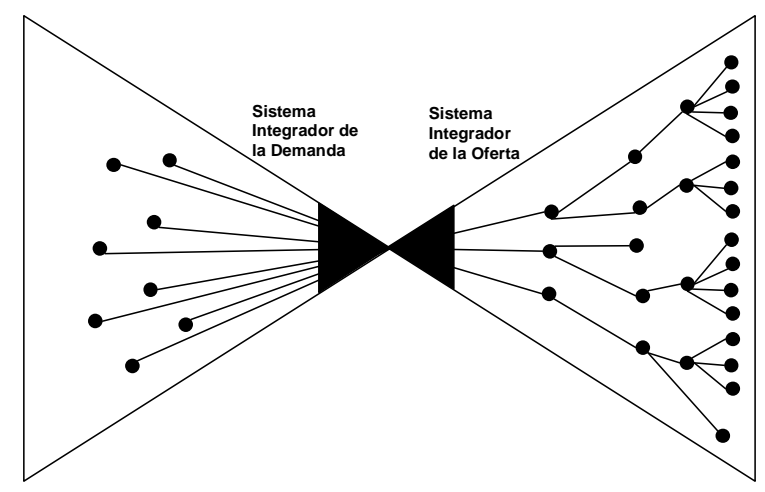

Fig 4_6_El papel del integrador de la demanda y la cadena de suministro. Vrijhoef y De Ridder (2005).

La propuesta de Vrijhoef (2007) con los sistemas de reingeniería e integración es mejorar la funcionalidad de la cadena de suministro de la construcción. Esto incluye un cambio de procesos, y de modelo, lo que llama una reconstrucción organizacional de la cadena de suministro. Para alcanzar esto, primero de todo, la cadena debe ser descompuesta. Seguidamente debe reorientarse y reconfigurarse las funciones y los interfaces entre las mismas. Haciendo esto los problemas endémicos y las irracionalidades deben resolverse, eliminando las existentes ineficiencias. El efecto se conseguirá controlando las diferentes funciones con una probablemente mayor centralización en una sola entidad, una empresa extendida.

Esta reorganización de la demanda y la integración de la cadena propuesta por Vrijhoef (2007) se basa en dos actores de la cadena que son el integrador de la demanda y el integrador de la cadena de suministro, Vrijhoef y De Ridder (2005), ver Fig 4_7. 

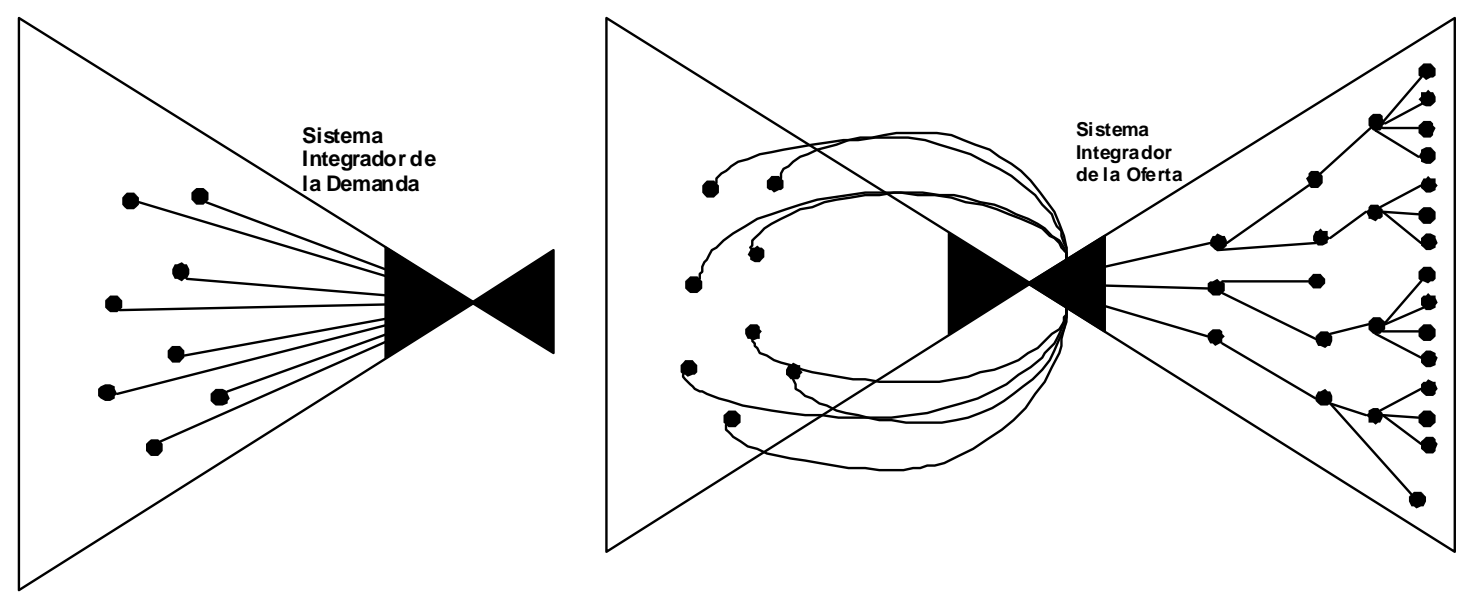

Fig 4_7_Papeles del Integrador de la demanda e del integrador de la cadena de suministro Vrijhoef y De Ridder (2005)

Con esto se pretenden mejorar los resultados de la industria de la construcción a través del incremento de la eficiencia y la efectividad integrando los procesos a través de la cadena de suministro. Como resultado se obtendrá una mejora económica en el sector, una mejora de la satisfacción de clientes y usuarios, una reducción de la utilización de capital, de los recursos humanos y de los naturales empleados en los proyectos, así como una mejora de la salud y el bienestar global de la sociedad. 


\section{Referencias bibliográficas:}

$>$ ABUDAYYEH, 0. (1994). "Partnering: a tearn building approach to quality construction management." J. Mgmt. Engrg., ASCE, 10(6), 26-29

$>$ AGRAWAL, N., SMITH, S. S., \& TSAY, A. A. (2002). "Multi-vendor sourcing in a retail supply chain". Production and Operations Management, 11, 157- 182

$>$ AKINTOYE, A, MCLNTOSH, G AND FITZGERALD, E (2000) "A survey of supply chain collaboration and management in the UK construction industry", European Journalof Purchasing and Supply Management, 6, 159-1 68.

$>$ ALFREDSSON, P., \& VERRIJDT, J. (1999). "Modeling emergency supply flexibility in a two-echelon inventory system". Management Science, 45, 1416- 1431.

$>$ ANUPINDI, R., \& AKELLA, R. (1993). "Diversification under supply uncertainty". Management Science, 39, 944- 963.

$>$ ARNTZEN, B. C., BROWN, G. G., HARRISON, T. P., \& TRAFTON, L. (1995). "Global supply chain management at Digital Equipment Corporation". Interfaces, 25, 69-93.

> BAGAHANA, M. P., \& COHEN, M. A. (1998). "The stabilizing effect of inventory in supply chains". Operations Research, 46, S72- S83.

$>$ BALLARD, G AND HOWELL G A (2003) "Lean project management", Building Research S Information, 31(2), 119-133.

$>$ BANWELL H.- (1964) "The Placing and Management of Contracts for Building and Civil Engineering Work”. HMSO, London,

D BASSOK, Y., \& ANUPINDI, R. (1997). "Analysis of supply contracts with total minimum commitment”. IIE Transactions, 29, 373-381.

$>$ BERRY, D., \& NAIM, M. M. (1996). Quantifying the relative improvements of redesign strategies in a PC supply chain. International Journal of Production Economics, 46- 47, 181- 196.

$>$ BOWERBOX, D.J. (1997). "Integrated Supply Chain Management: A Strategic Imperative", presented at the Council of Logistics Management 1997 Annual Conference, 5-8 Oct. Chicago, IL.

D BROWN, J. H. (1993). "Partnering on engineering/construction projects." PM Network, 7(12), 32-34.

BYGBALLE LENA, MARIANNE JAHRE Y ANNA R.S. SVÄRD. (2007). "Partnering in contruction" - Relationship connectedness 
CACHON, G. P., \& ZIPKIN, P. H. (1999). „Competitive and cooperative inventory policies in a two-stage supply chain”. Management Science, 45, 936- 953.

CAMM, J. D., CHORMAN, T., DILL, F., EVANS, J., SWEENEY, D., \& WEGRYN, G. (1997). "Blending OR/MS, judgment, and GIS: Restructuring P\&G's supply chain". Interfaces, 27, 128- 142.

CAMPUZANO BOLARÍN F., LISEC A. and CRUZ LARIO F. (2008). "Inventory Cost Consequences of Variability Demand Process within a Multi-Echelon Supply Chain". Logistics \& Sustainable Transport. Volume 1, Issues 3.

$>$ CAMPUZANO BOLARÍN F, ROS McDONNELL L, and MARTIN GARCIA J. (2008). "Reducing the Impact of Demand Process Variability within a Multi-Echelon Supply Chain". Icfai Journal of Supply Chain Management V(2): 7-21, Junio 2008.

$>$ CETINKAYA, S., \& LEE, C. (2000). "Stock replenishment and shipment scheduling for vendor-managed inventory systems". Management Science, 46, 217- 232.

> CHEN, F. (1999). "Decentralized supply chains subject to information delays". Management Science, 45, 1076- 1090.

> CLARK, A., \& SCARF, H. (1960). "Optimal policies for a multi-echelon inventory problem”. Management Science, 6, 475- 490.

$>$ COHEN, M. A., \& LEE, H. L. (1998). „Strategic analysis of integrated production and distribution system". Operations Research, 36, 216- 228.

$>$ CONSTRUCTION INDUSTRY INSTITUTE (CII). (1991). "In search of partnering excellence." Spec. Pub. No. 17-1, Partnering Task Force, Austin, Tex.

> COOPER, M. C.; LAMBERT, D. M.; PAGH, J. D. (1993). "Supply Chain Management: More Than a New Name for Logistics". The International Journal of Logistics Management Vol 8, No 1. pp. 1-14.

CRANE, T. G. (1995). "The benefits and implementation of partnering in the construction industry," ME thesis, Clemson Univ., Clemson, S.C.

> CRANE, T.G., FELDER, J.P., THOMPSON, P.J., THOMPSON, M.G., SANDERS, B.R., (1997). "Partnering process model". ASCE Journal of Management in Engineering 13 (4), 57-63.

CRANE, A., (1999). "The movement for innovation (M4I ) in construction in learning to succeed in construction". Conference Proceedings,CITB, November 25, London, pp. $2-8$. 
CRESPO MARQUEZ ADOLFO, OSCAR RUBIANO OVALLE, RAFAEL RUIZ USANO, MIGUEL ANGEL MUÑOZ PEREZ Y JOSÉ MIGUEL LEON BLANCO. (2002). "Implicación en la gestión del capital circulante. Un análisis mediante dinámica de sistemas".

DGAN, J. (Construction Task Force) (1998).”Rethinking Construction”, DETR, London.

FAWCETT, S.E. AND MAGNAN, G.M. (2002). "The rhetoric and reality of supply chain integration". International Journal of Physical Distribution \& Logistics Management 32 (5), 339-361.

FISHER, M., \& RAMAN, A. (1996). "Reducing the cost of demand uncertainty through accurate response to early sales". Operations Research, 44, 87- 99

> GANESHAN, R., JACK, E., MAGAZINE, M. J. Y STEPHENS, P. (1999). “A taxonomic review of supply chain management research". In S. Tayur, R. Ganeshan \& M. Magazine, Quantitative models for supply chain management (pp. 840-879). Boston, MA. Kluwer Academic Publishers.

DARG, A., \& TANG, C. S. (1997). «On postponement strategies for product families with multiple points of differentiation". IIE Transactions, 29, 641-650.

- GRAVES, S. C., KLETTER, D. B., \& WilliaM, H. B. (1998). "A dynamic model for requirements planning with application to supply chain optimization". Operations Research, 46, S35- S49.

$>$ GROUT, J. R. (1998). "Influencing a supplier using delivery windows: Its effect on the variance of flow time and on-time delivery". Decision Sciences, 29, 747- 764.

H. J., TAH M., (2004) "Towards an agent-based construction supply chain network modelling and simulation platform," Automation in Construction, 14, pp. 353-359.

HARTMUT STADTLER Y CHRISTOPH KILGER . (2004). "Supply chain management and advanced planning: Concepts, Models, Software ... Springer". 512 páginas. ISBN:3540220658.

$>$ HEIKKILA J. (2002). " From Supply to demand Chain Management: Efficiency and Customer Satisfaction”. Journal of Operations Management. Volume 20, Issue 6, November 2002, Pages 747-767.

> HENIG, M., GERCHAK, Y., ERNST, R., \& PYKE, D. F. (1997). „An inventory model embedded in designing a supply contract”. Management Science, 43, 184- 197.

HEWITT F. (1994). "Supply Chain Redesign". The International Journal of Logistics management, Vol. 5, No. 2, pp. 1-9. 
HONG-MINH, S.M., BARKER, R. AND NAIM, M.M. (1999). "Construction supply chain trend analysis." Proc. 7th Ann. Conf. of the Int'l. Group for Lean Construction (IGLC-7) Berkeley, California, USA, 26-28 July.

> JAYARAMAN, V. (1999). "A multi-objective logistics model for a capacitated service facility problem". International Journal for Physical Distribution and Logistics Management, 29, 66- 81.

KULP, S. C. (2002). "The effect of information precision and information reliability on manufacturer retailer relationships". The Accounting Review, 77, 653- 677.

LAMMING, R., (1996). "Squaring the lean supply with supply chain management". International Journal of Operations and Production Management 16 (2), 188-196.

LATHAM, M., (1994). "Constructing the Team”. HMSO, London.

$>$ LEE, K., \& WEI, C. J. (2001). "The value of production schedule integration in supply chains". Decision Sciences, 32, 601- 633.

$>$ LISKA, R., (1993). "Partnering for project success". Assoc. Builders and Contractors. Inc.. Washington, D.C.

LOVE P.E.D. GUNASEKARAN A. AND LI, H., (1998), "Putting an engine into reengineering: toward a process based organisation", International Journal of Operations \& Production Management, Vol. 18 No 9. pp. 937-949

$>$ LOVE, P.E.D., LI, H., IRANI, Z. \& FANIRAN, O. ,(2000), “Total quality management and the learning organization, a dialogue for change in construction". Construction Management and Economics, 18, 321-332.

DOVE, P.E.D., LI, H., IRANI, Z. \& HOLT, G.D, (2000), "Total quality management: a framework for facilitating organizational learning and change in construction". International Monthly for Total Quality Management: TQM Magazine, 12, 107-117.

LOVE PETER E. D , ZAHIR IRANI, EDDIE CHENG, HENG LI, (2002) "A model for supporting inter-organizational relations in the supply chain" Engineering Construction and Architectural Management 9 (1), 2-15.

LOVE P.E.D., ZAHIR IRANI AND DAVID J. EDWARDS, (2004), "A seamless supply chain management model for construction". Supply Chain Management: An International Journal Vol. 9 Number 1 pp 43-56.

McCULLEN P. and TOWILL D. (2004). "Diagnosis and Reduction of Bullship in Supply Chains". Supply Chain Management: An International Journal Vol 7 Iss: 3, pp 164-179. MCB UP Ltd. 
MIN H. AND G. ZHOU (2002) "Supply Chain Modeling: past, present and future”. Computer \& Industrial Engineering 43.Lummus, R. R. y Vokusrka, R. J. (1999). Defining supply chain management: a historical perspective and practical guidelines. Industrial Management \& Data Systems, 99(1): 11-17.

MOINZADEH, K., \& AGGARWAL, P. K. (1997). «An information based multiechelon inventory system with emergency orders". Operations Research, 45, 694- 701 .

$>$ MOINZADEH, K. (2002). "A multi-echelon inventory system with information exchange". Management Science, 48, 414- 426.

$>$ MORRISON, M. \& MEZENTSEFF, M. (1997). "Learning alliances, a new dimension of strategic alliances". Management Decision, 35, 351-357.

$>$ MUNSON, C. L., \& ROSENBLATT, M. J. (2001). "Coordinating a three-level supply chain with quantity discounts". IIE Transactions, 35, 371-384.

> NAIR, A., \& NARASIMHAN, R. (2003). "Product development and innovationbased competition between collaborating supply chain partners-a differential game based analytical investigation". 14th Annual North American Research Symposium on Purchasing and Supply Management, p. 329.

> NARASIMHAN, R., TALLURI, S., \& MAHAPATRA, S. (2003). "A mathematical model for evaluating multi-factor bids for agile supply base configuration", Working paper.

> NARASIMHAN, R., TALLURI, S., \& MAHAPATRA, S. (2003). "Effective multifactor bidding strategies: A seller's perspective", Working paper.

> NARASIMHAN R. Y SANTOSH MAHAPATRA. (2004). "Decision models in golbal supply chain management”. Industrial Marketing Management 33, 21-27.

$>$ NESAN J-L AND HOLT G.D., (1999), "Empowerment in Construction: The Way Forward for Performance Improvement", Research Studies Press, Taunton.

$>$ O'BRIEN W J, LONDON K, VRIJHOEF R. (2002) "Construction supply chain modeling: a research review and interdisciplinary research agenda". Proceedings IGLC-10 Aug.

$>$ OFORI, G., (2000), "greening the construction supply chain in Singapore", European Journal of Purchasing and Supply Management, Vol 6 No 3-4, pp.195-206.

> PARASKeVOPOUlOS, D., KARAKITSOS, E., \& RUSTEM, B. (1991). "Robust capacity planning under uncertainty". Management Science, 37, 787-800.

$>$ POIRIER. C. C., AND HOUSER, W. E ,(1993). "Business partnering for continuous improvement”. Berrett-Koehler Publishers, San Francisco, Calf. 
POIRIER C.C. (1999). “Advanced Supply Chain Management”. Berret-Koehler Publishers. Inc. San Francisco.

PROVERBS, D G. AND HOLT, G D (2000) "Reducing construction costs: European best practice supply chain implications", European Journalof Purchasing and Supply Managemenf, 6(Speciai Issue), 149-158.

RAGHUNATHAN, S. (1999). "Interorganizational collaborative forecasting and replenishment systems and supply chain implications". Decision Sciences, 30, 10531071.

REVELLE, C. S., \& LAPORTE, G. (1996). «The plant location problem: New models and research prospects". Operations Research, 44, 864-874.

> ROBINSON, E. P., \& SATTERFIELD, R. K. (1998). "Designing distribution systems to support vendor strategies in supply chain management". Decision Sciences, 29, 685-706.

> ROS McDONELl L., CAMPUZANO BOLARIN F. And DE LA FUENTE M.V. (2004). " Modelozación del Efecto Bullwhip en la gestión de las cadenas de Suministro Directa e Inversa”. VII Congreso de Ingeniería de Organización. Leganés 9 y 10 de septiembre de 2004.

SANDERS, S. R., CRANE, T. C., AND THOMPSON, P. J, (1996). "The partnering process-its benefits, implementation and measurement." Constr. Industry Inst., The Univ. of Texas at Austin, Austin, Tex.

> SRIDHAR TAYUR, RAM GANESHAN Y MICHAEL MAGAZINE. (1998). "Quantitative Models for Supply Chain Management". Springer. 885 páginas ISBN:0792383443 .

SCOTT CHARLES Y ROY WESTBROOK (1991). "New Strategic Tools for Supply Chain Management". International Journal of Physical Distribution \& Logistics Management Volume: 21 Issue: 1 Page: 23 - 33. DOI: 10.1108/09600039110002225 Publisher: MCB UP Ltd

SIMON REPORT, (1944), "Report of the Management and Planning of Contracts" (The Simon Report), HMSO London.

> SMITH J. AND JACKSON N., (2000), "Strategic needs analysis: its role in brief development" facilities, Vol 18 No. 13-14, pp. 502-512.

SOMMERVILLE J.(1994) "Multivariate barriers to total quality management within the construction industry". Total Quality Management \& Business Excellence, Volume 5, Issue 5, pages 289 - 298

STEVENS, G.C. (1989). "Integrating the Supply Chain". International Journal of Physical Distribution \& Materials Management 19:3-8. 
TAGARAS, G., \& LEE, H. L. (1996). "Economic models for vendor evaluation with quality cost analysis". Management Science, 42, 1531-1543.

TAH J.H.M. Y CARR V., (2001) "Towards a framework for project risk knowledge management in construction supply chain". Advances in Engineering Software, Volume 32, Number 10, October pp. 835-846

TALLURI, S. (2002). “A buyer-seller game model for selection and negotiation of purchasing bids". European Journal of Operational Research, 143, 171- 180.

TALLURI, S., \& NARASIMHAN, N. (2003). "Vendor evaluation with performance variability: A max-min approach". European Journal of Operational Research, 146, 543-552.

TANG, C. S. (1990). "The impact of uncertainty in a production line". Management Science, 36, 1518-1531.

TAYLOR, J., AND BJORNSSON, H.(1999). "Construction supply chain improvements through internet pooled procurement." Proceedings of IGLC-7, Berkeley, CA, July 26-28, 207-217.

> TOWILL, D. R., NAIM, N.M., AND WIKNER, J. (1992). "Industrial Dynamics Simulation Models in the Design of Supply Chains". International Journal of Physical Distribution and Logistics Management 22:3-13.

TSERNG, H. P. \& LIN, P. H. (2002), “An accelerated subcontracting and procuring (ASAP) model for construction projects". International Journal of Automation in Construction, 11(1), 105-25.

> VOORDIJK, H, DE HAAN, J AND JOOSTEN, G-J (2000) "Changing governance of supply chains in the building industry: a multiple case study", European Journalof Purchasing andsupply Management, 6(Special Issue), 217-225.

$>$ VRIJHOEF, RUBEN, AND LAURI KOSKELA, (2000). "The four roles of supply chain management in construction". European Journal of Purchasing \& Supply Management Volume 6, Issues 3-4, December, Pages 169-178

V VRIJHOEF, R. AND DE RIDDER, H. (2005). "Supply chain integration for achieving best value for construction clients: client-driven versus supplierdriven integration". Proceedings QUT Research Week. 4-6 July, Brisbane.

VRIJHOEF RUBEN. (2007). "Supply Chain Integration in Construction. Design and construction processes". TuDelft Technische Universitiet Delft. Paper series 2.

WANG, Y., \& GERCHAK, Y. (1996). "Periodic review production models with variable capacity, random yield, and uncertain demand". Management Science, 42, 130-137. 
WINCH, G M (2003) "Models of manufacturing and the construction process: the genesis of re-engineering construction", Building Research \& Informatmn, 31(2), 107 118.

XIALONG XUE, XIADONG LI, QIPING SHEN, YAOW WANG, (2004). "An agent-based framework for supply chain coordination in construction". Automation in Construction. Volume 14, pp. 413-430

ZINN, W., \& BOWERSOX, D. J. (1988). "Planning physical distribution with the principle of postponement". Journal of Business Logistics, 9, 117-136. 


\section{Capitulo 5}

\section{Estado del arte: Zachman Framework una sistemática para la modelización.}

\section{Introducción al capítulo:}

En este capítulo se pretende recoger una herramienta para el análisis y descripción del modelo para la integración de la cadena de suministro de la construcción que se ha denominado Modelo de Organización Global. Se recoge en este capítulo una visión preeliminar del Marco de Zachman que se utilizará en capítulos sucesivos para la ayuda de la descripción, catalogación y desarrollo del modelo que se propone.

\section{Revisión General:}

En este apartado se pretende tener una visión general de que significa el modelado propuesto por Zachman. Para ello se puede tener en cuenta lo que el propio John Zachman dice J.A. Zachman, (1987) el marco, como aplicación al mundo empresarial, es una estructura lógica para identificar y organizar los modelos que son tan importantes en la gestión de las empresas y en el desarrollo de los sistemas.

Tesis Doctoral_definitiva_impresión 
El Marco de Zachman es un esquema, la intersección entre dos clasificaciones históricas que han sido empleadas durante literalmente unos miles de años. La primera son los fundamentos de comunicación que se pueden encontrar en los interrogantes primitivos como son : ¿Qué?, ¿Cómo?, ¿Cuándo?, ¿Quién?, ¿Dónde?, y ¿Por qué?. Esto es la integración de respuestas a estas preguntas que permite la descripción comprensiva, compuesta de ideas complejas. La segunda está sacada de la cosificación, la transformación de una idea abstracta en una creación de ejemplares o copias que al principio fue postulada por filósofos antiguos griegos y etiquetas como el Marco: Identificación, Definición, Representación, Especificación, Configuración y Creación de ejemplares o copias.... Más expresamente, el Marco de Zachman es una ontología, una teoría de la existencia de un juego estructurado de los componentes esenciales de un objeto para el cual las expresiones explícitas son necesarias y quizás aún obligatorias para la creación, el funcionamiento y el cambio del objeto (el objeto que puede ser una empresa, un departamento, una cadena de valor, " una astilla, " una solución, un proyecto, un aeroplano, un edificio, un producto, una profesión según se puede ver en J.A.Zachman (2008).

Según Zachman, esta ontología fue sacada de las estructuras análogas que son encontradas en las más viejas disciplinas de Arquitectura/Construcción y traman/fabrican lo que clasifican y organizan los artefactos de diseño creados en el proceso de diseño y producción de productos complejos físicos (p.ej. edificios o aeroplanos). Esto usa unos modelos de clasificación dimensional basados en seis interrogantes básicos (Que, Como, Donde, Quien, Cuando y Por qué) cruzando seis perspectivas distintas, que se relacionan con grupos de integrantes de las empresas (el Planificador, el Propietario, el Diseñador, el Constructor, el Implementador y el Trabajador). Las células que se cruzan del Marco corresponden a los modelos que, de ser documentados, pueden proporcionar una visión holística de la empresa, según Roger Session (2007).

\section{El uso del Zachman Framework}

Marc Lankhorts et al. (2005) recogen en su libro "Enterprise Architecture at Work: Modeling Comumunications and Analysis" las ventajas y desventajas de usar esta taxonomía para el desarrollo de un modelo de negocio. 
La ventaja del Marco de Zachman consiste en que es fácil de entender, se refiere a la empresa en su totalidad, es definido independientemente de instrumentos o metodologías, y cualquier cuestión puede ser trazada en un mapa para que con ello se pueda entender donde cabe. Una desventaja importante es el número grande de células, que es un obstáculo para la aplicabilidad práctica del marco. También las relaciones entre las células no están bien especificadas. A pesar de estas desventajas, Zachman debe ser acreditado con el primer marco comprensivo que apareció para la arquitectura de las empresas, y su trabajo todavía es extensamente usado.

John Zachman describe cómo usar su propio marco en una presentación a la "Data Management Association of Puget Sound (2007) de la siguiente manera:

El Marco no prescribe nada sobre que modelos se tiene que construir antes de que se pueda entregar una puesta en práctica. Sólo usted (o su metodología) determina que modela ("o las astillas" de los modelos) que en realidad se va a construir (o no) sobre el proceso de sistemas que se desarrollan. De otra parte, el Marco, por definición, identifica la totalidad, el juego comprensivo de modelos relevantes para describir la empresa entera. Por lo tanto, el Marco es un instrumento analítico para ayudarle a determinar como se sentirá si usted (o su metodología) no va a producir todos los modelos o si se va a hacer algo que inhibirá la acumulación integrada del juego comprensivo de modelos a largo plazo mientras está atendiendo la demanda a corto plazo.

\section{Características del Zachman Framework}

El Marco de Zachman ha sido comparado con la Tabla Periódica. De la misma manera aquellos átomos en la Tabla Periódica de Elementos Químicos son identificados como los componentes básicos de la materia, las células en el Marco Zachman son identificadas como los componentes básicos de empresas, Roger Session (2007).

Las columnas del marco, que no tienen ninguna orden de importancia, representan las abstracciones únicas de la empresa para reducir la complejidad de cualquier modelo solo al que es construido. Los modelos de célula son descritos como " modelos primitivos, " en cada uno hay sólo una variable. " Modelos compuestos, " que son los que se componen de dos o más variables y son necesarios en el diseño de soluciones para satisfacer las exigencias de negocio. John Zachman mantiene que los modelos primitivos son necesarios para la reutilizabilidad y para la concordancia de la ingeniería a través de una empresa y que los modelos primitivos se pueden considerar como los elementos de la arquitectura, Roger Session (2007). 
Cada modelo de célula en cada columna obliga al contenido de la célula debajo de ella. Esto asegura la alineación entre las intenciones de los propietarios de la empresa, representados por la Fila 2 del marco, y por lo que es puesto en práctica para construir la empresa, representados por la Fila 5 del marco.

La granularidad del detalle en el Marco Zachman es una característica de cualquier célula individual independientemente de cualquier fila. Según la exigencia un modelo de célula puede tener relativamente poco detalle o un nivel insoportable de detalle según J. Zachman (2006).

El marco de Zachman puede ser usado en muchos niveles diferentes de una organización. Por ejemplo, un marco usado en el nivel de la empresa podría proporcionar artefactos para la empresa entera. Un marco separado podría ser creado en el nivel de una división sola dentro de la empresa, etc. así se recoge en Jaap Chekkerman (2006).

\section{El diagrama de Zachman y sus reglas}

Hay varias versiones del diagrama que representa el Marco de Zachman para la arquitectura de la empresa. El diagrama usado en esta tesis ha sido adaptado de una versión oficial que incluye detalles sobre los modelos de célula y que está disponible en Zachman Internacional Fig 5_1 Zachman Schema (Zachman International). 


\begin{tabular}{|c|c|c|c|c|c|c|}
\hline & Qué & cómo & Dónde & Quién & Cuándo & Porqué \\
\hline Planificador & \multicolumn{6}{|c|}{$\begin{array}{l}\text { El contenido de estas celdas define el ámbito de la empresa, } \\
\text { identificando que podría ser modelado }\end{array}$} \\
\hline Propietario & \multicolumn{6}{|c|}{$\begin{array}{l}\text { Estas celdas comparan el modelo de negocio con las expectativas del propietario desde la perspectiva } \\
\text { de las operaciones de la empresa }\end{array}$} \\
\hline Diseñador & \multicolumn{6}{|c|}{$\begin{array}{l}\text { Estos modelos incluyen la tecnología de células neutrales modelo de sistema - el plan del diseñador } \\
\text { para permitir el modelo de negocio }\end{array}$} \\
\hline Constructor & \multicolumn{6}{|c|}{$\begin{array}{l}\text { Estos modelos incluyen la tecnología de células de modelo - el plan del constructor para la aplicación } \\
\text { de la tecnología para el Modelo del Sistema }\end{array}$} \\
\hline Sub-contrata & \multicolumn{6}{|c|}{$\begin{array}{l}\text { En estas celdas se prepara una lista } \\
\text { Identificando las soluciones actuales que han sido implementadas }\end{array}$} \\
\hline $\begin{array}{l}\text { Funcionamiento } \\
\text { Empresa }\end{array}$ & \multicolumn{6}{|c|}{$\begin{array}{l}\text { El funcionamiento } \\
\text { De la empresa }\end{array}$} \\
\hline
\end{tabular}

Fig 5_1 Zachman Schema (Zachman International)

Las reglas para la aplicación del marco de Zachman se pueden ver a continuación adaptadas de Sowa, J.F. y J.A. Zachman (1992), y de Inmon, W.H, et al. (1997):

La regla 1: No se añaden filas o columnas al Marco. La estructura del Marco como ha sido diseñado identifica todas las representaciones posibles primitivas relevantes a la descripción de una empresa. La adición de filas o columnas introduciría superabundancia o discontinuidades.

La regla 2: Cada columna tiene un modelo simple genérico, este modelo simple genérico para cada columna es la variable representada por la columna como relacionada consigo misma, p.ej., el modelo genérico para la Columna 1 es la Cosa - la Relación - la Cosa.

La regla 3: Cada modelo de célula se especializa en el modelo genérico de su columna. El diseño de cualquier modelo de célula comienza con su modelo genérico y luego ajustado según las coacciones semánticas de la fila en la que está. 
La regla 4: Ningún concepto de meta puede ser clasificado en más de una célula. Cada célula es única. No hay ninguna redundancia.

La regla 5: No se deben crear relaciones diagonales entre la Gente de células en las perspectivas diferentes - el Propietario, el Diseñador, el Constructor - a menudo se usan los mismos términos para expresar conceptos diferentes. La creación de relaciones diagonales conduce a la discordia semántica y la mala interpretación.

La regla 6: No se debe cambiar los nombres de las filas y columnas. Por la misma razón que añadir filas y columnas, cambiando los nombres pueden cambiar la estructura lógica del Marco.

La regla 7: La lógica es genérica y recurrente. El Marco es genérico y por ello puede ser usado para clasificar las representaciones descriptivas de cualquier objeto físico, así como para objetos conceptuales como empresas. Es también recurrente y ello significa que puede ser usado para analizar la composición arquitectónica en sí misma.

Por último cabe señalar que el Marco Zachman no prescribe. Como cualquier modelo de célula debe ser creado, incluyendo cualquier anotación o nivel de detalle. Esto se deja al que lo emplea para que lo pueda determinar basándose en las metodologías que se hayan adoptado. Por dicho motivo las organizaciones que adoptan el uso del Marco de Zachman a la arquitectura de la empresa para diseñar sus modelos de empresas requieren una metodología para realizar las funciones siguientes, según J. Zachman (undated):

5.1. Construir los modelos primitivos.

5.2. Almacenar los modelos primitivos

5.3. Gestionar los modelos primitivos.

5.4. Cambiar los modelos primitivos.

5.5. Montar los modelos compuestos de modelos primitivos (para la puesta en práctica) 


\section{Referencias bibliográficas:}

> JOHN A. ZACHMAN, (1987), "A Framework for Information Systems Architecture”, IBM Systems Journal, vol. 26, no. 3, IBM Publication G321-5298.

$>$ MARC LANKHORST, (2005), "Enterprise Architecture At Work: Modeling Communications and Analysis". Springer page 24-25

$>$ JAAP SCHEKKERMAN, (2006), "How to Survive in the Jungle of Enterprise Architecture Frameworks: Creating or Choosing an Enterprise Architecture Framework", Trafford.

$>$ JOHN ZACHMAN, (2006), "Enterprise Physics 101 Presentation", undated, posted by the Data Management Association (www.dama.org)

$>$ JOHN ZACHMAN, (2007). "Enterprise Physics 101, a Framework for Enterprise Architecture", Presented by Zachman to the DRMA of Puget Sound.

$>$ ROGER SESSIONS , (2007), "Interview with John Zachman", Editor-in-Chief, Perspectives of the International Association of Software Architects

$>$ JOHN A. ZACHMAN, (2008), "John Zachman's Concise definition of the Zachman Framework", Zachman International.

$>$ ZACHMAN INTERNATIONAL: http://www.zachmaninternational.com/index.php/home-article/13

> UNIVERSITY OF OMAHA: http://www.isqa.unomaha.edu/vanvliet/arch/ISA/isa.htm

$>$ JOHN ZACHMAN Straight from the Shoulder Presentation, undated, posted by the Data Management Association (www.dama.org) 
UNIVERSIDAD

POLITECNICA

DE VALENCIA 


\title{
Capitulo 6
}

\section{Propuesta de un modelo de integración para la cadena de suministro en el sector de la construcción:}

\author{
Modelo de Organización Global
}

\section{Introducción:}

En este capítulo se pretende desarrollar un modelo para la integración de la cadena de suministro de la construcción que se ha denominado Modelo de Organización Global. Dicho modelo se debe entender de manera total que es como realmente está concebido. De todos modos, y para un mejor conocimiento se expondrá en tres apartados: En un primer punto recoge la concepción general del Modelo de Organización Global. Se le ha llamado funcionamiento general. Este nivel se ocupa de la organización intra e inter-compañías vistas como un todo. En segundo término tenemos el funcionamiento con el cliente: llamado el círculo del cliente. Se ocupa del cómo se debe trabajar con el cliente. Un tercer apartado hace lo propio con los aliados (proveedores). Cómo se plantea que se trabaje con los aliados para poder llevar el Modelo de Organización Global a la práctica. A este último tema se le denomina el funcionamiento con los proveedores: desarrollando una alianza. La exposición del Modelo de Organización Global es un desarrollo conceptual que ayuda a la implantación práctica de la filosofía que se pretende trasladar en el desarrollo de una estrategia diferente de integración de la cadena de suministro de la construcción.

\section{Funcionamiento general: Modelo de Organización Global:}


Como se ha dicho en repetidas ocasiones el cliente es el eje principal de desarrollo del modelo propuesto. En este apartado se va a contemplar el funcionamiento general del modelo que se presenta basado sobre todo en la creación, personalización, desarrollo, diseño y construcción de productos finales. Un concepto parecido al que se expondrá a continuación se puede ver en Love et al. (2004). Los autores citados configuran un modelo de funcionamiento para la gestión de la cadena de suministro de la construcción creando un marco de funcionamiento en un ambiente abierto, con una colaboración y un enfoque común desde el prisma de lo que ellos llaman un colectivo multidisciplinar que va creando a su vez un colectivo de aprendizaje y conocimiento.

El modelo presentado por Love et al. (2004) y el Modelo de Organización Global tienen cinco diferencias fundamentales que los convierten en modelos distintos. Estas cinco diferencias son las que se recogen a continuación:

- En el modelo de Love et al. (2004) solo trabaja en equipo la parte de desarrollo arquitectónico y el diseño estructural, sin embargo en el Modelo de Organización Global trabajan todas las soluciones funcionales, estructurales y de diseño del producto a obtener (la vivienda residencial).

- El ámbito de aplicación de ambos modelos son distintos: el modelo de Love et al. (2004) tiene un ámbito de aplicación que se suscribe al diseño en detalle de la solución constructiva, sin embargo, el Modelo de Organización Global trabaja en todo el proceso promotor, desde la elección de la ubicación, pasando por el diseño del producto, la construcción del mismo y la puesta a disposición del cliente.

- En el modelo de Love et al. (2004) los trabajos se dan secuencialmente mientras que en el Modelo de Organización Global existen dos equipos de trabajo que primero trabajan secuencialmente pero que durante la elaboración del producto, fase de construcción del mismo, trabajan al unísono. 
- El Modelo de Organización Global es un modelo pensado para el desarrollo promotor de viviendas residenciales y sin embargo el modelo de Love et al. (2004) es un modelo de trabajo que se podría aplicar a cualquier proceso productivo dentro de la cadena de suministro del sector de la construcción.

- La quinta y última diferencia es que en el modelo de Love et al. (2004) no interviene el cliente dentro de los equipos de trabajo. El Modelo de Organización Global recoge el papel del cliente dentro de los equipos de trabajo, como se ha expresado anteriormente, tanto de diseño de producto como de construcción del mismo.

Siendo, pues modelos distintos, es de interés ver que existen modelos que trabajan en la linea de aportar soluciones a la compleja cadena de suministro de la construcción para mejorar su funcionamiento y obtener mejores resultados.

Para el desarrollo del concepto del Modelo de Organización Global ha sido de mucha utilidad basarse en el concepto de empresa extendida y de integración empresarial que aparece en varios autores citados en el capítulo 3 de la presente tesis, ver Sempere Ripoll F. et al. (2002), Alfaro Saiz et al (2002), Chen y Vernadat (2004), Shorter (1997), Doumeingts et al. (1998), Camarinha-Matos et al., (1997), Hayfron et al., (1998), NIIIP (1999), Capó Vicedo J. et al (2002), Preiss y Murray (2005), Capó Vicedo et al. (2007), Masiá Buades E. y Capó Vicedo J. (2004), Hidalgo Nuchera A. (2002), Moller et al. (1998) y J. Capó et. al. (2003) entre otros. Estos autores señalan que dicha integración consiste de alguna manera en facilitar los flujos de materiales, información, decisiones y control a través de organización ligando las funciones con la información, los recursos, las aplicaciones y las personas, con la finalidad de mejorar la comunicación, la cooperación y la coordinación en la empresa, de tal forma que ésta se comporte como un todo y que funcione alineada con la estrategia de la empresa. 
Como factor distintivo, en la propuesta que se presenta, destaca la influencia y el papel del cliente en todo el funcionamiento del modelo. Estudios como los de Himes (1995) ,Bresnen y MarshalI, (1998), (1999) y Briscoe et al., (2003) recogen específicamente las relaciones entre la cadena de suministro de la construcción, los clientes y el contratista principal, Briscoe et al. (2003) en su investigación analiza la manera de cómo el cliente puede influir en la integración de la cadena de suministro de la construcción. En los negocios en general, New y Payne (1995) investigaron un modelo para el propósito de la cadena de suministro. Indicaron una relación entre el entorno, la práctica y los resultados. Sin embargo, Briscoe et al., (2003) modificaron este modelo. Se cree que el funcionamiento del cliente en el modelo enriquece los conceptos anteriores y da una visión novedosa de la manera de entender las relaciones dentro de la gestión de la cadena de suministro en el sector de la construcción.

Para poder describir de una mejor forma el concepto propuesto se dispone de la figura Fig 6_1_ Funcionamiento general: Modelo de Organización Global. En esta representación gráfica se puede ver, si se observa desde el centro hacia fuera, un primer círculo que se ha llamado información directa del cliente, es lo que se verá en el apartado siguiente. Funcionamiento del cliente: El Círculo del Cliente, como gestión del conocimiento y se basa en una relación continua con él en todo el proceso de diseño, desarrollo y creación del producto. Esta relación continua con el cliente se fundamenta en un equipo multidisciplinar de diseño del producto en donde aparecen figuras como los arquitectos, interioristas, constructores, técnicos, estructuristas, etc. Este equipo tiene como objetivo fundamental garantizar que el producto es el que el cliente desea y es, a su vez, el que se va a obtener. 


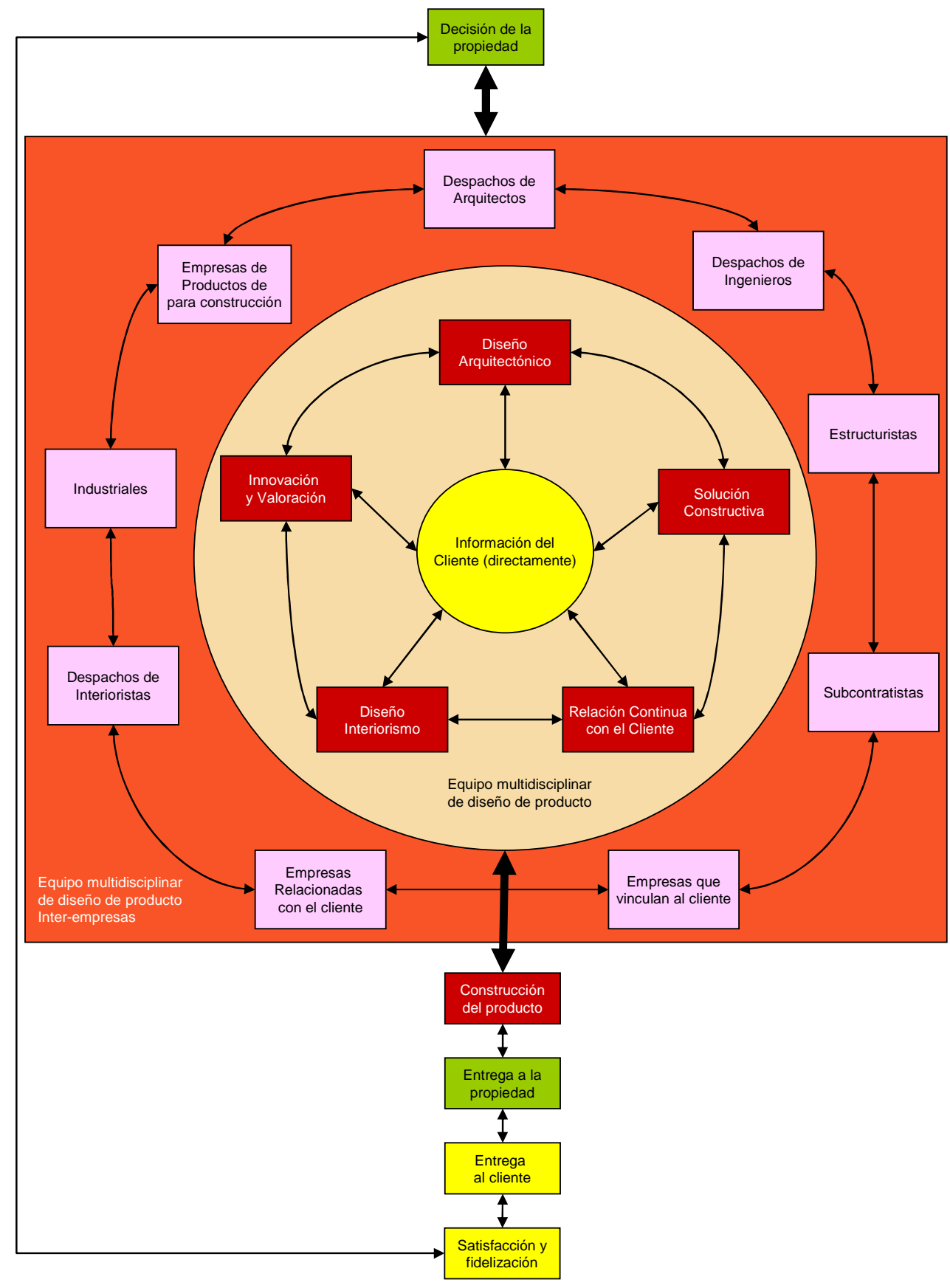

Fig 6_1_Funcionamiento general: Modelo de Organización Global. Elaboración propia. 
El equipo multidisciplinar de diseño de producto es un equipo compuesto por empleados de distintas compañías. Por lo tanto se abre el círculo y se empieza a trabajar inter-compañías en lugar de solamente intra-compañía. Estos dos niveles, el de la compañía y el de la relación de la compañía con sus proveedores pueden ir variando en función de las actividades que una empresa tenga internamente y aquellas en las que se debe apoyar de forma externa.

En los siguientes apartados se puede ver cómo se desarrolla una alianza que permita el funcionamiento de estos equipos multidisciplinares. Una vez que este equipo ha diseñado el producto y de forma interactiva en todo momento, ya que se está trabajando de forma continua con el cliente, este equipo traslada lo que se ha venido a representar con un cuadro exterior, sus conclusiones y trabajos. De forma gráfica se puede entender que el círculo exterior de lo que se ha llamado equipo multidisciplinar de diseño de producto, es como una membrana que mantiene relación constante con todos los elementos que están en el exterior de ese círculo. De esta manera el diseño arquitectónico se comparte con los despachos de ingenieros, despachos de arquitectos, empresas para la construcción, estructuristas, subcontratistas, industriales, etc. Dicha relación tiene un doble sentido, también hacia dentro de la membrana debe fluir información de las empresas externas del círculo. Esta permeabilidad es la que garantiza que en todo momento se esté desarrollando un producto realizable, con las últimas innovaciones, y ajustado a las necesidades del cliente.

Se tienen dos equipos de trabajo. El primer equipo de trabajo es el que hemos denominado equipo multidisciplinar de diseño. Este equipo, que ya se ha comentado quienes lo componen, trabaja desde la elección del suelo dónde se ubicará la promoción de viviendas hasta en el desarrollo de la solución constructiva y planos definitivos de ejecución del producto a construir. Así mismo aparece un segundo equipo, llamado equipo multidisciplinar de diseño de producto inter-empresas, que es el encargado de llevar el proyecto hasta convertirlo en un producto que entregamos al cliente para su disfrute. Este segundo equipo trabaja al mismo tiempo que el anterior a partir del primer movimiento físico que se realice sobre el terreno. Los dos equipos, durante la fase de ejecución (construcción), entrega y atención post venta (entrega) al cliente trabajan de forma conjunta trasladando soluciones, problemas y matices que pueden surgir del mismo proceso productivo o por falta de definición en los detalles del proyecto de ejecución del primer equipo. 
No se debe olvidar que en el mundo en el que se desarrolla el presente modelo, aparece la figura del promotor, que se ha denominado en el presente gráfico con el nombre de: Propiedad. El promotor es el empresario que toma la decisión de desarrollar un producto inmobiliario, en el presente caso un producto residencial. Dicho empresario es el que corre con los riesgos y se lleva los beneficios de la promoción. Es la decisión de la Propiedad la que arranca el proceso y la que de forma indirecta supervisa todo su funcionamiento, con la idea de fidelizar y satisfacer al cliente. Este último concepto es el mismo que aparece en el círculo del cliente desarrollado en el siguiente apartado.

\section{Funcionamiento con el Cliente: El Círculo del Cliente.}

Todo el modelo que se plantea, se basa como pieza fundamental en el cliente. El cliente es el eje sobre el que gira conceptualmente todo el desarrollo del modelo presentado. Como se ha dicho en los apartados anteriores se va a desarrollar el modelo en tres apartados que se han denominado funcionamiento general, funcionamiento con el cliente, y funcionamiento con los proveedores. En este apartado se va a profundizar en el funcionamiento con el cliente. Para ello es conveniente entender cuál es la filosofía que impregna todo el modelo conceptual.

Lo que se ha llamado Circulo del Cliente tiene su origen en el concepto de círculo virtuoso que otros autores también han definido y explicado en documentos desarrollados anteriormente, por ejemplo ver Huete L.M. (2001). Estos círculos parten del concepto de la auto regeneración y por tanto se pueden entender que evolucionan sobre si mismos. Si se fija la atención en la figura Fig. 6_2_Modelo de Funcionamiento del Cliente: El Círculo del Cliente, se ve recogido de forma gráfica lo que se acaba de exponer. 


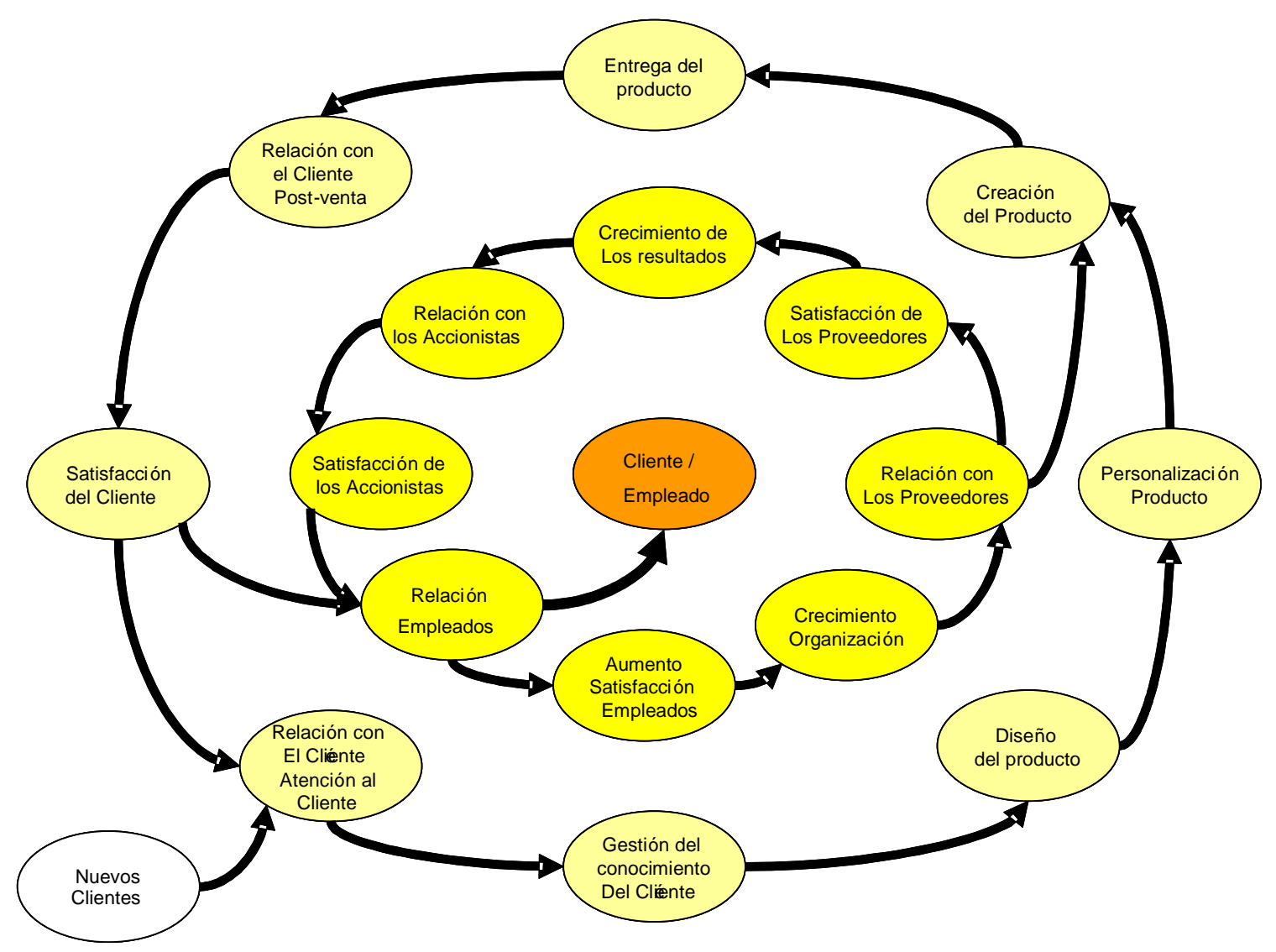

Fig 6_2_ Modelo de Funcionamiento del Cliente: El Círculo del Cliente. Elaboración propia.

Dicho Círculo del Cliente se puede entender como dos círculos superpuestos que funcionan al unísono. El primer círculo, más exterior, está conceptuado y basado en lo que tradicionalmente se ha llamado relaciones externas. En estas relaciones externas se recoge todo aquello que está más relacionado con el cliente. Su captación, que se entiende como el conocimiento de uno o más clientes, basándose en la relación y atención al mismo, la gestión del conocimiento y de la información que se tiene del cliente. Esa información y conocimiento permiten diseñar un producto adaptado a lo que el cliente quiere. Esto no sólo conduce a lo que se llama una personalización de la oferta ajustandose a las necesidades específicas que el cliente solicita, sino al diseño y elección de aquel producto que el cliente desea. 
Una vez diseñado y personalizado el producto (visto en el apartado anterior) aparece la fase de construcción del mismo. Posteriormente se entregará el producto al cliente. Aparece una segunda fase de mayor relación con el cliente ajustando lo que se conoce en el sector como la postventa. Esto puede llevar a una satisfacción del cliente que vuelve a empezar el círculo en otro proceso más, después de transcurrido un tiempo.

En paralelo se mueve otro círculo interno que garantiza con su funcionamiento el círculo que se ha llamado más exterior. La satisfacción del cliente ha de venir de su relación con los empleados, que a su vez producen un aumento de satisfacción en los mismos y por lo tanto crecimiento como organización. Esta organización es la que mantiene la relación con los proveedores que genera la satisfacción de estos y así un crecimiento de los resultados. Este último crecimiento es garantizar las relaciones de satisfacción con los accionistas, que es a su vez, el que cierra el círculo en su relación con los empleados y el aumento de satisfacción de los mismos.

Este modelo de círculo a dos niveles, es una herramienta muy potente que como se puede ver se retroalimenta a sí misma. Es una manera de obtener un motor que garantice el funcionamiento del modelo desarrollando una forma de trabajo y una orientación común para los distintos intereses que se presentan en las relaciones de negocio. El cliente del que se está hablando es el cliente final de productos inmobiliarios de carácter residencial según lo explicado en capítulos anteriores. Este hecho es significativamente diferencial con respecto a lo que se encuentra en los modelos actuales de negocio que se pueden ver en el mercado. 


\section{El funcionamiento con los Proveedores: Desarrollando una Alianza.}

Al igual que en los apartados anteriores se ha señalado que el cliente es el eje fundamental del desarrollo del modelo, en este apartado también es así. El cliente es el eje porque cuando ambas compañías deciden emprender la alianza que garantiza las relaciones entre las dos empresas deben tener presente el trabajo hacia adónde se dirije y con que finalidad. Es por tanto necesario que en los planteamientos de la alianza aparezca la figura del cliente como sujeto y fin del motivo de la alianza. Aquí se propone un modelo para garantizar y hacer funcionar de forma continua la alianza que permita crear el modelo multidisciplinar de diseño de producto y funcionamiento que se ha descrito en el apartado previo. Para ello se presenta la figura Fig 6_3_ Esquema de Funcionamiento con los Proveedores: Desarrollando una Alianza. En este gráfico se puede destacar, como se ve claramente al observarlo, que el cliente es el centro y la razón de ser de la unión de las dos compañías. Se ha representado la alianza como la intersección de los conjuntos. La alianza se basa en el cliente y tiene cuatro pilares fundamentales que configuran su unión.

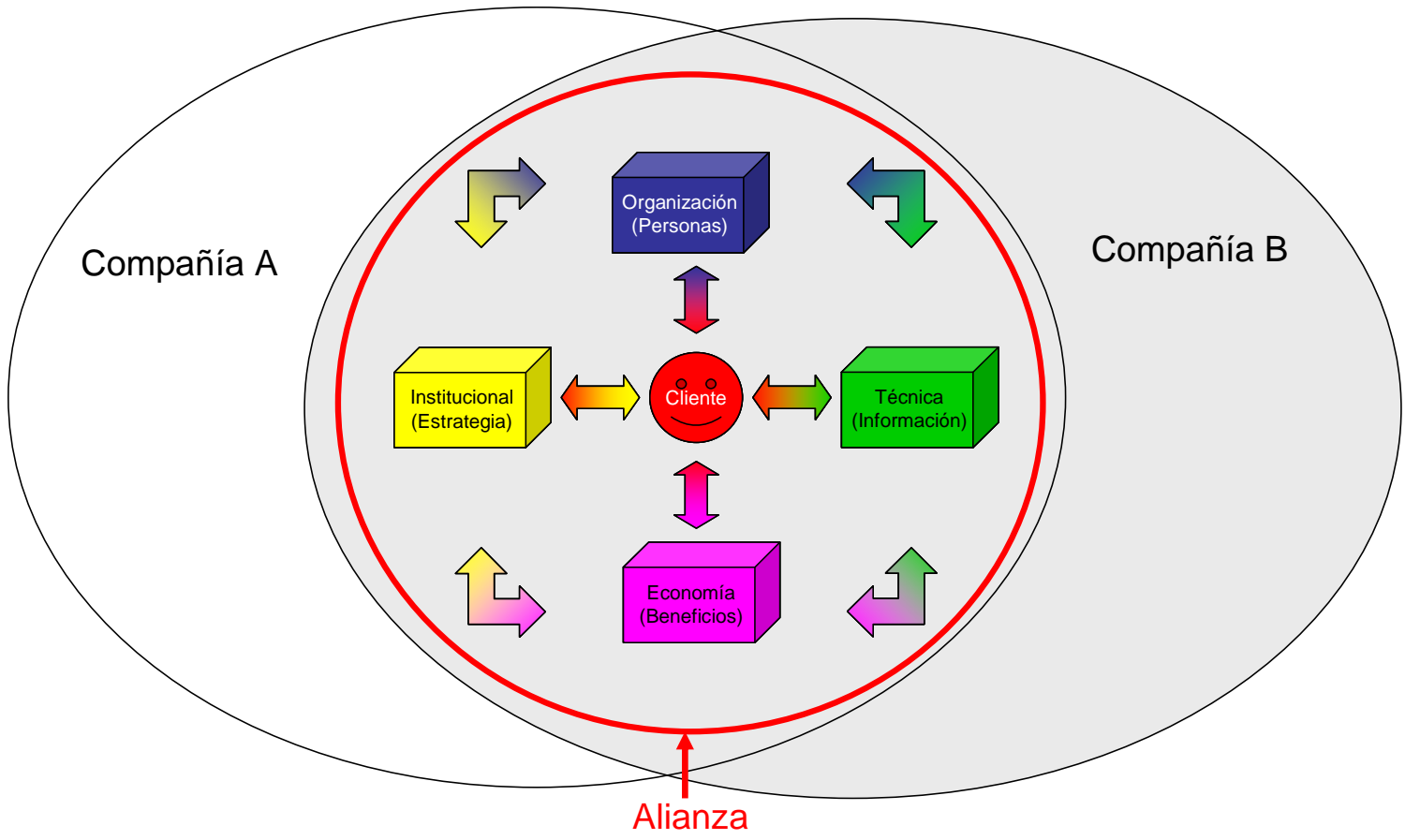

El "pegamento" de la alianza debe de ser El cliente

Fig 6_3_Esquema de Funcionamiento con los Proveedores: Desarrollando una Alianza 
Estos cuatro pilares son: el pilar institucional, el económico, el técnico y el organizativo. A continuación detallamos cuales son los contenidos fundamentales de los cuatro pilares básicos de la alianza:

En cuanto al primer pilar, el pilar institucional, se quiere recoger el enfoque común que debe existir entre ambas compañías en cuanto a la estrategia a seguir a largo plazo. Los cuatro pilares son importantes, y por eso se ha decidido llamarlos pilares, ya que garantizan el mantener la alianza viva. Este pilar institucional es el que se apoya la alianza para llegar a ser una relación duradera y a largo plazo puesto que hace coincidir las voluntades de las dos compañías en un proyecto común y duradero. Existen diversos trabajos sobre esta materia Capó J.et.al. (2003), Love et al (2002), Morrison y Menentself (1997) pero lo que aporta una novedad en esta materia es la forma de conjuntar los elementos y la forma de desarrollarlos, a su vez también la presencia y figura del cliente, ver Briscoe et al., (2003).

En segundo lugar, se ha descrito el pilar de la economía, es el pilar que garantiza los beneficios comunes de la alianza y que estos beneficios comunes son mayores que los beneficios que se obtienen separadamente. Es un pilar que trabaja en el medio plazo. Se sabe que en la mayoría de los países la construcción es la que ha experimentado descensos o ha permanecido estable en cuanto a su productividad se refiere en la pasada década (BNL 2002, Dainty et al. 2001, Love et al. 2004., Person y Solberg 1994). Sobre este aspecto y basándose en los estudios previos, H. Hakansson y M. Jahre, (2004), es necesario para el desarrollo de la alianza poner de forma explicita los beneficios económicos de la misma.

Los dos últimos pilares hacen referencia a problemas más a corto. Así como los primeros pilares se centran en la estrategia y en los beneficios, los dos siguientes se basan en la táctica: la técnica y la organización. 
El pilar de la técnica, hace referencia a la información. Este pilar es crucial a la hora de que la alianza se pueda desarrollar de forma ágil y práctica en el día a día. Es la información la que debe fluir entre ambas compañías de forma que sin perder la identidad de cada una de las mismas se pueda emprender un proyecto común facilitando de esta manera la consecución de los objetivos fijados en los pilares anteriores. En los trabajos de Briscoe y Dainty (2005) se expone como crítico para poder alcanzar la integración dentro de la cadena de suministro de la construcción una serie de aspectos: gestión de la comunicación, gestión de los flujos de información, mecanismos para la solución de problemas, la ingeniería como valor añadido de los proyectos, el alineamiento de los sistemas de la cadena suministro, aseguramiento de los estándares de calidad elevada, y por ultimo asegurar el compromiso del cliente y los objetivos del proyecto.

Por último, y tan importante como los demás, aparece lo que se ha denominado pilar de la organización. Este pilar de la organización es el que se ocupa de las personas que son las que hacen posible el desarrollo de la alianza. Se trata de desarrollar una organización de organizaciones que funcione como un solo organismo, para lo cual se tienen que tener habilidades especiales y una constante comunicación con el equipo. No se puede perder de vista que las personas que trabajan en este tipo de organizaciones deben observar los beneficios globales. Existen estudios realizados por Ashton et al., (1999) que fijaban el rango de habilidades genéricas que deberían existir en cualquier sector industrial que quisiera aplicar técnicas de partenariado. Asimismo, Briscoe et al. (2001) realizaron una primera aproximación a los contratistas principales del sector de la construcción para poder aplicar las mismas técnicas dentro de este sector. Estos estudios pueden servir de base para el desarrollo del pilar de la organización. 


\section{El Modelo de Organización Global y el Zachman Framework.}

En este último apartado del capítulo de presentación del modelo se cree de utilidad poder ver el modelo en detalle utilizando una herramienta de análisis de modelo que hemos visto en la parte de la tesis del Estado del Arte. Esta herramienta es el Marco de Zachman, con el se pretende analizar y desarrollar el Modelo de Organización Global. Esta herramienta, como se ha dicho, se ha explicado en uno de los capítulos del Estado del Arte, en este apartado se quiere utilizar para poder desarrollar el modelo en los aspectos relacionados con la definición del mismo. Para ello se puede seguir el esquema que Terry Bahill (2008) realiza sobre el Marco de Zachman y que se detalla seguidamente. Terry Bahill (2008) empieza con un cuadro en vacio para poder seguir una secuencia de "llenado" del cuadro. Fig 6_4_An empty Zachman framework, Terry Bahill (2008).

\begin{tabular}{|l|l|l|l|l|l|l|}
\hline & $\begin{array}{l}\text { Qué } \\
\text { (datos) }\end{array}$ & $\begin{array}{l}\text { Cómo } \\
\text { (función) }\end{array}$ & $\begin{array}{l}\text { Dónde } \\
\text { (red) }\end{array}$ & $\begin{array}{l}\text { Quién } \\
\text { (gente) }\end{array}$ & $\begin{array}{l}\text { Cuándo } \\
\text { (tiempo) }\end{array}$ & $\begin{array}{l}\text { Porqué } \\
\text { (motivación) }\end{array}$ \\
\hline $\begin{array}{l}\text { Ámbito de Aplicación } \\
\text { (contexto) }\end{array}$ & & & & \\
\hline $\begin{array}{l}\text { Modelo de Negocio } \\
\text { (concepto) }\end{array}$ & & & & \\
\hline $\begin{array}{l}\text { Modelo de Sistema } \\
\text { (lógica) }\end{array}$ & & & & \\
\hline $\begin{array}{l}\text { Modelo tecnológico } \\
\text { (fisico) }\end{array}$ & & & & \\
\hline $\begin{array}{l}\text { Representación detallada } \\
\text { (componente) }\end{array}$ & & & & \\
\hline Sistema Real & & & & \\
\hline
\end{tabular}

Fig 6_4_An empty Zachman framework, Terry Bahill (2008).

En la parte de las filas Bahill (2008) comenta cada una de ellas explicando que:

- Ámbito de aplicación (el alcance) se entiende que describe la visión del sistema, la misión, fronteras, arquitectura y restricciones. El alcance declara lo que el sistema debe hacer. Lo llaman un modelo de caja negra, porque nosotros vemos las entradas y salidas, pero no los funcionamientos internos. 
- El modelo de negocio muestra objetivos, estrategias y procesa que son usados para apoyar la misión de la organización.

- El modelo del sistema contiene exigencias como, objetos, actividades y funciones que ponen en práctica el modelo de negocio. El modelo del sistema declara como el sistema debe realizar sus funciones. Lo llaman un modelo de caja blanca, porque se pueden ver sus funcionamientos internos.

- El modelo tecnológico considera las restricciones de la gente, herramientas, tecnología y materiales.

- La representación detallada presenta los componentes individuales, independientes, que pueden ser asignados a contratistas para la puesta en práctica.

- El verdadero sistema representa el sistema operacional en estudio.

En cuanto a las columnas el mismo Bahill (2008) explica diciendo:

- El Qué, describe las entidades implicadas en cada perspectiva de la empresa. Los ejemplos incluyen el equipo, los objetos de negocio y el sistema de datos.

- Cómo, muestra las funciones dentro de cada perspectiva.

- Dónde, las redes muestran posiciones e interconexiones dentro de la empresa. Esto incluye ubicaciones principales geográficas de negocio, redes y el terreno de juego. 
- Quién, representa a la gente dentro de la empresa y la forma para evaluar sus capacidades y funcionamiento. El diseño de la organización de la empresa tiene que ver con la asignación de trabajo y la estructura de la autoridad y la responsabilidad.

- Cuándo, representa el tiempo, o las relaciones de acontecimientos que establecen criterios de funcionamiento. Esto es útil para diseñar planes, la arquitectura de tratamiento, la arquitectura de control y sistemas de engranaje de la distribución.

- Por qué, describe las motivaciones de la empresa. Esto revela los objetivos de la empresa, objetivos, el plan de negocio, la arquitectura de conocimiento, y la razona para pensar, haciendo cosas y tomando decisiones.

Expuesta esta definición de las filas y las columnas se procede de abajo a arriba y de la primera columna a la última siguiendo el mismo método que emplea Bahill (2008) en su exposición. 
Por este motivo lo primero es empezar por el Qué de la fila del Sistema Real, en nuestro caso particular es un Modelo de Organización Global que afecta a la cadena de suministro. Fig 6_5_Zachman Framework, 6_1. Elaboración propia.

\begin{tabular}{|l|l|l|l|l|l|l|}
\hline & $\begin{array}{l}\text { Qué } \\
\text { (datos) }\end{array}$ & $\begin{array}{l}\text { Cómo } \\
\text { (función) }\end{array}$ & $\begin{array}{l}\text { Dónde } \\
\text { (red) }\end{array}$ & $\begin{array}{l}\text { Quién } \\
\text { (gente) }\end{array}$ & $\begin{array}{l}\text { Cuándo } \\
\text { (tiempo) }\end{array}$ & $\begin{array}{l}\text { Porqué } \\
\text { (motivación) }\end{array}$ \\
\hline $\begin{array}{l}\text { Ámbito de Aplicación } \\
\text { (contexto) }\end{array}$ & & & & \\
\hline $\begin{array}{l}\text { Modelo de Negocio } \\
\text { (concepto) }\end{array}$ & & & & \\
\hline $\begin{array}{l}\text { Modelo de Sistema } \\
\text { (lógica) }\end{array}$ & & & & \\
\hline $\begin{array}{l}\text { Modelo tecnológico } \\
\text { (físico) }\end{array}$ & & & & \\
\hline $\begin{array}{l}\text { Representación detallada } \\
\text { (componente) }\end{array}$ & & & & \\
\hline Sistema Real & $\begin{array}{l}\text { Modelode } \\
\text { Organización } \\
\text { Global }\end{array}$ & & & \\
\hline
\end{tabular}

Fig 6_5_Zachman Framework, 6_1. Elaboración propia. 
De esta manera se van completando los datos de la columna uno, Qué. En la columna 1 fila 5 se detallaría la representación del modelo, en la columna 1 fila 4 se tiene el modelo tecnológico que se aplica para con el cliente como pieza clave del modelo. En la columna 1 fila 3 el Modelo del sistema, la relación única con los proveedores que los convierte en aliados. En la columna 1 fila 2 se tiene el concepto de negocio que es la integración de la cadena de suministro de forma global y por último en esta columna se tiene la columna 1 fila 1 en dónde aparece el contexto, el sector de la construcción. De esta manera se tendría la Fig 6_6_Zachman Framwork columna 1. Elaboración propia.

\begin{tabular}{|c|c|c|c|c|c|c|}
\hline & $\begin{array}{l}\text { Qué } \\
\text { (datos) }\end{array}$ & $\begin{array}{l}\text { Cómo } \\
\text { (función) }\end{array}$ & $\begin{array}{l}\text { Dónde } \\
\text { (red) }\end{array}$ & $\underset{\text { (gente) }}{\text { Quién }}$ & $\begin{array}{l}\text { Cuándo } \\
\text { (tiempo) }\end{array}$ & $\begin{array}{l}\text { Porqué } \\
\text { (motivación) }\end{array}$ \\
\hline $\begin{array}{l}\text { Ámbito de Aplicación } \\
\text { (contexto) }\end{array}$ & $\begin{array}{l}\text { Sectorde la } \\
\text { Construcción } \\
\text { viviendas }\end{array}$ & & & & & \\
\hline $\begin{array}{l}\text { Modelo de Negocio } \\
\text { (concepto) }\end{array}$ & $\begin{array}{l}\text { Integración de } \\
\text { lacs de forma } \\
\text { globall }\end{array}$ & & & & & \\
\hline $\begin{array}{l}\text { Modelo de Sistema } \\
\text { (lógica) }\end{array}$ & & & & & & \\
\hline $\begin{array}{l}\text { Modelo tecnológico } \\
\text { (fisico) }\end{array}$ & reg & & & & & \\
\hline $\begin{array}{l}\text { Representación detallada } \\
\text { (componente) }\end{array}$ & & & & & & \\
\hline Sistema Real & $\begin{array}{l}\text { Modelo de } \\
\text { Organización } \\
\text { Global }\end{array}$ & & & & & \\
\hline
\end{tabular}

Fig 6_6_Zachman Framwork columna 1. Elaboración propia. 
En el caso de la columna 2 se aborda el cómo. En el modelo que se estudia el cómo es muy extenso porque depende de un número de variables muy basto cómo son la especialidad de negocio del que se esté hablando, las empresas participantes en el mismo y el cliente al que se quiera dirigir el modelo, pero se intentará ilustrar el tema teniendo en cuenta las restricciones mencionadas. En la columna 2 fila 6 en esencia el cómo se puede concretar como en recoger las inquietudes del cliente y ofrecerle el producto (solución constructiva) que satisfaga esas necesidades, aunando una serie de procesos (en su mayoría distintas empresas) y especialidades técnicas muy diversas también, resumiendo se puede esquematizar en Deseo Cliente $\rightarrow$ Solución Constructiva. Esto es lo que en el modelo se resuelve a través del equipo multidisciplinar de producto. En la fila 5 se tiene el esquema de funcionamiento que responde a la representación detallada del modelo. En la fila 4 el modelo de tecnología son las técnicas de trabajo en equipo y la gestión del conocimiento. En la fila 3 se tiene la relación existente entre el equipo de trabajo interdisciplinar y los equipos de trabajo interempresas. En la fila 2 se pone de manifiesto este concepto entre los equipos de trabajo multidisciplinar y los trabajos interempresas y en la fila 1 como contexto se tiene la situación de mercado en el sector de la construcción que recoge una atomización de empresas con relaciones de subcontratación muy habituales y poca cualificación desde el punto de vista empresarial. Se puede ver esto en la Fig_6_7_Zachaman Framework. Elaboración Propia.

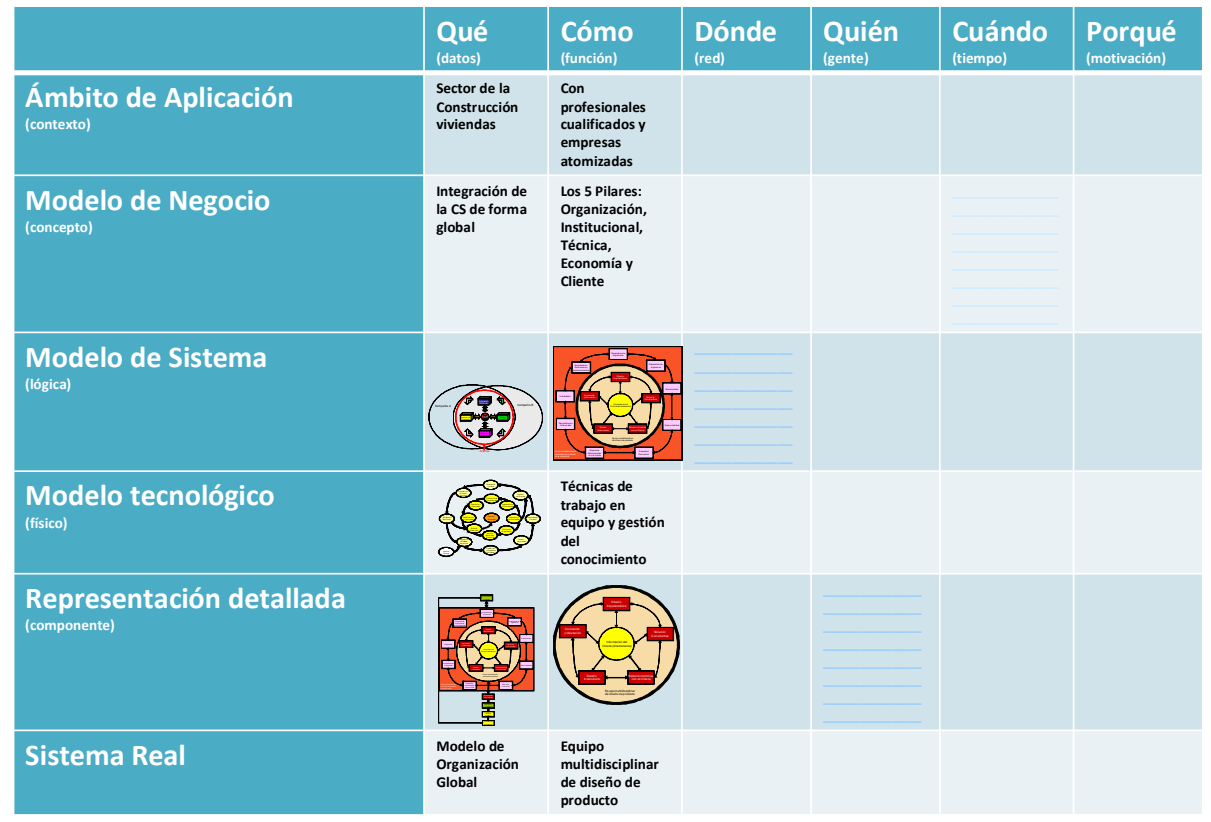

Fig_6_7_Zachaman Framework. Elaboración Propia. 


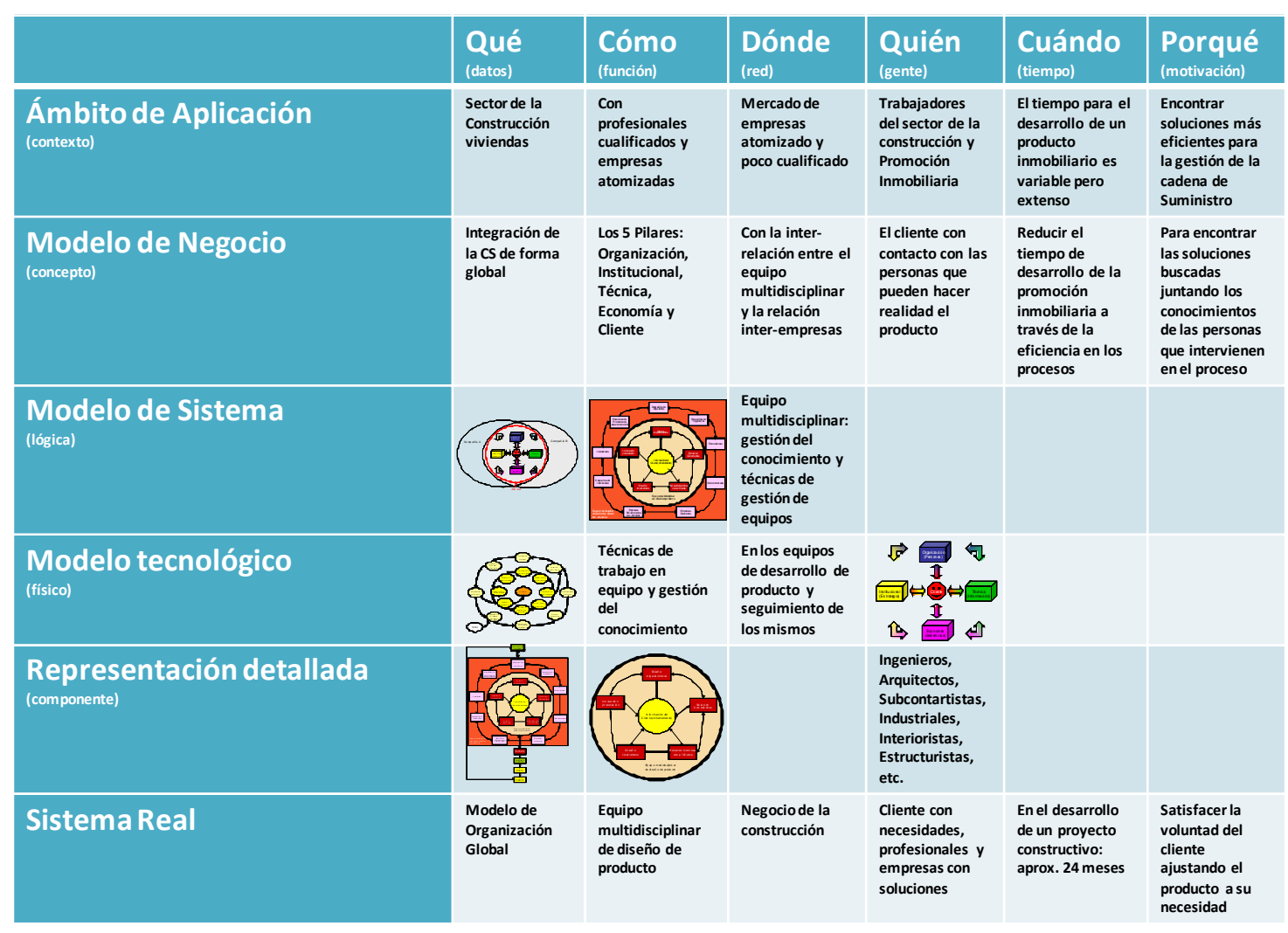

Fig_6_8_Zachaman Framework. Elaboración Propia.

Siguiendo el mismo sistema de trabajo podemos ir completando el Marco de Zachman en las columnas 3, 4, 5 y 6 que responden a Dónde, con Quién, Cuándo y Por Qué. Se pueden ir completando las distintas filas. Existen aspectos del cuadro de Zachman que se ha creído poco interesante completarlo puesto que el modelo que se presenta es un modelo conceptual y estos aspectos son aspectos operativos, es pues que se han dejado en blanco en la tabla. Ver Fig_6_8_Zachaman Framework. Elaboración Propia. 


\section{Referencias bibliográficas:}

> ALFARO SAIZ J.J., ÁNGEL ORTIZ BAS Y RAÚL POLER ESCOTO (2002). "Definición de Parámetros de Prestaciones bajo un Enfoque de Integración Empresarial”. II Conferencia de Ingeniería de Organización. Vigo, 5-6 Septiembre

$>$ ASHTON, D., DAVIES, B., FELSTEAD, A., GREEN, F., (1999). "Work skills in Britain". Centre for Skills, Knowledge and Organisational Performance (SKOPE), Oxford and Warwick Universities.

$>$ BNL (2002) "Research and Development in the Construction Industry" (In Norwegian: Forskning og utvikling i bygg-, anleggs- og eiendomsnæringen), http: www.bnl.no.

BRESNEN, M. AND MARSHALL, N. (1998) "Partnering strategies and organizational cultures in the construction industry, in Hughes", W. (ed.) ARCOM 14th Annual Conference, Reading, 9-11 September, pp. 465-76.

BRESNEN, M. AND MARSHALL, N. (1999) "Achieving customer satisfaction?" Client-contractor collaboration in the UK construction industry, in Bowen, P. and Hindle, R. (eds) CIBW55 \& '65 Joint Triennial Symposium, Cape Town, South Africa.

BRISCOE, G., DAINTY, A. R. J. AND MILLETT, S., (2001). "Construction supply chain partnerships: skills, knowledge and attitudinal requirements", European Journal of Purchasing \& Supply Management, Vol 7, Iss 4, pp.243-255.

$>$ BRISCOE G., ANDREW R.J. DAINTY, SARAH J. MILLETT AND RICHARD H. NEALE (2003) "Client-led strategies for construction supply chain improvement", Construction Management and Economics.

$>$ BRISCOE G., AND ANDREW R.J. DAINTY, (2005), "Construction supply chain integration: an elusive goal?" Supply Chain Management: An International Journal 10/4 319-326

C CAMARINHA-MATOS L.M., H. AFSARMANESH, C. GARITA Y C. LIMA (1997). "Towards an architecture for virtual enterprises". Journal of Intelligent Manufacturing. Springer Netherlands. ISSN 0956-5515 (Print) 1572-8145 (Online) Volume 9, Number 2 / marzo 189-199.

CAPÓ VICEDO JOSEP, GUILLERMINA TORMO CARBÓ Y FRANCISCO CRUZ LARIO ESTEBAN (2002). "Las Redes Interorganizacionales como Alternativa Competitiva en las Empresas Constructoras". II Conferencia de Ingeniería de Organización. Vigo, 5-6 Septiembre. 
CAPÓ J. V., LARIO F. C., ORTIZ A., (2003), “Integración Empresarial y Redes Interorganizacionales en la Gestión de la Cadena de Suministro". Aplicación al Sector de la Construcción. V Congreso de Ingeniería de Organización: Valladolid-Burgos, 45 Septiembre.

CAPÓ VICEDO, JOSEP, TOMAS MIQUEL, JOSÉ V Y EXPOSITO LANGA, MANUEL (2007). "La Gestión del Conocimiento en la Cadena de Suministro: Análisis de la Influencia del Contexto Organizativo". Inf. tecnol, vol.18, no.1, p.127136. ISSN 0718-0764.

$>$ CHEN D., F. VERNADAT (2004) "Standard on enterprise integration and engineering-state of the art". Int.J. Computer Integrated Manufacturing, vol.17 no.3 235-253. Taylor \& Francis

DAINTY, A.R.J., BRISCOE, G.H. AND MILLETT, S.J. (2001) "Subcontractor perspectives on supply chain alliances", Construction Management and Economics, Vol. 19, pp. 841-848.

DOUMEINGTS, BRUNO VALLESPIR Y DAVID CHEN(1998) "Decision modelling GRAI grid". Handbook on Architectures of Information Systems. ISBN 978-3-540-25472-0 (Print) 978-3-540-26661-7 (Online) Páginas 321-346

HÅKANSSON, H. AND PERSSON, G. (2004) "Supply Chain Management: The logic of supply chains and networks", under review for publication in International Journal of Logistics Management.

> HAYFRON, L.E., CARRIE, A.S., BITITCI, U.S. Y K. PANDYA, (1998). "Manufacturing Franchising and Enterprise Networks". En Bititci, U.S. y A.S. Carrie (ed.): Strategic Management of the Manufacturing Value Chain. Kluwer Academic Publishers, Dordrecht.

HIDALGO NUCHERA, ANTONIO (2002) "La planificación del desarrollo de nuevos productos en la empresa extendida". Economía Industrial N 347

HIMES, P.E. (1995) "Partnering in the construction process: the methodology for the 1990s and beyond". Facilities, 13(6), 13-15.

HUETE, LUIS MARÍA, (2001), "Servicios \& Beneficios : la fidelización de clientes y empleados : la inteligencia emocional en los negocios". P.imprenta: Editora El Comercio . Ilust.. 244. Serie: Curso de Gestión Empresarial. 9.

LOVE PETER E. D , ZAHIR IRANI, EDDIE CHENG, HENG LI, (2002) “A model for supporting inter-organizational relations in the supply chain Engineering Construction and Architectural Management" 9 (1), 2-15. 
LOVE P.E.D., ZAHIR IRANI AND DAVID J. EDWARDS, (2004(, "A seamless supply chain management model for construction". Supply Chain Management: An International Journal Vol. 9 Number 1 pp 43-56.

MASIÁ BUADES ENRIQUE Y JOSEP CAPÓ VICEDO (2004). "Propuesta de una metodología para la creación de redes interorganizacionales dentro de un microcluster". VIII Congreso de Ingeniería de Organización. Leganés, 9 y 10 de septiembre.

MOLLER, C. J.O. RIIS Y M. HANSEN, (1998). "Interorganisational network classification. A framework for studying industrial networks". U.S. Bititci, A.S. Carrie (Edits.) Strategic Management of the Manufacturing Value Chain, Kluwer Academic Publishers.

MORRISON, M. \& MEZENTSEFF, M. (1997) "Learning alliances, a new dimension of strategic alliances". Management Decision, 35, 351-357.

$>$ NEW, S.J. AND PAYNE, P. (1995) "Research frameworks in logistics: three models, seven dinners and a survey". International Journal of Physical Distribution and Logistics Management, 25(10), 60-77.

$>$ PERSSON, G. (1994) "Central research areas within the construction industry. Some views concerning the quality and productivity of the building process". (In Norwegian: Sentrale forskningsområder innen byggenøringen. Noen synspunkter på byggeprosessens kvalitet og produktivitet), Research report 7, Norwegian School of Management, BI.

PREISS, K.J. Y P.A. MURRIA:(2005) "Fashions of learning: improving supply-chain relationships". Supply Chain Management: An International Journal, 10 (1): 18-25

SEMPERE RIPOLL F., RAÚL POLER ESCOTO Y ANGEL ORTIZ BAS. (2002) "Un Acercamiento a un Lenguaje Unificado de Modelización Empresarial". II Conferencia de Ingeniería de Organización Vigo, 5-6 Septiembre.

SHORTER, D.N.(1997) "Requirements for enterprise model execution and integration services". 


\section{Capitulo 7}

\section{Propuesta de un modelo de integración en la Gestión de la Cadena de Suministro para el sector de la Construcción: Clientes y Proveedores}

\section{Introducción:}

En este capítulo, y una vez conocido cuál es el modelo propuesto para la integración de la gestión dentro de la cadena de suministro en el sector de la construcción, se pretende centrar la discusión en el papel del cliente dentro de cada uno de los aspectos necesarios para que esa integración llegue a buen puerto. Así se verá, en primer lugar, el círculo del cliente, como base de desarrollo de los otros dos aspectos: el equipo multidisciplinar de diseño y el funcionamiento de la alianza. También se quiere profundizar en la relación con los proveedores según la propuesta del modelo de integración que realizamos. Se puede entender como que es importante el concepto de relación a largo plazo que lleva a la concepción de un modelo distinto de interacción entre ambas partes. Asimismo, se intentará ver el porqué de la aparición del equipo multidisciplinar y su concepción global como una solución a los problemas que aparecen en la gestión de la cadena de suministro de la construcción. Se verá cómo se puede crear ese equipo multidisciplinar desarrollando alianzas entre compañías y como estas alianzas se basan en cinco aspectos fundamentales que permiten la unión y consolidan el modelo de integración. 


\section{El Cliente y su papel en el modelo propuesto:}

Como ya se señalaba en el Capitulo 3 de este mismo trabajo de investigación, los autores Briscoe et al., (2003) reconocen en su estudio que la industria de la construcción ha sufrido durante un largo período de tiempo sobre costes, retrasos en sus programaciones y una baja productividad. Así mismo y en documentos más recientes podemos encontrar estudios que se han centrado específicamente en las relaciones entre la cadena de suministro de la construcción, los clientes y el contratista principal (Himes, 1995,Bresnen y MarshalI, 1998, 1999), y las relaciones entre los contratistas principales y los subcontratistas (Uher y Runeson, 1985,Hinze y Tracey, 1994, Matthews et al., 1996). Las investigaciones a través de más de dos eslabones dentro la cadena de suministro de la construcción han sido muy pocas (London et al., 1998, Murray et al., 1999), pero ha reconocido los beneficios de las relaciones a largo plazo de estabilidad entre varios agentes.

Briscoe et al., (2003) recogen en su investigación la manera de cómo el cliente puede influir en la integración de la cadena de suministro de la construcción. En los negocios en general, New y Payne (1995) investigaron un modelo para el propósito de la cadena de suministro. Indicaron una relación entre el entorno, la práctica y los resultados. Sin embargo, Briscoe et al., (2003) modificaron este modelo. En esencia en él se indica que el entorno de la organización de negocios tendrá influencia en la manera de aprovisionarse. Y este cambio afectará al nivel de integración de la cadena de suministro, y el nivel de integración de la cadena de suministro afectará a las futuras decisiones de aprovisionamiento. Las conclusiones a las que llegan Briscoe et al., (2003) en su estudio apuntan a que el cliente es el factor más significativo en el éxito de la integración de la cadena de suministro y que con el cliente se deben desarrollar prácticas que faciliten dicha integración en el proceso de construcción para alcanzar mejoras. Asimismo comentan que en las discusiones para alcanzar el máximo grado de integración del equipo es esencial tener en cuenta a los clientes que deben participar activamente en la creación e integración de los equipos. 
Desde el punto de vista del modelo que se propone, es un salto y una profundización en el papel del cliente dentro la gestión de la cadena suministro de la construcción. Briscoe et al., (2003) consideran al cliente como un factor significativo dentro de la cadena y proponen desarrollar prácticas que alcancen una mayor integración del mismo. En todo el modelo propuesto, el cliente se plantea como pieza fundamental. El Cliente es el eje sobre el que gira conceptualmente todo el desarrollo del modelo que se presenta. No debemos desarrollar prácticas para la integración del cliente, puesto que como se puede ver en los distintos esquemas que se han ido presentando, el cliente está presente y sin él no se puede desarrollar la gestión de la cadena de suministro que se plantea. A modo de ejemplo se puede echar un vistazo al Círculo del Cliente. Fig. 7_1_Modelo de funcionamiento interno.

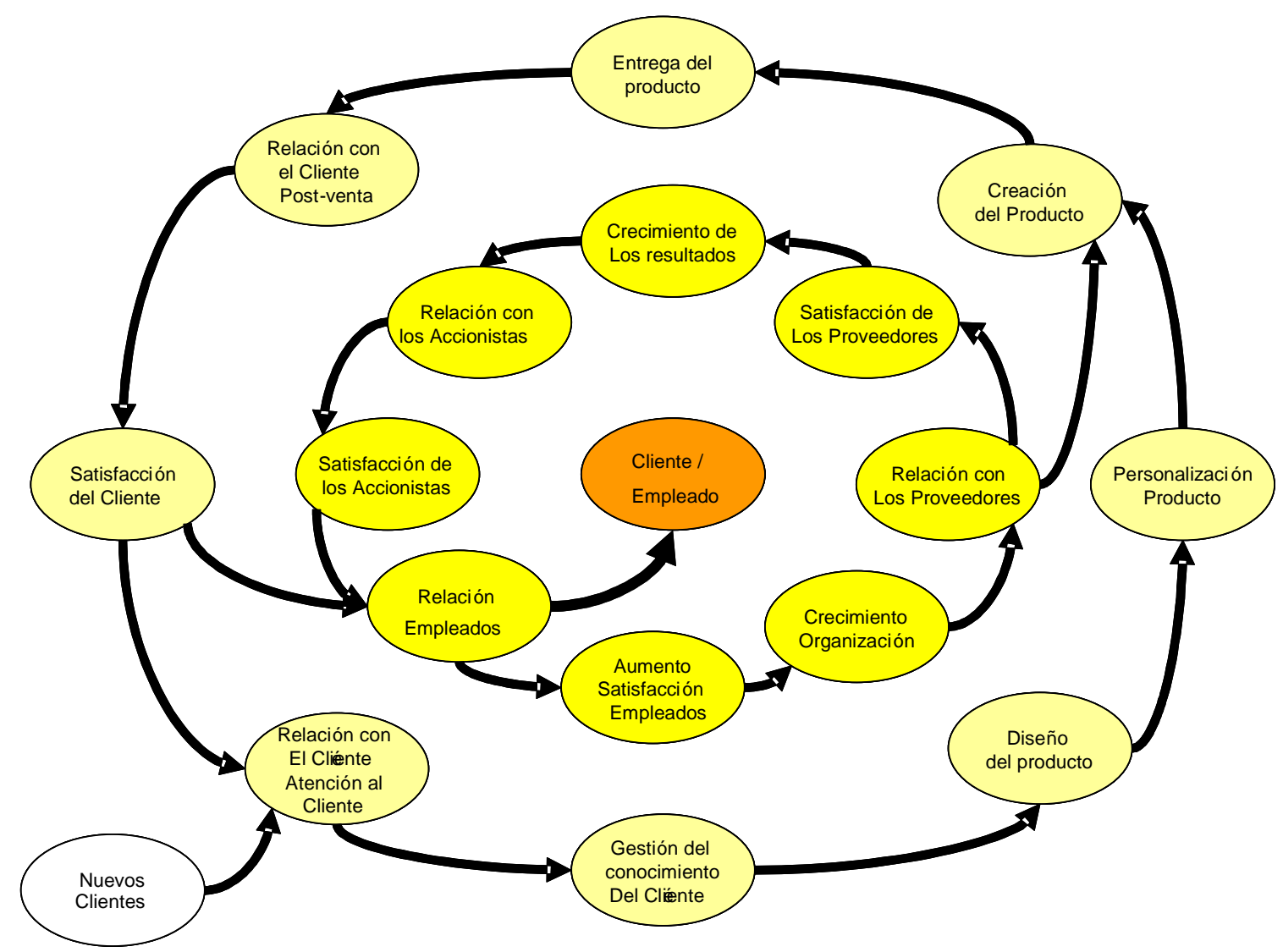

Fig 7_1_ Modelo de Funcionamiento interno: El Círculo del Cliente. Elaboración propia. 
Toda la parte más externa de este doble círculo está relacionada con el cliente. $\mathrm{Su}$ captación, la gestión del conocimiento y de la información que se tiene del cliente, la personalización del producto, diseño del mismo, creación, entrega, servicio postventa y satisfacción del cliente, son aspectos que sólo podemos realizar con el cliente. Sin el cliente toda esta parte no tiene sentido. Se señala que el cliente no es el centro del modelo porque se haya dibujado en esa posición dentro del modelo, sino porque se cuenta con él en las decisiones de diseño del producto, desarrollo del mismo y satisfacción postventa.

\section{El Cliente en el equipo multidisciplinar de diseño.}

El equipo multidisciplinar de diseño es el núcleo central de la propuesta del modelo de integración para la gestión de la cadena de suministro en el sector de la construcción. Si volvemos sobre el gráfico Fig 7_2_ Funcionamiento global: La organización expandida. Se aprecia claramente este papel del equipo multidisciplinar. Aquí se debe entender, enlazando con el apartado anterior, que el cliente participa en lo que se ha dicho gestión del conocimiento del cliente, diseño del producto, personalización del producto y creación del producto. Todas estas frases que están recogidas en el ciclo del cliente, forman parte fundamental y están integradas en el funcionamiento del equipo multidisciplinar de diseño de producto del esquema que se ha visto en el gráfico Fig 7_2. Este equipo es el responsable de trasladar hacia los otros elementos de la cadena de suministro todo lo que con el cliente se ha trabajado. Asimismo, el equipo recibe la información del resto de la cadena de suministro para poderla compartir también con el cliente que forma parte de este equipo multidisciplinar.

De esta manera se garantiza un proceso constante de información en un sentido y en el otro, de forma que el conocimiento que se tiene de los pensamientos y necesidades del cliente está en todo momento presente para así lograr a través de la gestión de la cadena de suministro el producto que el cliente quiere. Pero no solamente se actúa en la dirección del cliente hacia la cadena, sino que las posibles variaciones por razones técnicas, de constructibilidad, económicas, de seguridad o de cualquier otro tipo que se tengan que realizar dentro del proceso de creación del producto se trasladan de forma inmediata al cliente para su conocimiento. De esta suerte el cliente no descubre nada nuevo cuando se le entrega el producto puesto que ha sido partícipe y conocedor de todo el proceso de creación del producto hasta su final. 


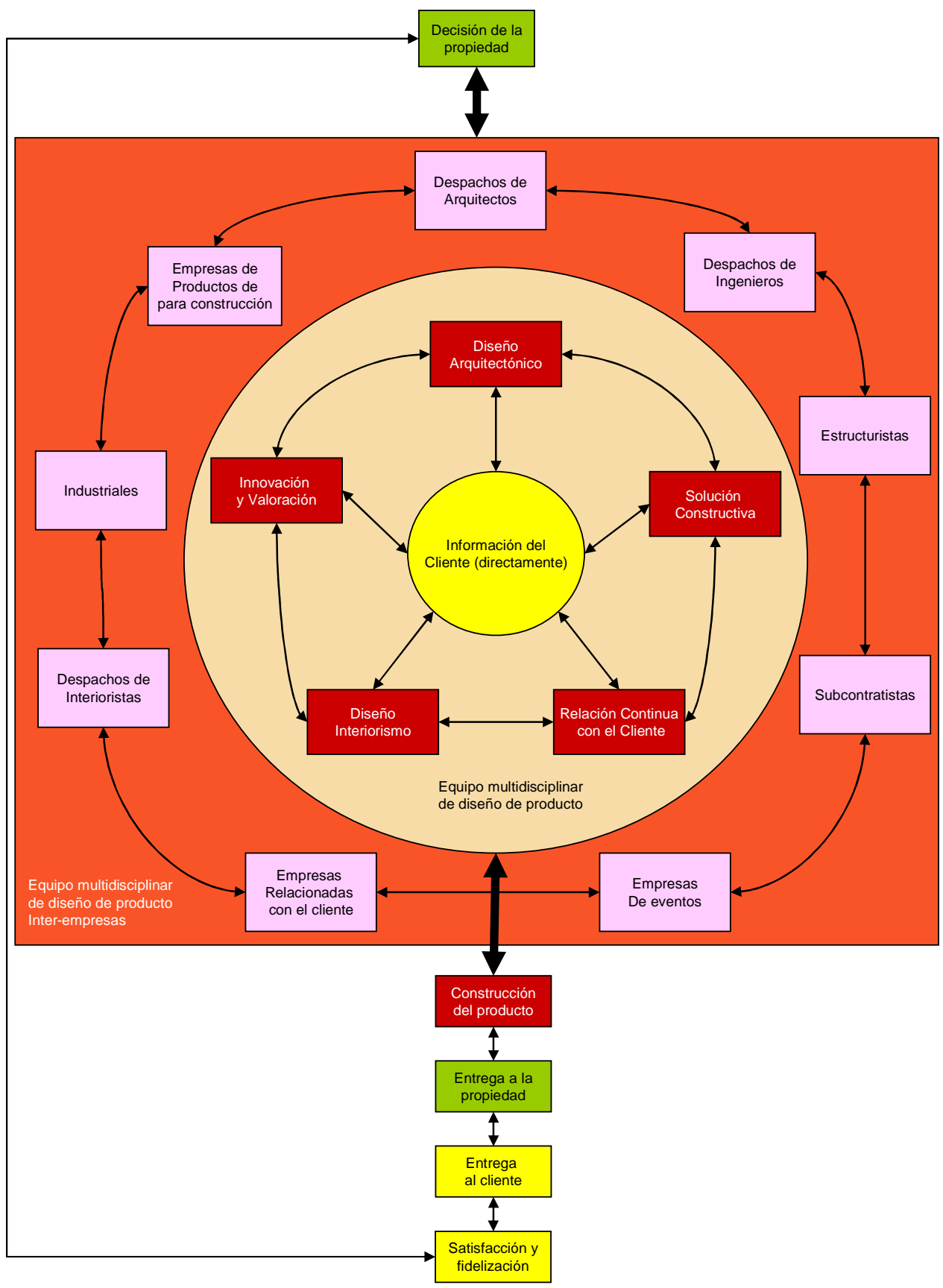

Fig 7_2_ Funcionamiento global: La Organización expandida. Elaboración propia. 
La manera en que se hace partícipe al cliente dentro del equipo multidisciplinar se basa en el Circulo del Cliente, pero tenemos que tener en cuenta que como esencia del mismo equipo existen miembros de distintas compañías. Es por este motivo que es fundamental el funcionamiento de todos ellos como un equipo, y por lo tanto, aparece el concepto que se ha llamado funcionamiento de la alianza. Fig 7_3_Esquema del modelo propuesto para el desarrollo de la alianza, pero se puede ver con más detalle en el siguiente apartado.

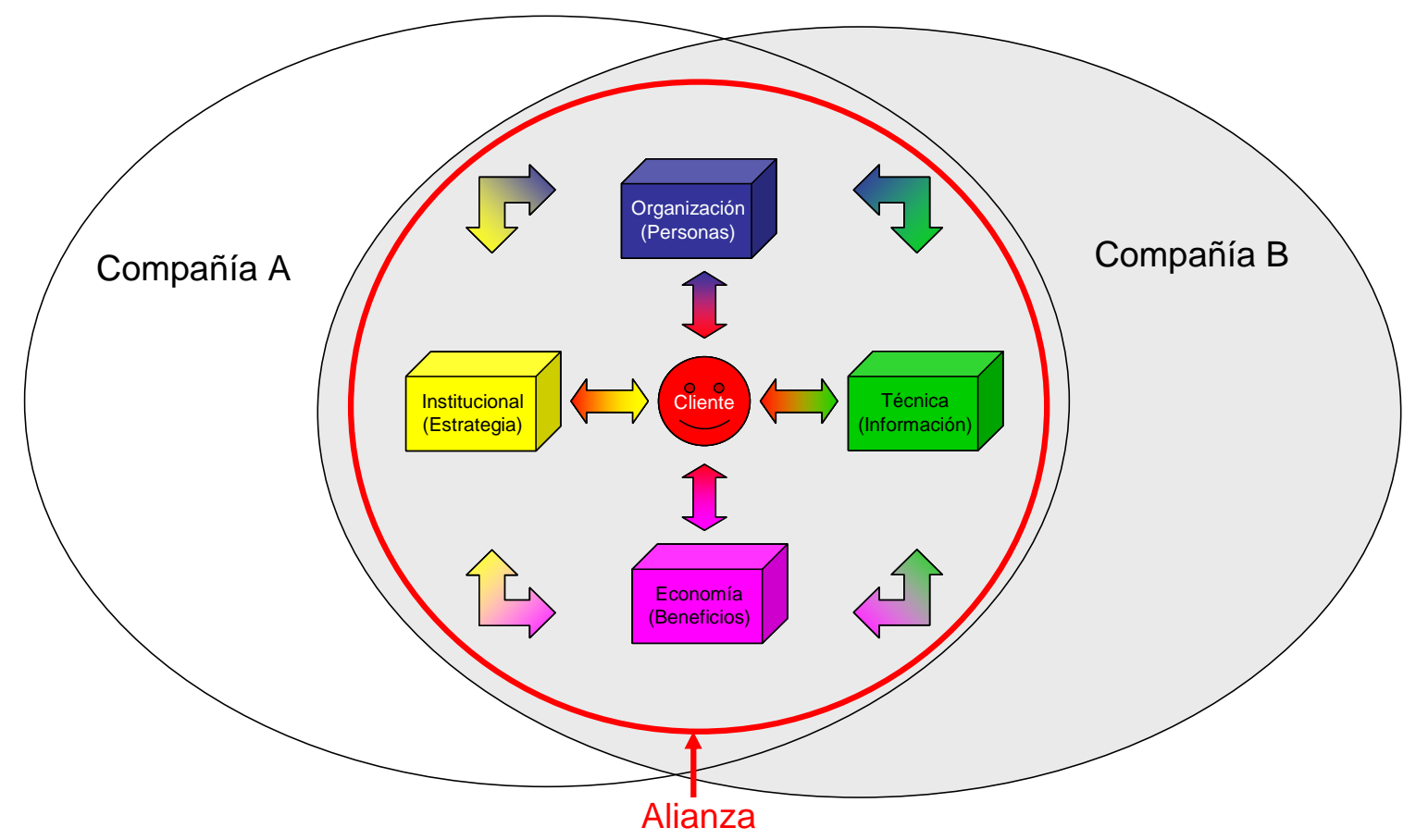

El "pegamento" de la alianza debe de ser El cliente

Fig 7_3_ Esquema del modelo propuesto para el desarrollo de la alianza. Elaboración propia. 


\section{El funcionamiento de la alianza y el cliente como "pegamento" de la misma.}

Para el desarrollo de forma adecuada de la integración del modelo propuesto para la gestión de la cadena de suministro en el sector de la construcción se cree necesario el desarrollo de una serie de alianzas cuyo funcionamiento se ha descrito en la figura Fig 7_3_ Esquema del modelo propuesto para el desarrollo de la alianza. Ya se trata en el capítulo cinco de este documento de investigación el estado del arte en cuanto a este aspecto se refiere. Es por tanto, en el presente apartado dónde se resalta como aportación el funcionamiento de la alianza y el papel del cliente dentro de este funcionamiento.

En el funcionamiento de la alianza existen cinco factores que hacen que la unión de la alianza sea efectiva: la estrategia común, los beneficios económicos, la organización de las personas, la integración de los sistemas de información y el foco en el cliente. De todos estos factores existen investigaciones previas. Así, se puede encontrar en cuanto a la organización de las personas, como en un estudio realizado por Ashton et al., (1999) fijaba el rango de habilidades genéricas que debería existir en cualquier sector industrial que quisiera aplicar técnicas de partenariado. Asimismo, Briscoe et al. (2001) realizaron una primera aproximación a los contratistas principales del sector de la construcción para poder aplicar las mismas técnicas dentro de este sector.

En cuanto a la estrategia también es interesante ver el trabajo realizado por J. Capó et. al. (2003) en donde se señala la cadena de suministro y se establece una relación de negocio común entre proveedor y cliente, desde el punto de vista de una mejora conjunta de la integración global, lo cual permite desarrollar estrategias de gestión eficaces. O como, los profesores H. Hakansson y M. Jahre, 2004, explican que la lógica económica de la industria de la construcción está caracterizada por una combinación de distintas lógicas económicas.

En cuanto a la integración de los sistemas de información, podemos encontrar muchos autores que han argumentado que las prácticas de gestión en la mejora pueden conseguir mayor integración a lo largo de los diferentes actores de la cadena de suministro de la construcción (por ejemplo Bresnen y Marshall, 1999; Briscoe et al., 2005). 
Así mismo se ha visto como en otros sectores industriales, como son la fabricación de automóviles o el sector de la distribución comercial, se han hecho significativos progresos hacia la mejora de eficiencia y una mayor integración de las cadenas de suministro. Aunque el sector de la construcción y sus suministros tienen características diferenciales frente a otros sectores (ver Koskela, 1997), no parecen suficientes para mantener que esta industria continúe con sus ineficiencias.

Por último, y profundizando en el aspecto del cliente, cómo se ha dicho con anterioridad, las conclusiones a las que llegan Briscoe et al., (2003) en su estudio apuntan a que el cliente es el factor más significativo en el éxito de la integración de la cadena de suministro y que con el cliente se deben desarrollar prácticas que faciliten dicha integración en el proceso de construcción para alcanzar mejoras.

Desde el punto de vista del modelo, la gran potencia que tiene el sistema propuesto es que combina estos cinco factores. Pero es diferencial, como reconocen los mismos Briscoe et al. (2003) el papel del cliente. Ese funcionamiento con el cliente, al igual que el apartado anterior, debe remitirse al círculo del cliente, en donde se presenta una forma de funcionar con él que permite garantizar que el proceso que se quiere abordar es el adecuado.

\section{Las relaciones con los proveedores: una estrategia a largo plazo.}

La cadena de suministro es como un prisma con el que poder ver las relaciones que existen entre los clientes y los proveedores. Es evidente que se pueden encontrar con toda la variedad posible de relaciones existentes entre dos compañías. Desde enfoques que llevan una relación de muy poco contacto entre las dos compañías, hasta enfoques de integración de ambas compañías que terminan funcionando como una sola.

Adicionalmente, el interés es la cadena de suministro de la construcción. Según Briscoe G. et al (2001) en comparación con otros sectores, como puede ser el de la automoción, los principales contratistas en el mundo de la construcción están relativamente poco sofisticados en cuanto a la cadena de suministro se refiere. Esto implica directamente que las relaciones entre ambos, cliente-proveedor, son relaciones que se pueden considerar dentro de una evolución como relaciones con bajo nivel de sofisticación. 
Aunque exista una tendencia a cambiar las operaciones a lo largo de la cadena de suministro de la construcción, especialmente debida a la exigencia de los clientes por tener un mejor producto y servicios relacionados, Crane (1999) avanza que la implantación de mejoras en las operaciones relacionadas con la cadena de suministro de la construcción pasa necesariamente por cambiar mentalidades y desarrollar nuevas habilidades, Stannack (1995).

Se ha señalado con anterioridad que G. Crane et al. (1997) afirma que las relaciones de alianzas se han ido incrementando paulatinamente en las empresas de ingeniería y construcción. Asimismo muchas investigaciones se han realizado para describir el concepto de alianza, y como se deben estructurar los grupos de trabajo y los beneficios del mismo (Abudayyeh 1994; Brown1993; In Search 1991; Crane 1995; Liska 1993; Poirier and Houser 1993). Éstas publicaciones han demostrado que las relaciones de alianza creadas en entornos armoniosos, han facilitado la reducción de costes y litigios legales, han incrementado la calidad, la productividad y los beneficios. Existen trabajos que han hablado de cómo crear esas relaciones de alianza, incluso de las barreras existentes para llegar al éxito en estas relaciones (Sanders et al. 1996).

Como se puede ver en S.M. Hong-Minh et al. (1999) para incrementar la competitividad de la cadena de suministro de la construcción hay que estimular a las compañías a que respondan de una manera más eficiente y eficaz a los requerimientos de los clientes. Sin embargo, se debe recordar que existe un número de aspectos críticos que es conveniente revisar en la industria de la construcción para su rectificación. Dentro de esta larga lista S.M. Hong-Minh et al. (1999) incluyen relaciones de competencia, falta de compromiso y confianza, problemas de coordinación, falta de entrenamiento, etcétera. Las conclusiones de su estudio llevan a identificar tres aspectos principales que mejorar para obtener los resultados deseados. Estos tres aspectos son: cambiar las mentalidades, orientarse hacia el proceso y el intercambio de personas.

Los problemas relacionados con el cambio de mentalidad incluyen problemas en la comunicación y en la información que se comparte por tener relaciones pobres o enfrentadas entre los jugadores claves de la cadena, como son el cliente, el contratista principal, los arquitectos y los subcontratistas, con un nivel muy bajo de confianza y compromiso. 
Otro aspecto dentro de este apartado son las relaciones basadas en "Win-lose" que buscan un beneficio a corto plazo obtenido de la relación con el proveedor. Y por último en ese aspecto es el trabajo realizado con baja calidad y tarde como resultado de una falta de compromiso entre los miembros de la cadena, el trabajo es a menudo de muy baja calidad teniendo que consumir tiempo para comprobar la realización correcta del mismo. De esta manera las compañías no tienen compromiso en completar su trabajo en tiempo y consecuentemente el resultado es poco competitivo e inaceptable desde el punto de vista del cliente.

La reorientación hacia los procesos de negocio es el segundo aspecto que se señala en este estudio como resultado de las barreras existentes que se generan por la departamentalización de la mayoría de las compañías. Es el resultado de las empresas que no pueden establecer una visión de proceso de su trabajo y por lo tanto no pueden focalizarse hacia las necesidades y requerimientos de los clientes. Las organizaciones son también a menudo rígidas según Christopher (1992). Cada actividad dentro las compañías son secuenciales y las órdenes van de un departamento al otro para ser procesadas. La orientación hacia el proceso de negocio es una herramienta que mejora el modo de funcionar y orienta hacia el cliente final, Hammer y Champy (1993). Existen tres puntos esenciales para constituir una orientación hacia los procesos de negocio: los procesos siempre tienen un cliente interno o externo, los procesos deben cruzar las fronteras de la organización, y los procesos deben ser evaluados desde el punto de vista del cliente.

El intercambio de personal entre compañías es a la vez síntoma y causa de tener buenas relaciones entre compañías y de estar orientados hacia el proceso. Éste intercambio ayuda a generar confianza entre una compañía y su proveedor, un cliente y otro negocio. También indica que una compañía está dispuesta a aprender de otras compañías a través del conocimiento y la tecnología.

J. Matthews et al. (2000) en su estudio "Quality relationships: partnering in the construction supply chain" señalan en primer lugar, la importancia de la subcontratación y comentan que de acuerdo con Nobbs (1993) la contribución de la subcontratación se sitúa por encima del $90 \%$ del total del valor del proceso de construcción. Esto sugiere que la orientación que toma la cadena de suministro en el sector de la construcción es que el contratista general se oriente hacia una dirección de operaciones, en lugar de a la realización directa de las mismas. Jamieson et al. (1996) también atribuyó el incremento del uso de la subcontratación al cada vez más complejo proceso de construcción y de la relación entre las organizaciones. 
También los autores señalan que además de las relaciones de su contratación existen relaciones de más cercanía en forma de alianza. Sin embargo dentro de este punto podemos distinguir distintos tipos de relaciones de alianza: relaciones de alianza para un proyecto y relaciones de alianza estratégica. Kubal (1994) y The Reading Construction Forum (1998) identificaron lo que se denominó alianzas de tercera generación. Se señaló que estas alianzas de tercera generación pueden aparecer cuando la industria de la construcción se vuelva más colaborativa, produciendo y creando un rango de servicios en donde los clientes quieran que se invierta. The Reading Construction Forum (1998) señaló que la naturaleza colaborativa a largo plazo de las alianzas de tercera generación producen ahorros de costes del $50 \%$ o más y ahorros de tiempo del $80 \%$.

Matthews (1996) identificó que los beneficios de la alianza se alcanzan en las siguientes áreas: situación contractual, comunicación y flujos de información, nivel de entendimiento, eficiencia de los recursos, posición financiera y calidad. También señala que en esta relaciones suelen aparecer los siguientes hitos: objetivos y metas, confianza, resolución de problemas, compromiso, evaluación constante, grupos de trabajo y equipos, equidad, riesgo compartido, filosofía “win-win” y colaboración-cooperación.

Podemos encontrar numerosas definiciones de lo que entendemos como alianza estratégica (Bronder y Pritzl, 1992; Takac y Singh, 1992; Mason, 1993; Dowling et al. 1994). De esta manera por ejemplo, Lamming et al.(2000) y Walters y Lancaster (2000) han sugerido que las alianzas estratégicas existen cuando la cadena de valores entre al menos dos organizaciones con metas compatibles se combinan para obtener significativas ventajas competitivas. La razón sin embargo, común a todas las definiciones es que las relaciones inter organizacionales se establecen por un motivo específico cuando todas las partes están envueltas en un ambiente colaborativo. Estos términos están muy de moda en la ciencia social y la literatura de gestión (Kanter, 1994; Mintzberg ar al. 1996). Algunos autores como Hamel (1989), Bronder y Pritzl (1992) y Morrison y Mezentseff (1997) describen las alianzas como colaborativas y cooperativas en su naturaleza. Dicho de otro modo, las alianzas estratégicas colaborativas se refieren a aquellas en que las partes trabajan juntas con un horizonte temporal a corto y las alianzas estratégicas cooperativas son las que lo hacen a largo plazo. Es evidente que dentro de la cadena de suministro de la construcción existen más relaciones centradas en el corto plazo bajo el prisma del proyecto, estableciéndose relaciones para un proyecto de construcción concreto. 


\section{Alianzas a largo plazo}

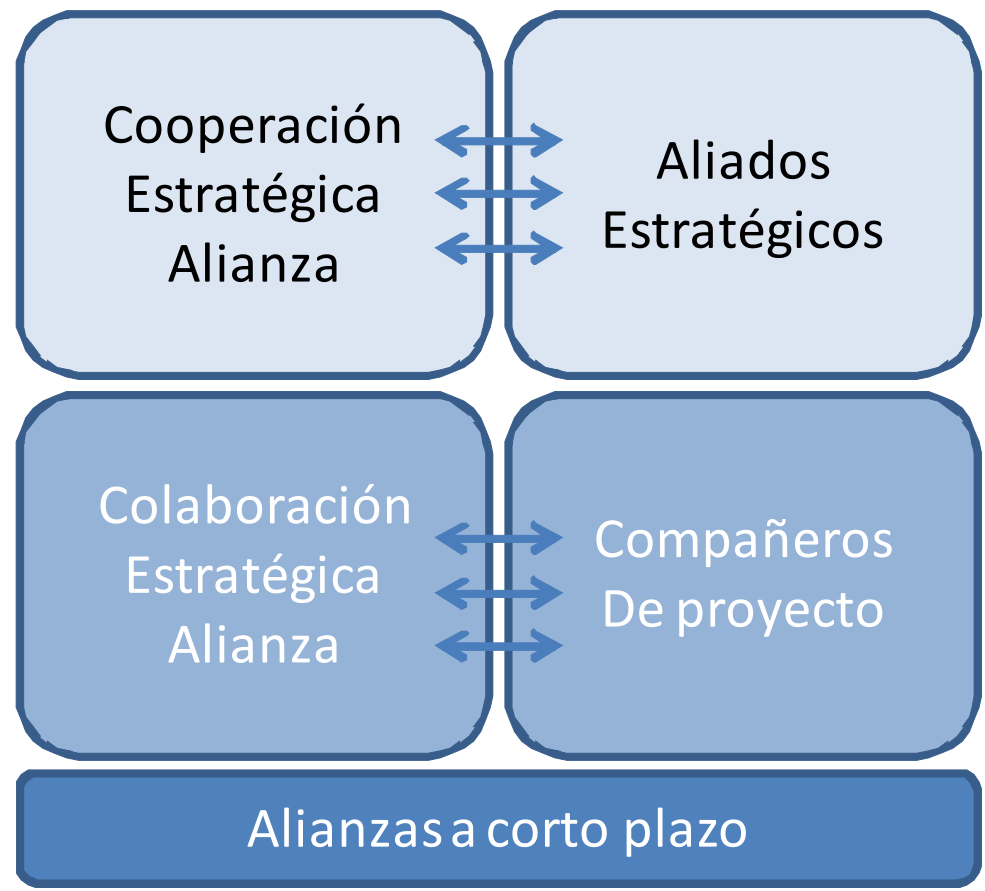

Fig 7_4 Alianzas a corto plazo y alianzas a largo plazo. "A model for supporting inter-organizational relations in the supply chain” Peter E.D. Love et al. (2002).

En la figura Fig 7_4 Alianzas a corto plazo y alianzas a largo plazo. "A model for supporting inter-organizational relations in the supply chain" Peter E.D. Love et al. (2002) muestran las relaciones existentes en los dos tipos de alianzas estratégicas y relaciones de partenariado en la construcción. Las alianzas de largo plazo se refieren a las alianzas cooperativas entre al menos dos organizaciones que establecen objetivos y metas a alcanzar a largo plazo con el propósito de desarrollar ventajas competitivas. Más específicamente las alianzas a largo plazo son la manifestación interorganizacional de estrategias cooperativas, poniendo en común habilidades y recursos a través de la cooperación de las organizaciones para alcanzar objetivos comunes, en vez del seguimiento de objetivos específicos de cada una de las organizaciones por separado. En estas situaciones el capital intelectual y la organización inteligente deben estar motivadas para el desarrollo a largo plazo de la alianza, Morrison Y Mezentseff, (1997) y Joia (2000). 
La propuesta que se presenta profundiza en este enfoque a largo plazo de las relaciones dentro de la cadena. De hecho se puede ver como una evolución lógica y como una manera de plasmar en la práctica ese enfoque de alianza estratégica a largo plazo. Se entiende, que la única forma en que la propuesta presentada del modelo de Organización Global para la gestión de la cadena de suministro del sector de la construcción, se pueda llevar a la práctica, es la creación de dicha alianza estratégica entre las compañías que forman parte de esta cadena de suministro.

Ya se ha visto con anterioridad que existen muchos aspectos a considerar en la identificación de las mejoras a realizar en la alianza, la evaluación de la relación de la alianza por aquellos factores que se consideran claves, la identificación y medida de los beneficios generados, etc.. Pero en este capítulo se quiere señalar como poner los cimientos para poder desarrollar una estrategia que permita llegar a la relación de alianza con los proveedores como paso previo para la construcción de la propuesta de modelo de gestión en la cadena de suministro en el sector de la construcción.

El modelo que se presenta reúne las características que mejoran los aspectos señalados como críticos por los distintos autores citados con anterioridad. De esta suerte se recogen a continuación nueve características del modelo en relación a dichos aspectos:

- La aplicación del Modelo de Organización Global produce una integración funcional entre compañías que trabajan de forma única frente a los modelos clásicos de gestión de cadenas de suministro.

- El Modelo de Organización Global crea un cambio de mentalidades en las personas que participan en el mismo dada la distinta manera de funcionar. Esto conlleva un cambio en las habilidades de las personas que trabajan bajo este modelo.

- Así mismo, la aplicación del modelo, por lo expuesto con anterioridad, implica una rebaja en multitud de costes derivados de los procesos entre compañías no aliadas y lleva a la reducción de costes totales. Esta manera de trabajar implica una mejora de la productividad y una mejora de los beneficios. 
- El modelo presenta una mejora en la respuesta al cliente en cuanto a su eficiencia y en su eficacia, se debe recordar la presencia misma del cliente en los equipos de trabajo.

- El modelo de Organización Global muestra una manera de trabajar que implica un aumento del compromiso y de la confianza que soluciona los problemas de coordinación y falta de entendimiento que aparecen en otros modelos de funcionamiento.

- La mejoría de comunicación y el entendimiento entre los distintos actores de la cadena de suministro viene de tener unas relaciones más estables a largo plazo y duraderas.

- Otro aspecto que mejora el Modelo de Organización Global es el que se presenta por la departamentalización de las compañías y la consecuente gestión secuencial del proceso perdiendo la falta de visión global del mismo.

- Es también necesario en la forma de trabajar que el modelo presenta que la subcontrata general opere como una verdadera dirección de las operaciones y no como empresas de subcontratación.

- Un último aspecto que se quiere señalar del modelo presentado, es que trabaja bajo los parámetros de "win-win" porque de otro modo no se podría concebir este modelo de trabajo. 


\section{La construcción de la alianza con los proveedores y sus aspectos más importantes.}

Como se viene expresando, para el desarrollo de la propuesta del modelo para la gestión de la cadena de suministro de la construcción presente, es básico el desarrollo de las alianzas dentro de los actores de dicha cadena de suministro. Visto que el enfoque debe estar basado en una relación a largo plazo, lo que se pretende es lo que se entiende por una relación estratégica a largo plazo cooperativa, por lo tanto, se presenta en este apartado cuáles son los pilares en los que se debe apoyar esta alianza.

En primer lugar, y basándose en el estudio de Vrijhoef R. y Koskela L. (2000), en el que se describe la configuración típica de una cadena de suministro, en el sector de la construcción de un estudio realizado en Holanda y Finlandia se ve representada en la figura Fig 7_5_Configuración Típica de una Cadena de Suministro de la Construcción donde se puede observar la típica relación pedido contra orden del proceso de construcción.

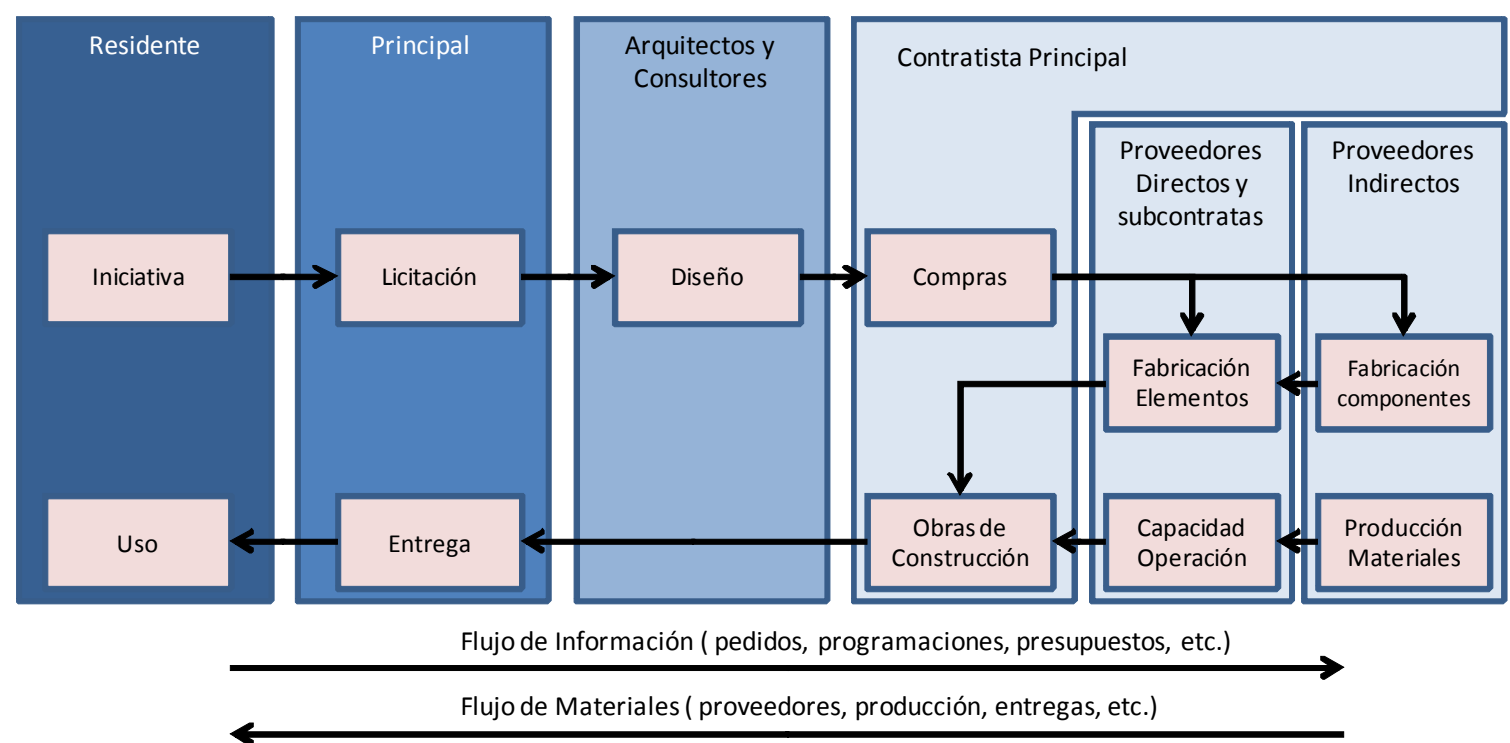

Fig 7_5_Configuración Típica de una Cadena de Suministro de la Construcción. "The four roles of supply chain management in construction" Ruben Vrijhoef y Lari Koskela (2000) 


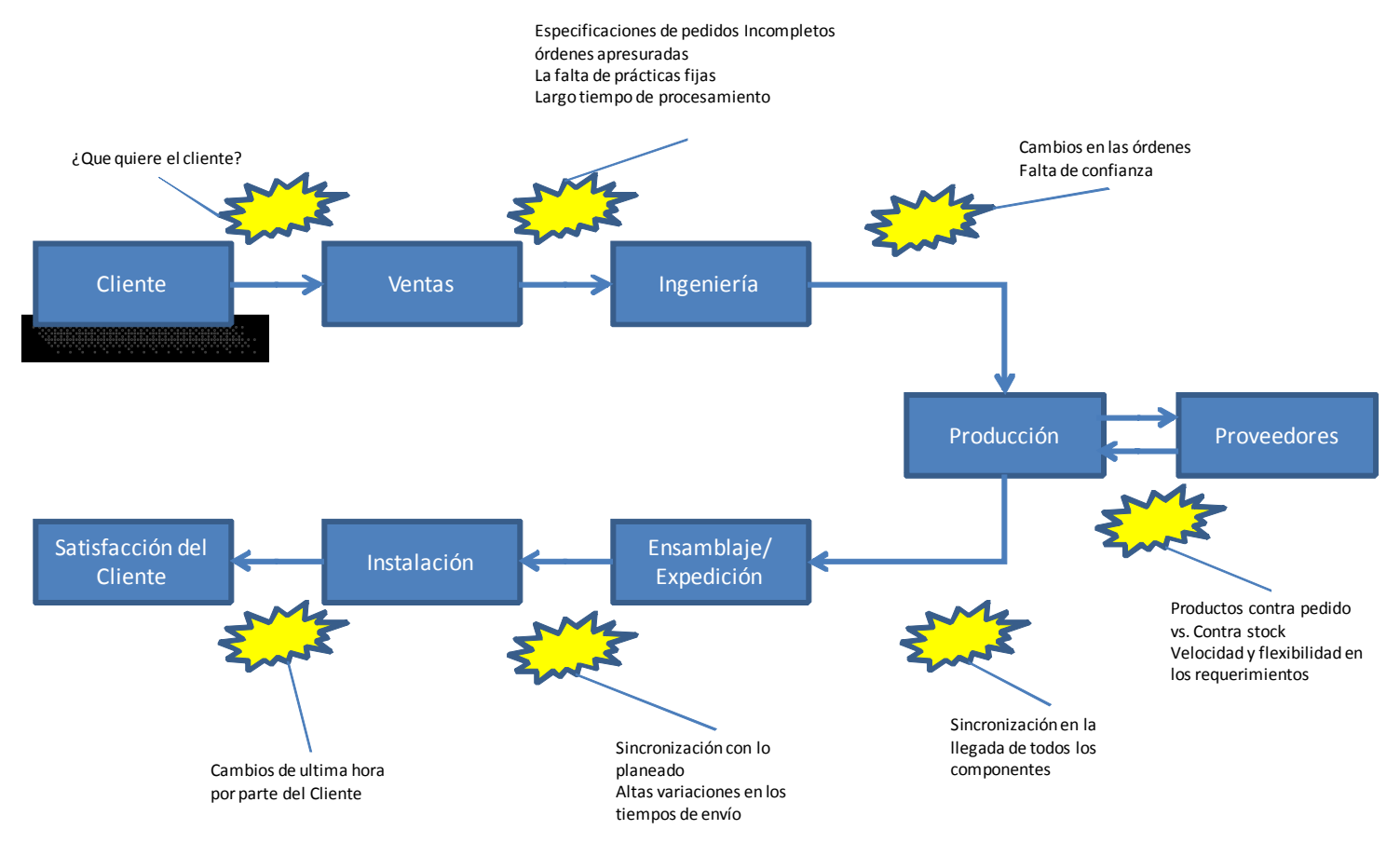

Fig 7_6_Resumen de los problemas más habituales en la cadena de suministro de la construcción. Luhtala et al. (1994).

Y basándose en varios análisis en diferentes compañías que elaboran productos no estándares, Luhtala et al. (1994), se observan los típicos problemas de la fabricación contra pedido de las cadenas de suministro. Los problemas aparecen a lo largo de toda la cadena debido a la existencia de muchos "interfaces" en el global del proceso (Ver Fig 7_6 _Resumen de los problemas más habituales en la cadena de suministro de la construcción. Luhtala et al., 1994). 
Los clientes son los que a menudo aparecen como la última fuente de los cambios en las especificaciones del producto, en las relaciones de fabricación contra pedido de la producción. Sin embargo, en este estudio de Luhtala et al. (1994), aparece que la mayoría de los problemas de control y cambios de las especificaciones de producto tienen un origen interno en la cadena. Aparecen como interacción de varias unidades de la cadena de suministro. Por otro lado, a menudo se cree que la baja calidad de entregas de las fábricas de componentes crean la mayor parte de los problemas en la fase de instalación. En lugar de eso, aparece en el estudio que el papel de las unidades de "front-line", responsables de las ventas y a menudo de la coordinación de la instalación, es crucial en los resultados del global de la cadena, incluyendo el proceso de instalación. El estudio concluye que las redes logísticas de fabricación contra pedido contienen un gran potencial de desarrollo que puede ser utilizado en una gestión global del proceso en vez de unidades individuales.

Otro ejemplo más aplicado a la cadena de suministro de la construcción que se puede encontrar es el estudio de X. Xue et al. (2004), en donde se pone de manifiesto que la mayor parte de los problemas que aparecen en la cadena de suministro de la construcción se originan en las relaciones entre los diferentes participantes de las distintas fases que envuelven la cadena de suministro de la construcción, como podemos ver en la figura Fig 7_7_Problemas en la cadena de suministro de la construcción. "An agent-based framework for supply chain coordination in construction", X. Xue et al. (2004). Los problemas se originan por una miopía y un control independiente de la cadena de suministro.

Love et al.(2004) y Mohamed (2003) señalan la alta fragmentación característica de la industria de la construcción. Por ejemplo la separación entre el diseño y la construcción que crea una descoordinación y falta de integración entre varias funciones básicas en el proceso, creando baja productividad, elevados costes y plazos, conflictos y disputas. 


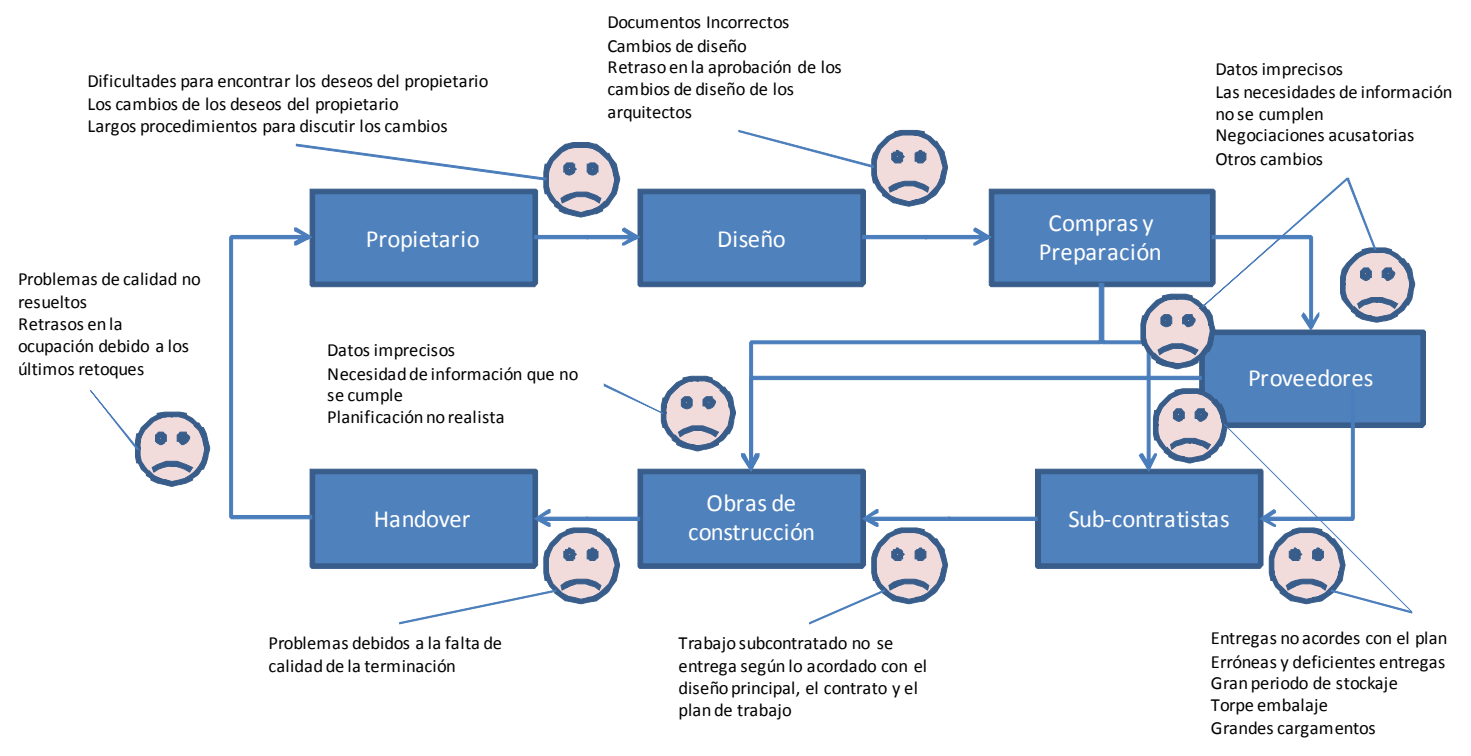

Fig 7_7_Problemas en la cadena de suministro de la construcción. "An agent-based framework for supply chain coordination in construction”, X. Xue et al. (2004).

Todo esto es lo que lleva a proponer un modelo de integración MOG en el cual este tipo de situaciones se minimicen por la configuración estructural del modelo. Es por tanto necesario abolir el concepto tradicional de proveedor y pensar en un equipo multidisciplinar e inter empresas que permita trabajar todos juntos para poder alcanzar los objetivos que se marcan de cara al cliente. Es aquí donde aparece uno de los pilares básicos de la propuesta de modelo de integración MOG, ver la figura Fig 7_8_Funcionamiento General: Modelo de Organización Global. Elaboración propia.

Esta forma de entender la organización hace desaparecer las relaciones individuales de cada uno de los agentes de la cadena, y pone de manifiesto el trabajo en equipo para alcanzar las metas señaladas por el cliente. Éste enfoque por el cliente es otro de los aspectos diferenciales de la propuesta de modelo de integración que se presenta. El enfocarse hacia el receptor final y por lo tanto usuario del producto que la cadena elabora simplifica y focaliza los esfuerzos en la dirección adecuada, el deseo y la necesidad del que va a utilizar el producto elaborado. 


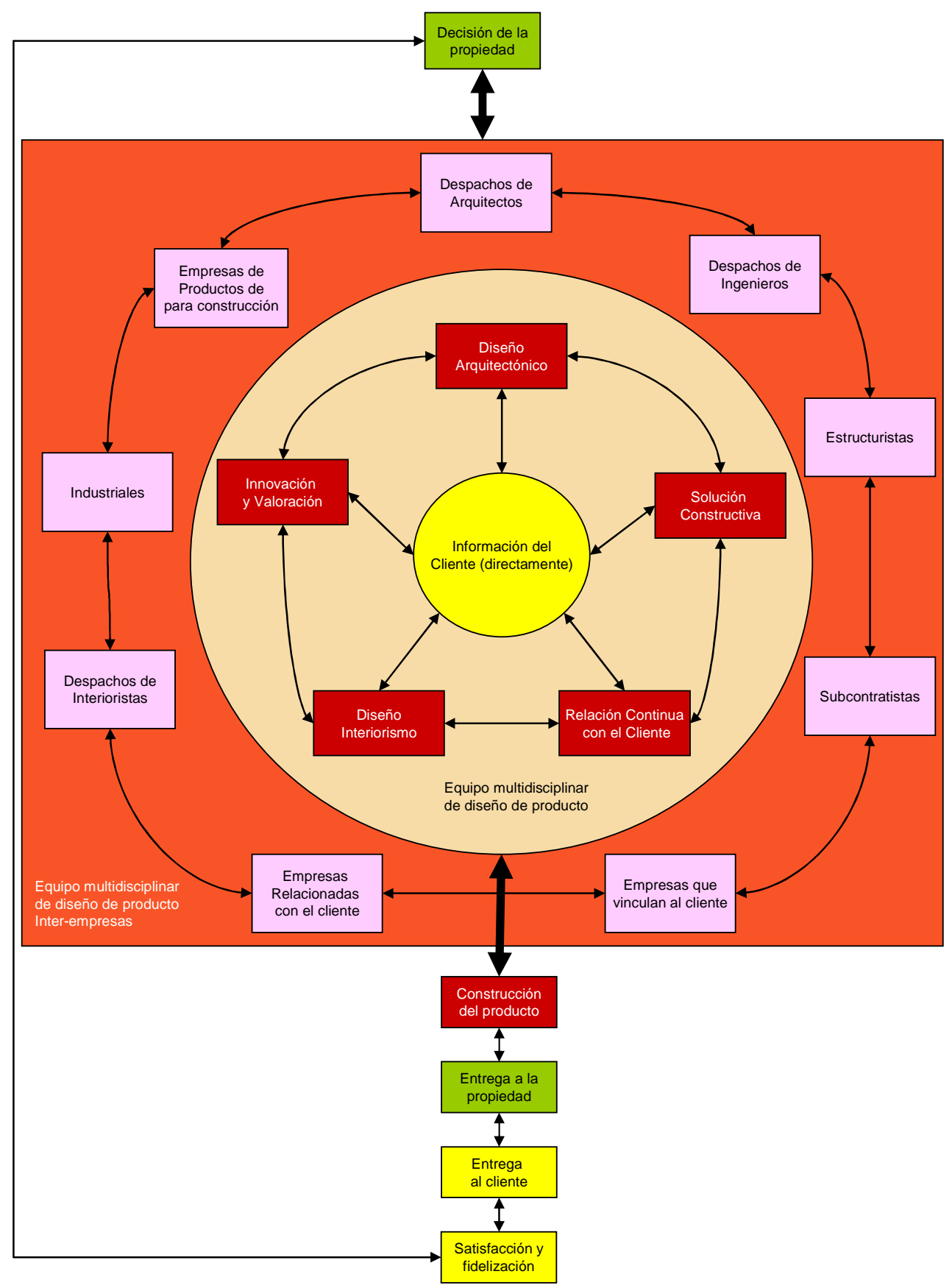

Fig 7_8_Funcionamiento General: Modelo de Organización Global. Elaboración propia.. 
Esta integración global no se puede entender sin una etapa de crecimiento con interacciones individuales dentro del equipo de trabajo, es aquí donde aparece el concepto desarrollado para la implantación de la alianza uno a uno de los integrantes de la cadena, ver figura Fig 7_9_ Esquema del modelo propuesto para el desarrollo de la alianza. Elaboración propia.

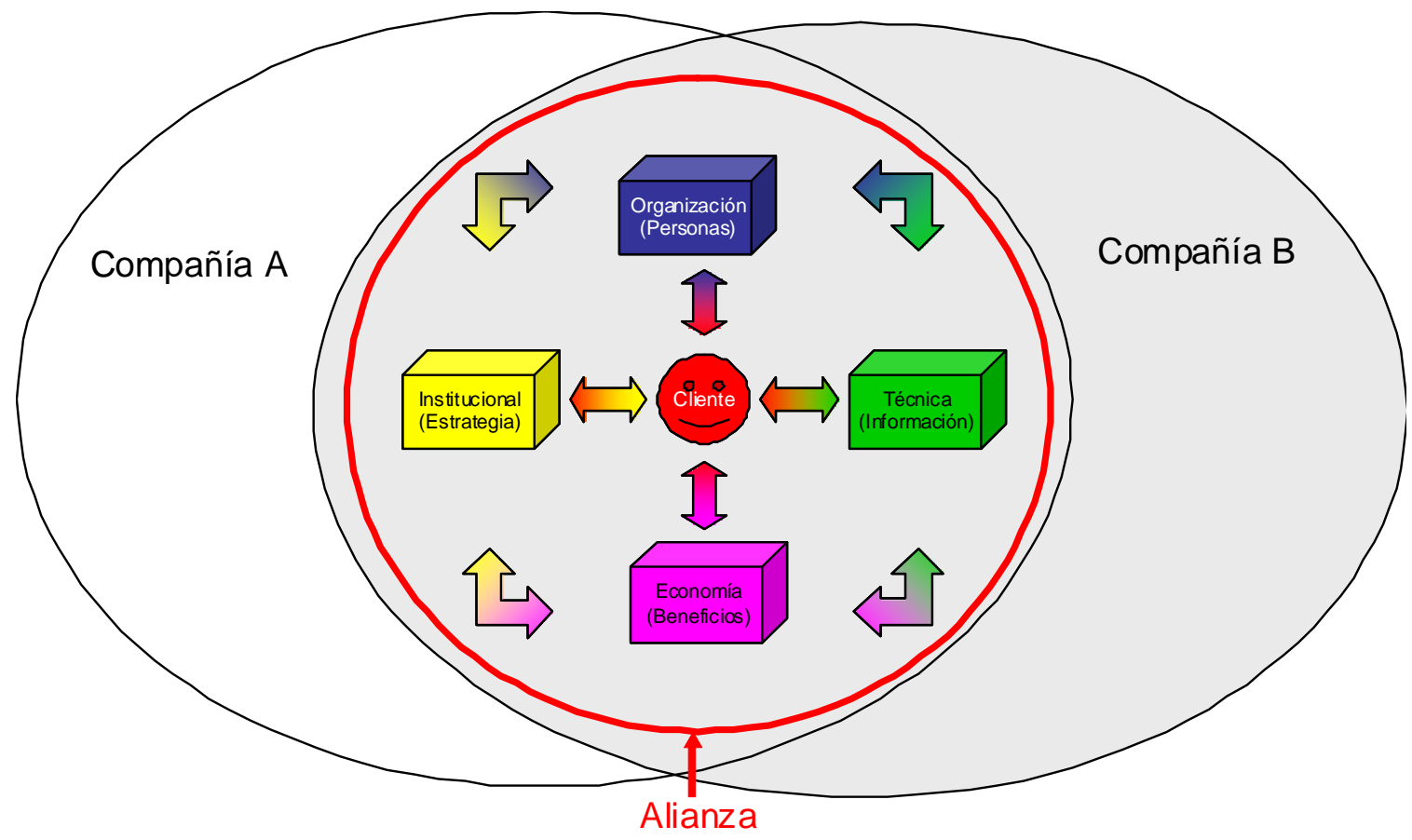

El "pegamento" de la alianza debe de ser El cliente

Fig 7_9_Esquema del modelo propuesto para el desarrollo de la alianza. Elaboración propia.

El desarrollo de esta alianza en la propuesta del modelo que se presenta se basa en los cinco pilares que se ven en la figura: organización (personas), institucional (estrategia), economía (beneficios), técnica (información) y cliente. Se entiende que estos cinco pilares son los elementos básicos que garantizan que la alianza tenga un desarrollo a largo plazo y que los objetivos de unión dentro del equipo multidisciplinar de trabajo señalado como núcleo dentro de la propuesta de modelo se cumplan. 


\section{Referencias bibliográficas:}

$>$ ABUDAYYEH, O. (1994) "Partnering: a team building approach to quality construction management". ASCE Journal of Management in Engineering, 10, $26 \pm 29$.

$>$ ASHTON, D., DAVIES, B., FELSTEAD, A., GREEN, F., (1999). "Work skills in Britain. Centre for Skills", Knowledge and Organisational Performance (SKOPE), Oxford and Warwick Universities.

$>$ BRESNEN, M. AND MARSHALL, N. (1998) "Partnering strategies and organizational cultures in the construction industry", in Hughes, W. (ed.) ARCOM 14th Annual Conference, Reading, 9-11 September, pp. 465-76.

> BRESNEN, M. AND MARSHALL, N. (1999) "Achieving customer satisfaction?" Client-contractor collaboration in the UK construction industry, in Bowen, P. and Hindle, R. (eds) CIBW55 \& '65 Joint Triennial Symposium, Cape Town, South Africa.

BRISCOE, G., DAINTY, A. R. J. AND MILLETT, S., (2001). "Construction supply chain partnerships: skills, knowledge and attitudinal requirements", European Journal of Purchasing \& Supply Management, Vol 7, Iss 4, pp.243-255.

$>$ BRISCOE G., ANDREW R.J. DAINTY, SARAH J. MILLETT AND RICHARD H. NEALE (2003) "Client-led strategies for construction supply chain improvement", Construction Management and Economics.

> BRISCOE G., AND ANDREW R.J. DAINTY (2005) "Construction supply chain integration: an elusive goal?" Supply Chain Management: An International Journal 10/4 319-326

> BRONDER, C. \& PRITZL, R. (1992) "Developing strategic alliances: a successful framework for cooperation". European Management Journal, 10, 412-420.

B BROWN, J. H. (1993). "Partnering on engineering/construction projects." PM Network, 7(12), 32-34.

$>$ CAPÓ J.et.al. (2003), "Integración Empresarial y Redes Interorganizacionales en la Gestión de la Cadena de Suministro". Aplicación al Sector de la Construcción. V Congreso de Ingeniería de Organización: Valladolid-Burgos, 4-5 Septiembre.

$>$ CRANE, T. G. (1995). "The benefits and implementation of partnering in the construction industry," ME thesis, Clemson Univ., Clemson, S.C.

$>$ CRANE, T.G., FELDER, J.P., THOMPSON, P.J., THOMPSON, M.G. AND SANDERS, S.R. (1997), "Partnering process model", Journal of Management in Engineering, Vol. 13 No. 3, pp. 57-63. 
CRANE, A., (1999). "The movement for innovation (M4I ) in construction in learning to succeed in construction". Conference Proceedings, CITB, November 25, London, pp. $2-8$.

> CHRISTOPHER, M., (1992). "Logistics and Supply Chain Management: Strategies for Reducing Costs and Improving Service”. Pitman Publishing, London.

$>$ CONSTRUCTION INDUSTRY INSTITUTE (CII). (1991). "In search of partnering excellence." Spec. Pub. No. 17-1, Partnering Task Force, Austin, Tex.

$>$ DOWLING, P., SCHULER, R. \& WELCH, D. (1994) "International Dimensions of Human Resources Management”. Wadsworth Publishing Company, Belmont, CA.

JAMIESON, M.J., THORPE, A. AND TYLER, A. (1996), "Refocusing collaboration technologies in the construction value system", Proceedings of the CIB W78 Conference Construction on the Information Superhighway, Bled, April, pp. 279-89.

> HÅKANSSON, H. AND PERSSON, G. (2004) "Supply Chain Management: The logic of supply chains and networks", under review for publication in International Journal of Logistics Management.

$>$ HAMEL, G. (1989) “Collaborate with your competitors \pm and win”. Harvard Business Review, January \pm February, $133 \pm 139$

DAMMER, M. AND CHAMPY, J. (1993). "Reengineering the Corporation", London.

$>$ HIMES, P.E. (1995) "Partnering in the construction process: the methodology for the 1990s and beyond". Facilities, 13(6), 13-15.

$>$ HINZE, J. AND TRACEY, A. (1994) "The contractor-subcontractor relationship: the sub-contractors view". Journal of Construction Engineering and Management, 120(2), 274-87.

$>$ JOIA, L.A. (2000) W3E \pm a web-based instruction system for leveraging corporate intelligence. Journal of Workplace Learning, 12, $5 \pm 12$.

$>$ KANTER, R.M. (1994) "Collaborative advantage: art of alliances". Harvard Business Review, 73, 96 \pm 108 .

$>$ KOSKELA, L. (1997), "Lean production in construction”, in Alarcon, L. (Ed.), Lean Construction, A.A. Balkema Publishers, Rotterdam, pp. 1-10.

$>$ KUBAL, M.T. (1994), "Engineering Quality in Construction: Partnering and TQM", McGraw-Hill, New York, NY.

LAMMING, R., JOHNSEN, T., ZHENG, J. \& HARLAND, C. (2000) "An initial classication of supply networks". International Journal of Operations and Production Management, 20, 675 \pm 691 . 
LISKA, R. (1993). "Partnering for project success". Assoc. Builders and Contractors. Inc.. Washington, D.C.

LOVE P.E.D., ZAHIR IRANI, EDDIE CHENG Y HENG LI (2002).”A model for supporting inter-organizational relations in the supply chain". Engineering, Construction and Architectural Management $91,2 \pm 15$

LOVE P.E.D., Z. IRANI, D.F. EDWARDS (2004), “A seamless supply chain model for construction", Supply Chain Management: An International Journal 9 (1) 43-56.

LONDON, K., KENLEY, R. AND AGAPIOU, A. (1998) "Theoretical supply chain network modelling in the building industry", in Hughes, W. (ed.) ARCOM 14th Annual Conference, Reading, 9-11 September, pp. 369-79.

LUHTALA, M., KILPINEN, E., ANTTILA, P., (1994). "LOGI: Managing Make-ToOrder Supply Chains”. Helsinki University of Technology,Espoo.

> MASON, D. (1993) "Strategic alliances: partnering for success". Management Review, 3, $10 \pm 15$.

MATTHEWS, J., TYLER, A. AND THORPE, A. (1996) "Pre-construction project partnering: developing the process". Engineering, Construction \& Architectural Management, 3(1, 2), 117-31.

> MATTHEWS, J., LEAH PELLEW, FLORENCE PHUA AND STEVE ROWLINSON. (2000) "Quality relationships in the construction supply chain". International Journal of Quality and Realiability Management Vol 17 Nos 4/5 pp 493510 .

> MinTZBERG, H., DOUGHERTY, D., JORGENSEN, J. \& WESTLEY, F. (1996) "Some surprising things about collaboration \pm knowing how people make contact

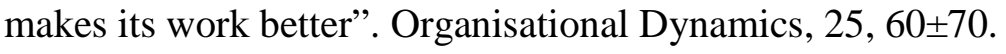

$>$ MOHAMED S.(2003), "Web-based technology in support of construction supply chain networks", Work Study 52 (1) 13- 19.

$>$ MORRISON, M. \& MEZENTSEFF, M. (1997) "Learning alliances \pm a new dimension of strategic alliances". Management Decision, 35, 351 \pm 357 .

> MURRAY, M., LANGFORD, D., HARDCASTLE, C. AND TOOKEY, J. (1999) "Organisational design, in Rowlinson, S. and McDermott, P. (eds) Procurement Systems: A Guide to Best Practice in Construction", E \& FN Spon, London, pp. 83118.

NEW, S.J. AND PAYNE, P. (1995) "Research frameworks in logistics: three models, seven dinners and a survey". International Journal of Physical Distribution and Logistics Management, 25(10), 60-77. 
NOBBS, H. (1993), "Future Role of Construction Specialists", The Business Round Table, London.

$>$ POIRIER. C. C., AND HOUSER, W. E (1993). "Business partnering for continuous improvement”. Berrett-Koehler Publishers, San Francisco, Calf.

$>$ READING CONSTRUCTION FORUM (1998), "The Seven Pillars of Partnering: A Guide to Second Generation Partnering", Thomas Telford, London.

$>$ RUBEN VRIJHOEF Y LAURI KOSKELA (2000), "The four roles of supply chain management in construction". European Journal of Purchasing \& Supply Management 6. $169 / 178$.

SANDERS, S. R., CRANE, T. C., AND THOMPSON, P. J. (1996). "The partnering process-its benefits, implementation and measurement." Constr. Industry Inst., The Univ. of Texas at Austin, Austin, Tex.

> STANNACK, P., (1995). "Building organisational communities: The role of purchasing and supply chain management”. In: Kemp, R. A., Lamming, R. C. (Eds.), Proceedings of the First Worldwide Research Symposium on Purchasing and Supply Chain Management, Arizona State University, Tempe, USA.

> S.M. HONG-MINH, R. BARKER, Y M.M. NAIM (1999). "Construction supply chain trend analysis". Proceedings IGLC-7.

TAKAC, P.F. \& SINGH, C.P. (1992) "Strategic alliances in banking”. Management Decision, $30,32 \pm 43$.

> UHER, T.E. AND RUNESON, G. (1985) "Subcontractor-general contractor relationship in Australian building industry". Project Management, 3(1), 35-8.

WALTERS, D. \& LANCASTER, G. (2000) "Implementing value strategy through the value chain". Management Decision, 38, 160-178.

> XIAOLONG XUE, XIAODONG LI, QIPING SHEN Y YAOWU WANG (2004) "An agent-based framework for supply chain coordination in construction". Automation in Construction 14 (2005) 413-430 


\section{Capitulo 8}

\section{Investigación sobre la necesidad del modelo propuesto.}

\section{Introducción:}

Como conclusión de la presente tesis y para poder testar la necesidad del modelo propuesto en el trabajo de investigación se propone la realización de una encuesta a profesionales cuyas empresas están relacionadas directamente con el sector de la promoción inmobiliaria e intervienen en la gestión de la cadena de suministro. En el presente capítulo se recogen los aspectos fundamentales relacionados con dicha encuesta y cuales son las conclusiones de las respuestas recibidas. 


\section{Ficha Técnica:}

La encuesta se realizó mediante un cuestionario a responder vía web y con el tratamiento automatizado de los datos y resultados obtenidos de cada una de las preguntas. Se eligió para la realización de la misma a Survey Methods en http://www.surveymethods.com . La encuesta se pasó a profesionales del sector elegidos entre distintas empresas y se abrió a profesionales que forman parte de foros especializados en la promoción inmobiliaria y la construcción. A la encuesta se invitó a cincuenta profesionales relacionados con el sector de la promoción inmobiliaria y la construcción. La invitación se realizó a profesionales de empresas proveedoras de materiales de construcción, empresas de ingeniera, despachos de arquitectura, etc. Adicionalmente se solicitó la participación a los miembros de foros especializados y directamente relacionados con el mundo de la promoción inmobiliaria:

-IESE UNAV Open Networkers: Building Alumni Social Value

-World Office Forum

-Profesionales Promoción Inmobiliaria y Construcción. Promoción Inmobiliaria, construccion.

-CREPIG - Commercial Real Estate Professionals \& Investors Group

-www.realestatepress.es Group Members Cómo

La encuesta se lanzó con fecha 1 de diciembre de 2010. De los invitados por correo a responder a la encuesta se recibieron diez respuestas. De los invitados de los foros especializados se recibieron cincuenta respuestas adicionales, es decir se cuenta con un total de sesenta respuestas de profesionales expertos en el sector. El tiempo medio para rellenar las respuestas de la encuesta fue de tres minutos y treintaisiete segundos.

Las preguntas se realizaron en cuatro bloques temáticos: un primer bloque hablaba sobre la implicación que la crisis inmobiliaria puede tener sobre un cambio de modelo en el negocio de la promoción y la construcción. Un segundo bloque que intenta definir los tipos de empresas que surgirán después de la crisis. El tercer bloque hablaba sobre los modelos de negocio y un cuarto y último bloque que hablaba sobre las características de esos modelos de negocio. 


\section{Implicación que la crisis inmobiliaria actual tendrá en un cambio de modelo.}

Para abordar este bloque conceptual se ha creído conveniente plantear una pregunta que de algún modo resume perfectamente la información que se busca. La pregunta es: "En el sector de la promoción inmobiliaria estamos viviendo una de las peores crisis que se recuerdan en la historia del mismo, ¿Cree que esta crisis implicará un cambio de modelo de negocio?". Las posibles contestaciones eran únicamente dos, o si o no. Los resultados son muy contundentes: tenemos un $93,22 \%$ de contestaciones positivas y un $6,78 \%$ de contestaciones negativas.

Es por ello que, de una manera rotunda, se concluye que los expertos piensan que la crisis inmobiliaria actual necesariamente implicará un cambio en el modelo de negocio que conocemos actualmente. (Ver Fig 8_1_La crisis inmobiliaria iimplicará un cambio de modelo de negocio?. Elaboración Propia). Este cambio en el modelo de negocio, evidentemente, se realizará de distintas maneras y tendrá con toda seguridad varios modelos de negocio alternativos. Veamos en los otros bloques de la entrevista si el Modelo propuesto podría ser uno de los modelos que fueran de utilidad al sector.

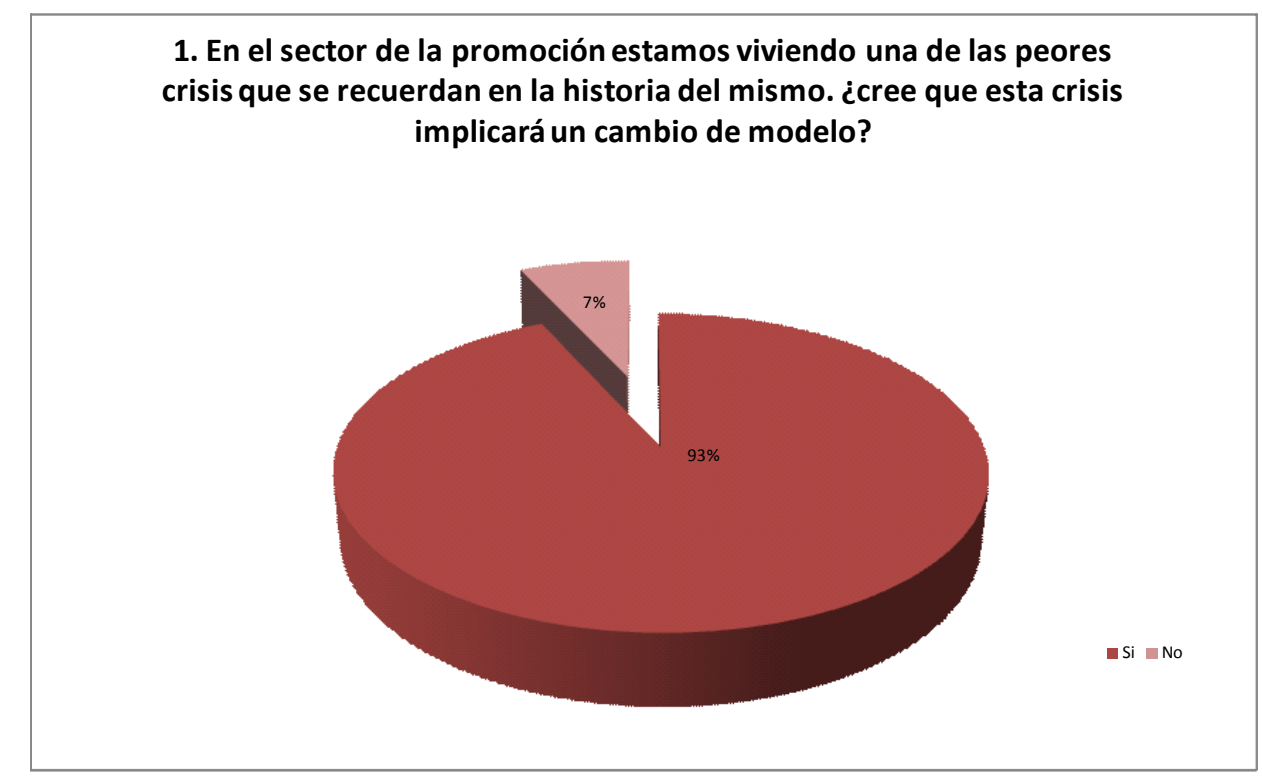

Fig 8_1_La crisis inmobiliaria ¿implicará un cambio de modelo de negocio?. Elaboración Propia 


\section{Tipos de empresas que surgirán después de la crisis inmobiliaria.}

Una vez conocido que según los expertos encuestados la crisis inmobiliaria actual implicaría un cambio de modelo, la propuesta del bloque dos de preguntas es poder averiguar qué tipo de empresas serían las que podrían desarrollar su actividad en el escenario que se encontrará el sector. Esta pregunta se plantea de una forma abierta de forma que se sugieren características de las empresas y también se da la oportunidad al encuestado a que ofrezca soluciones distintas a las propuestas en una pregunta a especificar. La pregunta es: "Este cambio de modelo ¿en qué cree que influirá...? (Marque todas las que usted crea correctas)".

Las contestaciones fueron también muy contundentes en algunas de las características a cumplir por las empresas que sobrevivan y compitan en el nuevo escenario que se plantée en el sector inmobiliario. Se señala como de mayor interés que las empresas deben ser más dinámicas y flexibles con un $64,41 \%$ de respuestas. La segunda característica más votada es la de ser empresas más especializadas con un $62,71 \%$ de los votos.

En un terreno mucho menos contundente aparecen características como que las empresas deberán tener menos deuda en sus balances con un 55,93\% de los votos y que las empresas tendrán modelos de relación distinta entre ellas y con tamaños distintos a los actuales con un $44,07 \%$ de los votos. 
Lo que también parece claro es que para los expertos encuestados el tiempo no es la solución a la situación actual con un 3,39\% de los votos. En cuanto a la respuesta abierta de la cual han hecho uso un $20,34 \%$ de los encuestados las respuestas recogidas se detallan a continuación:

1. Reordenación de la gestión y financiación del suelo

2. Potenciar el alquiler

3. No creo que se pueda cambiar el modelo si no se liberaliza el suelo y los políticos corruptos van a la cárcel.

4. A largo plazo todo volverá al modelo actual, de especulación, engaños. Quizás la Administración cambie vender suelos que no tiene ya, por inmuebles. eso me gusta

5. Mayor diversificación en otros sectores y mercados.

6. Mas freelancing en el área comercial y mas externalización de servicios no Core.

7. Diferentes modelos de financiación

8. Márgenes de negocios tradicionales

9. Otro tipo de productos

10. Mayor inteligencia implícita en el producto final.

11. Empresas con más freelances

12. Concentración del mercado en todas las empresas tipo "winner takes it all". 
UNIVERSIDAD

POLITECNICA

DE VALENCIA

J.Francisco Carbonell Ureña

Página 194 de 224

sábado, 21 de enero de 2012

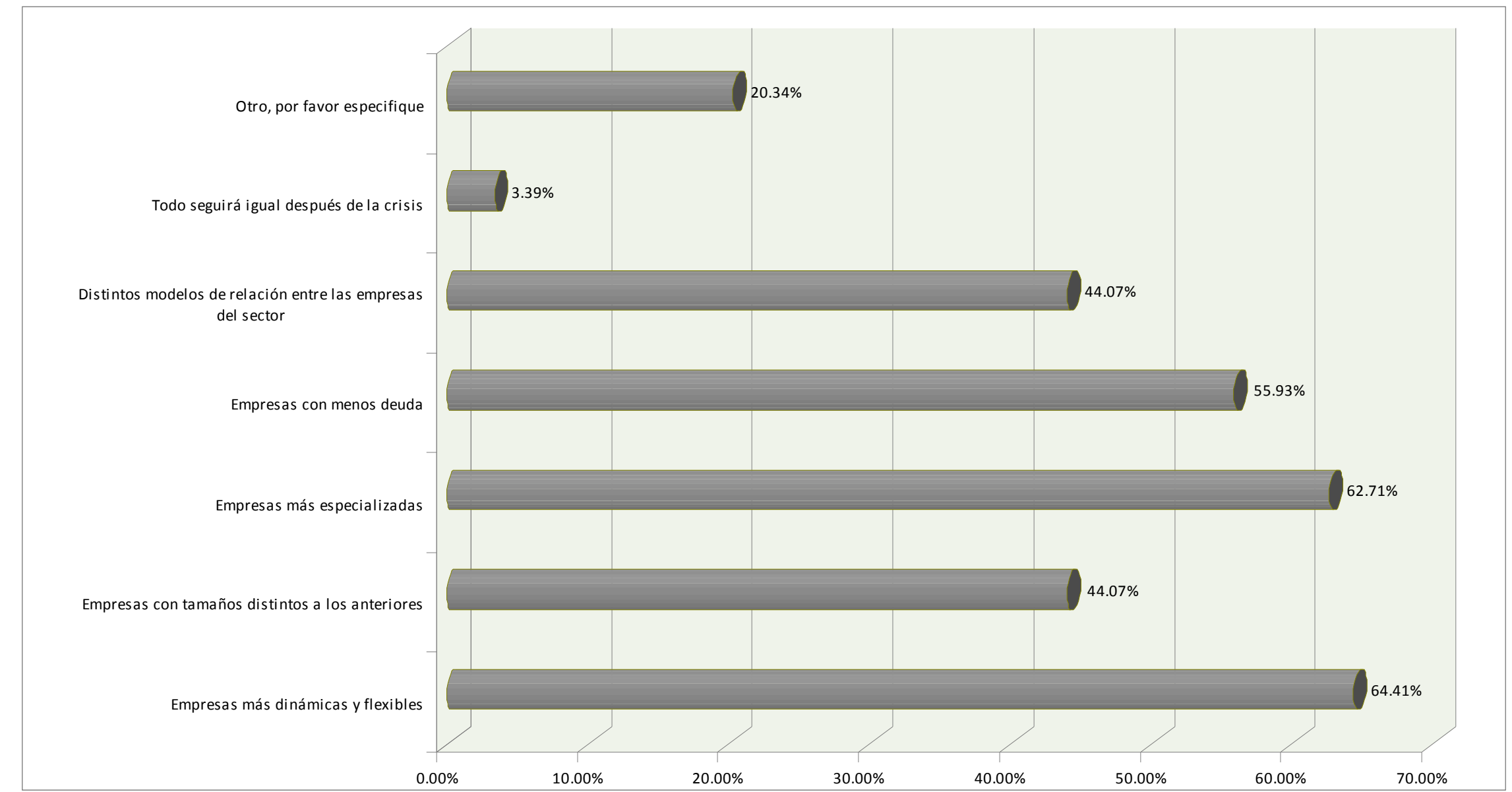

Fig. 82 Este cambio de modelo ¿en qué cree que influirá...? (Marque todas las que usted crea correctas). Elaboración Propia Tesis Doctoral_definitiva_impresión 


\section{Modelos de negocio.}

El tercer bloque, tal y como comentábamos anteriormente, plantea unas cuestiones relativas a la modelización de negocio. La importancia que esta modelización tendrá para el desarrollo del sector y para ayudar al mismo a salir de la crisis. En esta ocasión se ha sugerido una valoración del 1 al 5 sobre ocho afirmaciones concretas. La valoración de 1 al 5 consiste en asignar 1 a la valoración de muy poco probable y 5 a la de muy probable. Las ocho afirmaciones a valorar por los expertos eran:

1. En el sector se desarrollarán nuevos modelos de negocio.

2. Los nuevos modelos de negocio co-existirán con los antiguos.

3. Los modelos de negocio podrían ser de integración de empresas de tamaño menor para proyectos concretos.

4. Los modelos con más futuro son los que integren empresas.

5. Crear modelos de negocio distintos puede ayudar a salir de la crisis.

6. Solo el tiempo nos sacará de la crisis del sector.

7. Solo cambiando de estrategias podremos salir de la crisis.

8. Construir modelos de negocio nuevos es lo mejor que podemos hacer.

Vamos a ver los resultados, los presentaremos de forma gráfica y los comentaremos de forma individual y de forma colectiva al final del presente apartado.

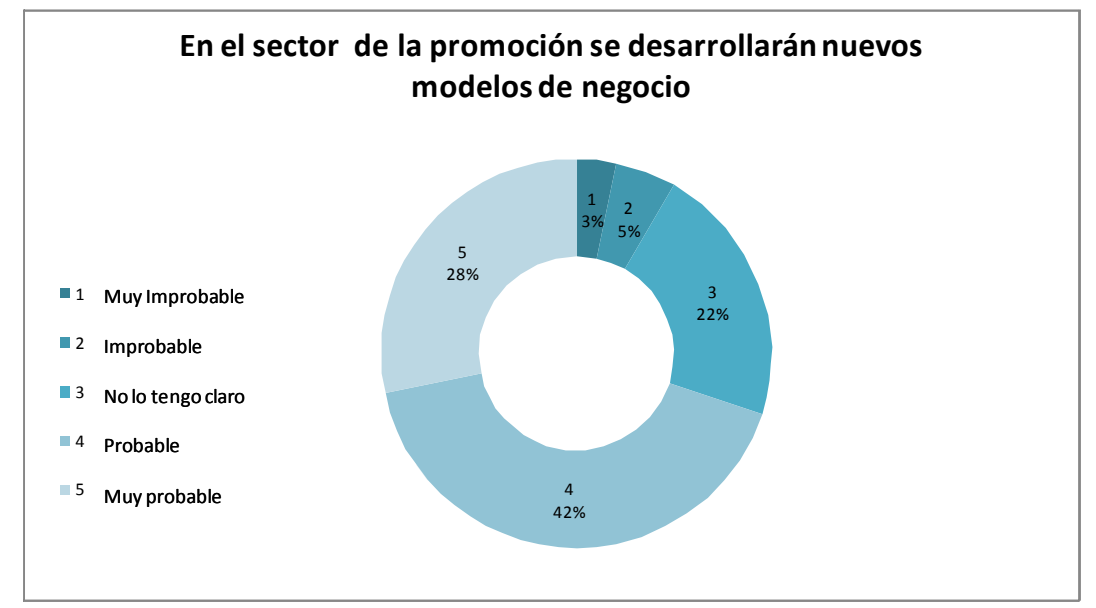

Fig. 8_3_ Modelos de Negocio: En el sector se desarrollarán nuevos modelos de negocio. Elaboración Propia 
En esta primera afirmación se ve que, si se considera la valoración 1 y 2 como en desacuerdo y la 4 y 5 como en acuerdo se tiene que un $70 \%$ de los encuestados opinan que en el sector inmobiliario se desarrollarán nuevos modelos de negocio frente a un $8,33 \%$ que opina lo contrario, y un 21,67\% que se mantiene imparcial. Se ha de concluir que se tiene una posición clara a que habrá nuevos modelos de negocio en el sector de la promoción inmobiliaria. (Ver Fig. 8_3_ Modelos de Negocio: En el sector se desarrollarán nuevos modelos de negocio. Elaboración Propia).

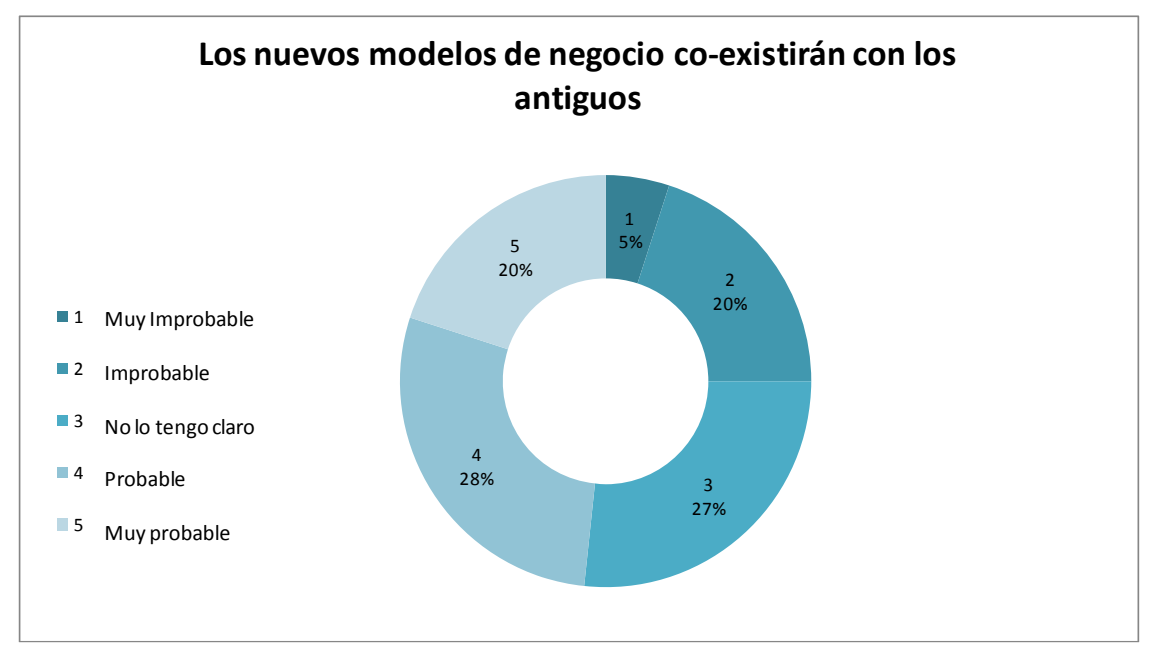

Fig. 8_4_Modelos de Negocio: Los nuevos modelos de negocio co-existirán con los antiguos. Elaboración Propia

La segunda afirmación consistía en ver si los nuevos modelos de negocio coexistirán con los antiguos. Siguiendo con la misma forma de valorar que se ha comentado en la primera afirmación los resultados son los siguientes: un 48,33\% opina que si frente a un $25 \%$ que opina que no y un $26,67 \%$ que no se define. La conclusión en esta pregunta es que según los expertos no hay una posición clara frente a la posibilidad de que convivan ambos modelos de negocio. (Ver Fig. 8_4_ Modelos de Negocio: Los nuevos modelos de negocio co-existirán con los antiguos. Elaboración Propia). 


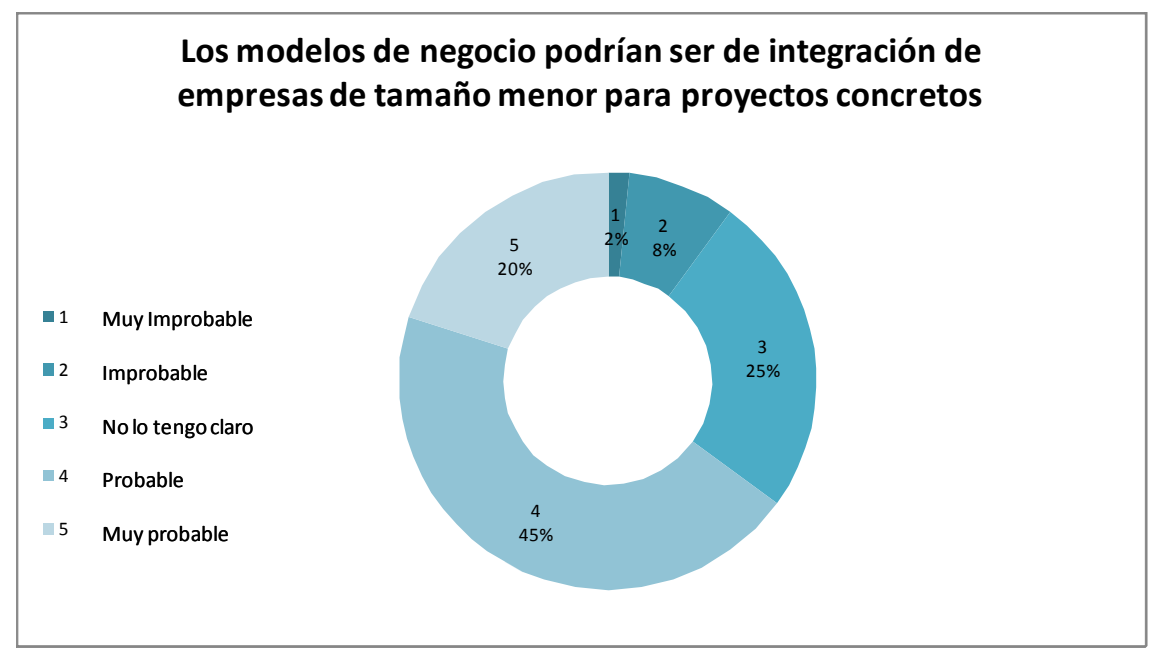

Fig. 8_5_Modelos de Negocio: Los modelos de negocio podrían ser de integración de empresas de tamaño menor para proyectos concretos. Elaboración Propia

La tercera afirmación es sobre la posibilidad de integrar empresas de tamaño menor para abordar proyectos concretos En esta ocasión se tiene un $65 \%$ de votos afirmativos para esta sentencia, frente a un $10 \%$ de negativos y un $25 \%$ de imparciales. La conclusión es que la integración entre empresas, en el caso de proyectos concretos y sabiendo que las empresas serán más pequeñas, dinámicas y flexibles según se recoge anteriormente, se dará este hecho según los expertos consultados. (Ver Fig. 8_5_ Modelos de Negocio: Los modelos de negocio podrían ser de integración de empresas de tamaño menor para proyectos concretos. Elaboración Propia). 


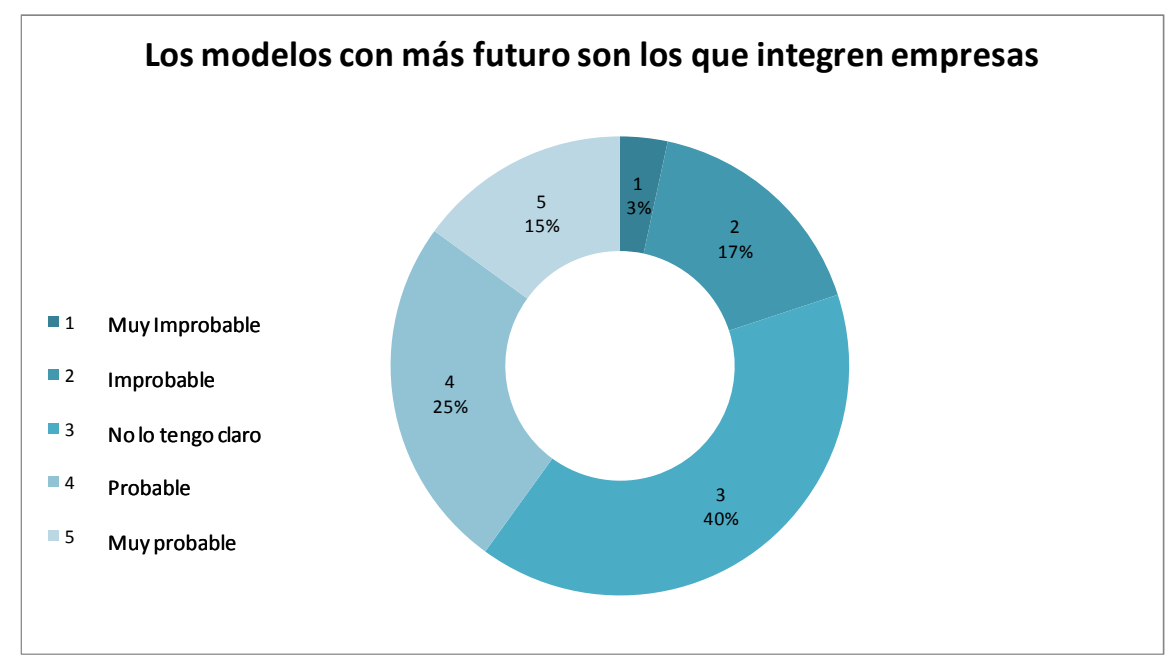

Fig. 8_6_Modelos de Negocio: Los modelos con más futuro son los que integren empresas. Elaboración Propia

La cuarta afirmación se basa en la posibilidad de futuro de que los modelos de integración de empresas sean la solución mayoritaria para el sector de la promoción inmobiliaria. Los resultados obtenidos muestran un $40 \%$ de acuerdo con la afirmación, un $20 \%$ en desacuerdo, y un $40 \%$ que no se decanta por ninguna de las dos. Es pues una respuesta con un alto grado de incertidumbre. Vemos que la respuesta mayoritaria es afirmativa o indecisa, frente a un $20 \%$ que se declaran como no partidarios de la afirmación. (Ver Fig. 8_6_ Modelos de Negocio: Los modelos con más futuro son los que integren empresas. Elaboración Propia). 


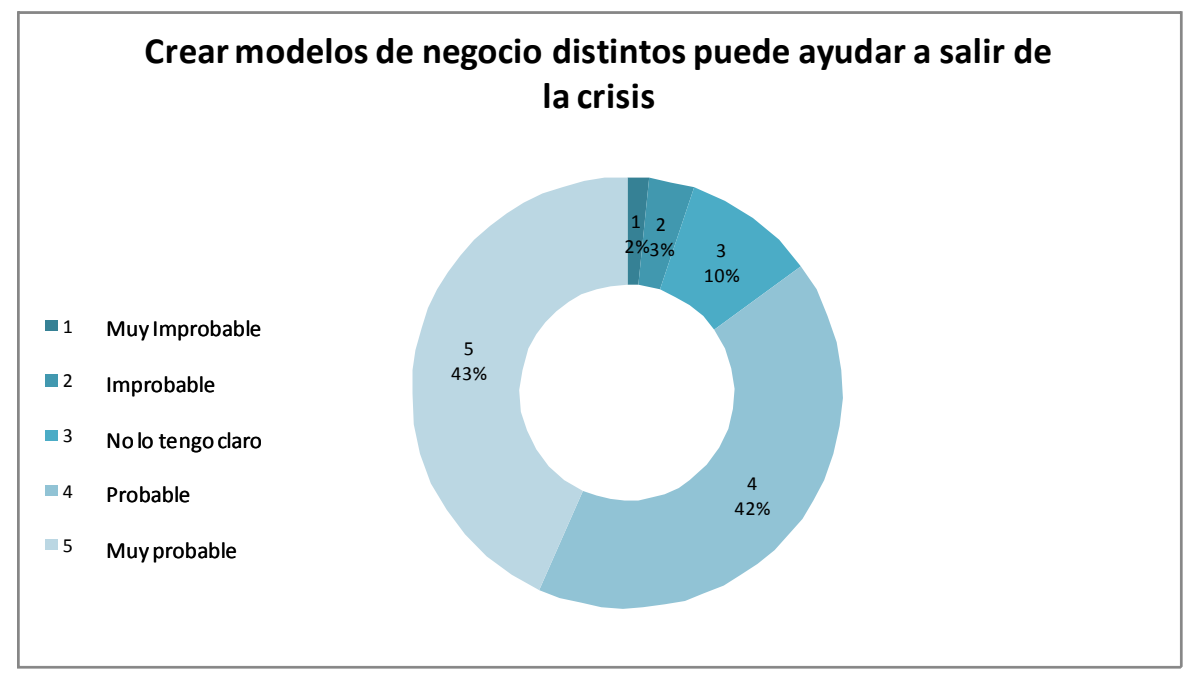

Fig. 8_7_ Modelos de Negocio: Crear modelos de negocio distintos puede ayudar a salir de la crisis. Elaboración Propia

La quinta afirmación es sobre la posibilidad de que la creación de modelos de negocio distintos pueda ayudar a salir de la crisis. Los resultados obtenidos en esta sentencia son un voto afirmativo del $85 \%$, frente a un $5 \%$ de negativos y un $10 \%$ de imparciales. En este caso existe un acuerdo mayoritario y contundente dentro de los expertos consultados, que indica que según su opinión, la creación de nuevos modelos de negocio dentro del sector de la promoción inmobiliaria ayudará a salir de la crisis en la que se encuentra el sector. (Ver Fig. 8_7_ Modelos de Negocio: Crear modelos de negocio distintos puede ayudar a salir de la crisis. Elaboración Propia). 


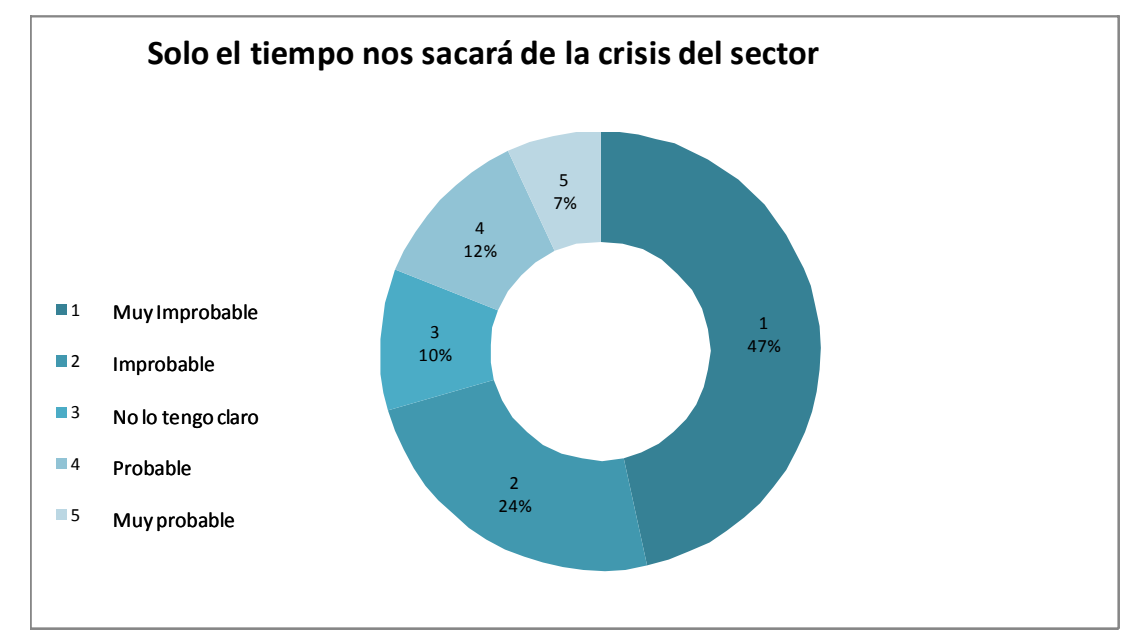

Fig.8_8_ Modelos de Negocio: Solo el tiempo hará que se salga de la crisis. Elaboración Propia

La sexta afirmación habla de que solo el tiempo será suficiente para salir de la crisis, de alguna manera es una proposición a esperar a que todo se arregle y a continuar con la situación anterior cuando las condiciones de mercado así lo permitan. En este caso los resultados son afirmativos en un 18,33\%, negativos en un $71,67 \%$ e indiferentes en un $10 \%$. Podemos concluir que existe una opinión mayoritaria acerca de que el tiempo por si solo no servirá para salir de la crisis, se tendrá que hacer alguna cosa más. (Ver Fig. 8_8_ Modelos de Negocio: Solo el tiempo hará que se salga de la crisis. Elaboración Propia).

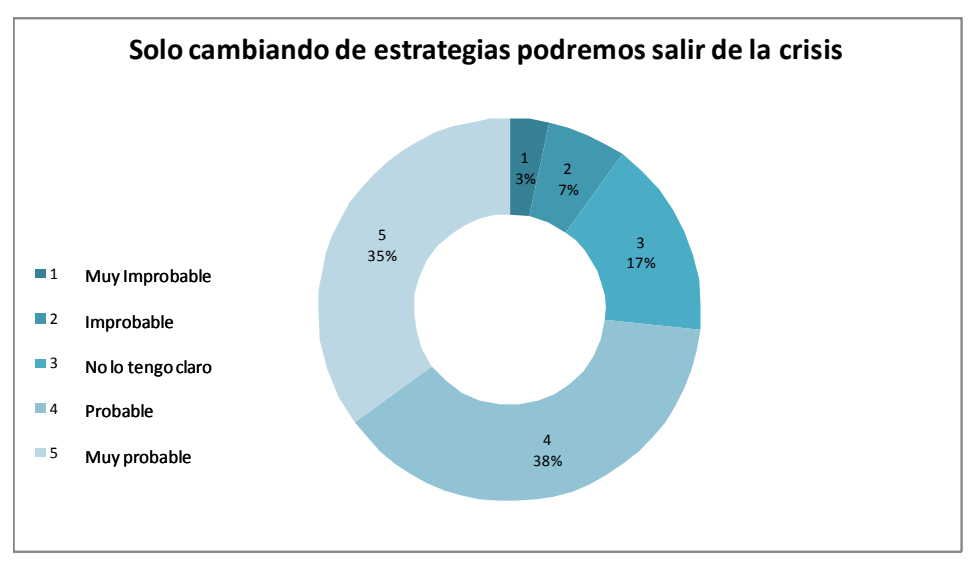

Fig .8_9_ Modelos de Negocio: Solo cambiando de estrategias podremos salir de la crisis. Elaboración Propia 
La séptima afirmación se plantea como complementaria a la anterior, si se ha concluido que el tiempo no es la solución que se debe plantear, ¿es acaso un cambio de estrategia lo que se debe hacer?. Las respuestas que se obtienen son resultados afirmativos en un $73,33 \%$, negativos en un $10 \%$ e indiferentes en un $16,67 \%$. En este caso y como conclusión se puede afirmar que existe una posición clara a que el cambio de estrategia es algo que podrá ayudar a salir de la crisis. (Ver Fig. 8_9_ Modelos de Negocio: Solo cambiando de estrategias podremos salir de la crisis. Elaboración Propia).

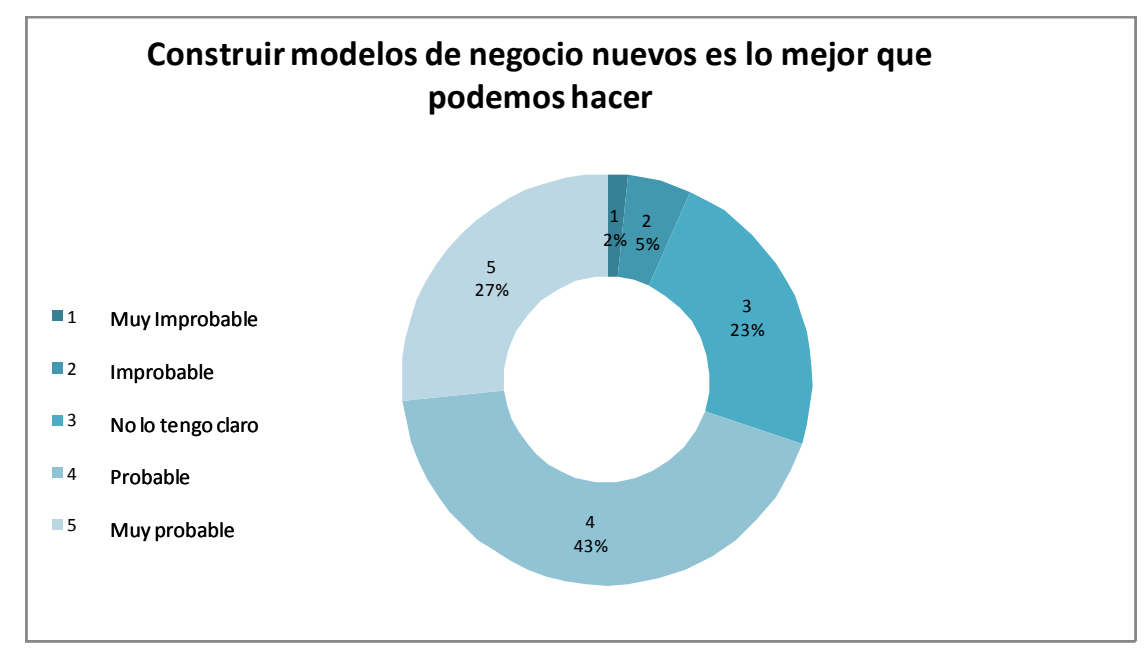

Fig. 8_10_Modelos de Negocio: Construir modelos de negocio nuevos es lo mejor que podemos hacer. Elaboración Propia

La octava y última afirmación de este bloque es la de que construir modelos de negocio nuevos es lo mejor que se puede hacer en la situación actual. Las respuestas son afirmativas en un $70 \%$, negativas en un $6,67 \%$ e indiferentes en un $23,33 \%$. Por lo tanto, la construcción de nuevos modelos de negocio se ve como una posibilidad acertada a la hora de enfocar soluciones en el sector inmobiliario. (Ver Fig. 8_10_Modelos de Negocio: Construir modelos de negocio nuevos es lo mejor que se puede hacer. Elaboración Propia).

Como conclusiones a las afirmaciones valoradas en este bloque se puede decir que según los expertos entrevistados el tiempo no solucionará los problemas planteados en el sector inmobiliario actualmente. Un cambio de estrategia, creando modelos de negocio nuevos con la integración de empresas para proyectos concretos es una de las posibles soluciones. Estos modelos nuevos convivirán con los anteriores y también con otro tipo de modelos. 


\section{Características de los Modelos de negocio.}

Con el cuarto bloque de preguntas se buscaba la posibilidad de ver las características del modelo y su adecuado enfoque para los expertos encuestados. Para ello se plantean nueve afirmaciones que se debían de valorar entre 1 y 5 siguiendo el criterio de que 1 es una valoración en total desacuerdo y un 5 en total acuerdo. Las afirmaciones que se plantearon fueron las siguientes:

1. Tendrán que tener en cuenta el papel del cliente final.

2. Deben de estar basadas en alianzas entre empresas del sector.

3. Los costes debe ser inferiores a los actuales.

4. Habrá una mayor especialización por empresa.

5. El tamaño de las empresas será menor que en la situación actual.

6. Hay que dirigir las operaciones hacia lo que el cliente quiere.

7. Integrar operaciones bajo un modelo conjunto es beneficioso.

8. Las empresas que tengan modelos integrados de funcionamiento mejoran su competitividad.

9. La integración de empresas permitirá mayor especialización y flexibilidad.

Al igual que en el apartado anterior se realizará un primer comentario afirmación a afirmación y dejando las conclusiones generales del bloque cuarto para el último apartado. Los ejes que caracterizan el modelo propuesto es la orientación al cliente, la integración de empresas mediante las alianzas, la especialización y flexibilidad de las empresas que intervienen en el modelo. 
En la primera sentencia del presente bloque se les preguntaba a los expertos sobre su opinión acerca del papel que el cliente debe jugar en el desarrollo del modelo. El cliente del que se habla es el cliente final al que va dirigido el producto. La pregunta en sí decía tendrá (el modelo) que tener en cuenta el papel del cliente final. Los resultados obtenidos es que el 91,87\% respondió afirmativamente mientras que un 8,33\% permaneció indiferente, no hubo contestaciones negativas para esta afirmación. En este caso es la afirmación que con más claridad han respondido los encuestados, mayoritariamente piensan que hay que ver el papel que el cliente final juega en un modelo de negocio. (Ver Fig. 8_11_Características de los Modelos de Negocio: Los Modelos de Negocio nuevos tendrán que tener en cuenta el papel del cliente final. Elaboración Propia).

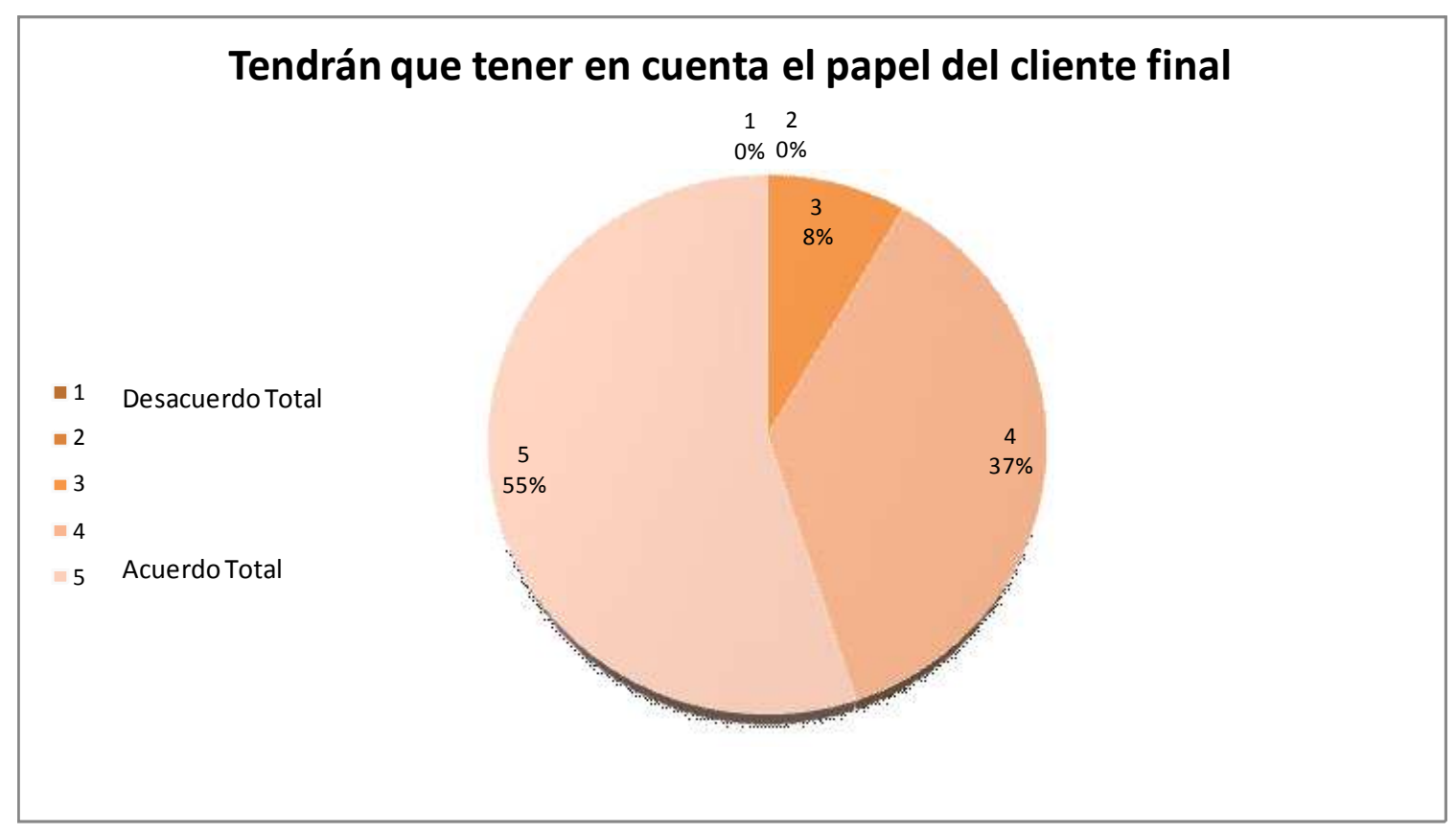

Fig. 8_11_Características de los Modelos de Negocio: Los Modelos de Negocio nuevos tendrán que tener en cuenta el papel del cliente final. Elaboración Propia 
La segunda afirmación iba sobre la posibilidad de construir el modelo de negocio basándose en las alianzas entre las empresas del sector. Los resultados para esta sentencia son un $38,33 \%$ de afirmativas, un $50 \%$ de indiferentes y un $11,67 \%$ de negativas. La conclusión que se puede extraer de estas contestaciones es que solo un tercio de los expertos entrevistados piensan que las alianzas entre las empresas del sector pueden ser una solución a aplicar en el modelo, mientras que la mitad de los mismos no se definen. (Ver Fig. 8_12_ Características de los Modelos de Negocio: Los Modelos de Negocio nuevos deben estar basados en alianzas entre empresas del sector. Elaboración Propia).

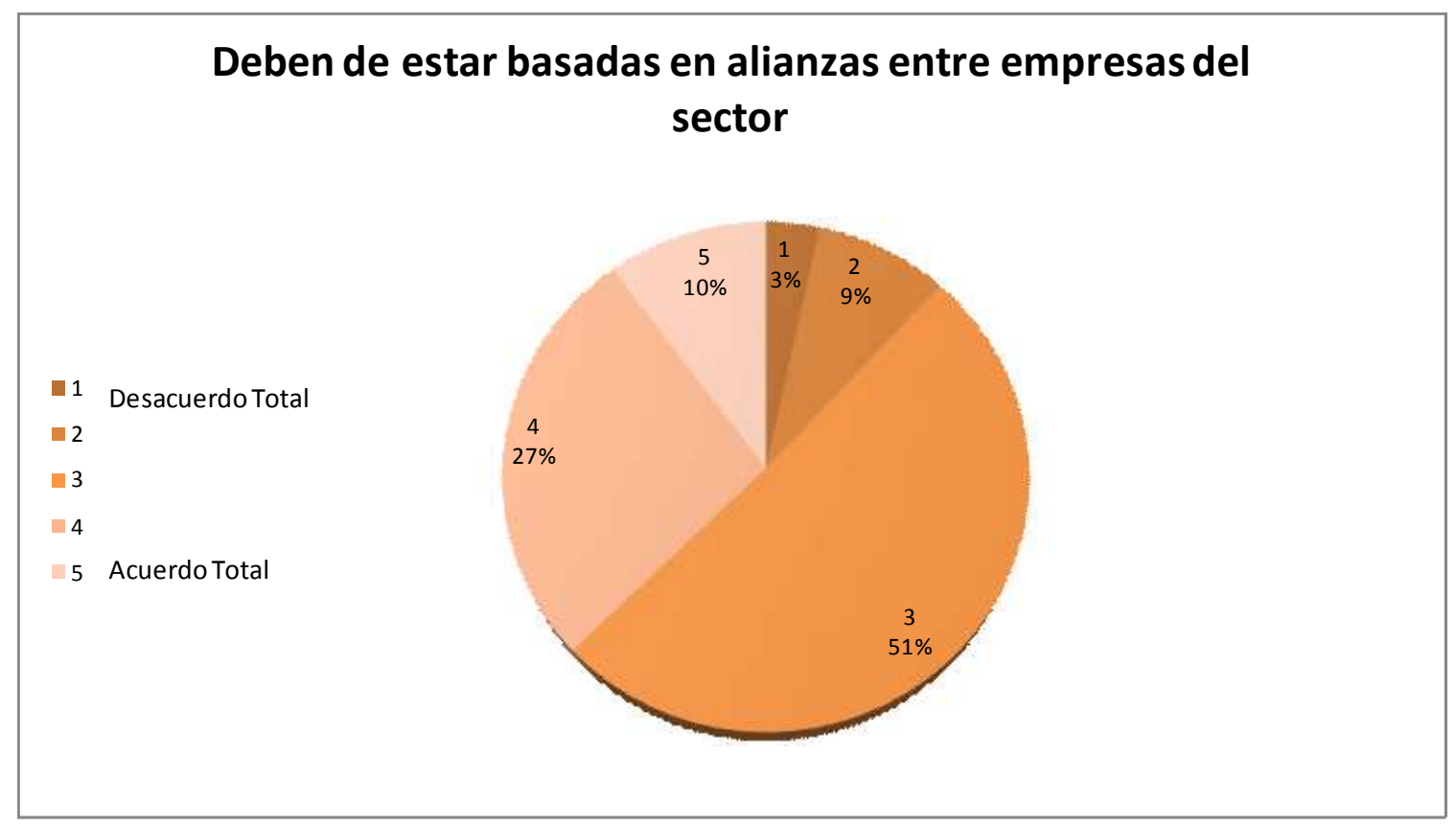

Fig. 8_12_Características de los Modelos de Negocio: Los Modelos de Negocio nuevos deben estar basados en alianzas entre empresas del sector. Elaboración Propia 
La tercera fase se plantea sobre la necesidad que los nuevos modelos sean más eficientes en costes. Los resultados en este caso son afirmativos un $66,67 \%$, frente a los negativos con un $8,33 \%$, los indiferentes son un $25 \%$ de los casos. Por tanto, en opinión de los expertos entrevistados, una característica importante de los nuevos modelos de negocio es que permitan operar con una reducción de los costes actuales. (Ver Fig. 8_13_Características de los Modelos de Negocio: Los Costes deben ser inferiores a los actuales. Elaboración Propia).

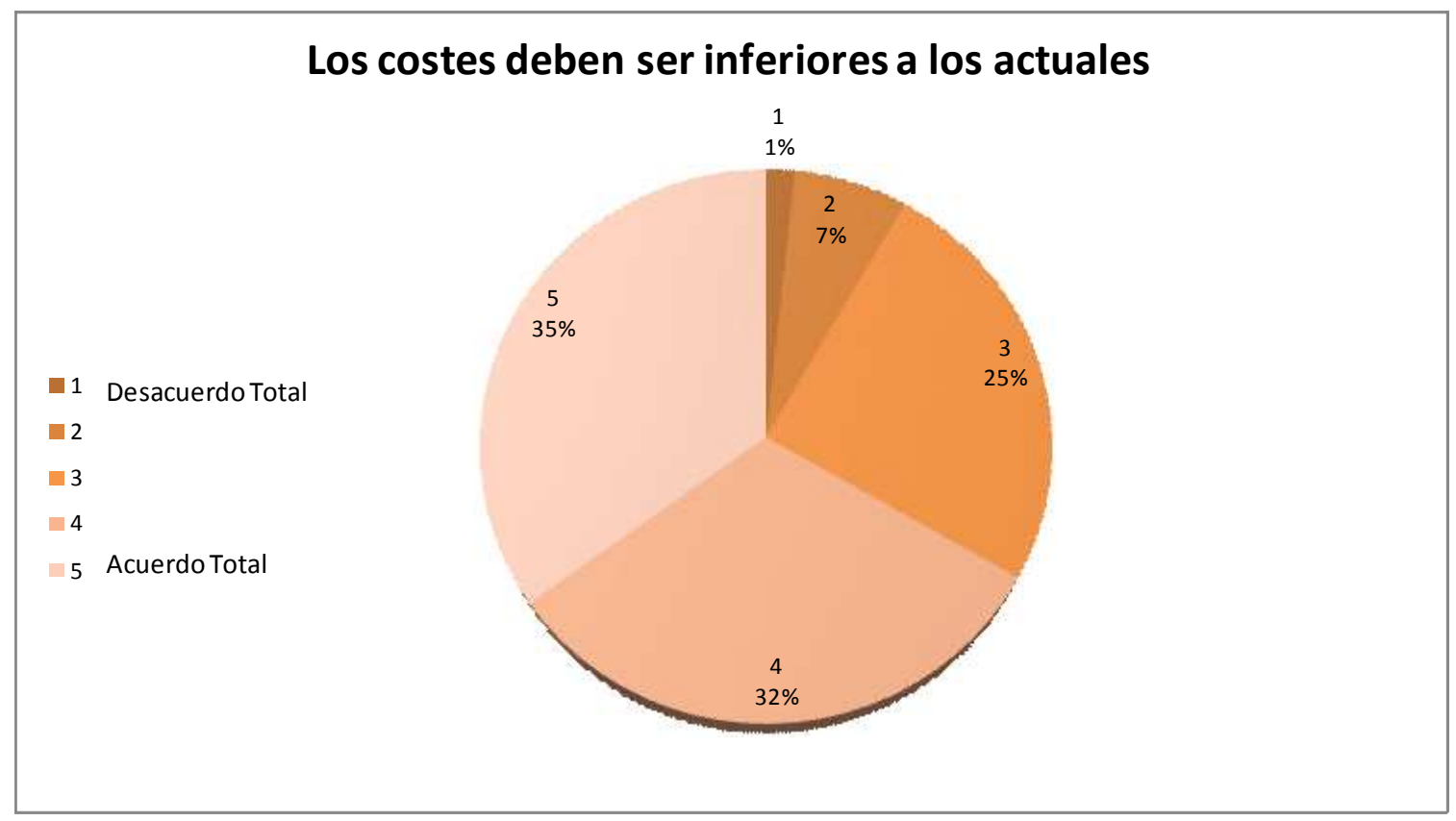

Fig. 8_13_Características de los Modelos de Negocio: Los Costes deben ser inferiores a los actuales. Elaboración Propia 
La cuarta afirmación que se estudió en este bloque fue la consideración sobre la mayor especialización que se plantearía en las empresas ante los nuevos modelos. El enunciado fue: En los nuevos modelos habrá una mayor especialización por empresas. Los resultados en este caso también son muy contundentes con un $85 \%$ de afirmativos frente a un $5 \%$ de negativos y un $10 \%$ de imparciales. Es por tanto lógico pensar en modelos que integrarán empresas con un nivel de especialización mayor que el actual. (Ver Fig. 8_14_ Características de los Modelos de Negocio: Los nuevos modelos supondrán una mayor especialización de las empresas. Elaboración Propia).

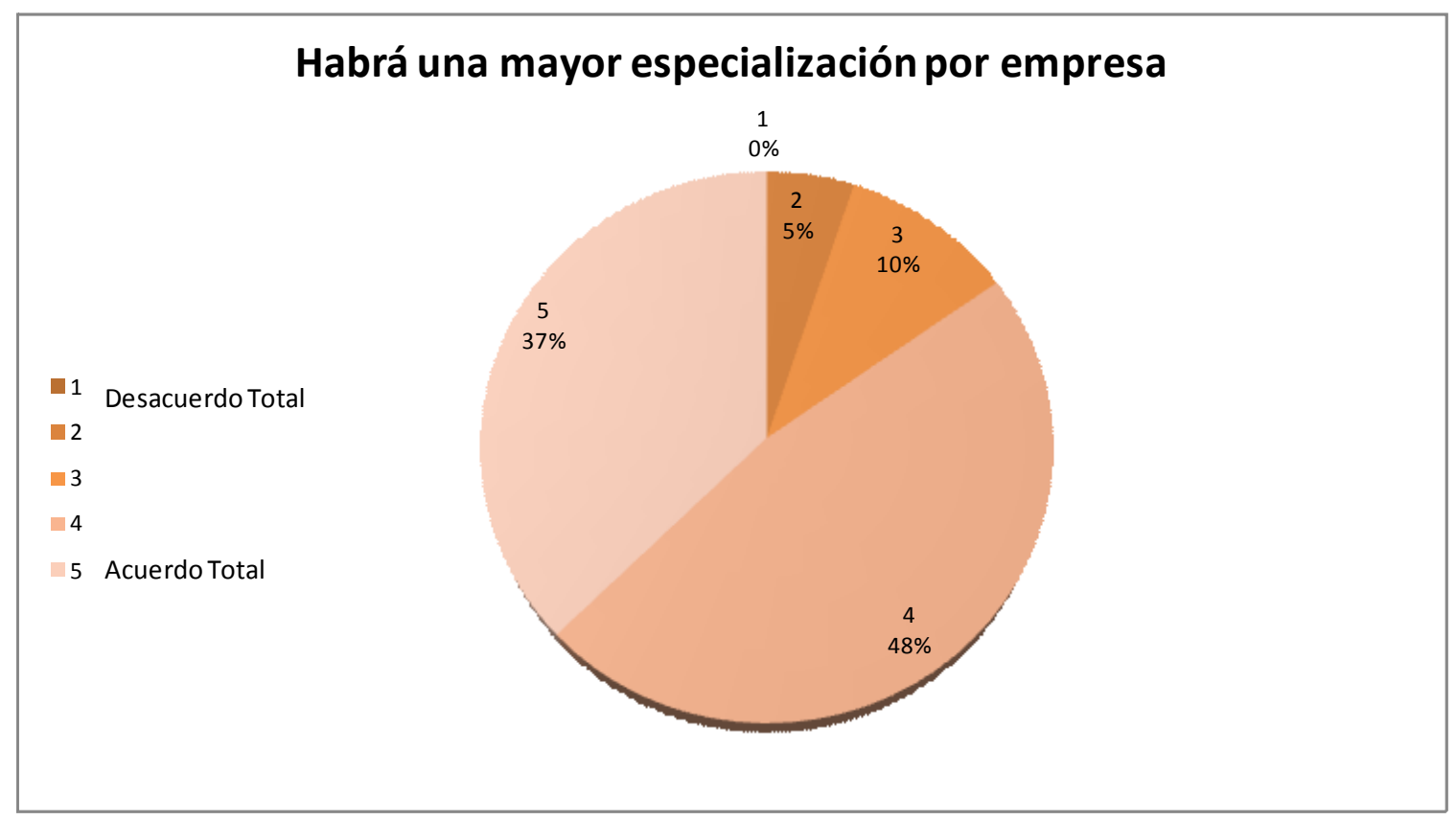

Fig. 8_14_Características de los Modelos de Negocio: Los nuevos modelos supondrán una mayor especialización de las empresas. Elaboración Propia 
La quinta sentencia habla sobre el tamaño de las empresas con respecto a las empresas actuales. La afirmación comenta que los nuevos modelos de negocio se desarrollarán con empresas de menor tamaño con respecto al tamaño actual. Los resultados son de un $43,33 \%$ de afirmaciones frente a un $15 \%$ de negaciones y un $41,67 \%$ de indecisos. Según los expertos puede haber una ligera opinión positiva a que se pueda reducir el tamaño de las empresas, aunque no es definitiva su opinión. (Ver Fig. 8_15_Características de los Modelos de Negocio: El tamaño de las empresas será menor que en la situación actual. Elaboración Propia).

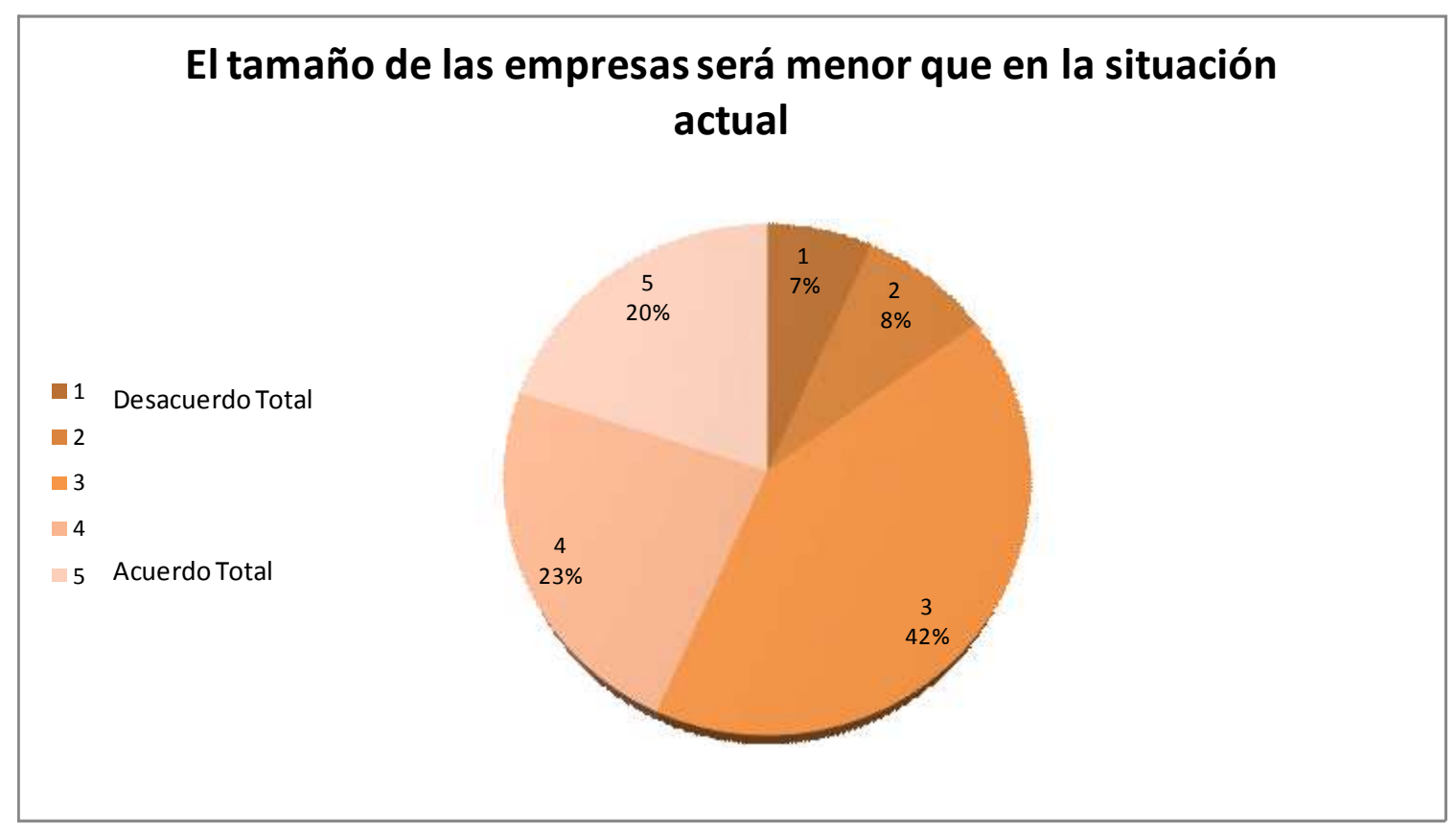

Fig. 8_15_Características de los Modelos de Negocio: El tamaño de las empresas será menor que en la situación actual. Elaboración Propia 
La sexta afirmación quiere recoger la orientación que deben tener las operaciones dentro de los nuevos modelos de negocio a plantear, en concreto la orientación hacia el cliente, si debe ser un valor fundamental o no. Los resultados en esta sentencia son de un acuerdo con la orientación de las operaciones hacia el cliente en el $85 \%$ de los casos frente al $1,67 \%$ que opina lo contario y un $13,33 \%$ que no se pronuncia. Es la respuesta con el valor más alto en el porcentaje de 5 que hemos obtenido en el test. Se piensa que es una afirmación rotunda hacia la necesidad de que los modelos a desarrollar orienten sus operaciones a las necesidades y objetivos del cliente. (Ver Fig. 8_16_ Características de los Modelos de Negocio: Hay que dirigir las operaciones hacia lo que el cliente quiere. Elaboración Propia).

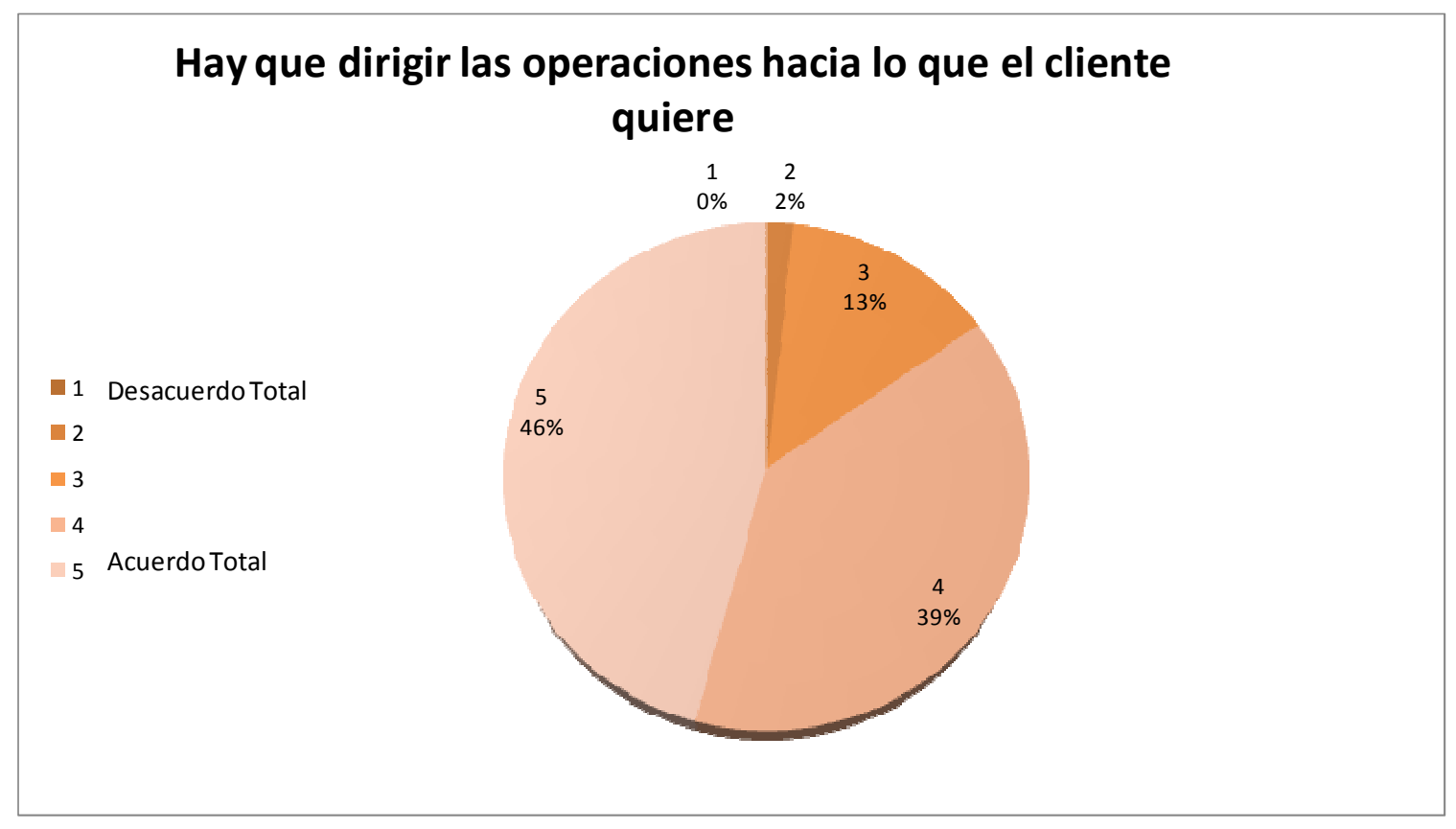

Fig. 8_16_Características de los Modelos de Negocio: Hay que dirigir las operaciones hacia lo que el cliente quiere. Elaboración Propia. 
La séptima frase hace hincapié sobre la conveniencia de la integración de operaciones bajo un modelo de negocio y los beneficios que de ello puedan salir. Los resultados en este apartado han sido de un $75 \%$ de afirmativos frente a un $8,33 \%$ de negativos y un $16,67 \%$ de indiferentes. Por lo tanto, y a juzgar por la respuestas de los expertos es beneficioso integrar bajo un modelo conjunto las operaciones. (Ver Fig. 8_17_Características de los Modelos de Negocio: Integrar operaciones bajo un modelo conjunto es beneficioso. Elaboración Propia).

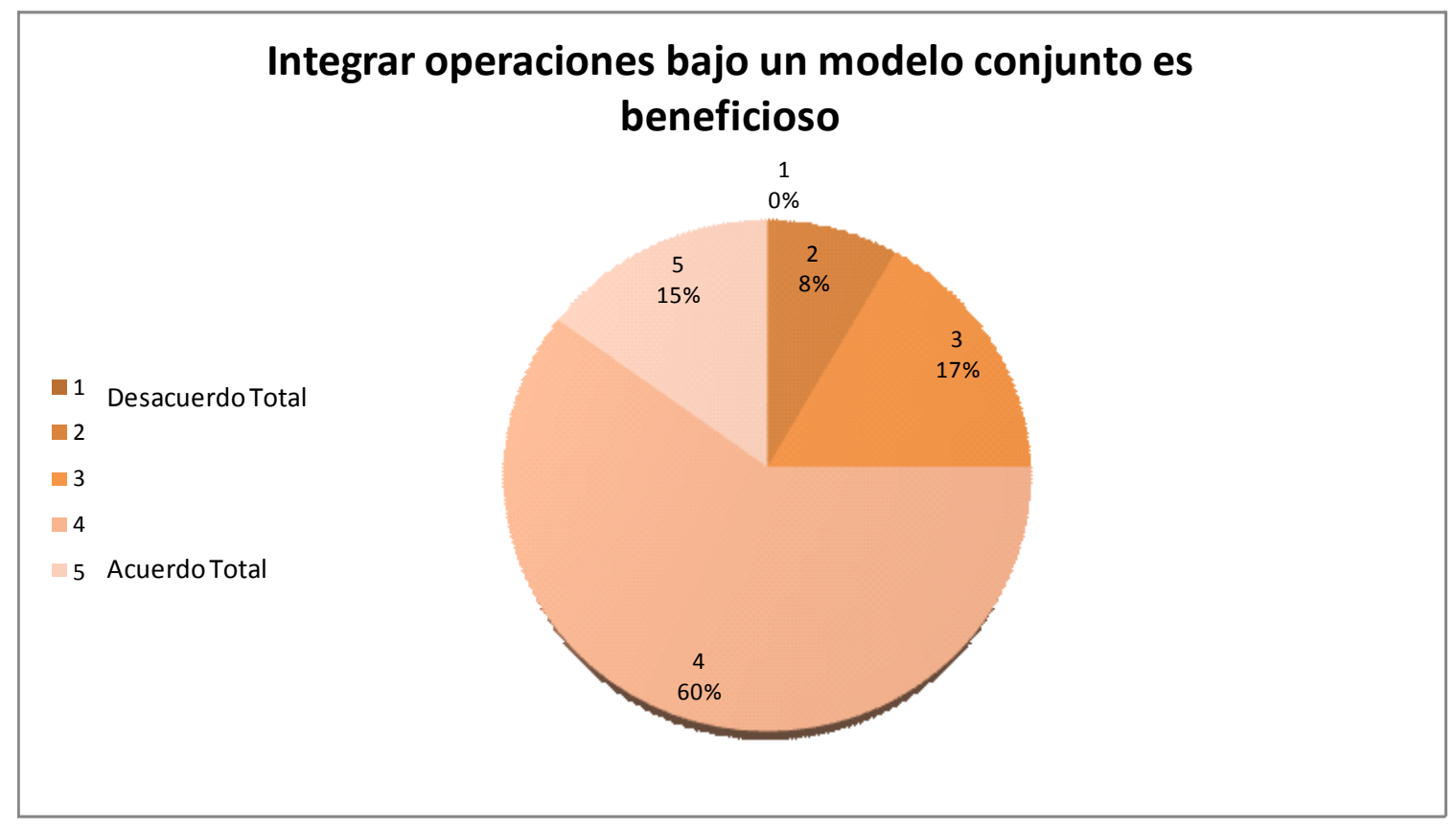

Fig. 8_17_Características de los Modelos de Negocio: Integrar operaciones bajo un modelo conjunto es beneficioso. Elaboración Propia. 
La octava afirmación habla sobre la mejora de la competitividad que puede aportar el funcionamiento de modelos de negocio integrados. Los resultado en este apartado son de un $78,33 \%$ de respuestas afirmativas frente a un $1,67 \%$ de respuestas negativas y un $20 \%$ de indecisos. La conclusión es que claramente, y según los entrevistados, los modelos de integración mejoran la competitividad de las empresas. (Ver Fig. 8_18_Características de los Modelos de Negocio: Las empresas que tengan modelos integrados de funcionamiento mejoran su competitividad. Elaboración Propia).

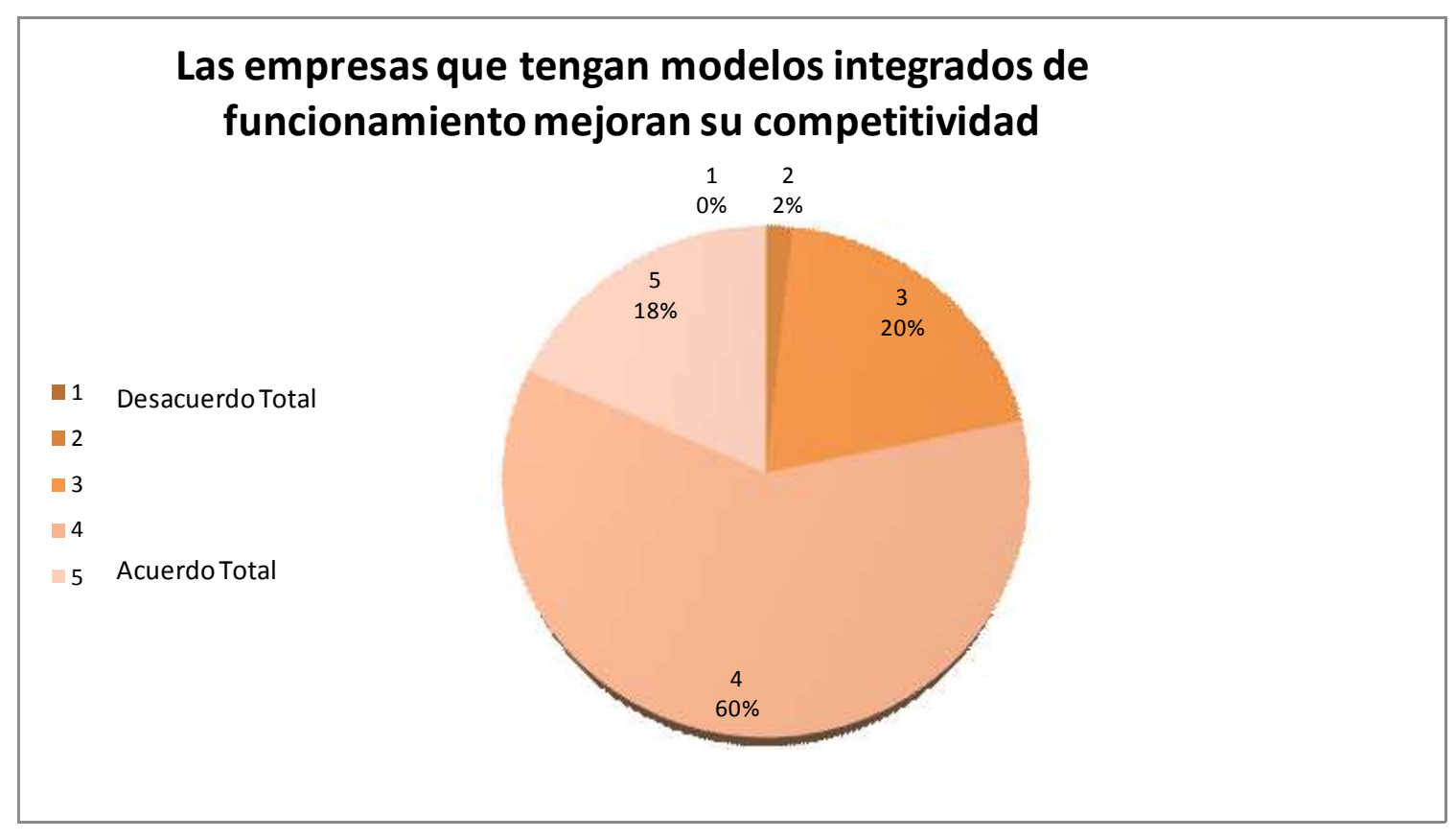

Fig. 8_18_Características de los Modelos de Negocio: Las empresas que tengan modelos integrados de funcionamiento mejoran su competitividad. Elaboración Propia. 
La última afirmación de este bloque y por tanto de la encuesta hace reflexionar sobre si la integración en modelos de negocio nuevos permitirá o no, una mayor especialización y flexibilidad en las empresas. Los resultados en este caso son de un 78,33\% de afirmativos frente al 1,67\% de negativos y un $20 \%$ de indecisos. Esta última afirmación también obtiene un apoyo fuerte hacia la afirmación de que la integración de empresas permitirá una mayor especialización y flexibilidad. (Ver Fig. 8_19_ Características de los Modelos de Negocio: La integración de empresas permitirá mayor especialización y flexibilidad. Elaboración Propia).

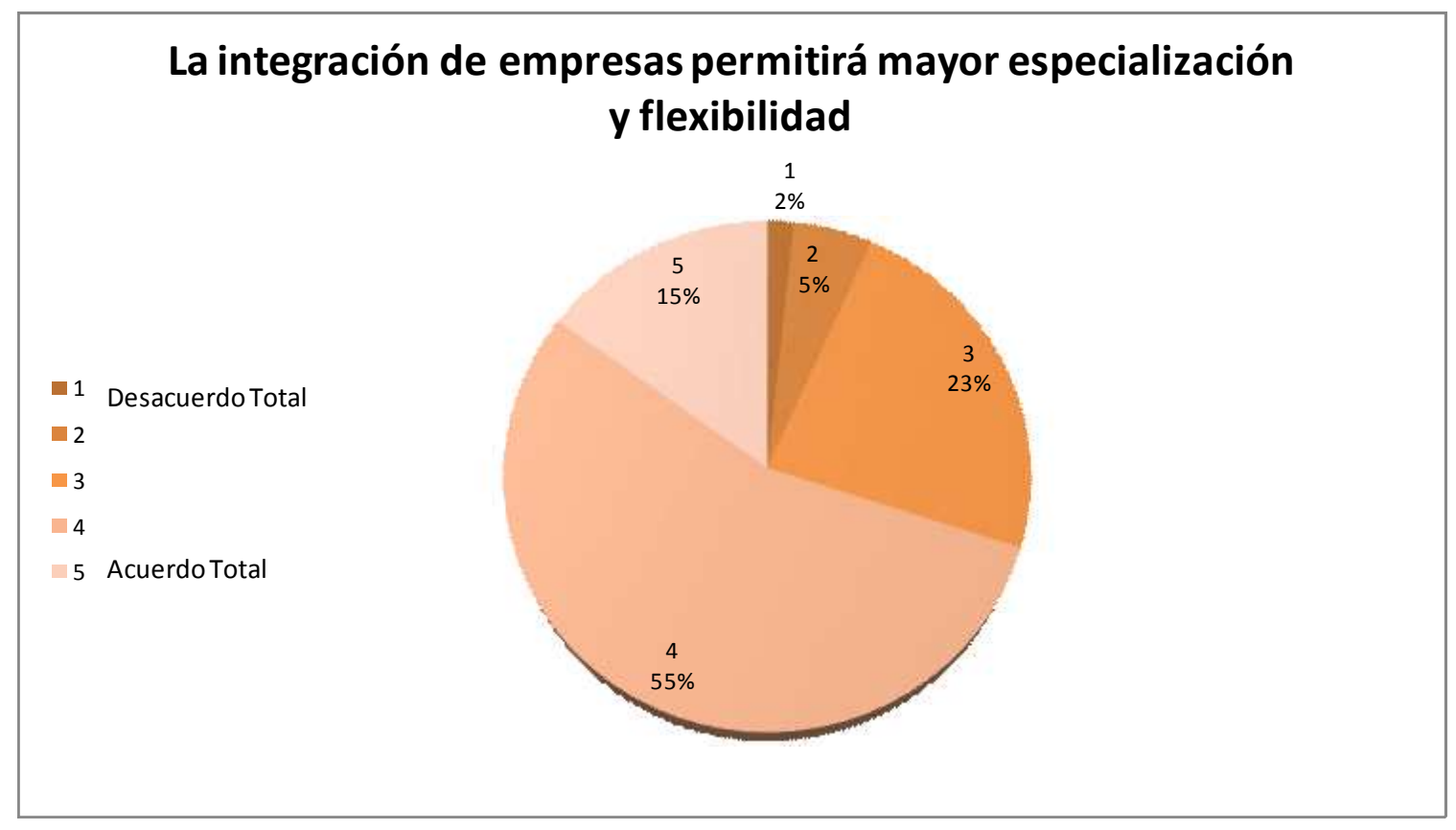

Fig. 8_19_Características de los Modelos de Negocio: La integración de empresas permitirá mayor especialización y flexibilidad. Elaboración Propia. 


\section{Conclusiones finales:}

Como conclusiones finales del presente capitulo se pretende recapitular los resultados obtenidos. Existe una mayoría de entrevistados un $93,22 \%$ que piensa que la crisis implicará un cambio de modelo de negocio en el sector de la promoción inmobiliaria y la construcción. Esta afirmación da pie a que modelos de negocio como el que se propone en la presente tesis sean modelos que puedan tener aceptación dentro del sector.

Las empresas que existirán después de la crisis tendrán unas características diferentes a las actuales, según los expertos consultados. Serán empresas más dinámicas y flexibles, más especializadas y con menor deuda. Empresas que podrán tener un tamaño distinto (menor) a lo que actualmente se está acostumbrado y que tendrán modelos de relación distintos entre ellas a los que hoy en día se conocen. Otra cosa que parece definitiva es que el tiempo no resolverá los problemas que se tienen hoy en día en el sector, se tendrá que implementar otro tipo de soluciones y no esperar a que todo pase para seguir haciendo lo mismo.

Los modelos de negocio se crearán porque son una de las soluciones que puede ser útil para el sector. De hecho, se piensa, que una de las mejores soluciones que el sector tiene es la de desarrollar modelos de negocio que enfoque a las empresas hacia relaciones y formas de funcionar distintas a las actuales. Estos modelos de negocio implicarán un cambio en la estrategia actual y en su mayoría deberían ser modelos de negocio que integren empresas.

Por último cabe señalar que los modelos de negocio deben orientarse al cliente, de forma que las operaciones de las empresas se orienten hacia la voluntad del cliente. Los costes de los nuevos modelos deben mejorar los actuales y la integración debe mejorar la competitividad del sector. Estas empresas podrán aliarse para abordar proyectos concretos configurando modelos de negocio que hoy en día todavía no conocemos.

Por todo lo expuesto anteriormente y a la luz de las contestaciones recibidas en la encuesta actual se puede concluir que modelos como el propuesto en el que el cliente juega un papel definitivo, que integran empresas y procesos orientados al cliente y que modifican la forma de trabajar actual de las empresas del sector tienen una receptividad alta por parte de los profesionales que conforman el sector de la promoción inmobiliaria y la construcción. 


\section{Capítulo 9}

\section{Conclusiones, recomendaciones y posibles líneas de investigación futuras.}

\section{Introducción:}

Después de todo lo visto a lo largo del presente documento, de las documentaciones estudiadas, los trabajos citados y los datos sobre la cadena de suministro del sector de la construcción en este capítulo se pretende, en primer lugar, poder recopilar una serie de conclusiones a modo de resumen. En segundo lugar exponer lo que podrían ser unas recomendaciones para poder afrontar con éxito los siguientes años dentro del sector. Por último, señalar cuales podrían ser las líneas de investigación futura en la materia relacionada con el modelo MOG presentado.

\section{Conclusiones Finales.}

Cómo se decía en el Capítulo 1 del presente trabajo la cadena de suministro en el sector de la construcción es posiblemente uno de los sistemas logísticos y productivos de mayor antigüedad y con un desarrollo e implantación más extenso a lo largo de todo nuestro planeta. Esto no debe desviar la atención sobre la situación real reflejada a lo largo del presente documento y de su grado de evolución comparada con otros sistemas logísticoproductivos con los que actualmente se pueden comparar. Esto hace plantearse una serie de conclusiones que a modo de puntos se han recogido a continuación: 
2.1. El sector de la construcción, pese a ser uno de los sectores con mayor presencia temporal en la historia es uno de los pocos sectores que no ha mejorado su competitividad de forma sustancial. Al contrario, es un sector que suele incrementar sus costes de una manera habitual y continuada. Como señalan Briscoe et al., (2003) en su estudio, la industria de la construcción ha sufrido durante un largo período de tiempo sobrecostes, retrasos en sus programaciones y una baja productividad. Al mismo tiempo los beneficios de las obras de construcción son frecuentemente desconocidos y extremadamente escasos en comparación con otras industrias. En el estudio de Latham report (1994) se señala la idea de la competitividad dentro del sector de la construcción y la tendencia a la subcontratación de trabajos y se remarca las actitudes adversas comúnmente existentes entre los contratistas principales y sus proveedores. En el estudio de Egan (1998) se critica la industria y se demandan mejoras en términos relacionados con la reducción de costes, tiempos, defectos y accidentes. Todas estas ideas se han aportado como potenciales mecanismos y aspectos de mejora en las relaciones entre empresas (O`Brien y Fisher,(1993), Naum y Mustapha ,(1994), Agapiou et al., (1998), Green y Lenard, (1999), Murray et al., (1999), Reed , (1999).

2.2. La cadena de suministro en el sector de la construcción tiene una composición en general muy atomizada si se ve desde el punto de vista del tamaño relativo de las empresas que operan dentro de dicha cadena. Esta atomización complica enormemente la comunicación fluida y la integridad de los mensajes que se desean comunicar. Es un sector muy tradicional, fragmentado y dominado por pequeñas compañías (BNL (2002), Dainty et al. (2001), Love et al. (2004), Persson y Solberge (1994), Vordijk et al. (2000). 
2.3. Las características de las empresas, salvando el tamaño ya comentado en el punto anterior, son de una baja cualificación y preparación tecnológica y de gestión en comparación con empresas de cadenas de suministro similares en cuanto a proceso se refiere. (Ejemplo: Cadena de Suministro de Construcción Naval, Aeronáutica, etc.). Este tipo de característica hace que sean mucho menos receptivos a las nuevas ideas y conceptos de gestión en cuanto a la modernización de los procesos y procedimientos de gestión. Los contratistas principales frecuentemente cambian de proveedores, y esto hace difícil compartir información estratégica, dificulta asimismo, el retorno de información del proceso a esos proveedores e incluso puede retrasar hasta los pagos (Briscoe y Dainty, (2005). Problemas similares han sido recogidos en un estudio de Thorpe et al., (2003), donde supuestamente los subcontratistas mejores tenían desventajas en algunas prácticas de la cadena de suministro. Briscoe et al.,(2001), también se centran en las relaciones entre los contratistas principales y sus subcontratistas y en este estudio se encuentran significativas barreras actitudinales que evitan la plena colaboración a este nivel.

2.4. El papel del cliente, verdadero usuario del producto resultante de la cadena de suministro de la construcción, es en la mayoría de los casos nulo. Se desarrolla el producto sin haber involucrado en el proceso al cliente, sin haber tenido en cuenta sus necesidades, sus opiniones y sus expectativas. Existen estudios que se han centrado en las relaciones entre la cadena de suministro de la construcción, los clientes y el contratista principal (Himes, (1995), Bresnen y Marshall, (1998, 1999), y las relaciones entre los contratistas principales y los subcontratistas (Uher y Runeson, (1985), Hinze y Tracey (1999), Matthews et al., (1996). Las investigaciones a través de más de dos eslabones dentro de la cadena de suministro de la construcción han sido muy pocas (London et al., (1998), Murray et al., (1999), pero ha reconocido los beneficios de las relaciones a largo plazo de estabilidad entre varios agentes. Briscoe et al., (2003) recogen en su investigación la manera de cómo el cliente puede influir en la integración de la cadena de suministro de la construcción. En los negocios en general, New y Payne (1995) investigaron un modelo para el propósito de la cadena de suministro. Indicaron una relación entre el entorno, la práctica y los resultados. Sin embargo, Briscoe et al., (2003) modificaron este modelo (como se ha señalado anteriormente). 
2.5. El mercado, entendido como el conjunto de consumidores que pretenden adquirir el producto resultante de la cadena de suministro estudiada, al igual que ocurre en otras cadenas, está cambiando y se vuelve más exigente con los productos que desea. Esta exigencia se concreta en productos de mayor calidad, mejor diseño, mejores acabados, con mayores prestaciones, pensados para hacer la vida más sencilla a sus usuarios y a precios más competitivos.

2.6. El producto actual resultante de la cadena de suministro en el sector de la construcción tal y como está concebida hoy en día se percibe en el mercado como un producto de calidad relativamente baja. El consumidor está acostumbrado a recibir un producto con un elevado número de defectos. Es en cierta manera habitual que el consumidor una vez recibido el producto tenga que acudir en repetidas ocasiones al fabricante para acabar de corregir los defectos que el producto tiene.

2.7. Otro aspecto que cabe señalar es la deficiencia en las habilidades necesarias para un buen desarrollo profesional de las personas que trabajan en este sector. Cómo hemos citado con anterioridad un estudio realizado por Ashton et al., (1999) fijaba el rango de habilidades genéricas que debería existir en cualquier sector industrial que quisiera aplicar técnicas de alianzas. Asimismo, Briscoe et al. (2001) realizaron una primera aproximación a los contratistas principales del sector de la construcción para poder aplicar las mismas técnicas dentro de este sector.

\section{Recomendaciones y posibles pasos a seguir.}

En este apartado de recomendaciones se pretende simplemente señalar aquellas posibles vías de actuación para poder de alguna manera soslayar o mejorar algunos puntos deficitarios en la cadena de suministro de la construcción. Igual que en el apartado anterior, se señalarán las recomendaciones a modo de puntos que se recogen a continuación:

- La primera recomendación sería animar a las empresas para qué creen y faciliten modelos de gestión que minimicen o superen los problemas detectados: 
- Mejorar la integración de la cadena de suministro: en este aspecto los modelos deben superar las barreras existentes entre las compañías fijando objetivos comunes y persiguiendo el beneficio global. Es necesario que se aborden los problemas nuevos con mentalidad abierta E.M. Goldratt y J. Cox (1984) porque no se necesita un cerebro excepcional para construir una nueva ciencia o ampliar las ya existentes. Lo que se necesita es valentía para afrontar lo que no tiene consistencia y no justificarlo porque "siempre se ha hecho así".

- Mejorar la competitividad del global de la cadena de producción, o cadena de suministro como la hemos llamado hasta ahora. Cómo recogería E.M. Golfdratt (1990) se deben centrar los esfuerzos en la creación del valor y no tomar decisiones en función de los costes.

- Se deben crear líderes que permitan el desarrollo de las personas en todos sus aspectos, tanto personales como profesionales capacitados para poder trabajar en ambientes inestables y cambiantes, con organizaciones flexibles y que interactúen entre sí. Hesselbein F. et al. (1996) comenta que la primera elección es que pueda haber líderes natos, pero que seguramente son demasiado pocos para contar con ellos. El liderazgo debe aprenderse y puede aprenderse. La segunda conclusión es que no existe la personalidad, ni el estilo, ni los rasgos de liderazgo. Entre los líderes más eficientes que se han encontrado no existen rasgos comunes fuera de que son personas que consiguen arrastrar a una serie de individuos. El líder eficaz no es alguien a quien se le quiera. Es aquel cuyos seguidores hacen lo que es debido. La popularidad no es liderazgo. Los resultados sí lo son. Los líderes son muy visibles, y por consiguiente establecen ejemplos. El liderazgo no es un rango, privilegios, títulos o dinero: es responsabilidad.

- El papel del cliente como aspecto decisivo a cuidar dentro de la cadena de suministro de la construcción. Chiesa C. (2002) recoge que muchas empresas piensan que los clientes son eternos y se olvidan que la captación de una cuenta, que da lugar a una primera venta, es sólo el principio de una posible relación que será duradera sólo en la medida que tengamos una auténtica vocación por mantener viva la satisfacción de nuestros clientes. 
- La mejora permanente como filosofía de actuación dentro las organizaciones. Muñoz-Seca B. y Riverola J. (2003) nos señalan como primera idea que la gestión del conocimiento no tiene futuro si no proporciona más productividad y competitividad para la empresa. Para ello los autores proponen una forma de integrar la gestión del conocimiento con las operaciones. La gestión del conocimiento es, por tanto, el inventario, aumento y aprovechamiento de lo que la empresa y sus personas realmente saben. Y las operaciones son el sistema que presta servicio y que debe hacer feliz al cliente. Para obtener resultados, la única forma de enfocar la gestión del conocimiento es como motor del sistema de mejora permanente. Y viceversa, la mejora permanente no puede plantearse sin la gestión de conocimiento.

- Buscar la calidad del producto y la perfección de las operaciones. "Sed perfectos como vuestro Padre Celestial es perfecto" (Mateo $5,48)$.

- Una segunda recomendación sería identificar y trabajar sobre aquellos aspectos que permitan a las empresas orientarse hacia las metas que se persiguen.

- La tercera recomendación sería a nivel institucional crear las condiciones en los ambientes necesarios para facilitar la integración de las empresas individuales beneficiando este tipo de uniones que consigan ganar mayor competitividad frente a las situaciones anteriores. 


\section{Posibles líneas de investigación futuras.}

En este apartado de posibles líneas de investigación futura se quieren señalar aquellos aspectos de la investigación que parecen más interesantes desde el punto de vista de la integración de la cadena de suministro, de esta manera se recogen los siguientes puntos:

- Investigación basada en los aspectos que pueden ayudar directamente a la integración de la cadena suministro en el sector de la construcción:

- Aspectos tecnológicos: integración de la información necesaria para la gestión de la cadena de suministro permitiendo la toma de decisiones más sencilla y ágil entre los distintos miembros de la misma.

- Aspectos económicos: búsqueda de la creación de valor y de su explicitación de forma que quede patente que la suma de las partes es mayor que cada una de ellas.

- Aspectos relacionados con el cliente: formas por las cuales se puede integrar al cliente dentro del proceso de la gestión de la cadena de suministro.

- Aspectos organizacionales: modelos que permitan la integración de varias compañías facilitando el trabajo de las personas de las distintas organizaciones.

- Aspectos institucionales: estudio del entorno macro donde se puedan dar las condiciones necesarias para el desarrollo de las integraciones que deseamos.

- Aspectos que tienen que ver con el desarrollo de las personas: al fin y al cabo los que hacen posible las distintas integraciones, alianzas y avances en la gestión de la cadena de suministro son las personas de las distintas compañías que participan en el proceso. 
- Otra línea que podría ser muy interesante para el desarrollo de posibles trabajos de investigación es la propuesta de nuevos modelos que aporten mayor flexibilidad y que permitan ganar competitividad a las empresas del sector, planteando nuevos escenarios en los que desarrollar su actividad. 


\section{Referencias Bibliográficas:}

$>$ AGAPIOU, A., CLAUSEN, L.E., FLANAGAN, R., NORMAN, G. AND NOTMAN, D. (1998) "The role of logistics in the materials flow control process". Construction Management and Economic, 16(2), 131-7.

$>$ ASHTON, D., DAVIES, B., FELSTEAD, A., GREEN, F., (1999). "Work skills in Britain". Centre for Skills, Knowledge and Organisational Performance (SKOPE), Oxford and Warwick Universities.

$>$ BNL (2002) "Research and Development in the Construction Industry" (In Norwegian: Forskning og utvikling i bygg-, anleggs- og eiendomsnæringen), http: www.bnl.no.

BRESNEN, M. AND MARSHALL, N. (1998) "Partnering strategies and organizational cultures in the construction industry", in Hughes, W. (ed.) ARCOM 14th Annual Conference, Reading, 9-11 September, pp. 465-76.

> BRESNEN, M. AND MARSHALL, N. (1999) "Achieving customer satisfaction?" Client-contractor collaboration in the UK construction industry, in Bowen, P. and Hindle, R. (eds) CIBW55 \& '65 Joint Triennial Symposium, Cape Town, South Africa.

BRISCOE, G., DAINTY, A. R. J. AND MILLETT, S., (2001). "Construction supply chain partnerships: skills, knowledge and attitudinal requirements", European Journal of Purchasing \& Supply Management, Vol 7, Iss 4, pp.243-255.

$>$ BRISCOE G., ANDREW R.J. DAINTY, SARAH J. MILLETT AND RICHARD H. NEALE (2003) "Client-led strategies for construction supply chain improvement", Construction Management and Economics.

$>$ BRISCOE G., AND ANDREW R.J. DAINTY (2005) "Construction supply chain integration: an elusive goal?" Supply Chain Management: An International Journal 10/4 319-326

$>$ COSIMO CHIESA DE NEGRI (2002). "Finalizado para fidelizar". Ediciones Universidad de Navarra S.A. Eunsa.

DAINTY, A.R.J., BRISCOE, G.H. AND MILLETT, S.J. (2001) "Subcontractor perspectives on supply chain alliances", Construction Management and Economics, Vol. 19, pp. 841-848.

EGAN, J. (Construction Task Force) (1998) "Rethinking Construction", DETR, London. 
FRANCES HESSELBEIN, MARSHALL GOLDSMITH Y RICHARD BECKHARD (1996). "El lider del futuro". Ediciones Deusto S.A.

> GOLDRATT ELIYAHU M. Y JEFF COX (1984) “The Goal”. A process of on-going improvement

$>$ GOLDRATT ELIYAHU M. (1990) "El Síndrome del Pajar”. Ediciones Díaz de Santos S.A. 61-66.

$>$ GREEN, S.D. AND LENARD, D. (1999), "Organising the project procurement process", in Rowlinson, S. and McDermott, P. (Eds), Procurement Systems: A Guide to Best Practice in Construction, E. \& F.N. Spon, London, pp. 57-82.

$>$ HIMES, P.E. (1995) "Partnering in the construction process: the methodology for the 1990s and beyond". Facilities, 13(6), 13-15.

HINZE, J. AND TRACEY, A. (1994) "The contractor-subcontractor relationship: the sub-contractors view". Journal of Construction Engineering and Management, 120(2), 274-87.

LONDON, K., KENLEY, R. AND AGAPIOU, A. (1998) "Theoretical supply chain network modelling in the building industry", in Hughes, W. (ed.) ARCOM 14th Annual Conference, Reading, 9-11 September, pp. 369-79.

LOVE, P.E.D., IRANI, Z. AND EDWARDS, D.J. (2004) "A seamless supply chain management model for construction”, Supply Chain Management: An International Journal, Vol. 9, No. 1, pp.43-56.

$>$ MATTHEWS, J., TYLER, A. AND THORPE, A. (1996) "Pre-construction project partnering: developing the process". Engineering, Construction \& Architectural Management, 3(1, 2), 117-31.

> MUÑOZ-SECA BEATRIZ Y RIVEROLA JOSEP (2003). "Del buen pensar y mejor hacer: mejora permanente y gestión del conocimiento". Editorial Mc Graw Hill.

> MURRAY, M., LANGFORD, D., HARDCASTLE, C. AND TOOKEY, J. (1999) "Organisational design", in Rowlinson, S. and McDermott, P. (eds) Procurement Systems: A Guide to Best Practice in Construction, E \& FN Spon, London, pp. 83118.

NAOUM, S.G. AND MUSTAPHA, F.H. (1994) "Influences of the client, designer and procurement methods on project performance", in Rowlinson, S. (ed.) Proceedings of CIB W92 - Procurement Systems: East Meets West, Hong Kong University, December.

NEW, S.J. AND PAYNE, P. (1995) "esearch frameworks in logistics: three models, seven dinners and a survey". International Journal of Physical Distribution and Logistics Management, 25(10), 60-77. 
O'BRIEN, W.J. AND FISCHER, M.A. (1993) "Construction supply chain management: a research framework". Civil Comp 93: Information Technology for Civil and Structural Engineers, pp. 61-4.

PERSSON, G. AND SOLBERG, M. (1994) "Time based strategies as part of the internationalisation of the Norwegian construction industry" (In Norwegian: Tidsbaserte 19 konkurransestrategier som virkemiddel for $\varnothing \mathrm{kt}$ internasjonalisering av norsk Bygge- og anleggsnæring), Research report 2, Norwegian School of Management, BI

REED, M. (1999) "Working Together: Tools for an Integrated Construction Supply Chain", Trant Engineering, Cardiff University and Southampton University.

THORPE, A., DAINTY, A.R.J. AND HATFIELD, H. (2003), "The realities of being preferred: specialist subcontractor perspectives on restricted tender list membership", Journal of Construction Procurement, Vol. 9 No. 1, pp. 47-55.

UHER, T.E. AND RUNESON, G. (1985) "Subcontractor-general contractor relationship in Australian building industry". Project Management, 3(1), 35-8.

VRIJHOEF, R. AND KOSKELA, L, (2000) "The four roles of supply chain management in construction", European Journal of Purchasing and Supply Management, Vol.6, Special Issue, pp. 169-178. 
UNIVERSIDAD

POLITECNICA

DE VALENCIA 